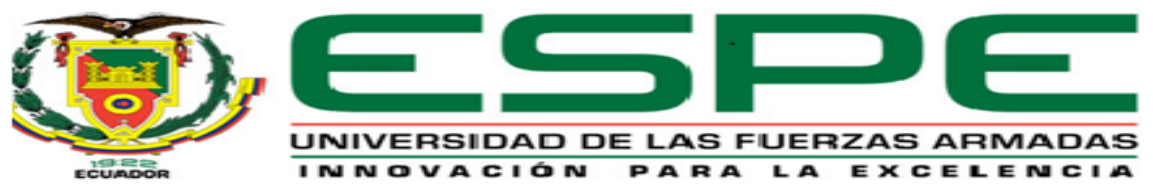

UNIVERSIDAD DE LAS FUERZAS ARMADAS ESPE

DEPARTAMENTO DE ELÉCTRICA Y ELECTRÓNICA CARRERA DE INGENIERÍA EN ELECTRÓNICA Y TELECOMUNICACIONES

PROYECTO DE GRADO PARA LA OBTENCIÓN DEL TÍTULO DE INGENIERÍA

SIMULACIÓN Y COMPROBACIÓN DE COBERTURA Y COMPATIBILIDAD ELECTROMAGNÉTICA DE OPERADORAS DE TRANSMISIÓN DE TELEVISIÓN DIGITAL PARA LA CIUDAD DE QUITO

FRANCISCO JAVIER PARREÑO COBA MARCO ANTONIO GARCÍA BENALCAZAR

SANGOLQUÍ - ECUADOR 


\section{CERTIFICACIÓN}

Certificamos que el presente proyecto de grado titulado: "SIMULACIÓN Y COMPROBACIÓN DE COBERTURA Y COMPATIBILIDAD ELECTROMAGNÉTICA DE OPERADORAS DE TRANSMISIÓN DE TELEVISIÓN DIGITAL PARA LA CIUDAD DE QUITO", ha sido desarrollado en su totalidad por el señor FRANCISCO JAVIER PARREÑO COBA con Cl: 171932453-3 y el señor MARCO ANTONIO GARCÍA BENALCAZAR con Cl: 040128734-7, bajo nuestra dirección.

Dr. Nikolai Espinosa

DIRECTOR

Ing. Darwin Aguilar. CODIRECTOR 


\title{
DECLARACIÓN DE RESPONSABILIDAD
}

\author{
Francisco Javier Parreño Coba \\ Marco Antonio García Benalcazar
}

\section{DECLARAMOS QUE:}

\begin{abstract}
El proyecto de grado denominado "SIMULACIÓN Y COMPROBACIÓN DE COBERTURA Y COMPATIBILIDAD ELECTROMAGNÉTICA DE OPERADORAS DE TRANSMISIÓN DE TELEVISIÓN DIGITAL PARA LA CIUDAD DE QUITO", ha sido desarrollado con base a una investigación exhaustiva, respetando derechos intelectuales de terceros, conforme las citas que constan al pie, de las páginas correspondientes, cuyas fuentes se incorporan en la bibliografía.
\end{abstract}

Consecuentemente este trabajo es de nuestra autoría.

En virtud de esta declaración, nos responsabilizamos del contenido, veracidad y alcance científico del proyecto de grado en mención.

Quito, 23 de Agosto 2014.

Francisco Javier Parreño Coba 


\section{AUTORIZACIÓN}

Nosotros, Francisco Javier Parreño Coba y Marco Antonio García Benalcazar, Autorizamos a la Universidad de las Fuerzas Armadas ESPE la publicación, en la biblioteca virtual de la Institución del trabajo "SIMULACIÓN Y COMPROBACIÓN DE COBERTURA Y COMPATIBILIDAD ELECTROMAGNÉTICA DE OPERADORAS DE TRANSMISIÓN DE TELEVISIÓN DIGITAL PARA LA CIUDAD DE QUITO", cuyo contenido, ideas y criterios son de nuestra exclusiva responsabilidad y autoría.

Quito, 23 de Agosto 2014.

Francisco Javier Parreño Coba 


\section{DEDICATORIA}

Este proyecto se los dedico a mis padres Consuelo e Iván, y a mis hermanos Santiago y Juan Carlos; por brindarme siempre apoyo y consejos acertados, por sus esfuerzos y cariño, por estar siempre a mi lado en cada paso que doy, por ser el pilar y la fuente de energía, que hoy me ha permitido alcanzar este logro en mi vida.

Francisco Javier Parreño Coba

Quiero dedicar este triunfo a mi Creador quien fue fortaleciéndome y sustentándome a lo largo de este proceso de formación, a mi madre por su amor, entrega y fe para ver hoy cristalizado un sueño. A mis hermanos que siempre estuvieron presentes.

Marco Antonio García Benalcazar 


\section{AGRADECIMIENTO}

Agradezco a Dios, por acompañarme y guiar, cada uno de los pasos que di a lo largo de mi vida universitaria, por infundirme la fuerza y entereza necesaria para alcanzar este sueño de verme hoy formado.

A mi universidad la "ESPE" y su cuerpo de docentes, en especial al Dr. Nikolai Espinosa y al Ing. Darwin Aguilar, por su apoyo y consejos durante el desarrollo de este proyecto.

A ECTV, y los ingenieros Henry Díaz y Luis Bravo, por compartir abiertamente sus conocimientos y facilitar los recursos técnicos a su disposición de forma oportuna.

Francisco Javier Parreño Coba

En primer lugar quiero darle las gracias a Mi Papa Dios por su amor incondicional durante todos los días de mi vida, a la familia del Centi porque fue el instrumento para ser formado. A mi Madre Lidia Benalcazar que ha sido un pilar fundamental en mi crecimiento integral. A cada miembro de mi familia que ha sido participe de este proceso. Todo lo que han sembrado a través de los anos seguro se vera recompensado.

Marco Antonio García Benalcazar 


\section{ÍNDICE GENERAL}

PORTADA

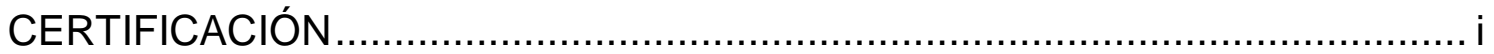

DECLARACIÓN DE RESPONSABILIDAD ............................................... ii

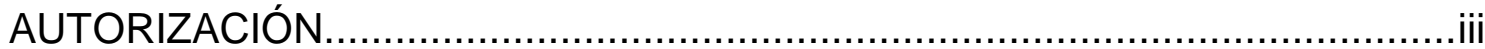

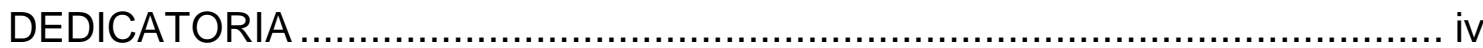

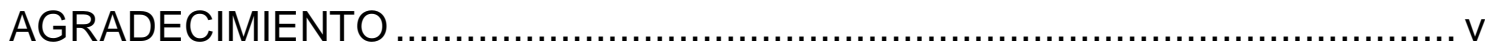

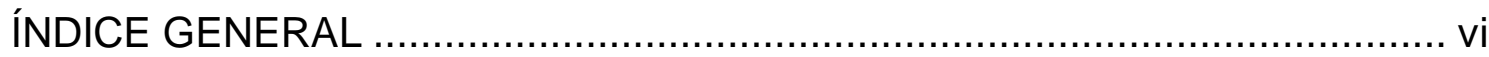

ÍNDICE DE TABLAS ............................................................................ ix

ÍNDICE DE ILUSTRACIONES.................................................

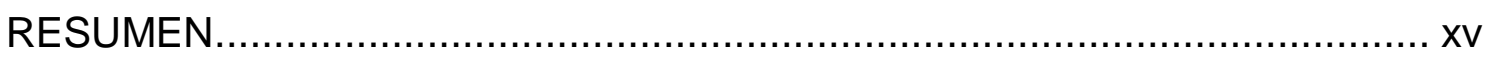

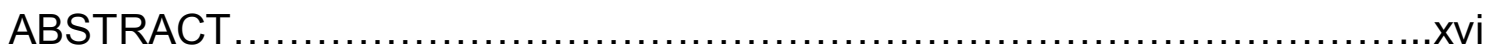

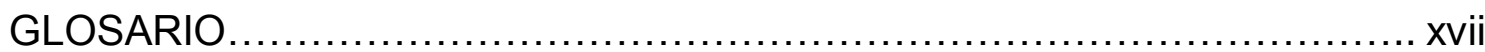

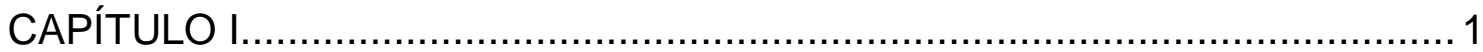

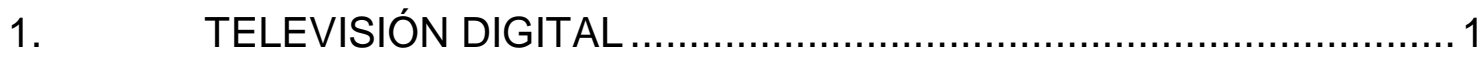

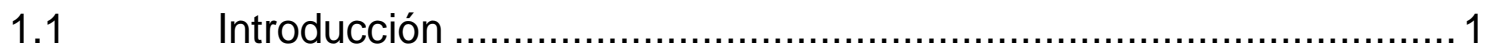

$1.2 \quad$ Transición de TV analógica a Digital.............................................. 3

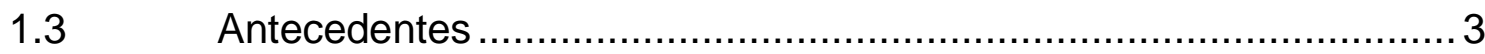

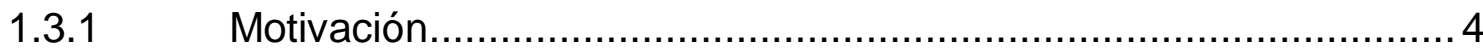

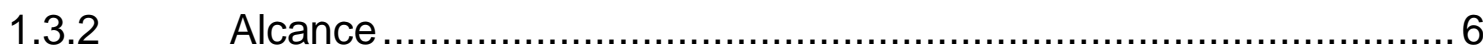

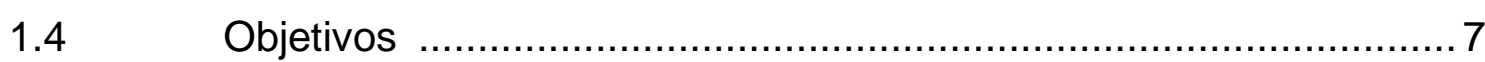

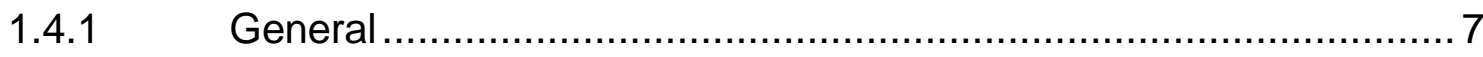

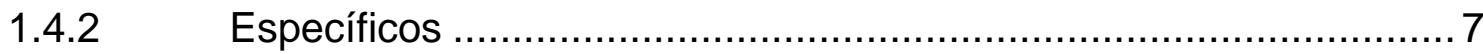

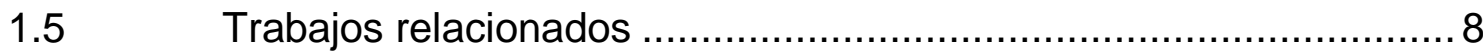

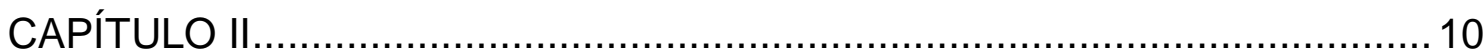

2. CARACTERÍSTICAS Y PARÁMETROS DE LA TELEVISIÓN

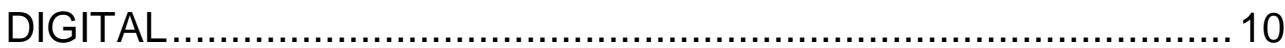

2.1 Estándares de televisión digital ............................................ 12

2.1.2 Estado de la televisión digital en la región ...................................13

2.1.3 Estado de la televisión digital en el Ecuador ................................. 22

2.1.3.1 Estándar de televisión adoptado por el Ecuador ..........................23

2.1.3.2 Proyección para el apagón analógico ..........................................24

$2.2 \quad$ Estudio del arte en el Ecuador .................................................25 
2.2.1 Aspectos técnicos del servicio ........................................... 25

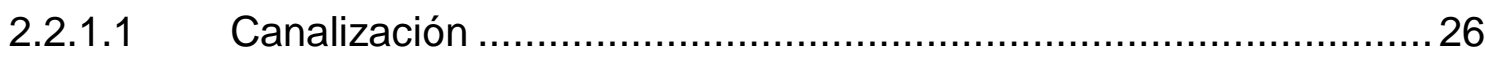

2.2.1.2 Categorías de las estaciones .................................................... 30

2.2.1.3 Parámetros de transmisión ......................................................... 30

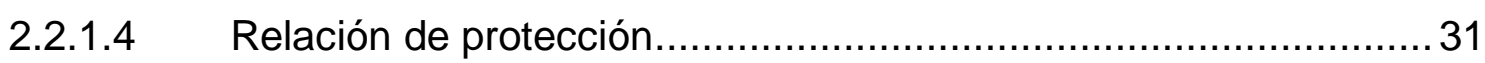

2.2.1.5 Equipos transmisores para estaciones de televisión .................... 45

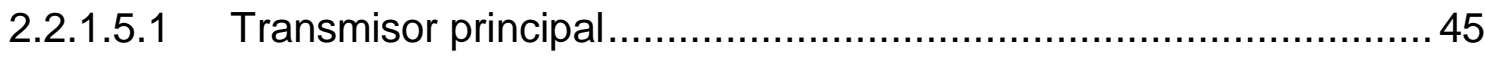

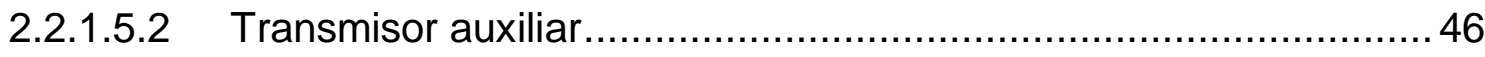

2.2.1.6 Estaciones reforzadoras de señal GAPFILLER ..........................46

2.2.1.7 Sistema Radiante................................................................... 48

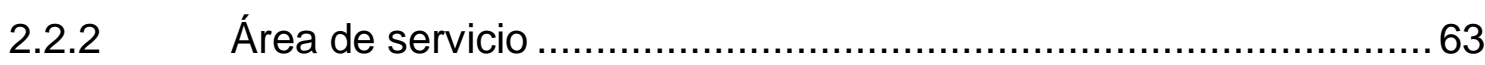

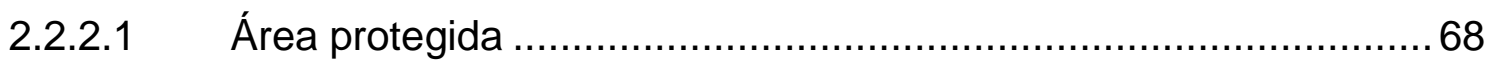

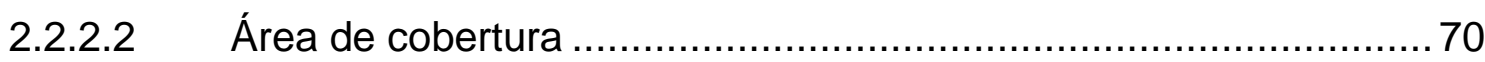

2.2.3 Ubicación de las estaciones transmisoras...................................71

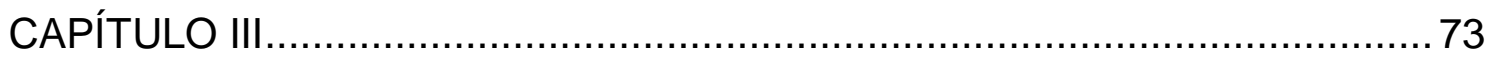

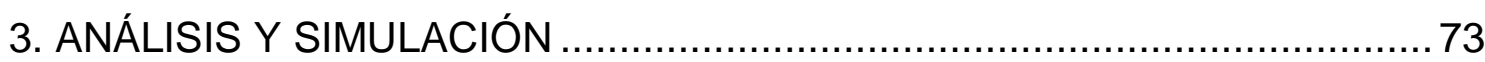

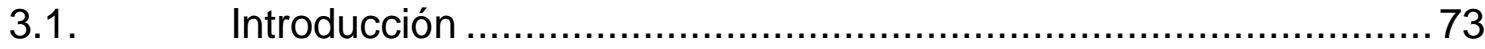

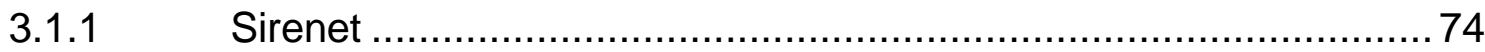

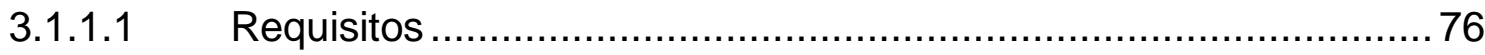

3.2. Mapas georeferenciados................................................... 77

3.3. Análisis de requerimientos .................................................. 78

3.3.1. Limitación de la zona de cobertura ........................................ 78

3.3.2. Elección de equipos receptores .............................................. 79

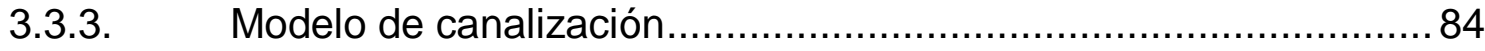

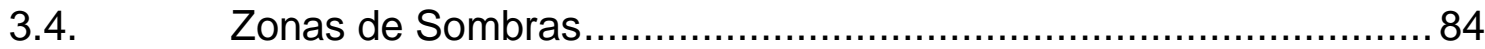

3.4.1 Parámetros técnicos de transmisión ......................................... 84

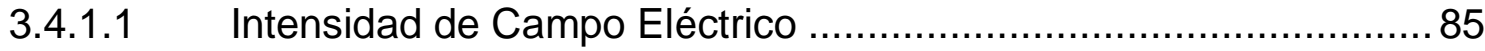

3.4.1.2 MER (Tasa de Error en la Modulación) …................................. 86

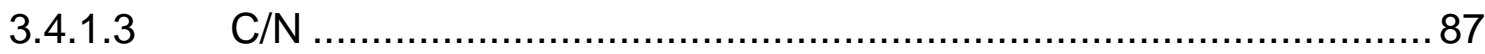

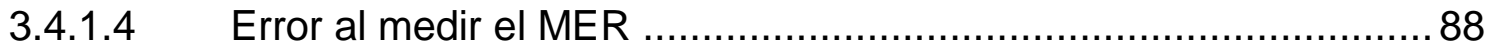

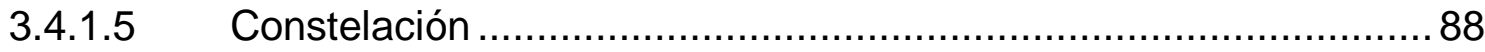

3.4.1.6 BER (Tasa de Errores de Bits) .............................................. 89

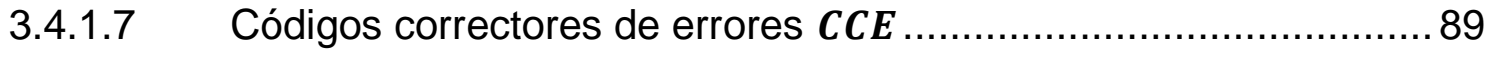




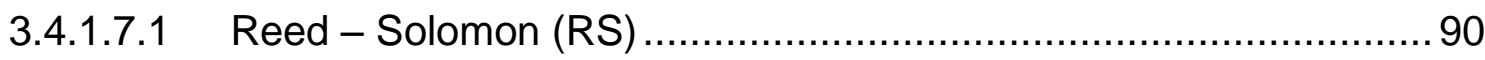

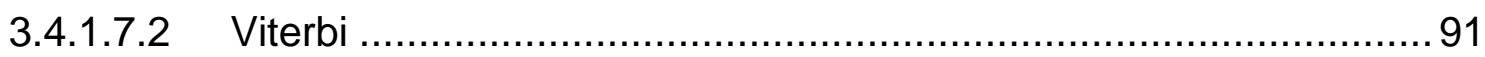

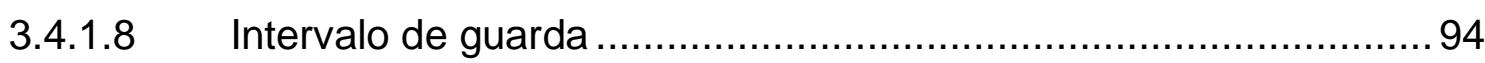

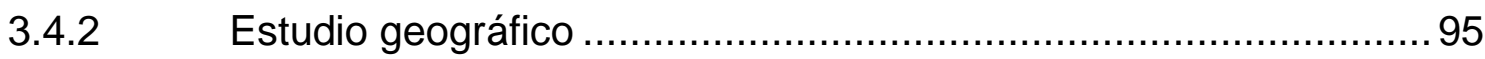

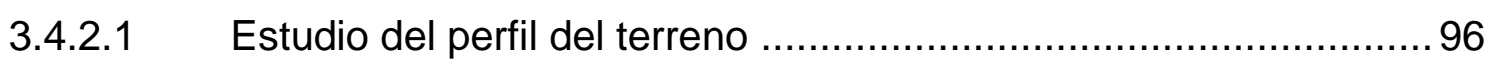

3.4.2.2 Definición de las Zonas de Sombra ............................................. 98

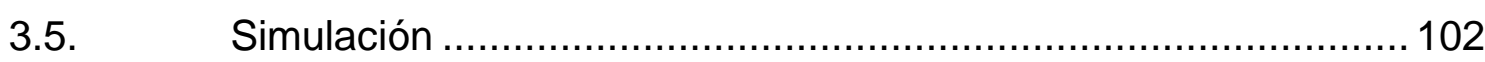

3.5.1 Simulación de Cobertura........................................................ 103

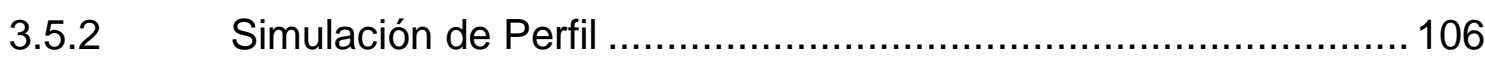

3.5.3 Ubicación de GAPFILLER ................................................... 112

3.5.3.1 Estación reforzadora Sur de Quito .......................................... 112

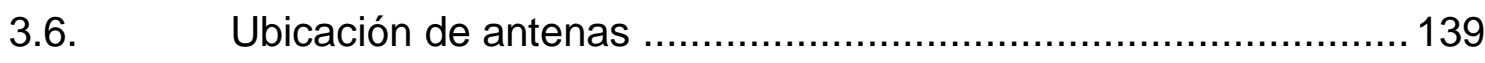

3.7. Análisis de simulación.......................................................... 141

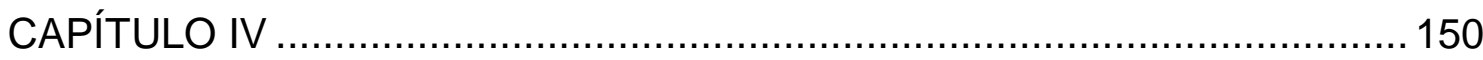

4. MEDICIONES Y ANÁLISIS DE RESULTADOS ......................... 150

4.1. Definición del protocolo de pruebas ......................................... 150

4.2. Mediciones y pruebas de campo ............................................ 151

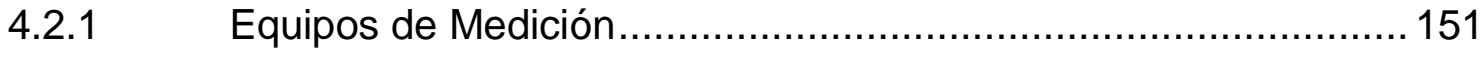

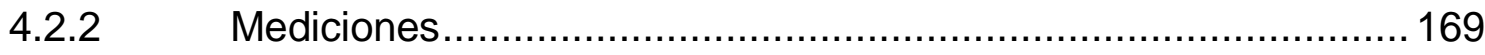

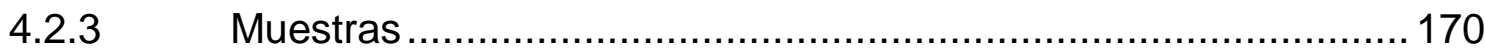

4.3. Análisis de parámetros de radiación ......................................... 178

4.4. $\quad$ Análisis de resultados obtenidos ........................................... 180

4.5. Desventajas y limitaciones ................................................... 182

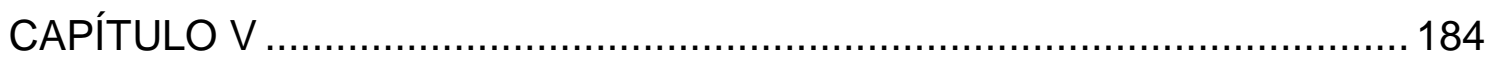

5. CONCLUSIONES Y RECOMENDACIONES .............................. 184

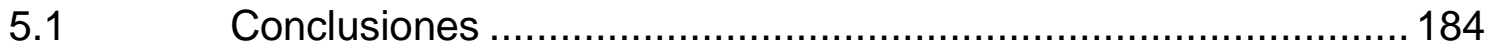

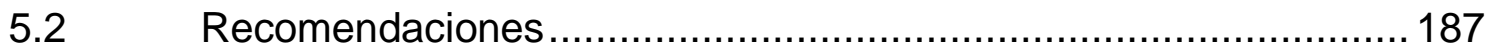

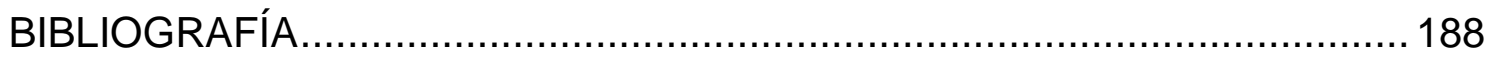

ANEXOS .................................................. Error! Bookmark not defined. 


\section{ÍNDICE DE TABLAS}

Tabla 2.1: Estándares de televisión en el mundo......................................... 13

Tabla 2.2: Estado de TDT en el Brasil. ....................................................... 14

Tabla 2.3: Estado de TDT en el Perú........................................................... 15

Tabla 2.4: Estado de TDT en la Argentina. .................................................. 16

Tabla 2.5: Estado de TDT en la Argentina. .................................................. 17

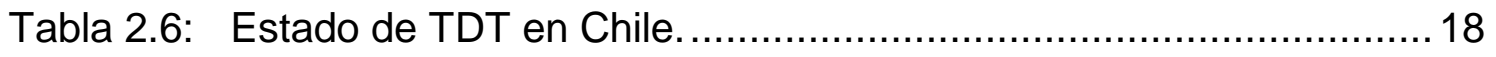

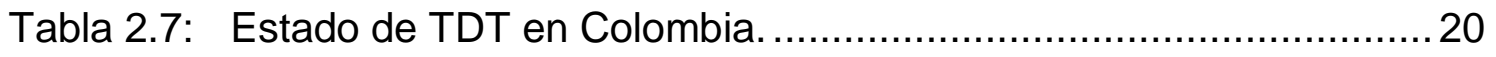

Tabla 2.8: Canalización del servicio de televisión digital terrestre ...................26

Tabla 2.9: Asignación de canales en la banda VHF................................... 27

Tabla 2.10: Asignación de canales en la banda VHF.................................... 28

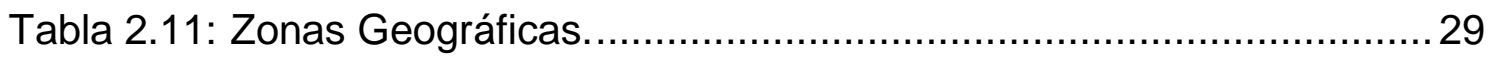

Tabla 2.12: Categoría de estaciones de televisión......................................... 30

Tabla 2.13: Parámetros de transmisión. ...................................................... 31

Tabla 2.14: Relación de protección de interferencias ..................................... 32

Tabla 2.15: Estándares Análogos - Digital de televisión.................................. 33

Tabla 2.16: Canales Digitales en operación (Quito)........................................ 33

Tabla 2.17: Consideraciones técnicas del GAPFILLER de OMB. ................... 48

Tabla 2.18: Consideraciones técnicas del Tx Digital. ......................................51

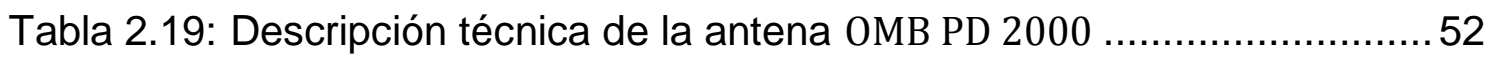

Tabla 2.20: Parámetros técnicos de operación de la estación de Ecuador Tv. 54

Tabla 2.21: Detalle de las dimensiones de la caseta de transmisión de ECTV.58

Tabla 2.22: Parámetros de consideración en la transmisión Análogo / Digital. 61

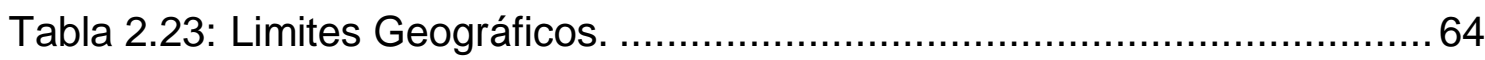

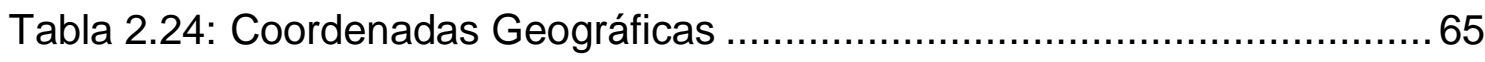

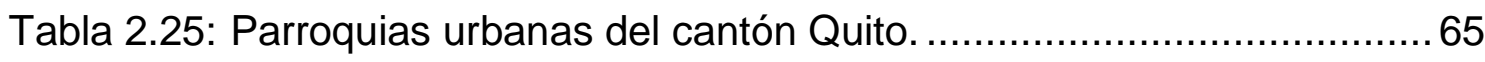

Tabla 2.56: Parroquias rurales del cantón Quito............................................ 66

Tabla 2.27: Requerimientos para recepción interna en el contorno de la zona

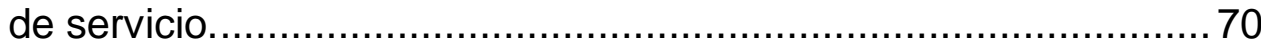

Tabla 2.28: Requerimientos para recepción externa en sitios dentro del

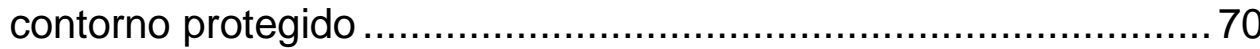

Tabla 2.29: Coordenadas geográficas del Tx de ECTV en el cerro Pichincha. 72 
Tabla 3.1: Componentes del hardware, receptor. .......................................... 82

Tabla 3.2: Parámetros de la unidad receptor. ................................................ 83

Tabla 3.3: Objetivos distantes de cobertura, con relación al cerro Pichincha. 98

Tabla 3.4: Rango de valoración de ICE...................................................... 106

Tabla 3.5: Coordenadas del GAPFILLER - Loma de Puengasí.....................113

Tabla 3.6: Coordenadas del GAPFILLER - La Ferroviaria. ........................115

Tabla 3.7: Coordenadas del GAPFILLER - Mitad del Mundo. .................... 118

Tabla 3.8: Descripción técnica para los canales adyacentes...................... 130

Tabla 3.9: Datos técnicos del transmisor. ............................................... 132

Tabla 3.10: Potencia y campo eléctrico obtenidos de la transmisión en la misma torre pero a diferente altura.................................................... 133

Tabla 3.11: Datos técnicos del transmisor. .............................................. 134

Tabla 3.12: Potencia y campo eléctrico obtenidos de la transmisión en una misma torre y a la misma altura. ............................................. 136

Tabla 3.13: Datos técnicos del transmisor. ............................................. 137

Tabla 3.14: Potencia y campo eléctrico obtenidos de la transmisión en dos

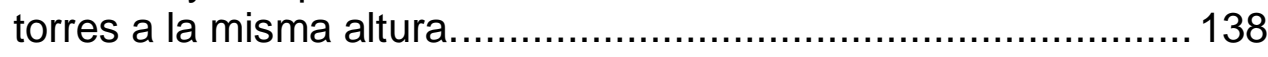

Tabla 3.15: Potencia y campo eléctrico obtenidos al analizar la compatibilidad electromagnética............................................................. 144

Tabla 4.1: Factor K del canal 26 (ECTV). ............................................ 161

Tabla 4.2: Valores promedio del ICE, a lo largo del Drive Test................... 171

Tabla 4.3: Valores promedio del ICE, a lo largo del Drive Test................... 174

Tabla 4.4: Valores promedio del ICE, a lo largo del Drive Test................... 175

Tabla 4.5: Valores promedio del ICE, a lo largo del Drive Test................... 177

Tabla 4.6: Valores promedio del ICE, a lo largo del Drive Test................... 178 


\section{ÍNDICE DE ILUSTRACIONES}

Figura 2.1: Representación grafica del estado de la TDT en América..............21

Figura 2.2: Transmisión análogo/digital de televisión....................................29

Figura 2.2.1: Distribución espectral de canales A/D..................................... 34

Figura 2.2.2: Distribución espectral de canales A/D.34

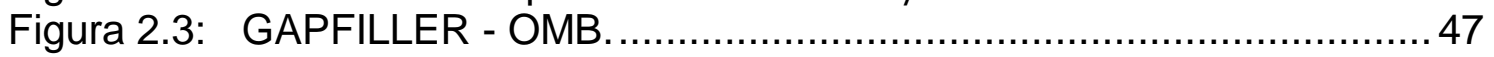

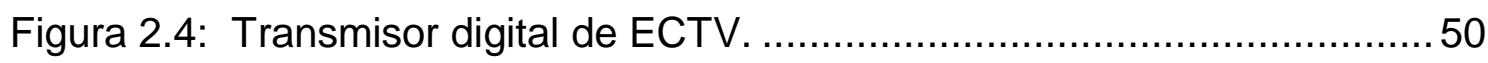

Figura 2.5: Transmisor analógico de ECTV. ............................................. 51

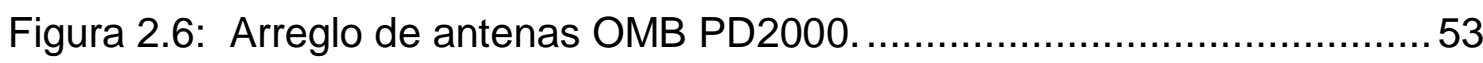

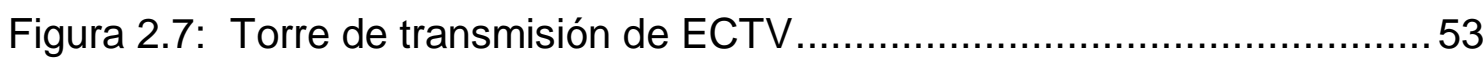

Figura 2.8: Red eléctrica del cerro Pichincha..............................................56

Figura 2.9: Banco de baterías FIRMESA ................................................... 57

Figura 2.10:Vista frontal de la caseta de transmisión de ECTV. .....................59

Figura 2.11:Vista lateral de la caseta de transmisión de ECTV.......................59

Figura 2.12:Vista interior de la caseta de transmisión de ECTV. .....................60

Figura 2.13: Área de servicio, análogo - digital. ............................................. 62

Figura 2.14: Representación grafica del enlace $\mu 0$, entre el estudio de ECTV

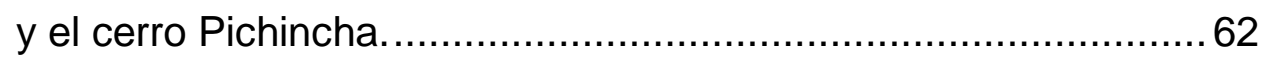

Figura 2.15: Mapa parroquial del distrito metropolitano de Quito. ....................66

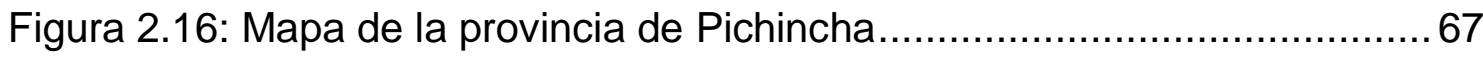

Figura 2.17: Representación grafica del área protegida, entre el Tx y Rx. ........68

Figura 2.18: Curvas para la determinación del campo eléctrico.......................69

Figura 3.1: Ambiente grafico de SIRENET ................................................... 75

Figura 3.2: Estructura básica de un receptor digital. .................................... 80

Figura 3.3: Arquitectura de la unidad receptora. ......................................... 81

Figura 3.4: Zona de cobertura mínima, bajo el estándar ISDB - Tb............... 85

Figura 3.5: Representación grafica del MER. (Chuurei, 2011) ....................... 86

Figura 3.6: Bloques Transmisión / Recepción participantes en la calidad

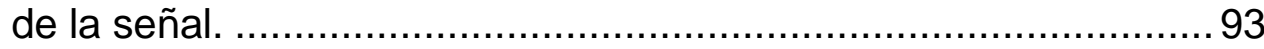

Figura 3.7: Representación grafica del intervalo de guarda (Tg).................... 95

Figura 3.8: Representación gráfica de las Zonas de Sombra..........................96 
Figura 3.9: Enlace en Google Earth, entre el Cerro Pichincha y la Parroquia de Chillogallo. 97

Figura 3.10: Zona de sombra, Mitad del Mundo..............................................99

Figura 3.11: Zona de sombra, Chillogallo. .................................................. 99

Figura 3.12: Zona de sombra, Tumbaco. ................................................. 100

Figura 3.13: Zona de sombra, Conocoto Alto.............................................. 100

Figura 3.14: Zona de sombra, Cumbayá........................................................ 101

Figura 3.15: Zona de sombra, El Panecillo. ............................................... 101

Figura 3.16: Cobertura del transmisor de ECTV, con azimut de $45^{\circ} \ldots \ldots \ldots \ldots . . . .104$

Figura 3.17: Cobertura del transmisor de ECTV, con azimut de 135 $5^{\circ} \ldots \ldots \ldots . . .105$

Figura 3.18: Perfil de cobertura, Mitad del Mundo. ................................... 107

Figura 3.19: Perfil de cobertura, Sur de Quito .......................................... 108

Figura 3.20: Perfil de cobertura, Conocoto Alto. ........................................ 109

Figura 3.21: Perfil de cobertura, Cumbayá Alto. ......................................... 110

Figura 3.22: Perfil de cobertura, Panecillo. .............................................. 111

Figura 3.23: Zona de Sombra, Sur de Quito. ............................................ 113

Figura 3.24: Cobertura de GAPFILLER - Loma de Puengasi. ...................... 114

Figura 3.25: Cobertura de GAPFILLER - Loma de Puengasí, con relación a la zona Sur de Quito. ........................................................ 115

Figura 3.26: Cobertura de GAPFILLER (Ferroviaria). .................................116

Figura 3.27: Cobertura de GAPFILLER - Ferroviaria, con relación a la zona Sur de Quito......................................................................... 117

Figura 3.28: Zona de Sombra Mitad del Mundo........................................ 118

Figura 3.29: Cobertura de GAPFILLER (Mitad del Mundo).......................... 119

Figura 3.30: Cobertura de GAPFILLER (Mitad del Mundo) con relación a la zona Mitad del Mundo........................................................ 120

Figura 3.30: Selección de un nuevo estudio, Interferencia sobre Receptor.... 121

Figura 3.31: Escenario de simulación de la interferencia sobre receptor. ...... 122

Figura 3.32: Ventana de identificación del transmisor................................. 123

Figura 3.33: Ventana de identificación de los parámetros de radio................ 124

Figura 3.34: Ventana de identificación de los parámetros de la antena. ........ 124

Figura 3.35: Ventana de identificación del transmisor................................. 125

Figura 3.36: Ventana de identificación de los parámetros de radio. ................ 126

Figura 3.37: Ventana de identificación de los parámetros de la antena. ........ 126 
Figura 3.38: Ventana de identificación del receptor.

Figura 3.39: Ventana de identificación de los parámetros de radio.

Figura 3.40: Ventana de identificación de los parámetros de la antena. ........ 128

Figura 3.41: Ventana de identificación de los parámetros de la antena. ........ 129

Figura 3.42: Transmisión a diferentes alturas.

Figura 3.43: Resultados de la simulación de interferencia sobre receptor en Sirenet.

Figura 3.44: Resultados de la simulación de interferencia sobre receptor en Sirenet.

Figura 3.45: Transmisión en una misma torre.

Figura 3.46: Resultados de la simulación de interferencia sobre receptor en Sirenet.

Figura 3.47: Resultados de la simulación de interferencia sobre receptor en Sirenet.

Figura 3.48: Transmisión en dos torres 136

Figura 3.49: Resultados de la simulación de interferencia sobre receptor en Sirenet.

Figura 3.50: Resultados de la simulación de interferencia sobre receptor en Sirenet.

Figura 3.51: Poca posibilidad de interferencia. ........................................ 140

Figura 3.52: Gran posibilidad de interferencia......................................... 140

Figura 4.1: Equipo de medición ETL TV Analyzer.................................... 152

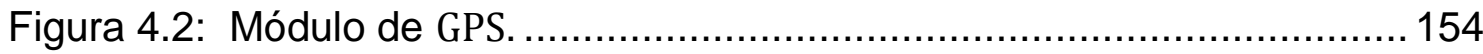

Figura 4.3: Estándares interpretados por el analizador TV R\&S ETL............ 155

Figura 4.4: Interfaz gráfica del Software, R\&S BCDRIVE Broadcast Drive

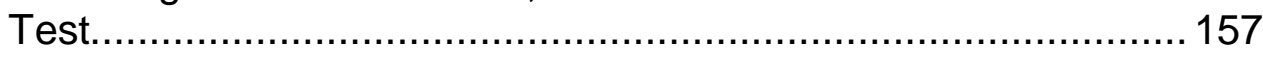

Figura 4.5: Configuración de las unidades de medición y estándar de Tv..... 158

Figura 4.6: Selección y configuración de Hardware. ................................... 159

Figura 4.7: Ventana de inicialización del moduló GPS................................. 160

Figura 4.8: Ventana de configuración de parámetros de antena................... 161

Figura 4.9 Ventana de configuración de la frecuencia intermedia y asignación de nombre al Test Drive.......................................... 162

Figura 4.10:Ventana de configuración de mediciones.................................. 163

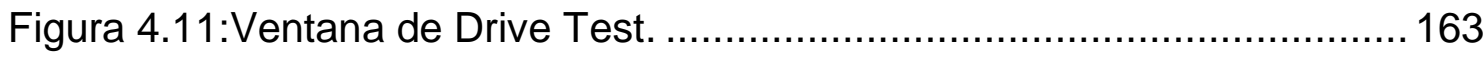

Figura 4.12:Visualización de resultados en Google Earth ............................ 164 
Figura 4.13: Ventana de selección de archivos............................................... 165

Figura 4.14: Ventana de configuración de parámetros de configuración......... 165

Figura 4.15: Ventana de discriminación de mediciones. ................................ 166

Figura 4.16: Ventana de asignación de patrón de colores a las variables a

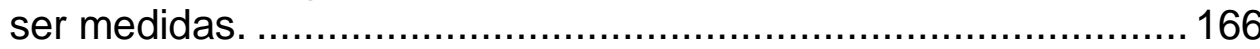

Figura 4.17: Ventana de confirmación de la creación de archivos . kmz......... 167

Figura 4.18: Ventana de importación de archivos a Ecxel. ........................... 167

Figura 4.19: Ventana de selección de archivos.......................................... 168

Figura 4.20: Creación de archivos . csv .................................................. 168

Figura 4.21: Muestras tomadas en la ruta, La Pampá - San Antonio - El Condado.

Figura 4.22: Porcentaje de cobertura por colores, La Pampá - San Antonio - El Condado. ........................................................................ 171

Figura 4.23: Muestras tomadas en la ruta, El Condado - Cotocollao............. 172

Figura 4.24: Porcentaje de cobertura por colores, El Condado - Cotocollao. 172

Figura 4.25: Muestras tomadas en la ruta, Cotocollao - Atucucho. ................ 173

Figura 4.26: Porcentaje de cobertura por colores, Cotocollao - Atucucho...... 173

Figura 4.27: Muestras tomadas en la ruta, Cochapamba - La Gasca - NNUU. .174

Figura 4.28: Porcentaje de cobertura por colores, Cochapamba - La Gasca NNUU. 175

Figura 4.29: Muestras tomadas en la ruta, Cima de La Libertad - La Mena Atahualpa 176

Figura 4.30: Porcentaje de cobertura por colores, Cima de La Libertad - La Mena - Atahualpa

Figura 4.3: Muestras tomadas en la ruta, Miraflores - La Mascota - San Gabriel.

Figura 4.32:Porcentaje de cobertura por colores, Miraflores - La Mascota - San Gabriel.

Figura 4.33:Resumen Ruta, La Pampá - San Antonio - El Condado 180

Figura 4.34:Resumen Ruta, Cima de la Libertad - La Mena - Atahualpa 181 


\section{RESUMEN}

El presente proyecto se enfoca en la simulación de Cobertura y Campo Electromagnético (CEM) de un operador de Televisión Digital en funcionamiento en el distrito metropolitano de Quito bajo el estándar ISDB-Tb elegido por el país, respaldado con pruebas de campo a través de un DRIVE TEST que permita medir los niveles de recepción de señal en recorridos establecidos con el fin de identificar su huella digital, área de cobertura, potencia de recepción y a partir de estos resultados determinar si es necesario o no el uso de estaciones repetidoras conocidas como GAP FILLERS, las mismas que funcionan como amplificadores de señal que brindarán cobertura en lugares que el transmisor principal no provea de señal, a la vez que describe el estudio de compatibilidad electromagnética que permitirá conocer si existe interferencia al momento de operar con la tecnología analógica y digital simultáneamente en una etapa conocida como SIMULCAST. Todo esto para proponer un diseño que optimice la red del operador elegido, garantizando un servicio de calidad y evitando encontrar interferencias lo que facilitará la implementación de la Televisión Digital Terrestre hasta llegar al momento del apagón analógico proyectado para el año 2018.

Palabras Claves: Cobertura, Compatibilidad, Digital, ISDB - Tb, Sirenet. 


\section{ABSTRACT}

This project focuses on the simulation of Electro Magnetic Field and Coverage (EMC) of a digital television operator operating in the metropolitan district of Quito under the ISDB-Tb standard chosen by the country, backed by field tests through TEST DRIVE one to measure the levels of signal reception in established routes in order to identify their fingerprint, coverage area, reception power and from these results it is necessary to determine whether or not the use of relay stations known as GAP FILLERS, the same that function as signal amplifiers that provide coverage in places that do not provide the main transmitter signal, while describing the study of electromagnetic compatibility which will reveal if there is interference when operating with analog and digital technology simultaneously in a stage known as SIMULCAST. All this to propose a design that optimizes the chosen network operator, ensuring quality service and avoiding interference we find that facilitate the implementation of the digital terrestrial television until the time of the analog switch designed for 2018.

Keywords: Coverage, Compatibility, Digital, ISDB -Tb, Sirenet. 


\section{GLOSARIO}

ATSC: $\quad$ (Advanced Television Systems Committee). Comité de Sistemas de Televisión Avanzados.

BER: $\quad$ Tasa de Errores de Bit.

CCE: $\quad$ Código Corrector de Errores.

C/N: Relación Portadora a Ruido.

CONATEL: Consejo Nacional de Telecomunicaciones.

DTS: $\quad$ (Decoding Time Stamps). Marcador de Tiempo de Decodificación.

DTV: $\quad$ (Digital Television). Televisión Digital.

DVB: $\quad$ (Digital Video Broadcasting). Radiodifusión de Televisión Digital.

ECTV: $\quad$ Televisión Pública del Ecuador, Ecuador TV.

GAPFILLER: Estación Reforzadora de Señal.

GPS: $\quad$ Sistema de Posicionamiento Global.

HDTV: $\quad$ (High Definition Television). Televisión de Alta Definición.

HD: $\quad$ Alta Definición.

ICE: Intensidad de Campo Eléctrico.

ISDB-T: (Integrated Services Digital Broadcasting Terrestrial). Servicios Integrados de Radiodifusión Digital - Terrestre. 
ISDB-Tb: (Integrated Services Digital Broadcasting Terrestrial Brazil).

Servicios Integrados de Radiodifusión Digital - Terrestre Brasil.

MER: $\quad$ Tasa de Error de Modulación.

MINTEL: Ministerio de Telecomunicaciones y de la Sociedad de la Información

MPEG: $\quad$ (Moving Picture Experts Group). Grupo de Expertos de Imágenes en Movimiento.

OFDM: (Orthogonal Frequency Division Multiplexing), Multiplicación por División de Frecuencias Ortogonales.

One Seg: (One Segment). Servicio de transmisión digital terrestre y datos complementarios para dispositivos móviles.

PIRE: $\quad$ Potencia Isotópica Radiada Eficaz.

RF: $\quad$ Radio Frecuencia.

RS: $\quad$ (Reed - Solomon). Código Corrector de Errores.

RX: $\quad$ Receptor.

PIB: $\quad$ Producto Interno Bruto

QAM: (Quadrature Amplitude Modulation). Modulación de amplitud en cuadratura.

QPSK: (Quadrature Phase Shift Keying). Modulación de fase en cuadratura.

SBTVD: $\quad$ Sistema Brasilero de Televisión Digital.

SDTV: $\quad$ (Standard Digital Televisión). Televisión de Definición estándar. 
SFN: $\quad$ Red de Frecuencia Simple.

SIMULCAST: Operación Simultanea de Radiodifusión.

SIRENET: Simulation of Radio Electric Networks.

STB: $\quad$ (Set Top Box). Receptor de Televisión Digital.

TDT: $\quad$ Televisión Digital Terrestre.

TMCC: (Transmission qnd Multiplexing Configuration Control). Control y Configuración de Multiplexación y Transmisión.

TS: $\quad$ (Transport Stream). Flujo de Datos.

TX: $\quad$ Transmisor.

UHF: $\quad$ Ultra Alta Frecuencia.

UIT: $\quad$ Unión Internacional de Telecomunicaciones.

VHF: $\quad$ Muy Alta Frecuencia. 


\section{CAPÍTULO I}

1. TELEVISIÓN DIGITAL

\subsection{Introducción}

La televisión ha sido considerada como el invento más influyente en los últimos 100 años, constituyéndose actualmente en el medio de comunicación con mayor alcance y penetración demográficamente influenciando en el pensamiento actual y por ende en el desarrollo de una sociedad.

De la composición de dos palabras se puede dar una definición etimológica TELE-VISIÓN, cuyo significado es ver a distancia.

En los primeros años del siglo XXI, se ha evidenciado un significativo avance tecnológico a nivel mundial, dentro de este ámbito el sector de las telecomunicaciones a sido directamente influenciado.

En la actualidad las telecomunicaciones se han definido como un sector estratégico, por ser una parte importante en el desarrollo economía de un país.

La tendencia mundial por un mejor servicio, así como la creciente demanda en procura de un servicio de alta calidad, generó a nivel regional la postura de 
adoptar la televisión digital; como la solución más idónea de satisfacer la creciente demanda.

El espectro radioeléctrico es una de los recursos no renovables claves en los que el ente Estatal debe intervenir, gestionándolo óptimamente. El uso del Espectro Radioeléctrico, como recurso finito o limitado (escaso, en la terminología tradicional), debe ser planificado y ordenado con la suficiente previsión que permita mantener el desarrollo del mercado apoyando transversalmente al desarrollo sostenible de todas las actividades económicas del país y, por ende, el crecimiento del PIB.

La situación actual, es que las políticas de liberalización, las innovaciones tecnológicas, el éxito que ha experimentado la Televisión Digital Terrestre (TDT), los servicios y aplicaciones de valor añadido desarrollados y la evolución de los terminales de usuario han incrementado la presión de llevar a cabo un estudio técnico que permita la operación simultánea (SIMULCAST), en primera instancia de las señales Analógicas y Digitales de Televisión; proceso que necesariamente deberá darse en el país, pues se ha planificado el apagón analógico hasta el 2016 en las principales ciudades del país y hasta el 2018 en todo el país. 
El dividendo digital es la estrategia que actualmente ofrece mayores oportunidades. En este contexto, varios son los retos a tener en cuenta para su plena adopción, siendo los más relevantes los siguientes:

\subsection{Transición de TV analógica a Digital}

La transición de la Televisión Analógica a la Televisión Digital, no solo por la economía del espectro que ello supone y que es la base del dividendo digital sino por la notable mejora del servicio y la convergencia con otras tecnologías.

\subsection{Antecedentes}

- El 25 de marzo del 2010 el Consejo Nacional de Telecomunicaciones resolvió, adoptar el estándar de TDT ISDB-T Internacional (Integrated Services Digital Bradcasting Terrestrial) para el Ecuador, con las modificaciones brasileras.

- $\quad$ El 29 de Julio del 2011 el CONATEL resuelve delegar al Ministerio de Telecomunicaciones como organismo coordinador y director del proceso de Implementación Digital Terrestre en el Ecuador. 
- $\quad$ De acuerdo a la agenda establecida por el Departamento pertinente del organismo encargado para el control de la implementación, actualmente se encuentra en la etapa de "Recepción de estudios para concesiones definitivas".

- Actualmente se maneja dos sistemas para la transmisión de televisión en el país (Analógico y Digital), existiendo en la actualidad algunas operadoras que trabajan bajo el estándar digital así (ECTV, Oromar TV, ECUAVISA), en similar camino se encuentran el resto de operadoras con señal abierta que han digitalizado sus set de televisión, proyectándose hacia la migración total de su infraestructura de transmisión.

- $\quad$ La Universidad de la FF.AA-ESPE cumpliendo con su deber de fomentar e incentivar la investigación y desarrollo científico ha venido desarrollando varios proyectos relacionados al proceso de implementación del estándar adoptado. En tal virtud plantea el estudio sobre la canalización y compatibilidad electromagnética que permita una correcta asignación de frecuencias para el funcionamiento de la televisión digital.

\subsubsection{Motivación}

Una vez indicado el 2016 como el año estimado en el que se realizará el apagón analógico en las principales ciudades del Ecuador, las operadores de TV existentes han iniciado a trabajar en la migración de su tecnología de 
análoga a digital, teniendo en cuenta que este es un proceso que alcanza no solamente el cambio de equipos tecnológicos y de radiodifusión sino demás procesos de transmisión de televisión como programación en general. En tal virtud ya se encuentran en transmisión con señales de prueba, expuestas a evaluaciones y para objeto de análisis varias operadoras principalmente en las ciudades de Quito y Guayaquil; Al no contar con un modelo de ejecución o protocolo de pruebas establecido que garantice que las frecuencias otorgadas a cada operadora, así como la ubicación de las estaciones transmisoras o repetidoras por nombrar algunos aspectos a considerar sean las correctas para su optimo funcionamiento, es razón evidente para plantear un estudio que ponga en consideración aspectos técnicos, matemáticos y geográficos como zonas de cobertura, zonas muertas, etc. para elaborar un modelo con un protocolo de pruebas establecido considerando el estado de funcionamiento con tecnología mixta(SIMULCAST) mientras ocurre el apagón analógico con pruebas de campo que soporten las recomendaciones a emitirse con el objeto de que dicho estudio sirva como soporte para futuras operadoras que inicien su proceso de migración.

A tiempo que con el anhelo de servir a nuestro país y ser participe con un grano de arena para el crecimiento social se enfoca dicho estudio a investigación para el desarrollo tecnológico por medio directo para el avance económico y social. 


\subsubsection{Alcance}

Se definirán un proveedor de televisión que se encuentre operando con señal analógica y que pretendan migrar a la tecnología digital, permitiéndole la transmisión de televisión digital en su área de cobertura y cuya matriz se encuentre en la ciudad de Quito.

Realizar una investigación sobre optimización de la distribución actual del espectro radioeléctrico y el planeamiento de frecuencias a otorgarse a las transmisoras de televisión digital.

Una vez se posea la información detalla y se conozca la realidad en el sector se procederá a realizar una simulación en la herramienta Sirenet en donde mediante una variación de parámetros de transmisión definidos por el estándar y normas internacionales se obtenga el mejor rendimiento del sistema en base a localización, potencia de transmisión, solapamiento, interferencia, cobertura, frecuencia; y se definan limitaciones y se pueda garantizar la posibilidad de operatividad mixta es decir análogo-digital durante un periodo de transición y establecer una referencia para la asignación de las frecuencias definitivas a ser entregadas.

Se realizarán pruebas técnicas aleatorias que sustenten y validen, los resultados obtenidos en el proceso de simulación (transmisor de ECTV), a fin 
de obtener un patrón de muestras que permita identificar las ventajas o limitaciones que puedan presentarse.

Al finalizar el Proyecto se definirán los parámetros de transmisión más adecuados para cada estación de televisión elegida previamente; sirviendo como referencia para esta empresa a fin de estudiar la factibilidad de realizar la transición a futuro de TV Digital.

\subsection{Objetivos}

\subsubsection{General}

Realizar el estudio y simulación para la optimización de la canalización digital que permita asignar frecuencias para la operación de operadoras de TDT en la ciudad de Quito.

\subsubsection{Específicos}

- Levantamiento de la información requerida referente a los estándares existentes sobre TDT.

- Definir el estándar elegido por el País conociendo su arquitectura y funcionamiento. 
- Determinar los proveedores de TV (Estaciones transmisoras) que se utilizarán para la simulación.

- $\quad$ Establecer la zona de trabajo de acuerdo a los requerimientos y parámetros técnicos, necesarios para la Transmisión de Televisión Digital Terrestre (TDT) de las operadora determinada.

- Realizar simulación del trabajo a desplegar en el software SIRENET facilitado por la ESPE y respaldado por la empresa desarrolladora APTICA-ESPAÑA.

- Realizar las mediciones dentro de los parámetros mínimos establecidos por normas, organismos de control y regulación; nacionales como internacionales.

- Diseñar los mapas de cobertura indicando zonas de alcance y estudios respecto a interferencia y solapamiento de frecuencias.

- $\quad$ Efectuar pruebas aleatorias sobre los procesos de simulación que sustenten el trabajo realizado.

\subsection{Trabajos relacionados}

El proceso de inclusión de televisión digital está en su etapa de implementación, por lo que a nivel local no existe un registro de trabajos similares de acuerdo al alcance que se evidencia en este documento, sin embargo para la decisión de adoptar el estándar Brasilero Japonés, existe un 
reporte de varios trabajos relacionados al tema, desde estudios de factibilidad, hasta aplicaciones de interactividad en revisión digital.

Se enuncian algunos proyectos en base a lo indicado:

"Estudio y análisis de factibilidad para la implementación de la televisión digital terrestre en el Ecuador"

http://dspace.ups.edu.ec/bitstream/123456789/1435/13/UPS-CT002165.pdf.

“Incidencia de la Televisión Digital Terrestre en las estaciones televisivas ecuatorianas"

http://www.advicom.ec/userFiles/files/Publicaciones/PAPER\%20TESISFINAL-PRV-AR\%20-\%20MGRTII\%20(NOV\%202011).pdf

“Incidencia de la Televisión Digital Terrestre en las estaciones televisivas ecuatorianas"

http://dspace.espoch.edu.ec/bitstream/123456789/179/1/38T00167.pdf

Los trabajos antes expuestos como se ha manifestado hacen mención a la etapa previa a la implementación, en el Ecuador un proyecto de tesis enfocado a considerar aspectos propios de la ejecución de la migración no tiene registro por lo que este trabajo es pionero, en nuestro país. 


\section{CAPÍTULO II}

\section{CARACTERÍSTICAS Y PARÁMETROS DE LA TELEVISIÓN DIGITAL}

El resultado de los evidentes avances tecnológicos, la reducción de tamaño de los circuitos electrónicos y fundamentalmente de la migración de sistemas analógicos a digitales ha generado las nuevas aplicaciones en el campo de las telecomunicaciones incluyendo técnicas y modos de difusión con una gran mejora en calidad y mayor diversidad de servicios.

Desde el aparecimiento de la televisión en la década de los 70's su evolución ha sido vertical a lo largo de los años pues es sin duda el medio de comunicación con mayor alcance a nivel mundial; para adquirir un concepto global a continuación el significado etimológico de la palabra televisión.

Televisión proviene de la composición de las palabras, griega (TELE) y de latín (VISION); las cuales juntas enuncian (Ver a Distancia).

Siendo necesario para el proceso de la comunicación contar con los elementos necesarios como Emisor - Transmisor - Receptor, cuyas características necesarias se detallaran en capítulos posteriores, TELEVISIÓN DIGITAL. 
A finales de la década de los 70 se experimento una evolución en la que se da lugar a la digitalización, sistemas computacionales, electrónicos que empezaron a convertirse en digitales, para esto la televisión también experimenta dicho fenómeno, manifestándose en dos etapas, la digitalización en la producción y en la transmisión.

La televisión digital presenta las siguientes características entre las principales:

- Utilización eficaz de las frecuencias, ya que las técnicas de compresión de datos están disponibles, en formatos:

Eje. MPEG2, AVC/H.264, etc.

- $\quad$ Los errores de datos que ocurren dentro de ciertos límites pueden ser completamente corregidos utilizando técnicas de corrección de errores, tales como:

Eje. RS, Viterbi, Turbo, LDPC, etc.

- Diferentes contenidos pueden ser multiplexados en un flujo de transmisión.

Eje. MPEG2-Systems

- $\quad$ Tasa de error de bits está disponible para evaluar el sistema de transmisión. 
En lo que corresponde a la producción se plantea digitalizar los componentes de la señal de video, como luminancia y los sistemas de color con sus diferencias obteniendo un resultado favorable. Se desarrollan sistemas de señales en paralelo que requieren de gruesos cables para cada bit, requiriendo el uso de gran cantidad de cables que luego seria sustituida por la transmisión multiplexada.

Técnicas de compresión permitieron alcanzar la digitalización en la transmisión al reducir el flujo de bits a menos de $5 \mathrm{Mbps}$, entendiendo que una señal de calidad es de 270Mbps. MPEG-2 permite dicha compresión ya que produce flujos entre 4 y 6 Mbps sin generar perdidas apreciables. El estándar MPEG es actualmente usado a nivel mundial para la comprensión de video en televisión digital.

\subsection{Estándares de televisión digital}

Desde el aparecimiento de la televisión digital se han venido desarrollando estudios en varias regiones lo que ha originado se definan algunos estándares a nivel de acuerdo a la región donde se originaron o al requerimiento entendido por cada país. 
Tabla 2.1:

Estándares de televisión en el mundo. (NCK- CTI Training manual , 2011)

\begin{tabular}{|c|c|c|c|c|c|}
\hline & JAPÓN & EUROPA & EEUU & BRASIL & OTROS \\
\hline $\begin{array}{c}\text { TV Terrestre } \\
\text { TDT }\end{array}$ & ISDB-T & $\begin{array}{l}\text { DVB-T } \\
\text { DVB-T2 }\end{array}$ & ATSC & & $\begin{array}{l}\text { DTMB } \\
\text { (CDMB-T) }\end{array}$ \\
\hline $\begin{array}{l}\text { TV Satelital } \\
\text { TDS }\end{array}$ & $\begin{array}{l}\text { ISDB-S (BS) } \\
\text { DVB_S (CS) } \\
\text { DVB_S2 (CS) }\end{array}$ & $\begin{array}{l}\text { DVB_S } \\
\text { DVB_S2 }\end{array}$ & $\begin{array}{l}\text { DSS (Direct TV) } \\
\text { DVB_S (Echo Star) }\end{array}$ & & \\
\hline Radio móvil digital & ISDB-TSB & $\begin{array}{l}\text { DRM, DRN } \\
\text { DAB } \\
\text { DAB+ }\end{array}$ & $\begin{array}{l}\text { v } 120 \mathrm{MHz}) \\
\text { IBOC (Radio HD) }\end{array}$ & & \\
\hline $\begin{array}{c}\text { TV Digital } \\
\text { Portable/Móvil }\end{array}$ & ISDB-T1Seg & $\begin{array}{l}\text { DVB-H } \\
\text { T-DMB }\end{array}$ & FLO Media & & T-DMB \\
\hline $\begin{array}{l}\text { Radio Satelital } \\
\text { SDARS }\end{array}$ & S-DMB & DVB-SH & $\begin{array}{l}\mathrm{XM} \\
\text { Sirius }\end{array}$ & & \\
\hline
\end{tabular}

\subsubsection{Estado de la televisión digital en la región}

Es una realidad que la televisan Digital se ha posesionado también en el continente americano, dejando atrás y con intención de reemplazo absoluto a la televisión analógica, después de casi un siglo desde su puesta en escena, dicha realidad se observa en dos posturas, la de algunos países que discuten la manera de implementar el cambio, y países que ya disfrutan de las ventajas de la Televisión Digital.

A continuación se detalla el estado de los principales países de la región respecto a la Televisión Digital, de tal manera que se pueda identificar las experiencias que pueden resultar de beneficio para su implementación en el Ecuador. 


\section{Brasil}

Norma: ISDB-Tb.

Transmisión: Full HD 1080i - 1Seg.

Fecha de la primera transmisión: domingo 2 de diciembre de 2007

Fecha del apagón analógico: miércoles 26 de junio del 2016.

Canales actualmente transmitiendo por TDT (solo en Rio de Janeiro):

Tabla 2.2:

Estado de TDT en el Brasil. (Estado de la TDT en América Latina, EPN, 2013)

\begin{tabular}{|lc}
\hline \multicolumn{1}{c}{ Nombre del canal } & Canal/Frecuencia \\
\hline Fundacao Veneza de TV e Radio Educativa & 45 \\
\hline Globo Comunicaçao e Part. & 29 \\
Radiobras Empresa Brasileira de Comunicaçao & 41 \\
Radio e Televisao Bandeirantes do Rio de Janeiro & 35 \\
Televisao Record Do Rio de Janeiro & 39 \\
\hline TV Corcovado & 27 \\
TV Ômega & 21 \\
TVSBT - Canal 11 do Rio de Janeiro & 24 \\
Cámara dos Deputados & 61 \\
Televisao Independente de S. J. do Rio Preto & 22 \\
Rede Mulher de Televisao & 53 \\
Canal Brasileiro da Informacao CBI & 16 \\
\hline Senado Federal & 62 \\
Abril Radiodifusao & 47 \\
\hline Fundacao Universo & 31 \\
\hline
\end{tabular}

Brasil fue el primer país en la región en iniciar con las transmisiones digitales de televisión, por tal razón actualmente es el país que mas avanzado se encuentra en el tema. Es el creador de la norma ISDB-Tb, adopción del sistema Japonés ISDB.T, con modificaciones realizadas básicamente en salto de códec de video y aumento de la velocidad de cuadros por segundo a 30. 


\section{Perú}

Norma: ISDB-Tb.

Transmisión: Full HD 1080i - 1Seg.

Fecha de la primera transmisión: Marzo de 2010.

Fecha del apagón analógico: martes 28 de julio de 2020.

Canales actualmente transmitiendo por TDT:

\section{Tabla 2.3:}

Estado de TDT en el Perú. (Estado de la TDT en América Latina, EPN, 2013)

\begin{tabular}{cc}
\hline Nombre del canal & Canal/Frecuencia \\
\hline TV-PERÚ & 16 \\
ATV & 18 \\
Frecuencia Latina & 20 \\
Global TV & 22 \\
América Televisión & 24 \\
Panamericana Televisión & 26 \\
La Tele & 28 \\
Perú TV & 32 \\
Enlace Perú & 34 \\
Bethel Televisión & 36 \\
RBC Televisión & 38 \\
\hline
\end{tabular}

Perú fue el segundo país de la región en seleccionar la norma ISDB-Tb como la definitiva para las transmisiones TDT. Actualmente está en progreso de aumentar la cobertura digital hacía el resto del país, ya que las primeras transmisiones comenzaron sólo en Lima, para luego quedar a la espera del apagón Analógico. 


\section{Argentina}

Norma: ISDB-Tb.

Transmisión: Full HD 1080i - 1Seg.

Fecha de la primera transmisión: domingo 7 de septiembre de 2008.

Fecha del apagón analógico: Se estima para el año 2019.

Canales actualmente transmitiendo por TDT:

Tabla 2.4:

Estado de TDT en la Argentina. (Estado de la TDT en América Latina, EPN, 2013)

\begin{tabular}{ccc}
\hline Nombre del Canal & $\begin{array}{c}\text { Canal / } \\
\text { Frecuencia }\end{array}$ & Cobertura \\
\hline Encuentro & 22.1 & Nacional \\
Paka Paka & 22.2 & Nacional \\
TaTeTi & 22.3 & Nacional \\
Incaa TV & 22.4 & Nacional \\
Encuentro Móvil & 22.5 & Nacional \\
TV Pública HD & 23.2 & Nacional \\
Tecnópolis & 23.3 & Nacional \\
TV Pública Móvil & 23.31 & Nacional \\
DEPORTV & 24.1 & Nacional \\
Vivra & 24.2 & Nacional \\
Suri TV & 24.3 & Nacional \\
Arppegio & 24.4 & Nacional \\
Viajar & 24.5 & Nacional \\
DEPORTV Móvil & 24.5 & Nacional \\
CN23 & 25.1 & Nacional \\
C5N & 25.2 & Nacional \\
Telesur & 25.3 & Nacional \\
G360 TV (Generación & 25.4 & Nacional \\
360 TV) & & Nacional \\
Construir & 25.5 & \\
CN23 Móvil & 25.31 & \\
\hline
\end{tabular}


Tabla 2.4:

Estado de TDT en la Argentina. (Estado de la TDT en América Latina, EPN, 2013)

\begin{tabular}{|c|c|c|}
\hline Canal 26 & 26.1 & Solo para Capital Federal y \\
\hline Telemax & $26 ?$ & Soln nara Canital Federalv \\
\hline temax & $\angle 0.2$ & Buenos Aires \\
\hline C5N HD & 27.1 & $\begin{array}{c}\text { Solo para Capital Federal y } \\
\text { Buenos Aires }\end{array}$ \\
\hline Stars HD & 27.2 & Solo para Capital Federal y \\
\hline C5N Móvil & 27.31 & $\begin{array}{c}\text { Solo para Capital Federal y } \\
\text { Buenos Aires }\end{array}$ \\
\hline Canal 13 HD & 99.1 & $\begin{array}{c}\text { Solo para Capital Federal y } \\
\text { Buenos Aires }\end{array}$ \\
\hline Canal 13 STD & 99.2 & $\begin{array}{c}\text { Solo para Capital Federal y } \\
\text { Buenos Aires }\end{array}$ \\
\hline Canal 13 Móvil & 99.3 & $\begin{array}{c}\text { Solo para Capital Federal y } \\
\text { Buenos Aires }\end{array}$ \\
\hline Telefe HD & 34.2 & $\begin{array}{c}\text { Solo para Capital Federal y } \\
\text { Buenos Aires }\end{array}$ \\
\hline Telefe SD & 34.3 & $\begin{array}{c}\text { Solo para Capital Federal y } \\
\text { Buenos Aires }\end{array}$ \\
\hline Telefe Móvil & 34.31 & $\begin{array}{c}\text { Solo para Capital Federal y } \\
\text { Buenos Aires }\end{array}$ \\
\hline Canal 9 HD & 35.2 & $\begin{array}{c}\text { Solo para Capital Federal y } \\
\text { Buenos Aires }\end{array}$ \\
\hline Canal 9 SD & 35.3 & $\begin{array}{c}\text { Solo para Capital Federal y } \\
\text { Buenos Aires }\end{array}$ \\
\hline Canal 9 1seg & 35.31 & $\begin{array}{c}\text { Solo para Capital Federal y } \\
\text { Buenos Aires }\end{array}$ \\
\hline América HD & 36.1 & $\begin{array}{c}\text { Solo para Capital Federal y } \\
\text { Buenos Aires }\end{array}$ \\
\hline A24 & 36.2 & $\begin{array}{c}\text { Solo para Capital Federal y } \\
\text { Buenos Aires }\end{array}$ \\
\hline América $1 \mathrm{seg}$ & 36.31 & $\begin{array}{c}\text { Solo para Capital Federal y } \\
\text { Buenos Aires }\end{array}$ \\
\hline
\end{tabular}

Es evidente que Argentina está bien avanzada en el tema TDT con algunos canales al aire. Actualmente está en proceso de ampliar su cobertura al resto 
del país, según la penetración de TDT se estima que la fecha del apagón analógico podría ser antes.

\section{Chile}

Norma: ISDB-Tb.

Transmisión: Full HD 1080i - 1Seg.

Fecha de la primera transmisión o selección de la norma: 14 de Septiembre de 2009.

Fecha del apagón analógico: Se estima para el año 2017.

Canales actualmente transmitiendo por TDT:

Tabla 2.5:

Estado de TDT en Chile. (Estado de la TDT en América Latina, EPN, 2013)

\begin{tabular}{cc}
\hline Nombre del canal & Canal/Frecuencia \\
La Red Digital & 4.1 \\
La Red Móvil & 4.2 \\
TVN HD1 & 7.1 \\
TVN SD & 7.2 \\
TVN Móvil & 7.3 \\
MEGA HD & 9.1 \\
MEGA Móvil & 9.2 \\
Chile visión HD & 11.1 \\
Chile visión Digital & 11.2 \\
Chile visión Móvil & 11.31 \\
Canal 13 HD & 13.1 \\
Canal 13C & 13.2 \\
Canal 13 Móvil & 13.3 \\
El Mostrador HD & 26.1 \\
El Mostrador Móvil & 26.31 \\
lquique TV HD & 25.1 \\
lquique TV Móvil & 25.2 \\
Antofagasta TV HD & 99.1 \\
Antofagasta TV Móvil & 99.2 \\
UCV TV HD & 26.1 \\
UCV TV Móvil & 26.2 \\
Bío Bío TV HD & 25.1 \\
Bío Bío TV Móvil & 25.2 \\
\hline
\end{tabular}




\section{Uruguay}

Norma: ISDB-Tb.

Fecha de la primera transmisión o selección de la norma: 27 de Diciembre de 2010.

Fecha del apagón analógico: 21 de Noviembre de 2015.

Uruguay en un principio, eligió la norma europea DVB-T, autorizando a los canales locales a iniciar pruebas bajo dicha norma. Pero al ver que Ecuador elegía la norma ISDB-Tb, el presidente de ese tiempo José Mujica, decidió abandonar la norma europea y el 27 de diciembre del 2010 eligió a ISDB-Tb como norma definitiva. Como era de esperarse, muchos estuvieron contentos con esta decisión, pero otros no.

Actualmente Uruguay se encuentra haciendo pruebas bajo la norma ISDBTb.

Colombia

Norma: DVB-T.

Transmisión: Full HD 1080i.

Fecha de la primera transmisión o selección de la norma: 21 de Diciembre de 2010.

Fecha del apagón analógico: 31 de Marzo de 2019. 
Canales actualmente transmitiendo por TDT:

Tabla 2.6:

Estado de TDT en Colombia. (Estado de la TDT en América Latina, EPN, 2013)

\begin{tabular}{cc}
\hline Nombre del canal & Canal/Frecuencia \\
\hline Caracol HD & 14.1 \\
Caracol SD & 14.2 \\
RCN HD & 15.1 \\
RCN SD & 15.2 \\
Canal Uno & 16.1 \\
Institucional & 16.2 \\
Señal Colombia & 16.3 \\
\hline
\end{tabular}

Colombia es el único de Sudamérica que eligió otra norma distinta a la que ya seleccionaron la mayoría de sus vecinos. Actualmente Colombia aún se encuentra con canales de prueba, esperando a que los demás canales se unan, para luego aumentar la cobertura dentro del país y finalmente tener todo listo para el Apagón Analógico que se realizará el 31 de marzo del 2019.

\section{México}

Norma: ATSC.

Transmisión: Full HD 1080i.

Fecha de la primera transmisión o selección de la norma: 5 de Julio de 2004.

Fecha del apagón analógico: Se estima para el año 2015.

México vendría siendo uno de los más avanzados junto a Brasil en el tema de la TDT, teniendo varios canales que transmiten de forma definitiva en 
diferentes sectores y ciudades del país. México optó por utilizar la norma de Estados Unidos, y sólo les queda esperar a que llegue el Apagón Analógico o estar atento a las pruebas de transmisión en 3D.

En la siguiente imagen se puede ver qué norma eligieron los países de América Latina y el Caribe:

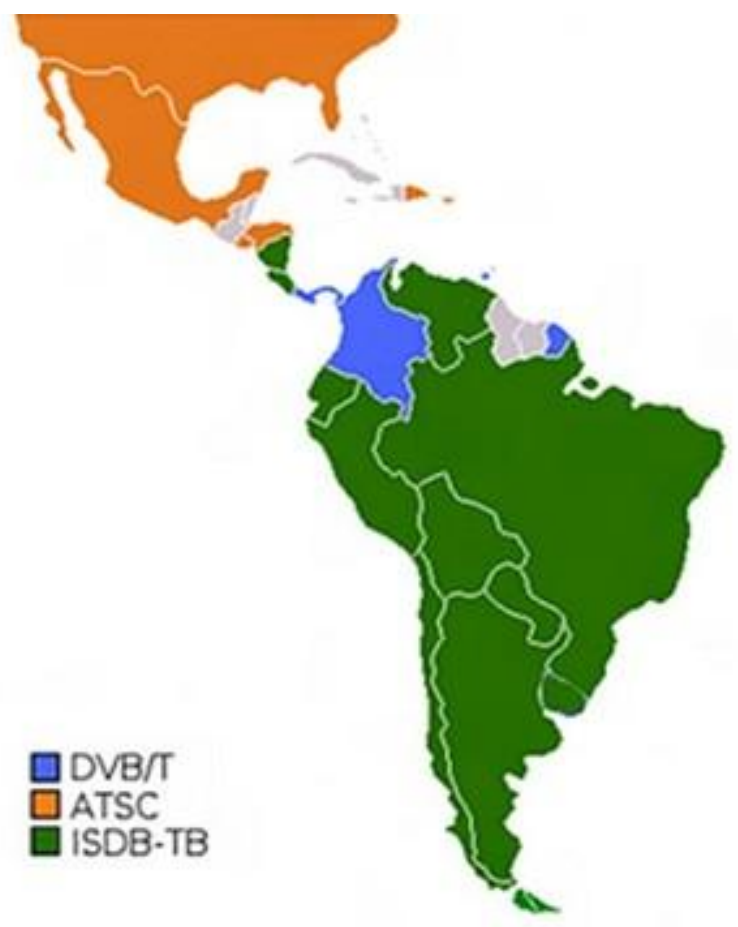

Figura 2.1: Representación grafica del estado de la TDT en América. (NCKCTI Training manual , 2011) 


\subsubsection{Estado de la televisión digital en el Ecuador}

En el Ecuador actualmente se encuentran en funcionamiento 5 operadoras de Televisión emitiendo señal digital:

- TEleamazonas

- $\quad$ ECUAVISA

- OROMAR

- $\quad$ TC TELEVISION

- $\quad$ ECUADOR TV

El primer Operador en incursionar en esta nueva tecnología fue TC televisión cuya primera emisión fue en el mes de Mayo transmitiendo un encuentro deportivo, según indicaron sus autoridades la inversión en equipos y procesos para dicho fin ascendió a los 6 millones de dólares. [REFERENCIA]

La mencionada Operadora actualmente tiene activa dos frecuencias las frecuencia $10.1[\mathrm{KHz}]$ para transmisión digital y al frecuencia $10[\mathrm{KHz}]$ para transmisión convencional estableciendo un periodo de mucha importancia para sobrellevar esta migración en el que es posible emitir señales tanto análogas como digitales, una tecnología mixta llamada (SIMULCAST) que concite en permitir recibir señales análogas mientras se dispone de un equipo capaz de procesar las nuevas señales, o en su defecto de un codificador que permita a los equipo tradicionales también disfrutar las mejoras indicadas. 


\subsubsection{Estándar de televisión adoptado por el Ecuador}

El 25 de Marzo del 2010, el Ecuador adopto el estándar de televisión digital ISDB-Tb (Integratedservice Digital BroadcastingTerrestrial), basado en el desarrollo Japonés y las innovaciones desarrolladas por el Brasil.

ISDB-Tb, ha sido adoptado por el Ecuador, ya que ha demostrado tener un mejor desempeño en cuanto a la TDT se refiere; con basta experiencia y operatividad demostrada tanto en el Japón como el Brasil.

A continuación, se describen algunas de las características técnicas del estándar ISDB-Tb:

- Alta calidad: TDT en alta definición (HD), con $6 \mathrm{MHz}$ de ancho de banda.

- Robustez: Contra ruidos urbanos, desvanecimiento y cualquier tipo de interferencia.

- Flexibilidad de Servicio: El ancho de banda de $6 \mathrm{MHz}$, soporta cualquier tipo de servicio.

- Múltiple Recepción: Acepta recepción, fija, móvil y portátil, en el mismo ancho de banda.

- SFN: Red de Frecuencia Simple, permite desplegar una red única dentro de un mismo estado, en una única frecuencia o canal. 
- Interactividad: Soporta aplicaciones interactivas, en plataformas como Java, Ginga, Androi, etc.

\subsubsection{Proyección para el apagón analógico}

Se planea que el apagón analógico en los canales nacionales se realice en tres fases. En la primera, comprenderá a las poblaciones mayores a los 500 mil habitantes: Quito, Guayaquil y Cuenca.

Luego se hará en las de 200 mil a 500 mil personas, en las capitales de provincia. Finalmente, en los sectores con menos de 200 mil habitantes. Este cronograma para el cese de emisiones analógicas concluirá a finales del 2018.

Hasta antes del lanzamiento oficial de la señal en TC Televisión, Ecuador TV, canal estatal, emitía señales de prueba en Quito con tecnología digital. Pero también espera continuar con pruebas en otras estaciones privadas.

Así mismo, se prepara un plan de distribución de 40 mil codificadores para aquellos ecuatorianos de escasos recursos. El resto de usuarios que no cuenten con aparatos con el estándar brasileño-japonés deberá invertir $\$ 30$ aproximadamente en la adquisición de un decodificador digital. Este recibirá la señal y la transformará, lo que permitirá una calidad seis veces mejor que la analógica, e incluso permitirá el acceso a sitios donde hoy la televisión no llega 
por medio de la ubicación de estaciones repetidoras GAPFILLER obteniendo mayor zona de cobertura.

\subsection{Estudio del arte en el Ecuador}

El estudio del arte detalla las investigaciones que se han realizado hasta el momento en nuestro entorno, dándonos un punto de partida en la presente investigación.

\subsubsection{Aspectos técnicos del servicio}

Los aspectos técnicos del servicio son aquellos que rigen el correcto modo de operación de una estación de televisión, en base a parámetros involucrados en una norma o estándar, definido y regulado por el ente competente de control.

Los cuales serán detallados a continuación, a fin de comprender de forma clara y concisa, los aspectos técnicos presentes en la transmisión de televisión digital en la ciudad de Quito. 


\subsubsection{Canalización}

Los planes de canalización son importantes porque permiten identificar los canales disponibles para ser asignados a la TDT y establecer las especificaciones técnicas (Potencia, Ubicación, etc.) para la coexistencia de ambas tecnologías.

\section{Canalización en la bandas VHF y UHF}

El Servicio Televisión Digital (S-TVDT), se encuentra enmarcado dentro del rango de frecuencias de $512-686 \mathrm{MHz}$, con un ancho de banda por canal de $6 \mathrm{MHz}$, en conformidad con la disponibilidad de frecuencias para una determinada zona geográfica, para lo cual se han definido los siguientes canales.

\section{Tabla 2.7:}

Canalización del servicio de televisión digital terrestre. (Pabón, 2011)

\begin{tabular}{cccc}
\hline $\begin{array}{c}\text { Rango de } \\
\text { Frecuencias [MHz] }\end{array}$ & \multicolumn{2}{c}{ Canal } & $\begin{array}{c}\text { Frecuencia Central } \\
{[\mathrm{MHz}]}\end{array}$ \\
\cline { 2 - 3 } & $\mathbf{N}^{\circ}$ & {$[\mathrm{MHz}]$} & \\
& $19^{*}$ & $(500-506)$ & $503+1 / 7$ \\
& 20 & $(506-512)$ & $509+1 / 7$ \\
& $21^{*}$ & $(512-518)$ & $515+1 / 7$ \\
22 & $(518-524)$ & $521+1 / 7$ \\
& $23^{*}$ & $(524-530)$ & $527+1 / 7$ \\
24 & $(530-536)$ & $533+1 / 7$ \\
& $25^{*}$ & $(536-542)$ & $539+1 / 7$ \\
26 & $(542-548)$ & $545+1 / 7$ \\
& $27^{*}$ & $(548-554)$ & $551+1 / 7$ \\
\hline
\end{tabular}




\begin{tabular}{|c|c|c|c|}
\hline \multirow{15}{*}{ UHF $500-608$} & 28 & $(554-560)$ & $557+1 / 7$ \\
\hline & $29^{*}$ & $(560-566)$ & $563+1 / 7$ \\
\hline & 30 & $(566-572)$ & $569+1 / 7$ \\
\hline & $31^{*}$ & (572 - 578) & $575+1 / 7$ \\
\hline & 32 & $(578-584)$ & $581+1 / 7$ \\
\hline & $33^{*}$ & $(584-590)$ & $587+1 / 7$ \\
\hline & 34 & $(590-596)$ & $593+1 / 7$ \\
\hline & $35^{*}$ & $(596-602)$ & $599+1 / 7$ \\
\hline & 36 & $(602-608)$ & $605+1 / 7$ \\
\hline & $38^{*}$ & $(614-620)$ & $617+1 / 7$ \\
\hline & 39 & $(620-626)$ & $623+1 / 7$ \\
\hline & $40^{*}$ & $(626-632)$ & $629+1 / 7$ \\
\hline & 41 & $(632-638)$ & $635+1 / 7$ \\
\hline & $42^{*}$ & $(638-644)$ & $641+1 / 7$ \\
\hline & 43 & $(644-650)$ & $647+1 / 7$ \\
\hline \multirow[t]{6}{*}{ UHF 614 - 686} & $44^{*}$ & $(650-656)$ & $653+1 / 7$ \\
\hline & 45 & $(656-662)$ & $659+1 / 7$ \\
\hline & 46 & $(662-668)$ & $665+1 / 7$ \\
\hline & 47 & $(668-674)$ & $671+1 / 7$ \\
\hline & 48 & $(674-680)$ & $677+1 / 7$ \\
\hline & 49 & $(680-686)$ & $683+1 / 7$ \\
\hline
\end{tabular}

\section{Grupos de Canales}

\section{- $\quad$ Para señal de Televisión en VHF}

\section{Tabla 2.8:}

Asignación de canales en la banda VHF. (Pabón, 2011)

\begin{tabular}{cc}
\hline Grupos & Canales \\
\hline A1 & 245 \\
A2 & 36 \\
B1 & 81012 \\
B2 & 791113 \\
\hline
\end{tabular}




\section{- $\quad$ Para señal de Televisión en UHF}

\section{Tabla 2.9:}

Asignación de canales en la banda VHF. (Pabón, 2011)

\begin{tabular}{cc}
\hline Grupos & Canales \\
\hline G1 & 192123252729313335 \\
G2 & 202224262830323436 \\
G3 & 394143454749 \\
G4 & 384042444648 \\
\hline
\end{tabular}

\section{Asignación de Canales}

Según la recomendación realizada por el organismo de control (MINTEL), se consideran los grupos de canales en la banda UHF, para la prestación de servicio de televisión digital terrestre, descritos en la Tabla 2.2.1.1.2.

\section{Relación de Protección}

Lo que corresponde al área de cobertura principal y secundaria, pero sin rebosar los límites de la correspondiente zona geográfica.

Solo es posible la utilización de canales adyacentes en una misma localidad si por lo menos uno de ellos utiliza el sistema de transmisión digital. 


\section{Zona Geográfica}

Tabla 2.10:

Zonas Geográficas. (Pabón, 2011)

\begin{tabular}{cccc}
\hline $\begin{array}{c}\text { Zona } \\
\text { Geográfica }\end{array}$ & Definición de Zona & Grupos VHF & $\begin{array}{c}\text { Grupos } \\
\text { UHF }\end{array}$ \\
\hline P1 & $\begin{array}{c}\text { Provincia de Pichincha } \\
\text { (Cantón Quito) }\end{array}$ & A2,B2 & G1,G3 \\
P2 & $\begin{array}{c}\text { Provincia de Pichincha } \\
\text { (Cantón Quito) }\end{array}$ & A1,B1 & G1,G4 \\
\hline
\end{tabular}

Para la operación en canales adyacentes las plantas de transmisión de las estaciones de TV analógicas y digitales deben estar ubicadas en una misma Zona.

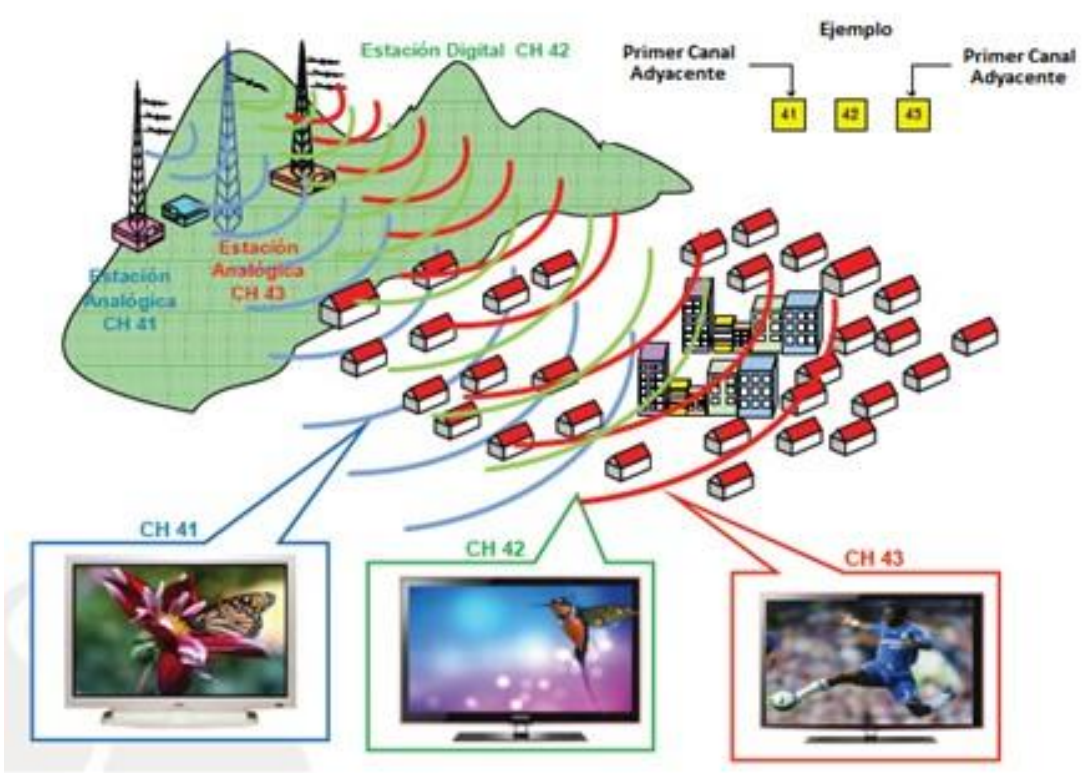

Figura 2.2: Transmisión análogo/digital de televisión.(Espinoza) 


\subsubsection{Categorías de las estaciones}

Las estaciones de televisión se enmarcan dentro de una determinada categoría, en relación a la potencia de transmisión y a la altura efectiva de su antena; de esta manera se han definido seis categorías como se detalla a continuación en la siguiente tabla.

\section{Tabla 2.11:}

Categoría de estaciones de televisión. (Pabón, 2011)

\begin{tabular}{ccc}
\hline $\begin{array}{c}\text { Categoría de } \\
\text { Estación }\end{array}$ & $\begin{array}{c}\text { Potencia Efectiva Máxima } \\
{[\mathrm{dB}]}\end{array}$ & $\begin{array}{c}\text { Altura Efectiva de la } \\
\text { Antena }[\mathrm{m}]\end{array}$ \\
\hline A & 100 & 300 \\
B & 10 & 150 \\
C & 5 & 75 \\
D & 1 & 75 \\
E & 0,5 & 75 \\
F & 0,1 & 45 \\
\hline
\end{tabular}

\subsubsection{Parámetros de transmisión}

Los parámetros de transmisión, están directamente relacionada a las características técnicas presentes en el estándar ISDB-Tb, las mismas que se encuentran detalladas en forma minuciosa en la Tabla 2.12. 
Tabla 2.12:

Parámetros de transmisión. (NCK- CTI Training manual , 2011)

\begin{tabular}{|c|c|c|c|c|}
\hline \multicolumn{2}{|c|}{ Codificación de Video } & \multicolumn{3}{|c|}{ MPEG-2 Video, MPEG-4 } \\
\hline \multicolumn{2}{|c|}{ Formato de Video } & \multicolumn{3}{|c|}{ 1080I, 480P, 480I, QVGA } \\
\hline \multicolumn{2}{|c|}{ Codificación de Audio } & \multicolumn{3}{|c|}{ MPEG-2 Audio (AAC) } \\
\hline \multicolumn{2}{|c|}{ Condiciones de Acceso } & \multicolumn{3}{|c|}{ Multi-2 } \\
\hline \multicolumn{2}{|c|}{ Multiplexación } & \multicolumn{3}{|c|}{ Sistema MPEG - 2} \\
\hline \multicolumn{2}{|c|}{ Radiodifusión de Datos } & \multicolumn{3}{|c|}{ ECTV } \\
\hline \multicolumn{2}{|c|}{ Información de Servicio } & \\
\hline \multirow{12}{*}{$\begin{array}{l}\text { Canal de } \\
\text { transmisión de } \\
\text { codificación }\end{array}$} & \multirow{3}{*}{ Modulación } & \multicolumn{3}{|c|}{$\begin{array}{l}\text { BST-OFDM (QPSK, 16QAM, } \\
64 \text { QAM, DQPSK) }\end{array}$} \\
\hline & & \multicolumn{3}{|c|}{ TransmisiónJerárquica } \\
\hline & & $\begin{array}{l}\text { Modo } 1 \\
(2 \mathrm{~K})\end{array}$ & $\begin{array}{l}\text { Modo } 2 \\
(4 \mathrm{~K})\end{array}$ & $\begin{array}{l}\text { Modo } 3 \\
(8 K)\end{array}$ \\
\hline & No. de Portadoras & 1450 & 2809 & 5617 \\
\hline & $\begin{array}{l}\text { Separación Entre } \\
\text { Portadoras }\end{array}$ & $4 \mathrm{KHz}$ & $2 \mathrm{KHz}$ & $1 \mathrm{KHz}$ \\
\hline & Símbolos Usados & $252 \mu s$ & $504 \mu s$ & $1008 \mu s$ \\
\hline & Intervalo de Guarda & $1 / 32,1 / 1$ & $/ 8,1 / 4$ & \\
\hline & Ancho de Banda & $\begin{array}{l}5.575 \\
\mathrm{MHz}\end{array}$ & $5.573 \mathrm{MHz}$ & $5.572 \mathrm{MHz}$ \\
\hline & $\begin{array}{l}\text { Código Corrector de } \\
\text { Errores }\end{array}$ & $\begin{array}{l}\text { Código i } \\
7 / 8,5 / 6,3\end{array}$ & $\begin{array}{l}\text { rior de conv } \\
2 / 3,1 / 2\end{array}$ & lución \\
\hline & & Código & erior: RS $(20$ & , 188) \\
\hline & Intercalado & Tiempo, & ecuencia, Bi & Byte \\
\hline & Frecuencia & $\begin{array}{l}\text { BST-OF } \\
\text { segmen }\end{array}$ & $\begin{array}{l}\text { M (Estructure } \\
\text { OFDM) }\end{array}$ & \\
\hline $\begin{array}{l}\text { Velocidad de } \\
\text { Datos }\end{array}$ & Arriba de $23.23 \mathrm{MHz}$ & & & \\
\hline
\end{tabular}

\subsubsection{Relación de protección}

La relación de protección es la diferencia en $(\mathrm{dB})$, que debe existir entre canales adyacentes y co-canales, a fin de evitar interferencias; las mismas que 
deberán ser sustentadas a través de pruebas de simulación previa la operación de una estación de televisión digital.

El presente proyecto centra su esfuerzo en el estudio y análisis, de las experiencias japonesas y brasileñas.

A continuación se ilustra la relación en $(\mathrm{dB})$, que debe existir entre los diferentes canales de televisión, analizando el cuadro de relaciones de protección UHF Digital sobre VHF Analógico; propuesto por Japón.

\section{Tabla 2.13:}

Relación de protección de interferencias. (Norma Japonesa). (Channel Planning for Digital Terrestrial Television Broadcasting, 2013)

\begin{tabular}{|c|c|c|c|}
\hline $\begin{array}{r}\text { Señal } \\
\text { deseada }\end{array}$ & $\begin{array}{r}\text { Señal } \\
\text { indeseada }\end{array}$ & Frecuencia & $\begin{array}{l}\text { Relación de } \\
\text { Protección }\end{array}$ \\
\hline \multirow[t]{3}{*}{ Analógico } & \multirow[t]{3}{*}{ Digital } & Co - Canal $(\mathrm{N} \leftarrow \mathrm{N})$ & $45 \mathrm{~dB}$ \\
\hline & & $\begin{array}{l}\text { Canal Adyacente } \\
\text { Inferior } \\
(\mathrm{N} \leftarrow \mathrm{N}-1)\end{array}$ & $0 \mathrm{~dB}$ \\
\hline & & $\begin{array}{l}\text { Canal Adyacente } \\
\text { Superior } \\
(\mathrm{N} \leftarrow N+1)\end{array}$ & $10 \mathrm{~dB}$ \\
\hline \multirow[t]{6}{*}{ Digital } & \multirow[t]{3}{*}{ Analógico } & Co - Canal $(\mathrm{N} \leftarrow \mathrm{N})$ & $20 \sim 30 \mathrm{~dB}$ \\
\hline & & $\begin{array}{l}\text { Canal Adyacente } \\
\text { Inferior } \\
(\mathrm{N} \leftarrow \mathrm{N}-1)\end{array}$ & $-21 d B$ \\
\hline & & $\begin{array}{l}\text { Canal Adyacente } \\
\text { Superior } \\
(\mathrm{N} \leftarrow \mathrm{N}+1)\end{array}$ & $-24 d B$ \\
\hline & \multirow[t]{3}{*}{ Digital } & Co - Canal $(\mathrm{N} \leftarrow \mathrm{N})$ & $28 \mathrm{~dB}$ \\
\hline & & $\begin{array}{l}\text { Canal Adyacente } \\
\text { Inferior } \\
(\mathrm{N} \leftarrow \mathrm{N}-1)\end{array}$ & $-26 d B$ \\
\hline & & $\begin{array}{l}\text { Canal Adyacente } \\
\text { Superior } \\
(\mathrm{N} \leftarrow \mathrm{N}+1)\end{array}$ & $-29 d B$ \\
\hline
\end{tabular}


Tabla 2.1.4:

Estándares Análogos - Digital de televisión. (Channel Planning for Digital Terrestrial Television Broadcasting, 2013)

\begin{tabular}{l}
\hline Analógico $\Rightarrow$ NTSC \\
\hline Digital $\Rightarrow I S D B-$ Tb $(64$ QAM $7 / 8)$ \\
Analógico $\leftarrow$ Digital $\Rightarrow$ Experimental \\
Digital $\leftarrow$ Analógico $\Rightarrow$ Experimental \\
Digital $\leftarrow$ Digital $\Rightarrow$ Experimental \\
\hline
\end{tabular}

Para ello es preciso conocer las estaciones de televisión que se encuentran en operación en la ciudad de Quito y cual es su ubicación en el espectro radioeléctrico.

\section{Tabla 2.1.5:}

Canales Digitales en operación (Quito). (Diseño Propio, 2014)

\begin{tabular}{ccc}
\hline Código & Operadora & Canal \\
\hline ECTV & ECTV & 26 \\
T-AM & Teleamazonas & 32 \\
RTS & RTS & 34 \\
ECUA & Ecuavisa & 36 \\
TSC & Telesucesos & 41 \\
O-TV & Oromar & 47 \\
\hline
\end{tabular}

\begin{tabular}{|c|c|c|c|c|c|c|}
\hline $\boldsymbol{A}$ & $\boldsymbol{D}$ & $\boldsymbol{A}$ & $\boldsymbol{D}$ & $\boldsymbol{A}$ & $\boldsymbol{D}$ & $\boldsymbol{A}$ \\
\hline 31 & 32 & 33 & 34 & 35 & 36 & 37 \\
\hline
\end{tabular}

\begin{tabular}{|l|l|l|l|l|l|l|} 
SI & $T-A M$ & SI & RTS & NO & ECUA & NO \\
\hline
\end{tabular}


Figura 2.2.1.4.1: Distribución espectral de canales A/D. (Diseño Propio, 2014)

\begin{tabular}{l|c|c|}
\hline A & D & A \\
\hline 25 & 26 & 27 \\
\hline \multicolumn{3}{|l}{} \\
\hline SI & ECTV & SI \\
\hline
\end{tabular}

A
\begin{tabular}{|c|c|c|}
\hline 40 & D & A \\
\hline NO & TCS & 42 \\
\hline
\end{tabular}

\begin{tabular}{|c|c|c|}
\hline A & $D$ & A \\
\hline 46 & 47 & 48 \\
\hline SI & O-TV & SI \\
\hline
\end{tabular}

Figura 2.2.1.4.2: Distribución espectral de canales A/D. (Diseño Propio, 2014)

La tabla 2.13, expresa la relación de potencia o energía, que debe existir entre dos canales de televisión, a partir de la ecuación 2.1; con relación a la interpretación matemática ilustrada en la ecuación 2.2.

$$
\text { Relación }=10 \lg \frac{\text { valor } 1}{\text { valor } 2}(d B) ;(E c .2 .1)
$$

La cual hace relaciona, positiva $(+\mathrm{dB})$ o negativamente $(-\mathrm{dB})$, una señal analógica o digital, encasillándola como deseada (D) o indeseada (I).

$$
\frac{D}{I}, \frac{+d B}{-d B}, \frac{D>I}{D<I} ;(E c .2 .2)
$$




\section{Análisis de la relación de protección de interferencias.}

Este análisis permitirá definir la potencia de transmisión que garantice la operación simultánea de canales analógicos y digitales, durante el periodo SYMULCAST.

Tomando en consideración el comportamiento electromagnético de los canales, a través del estudio de los efectos que dicha potencia provocará, definiendo así un valor máximo en la potencia de transmisión a fin de que no exista interferencia de canal Adyacente o Co-canal.

Para ello se estudian cada uno de los casos, enunciados en la tabla 2.13.

\section{Casos:}

\section{Analógico - Digital:}

1.- Debe existir una relación de $45[\mathrm{~dB}]$, entre la seña Digital indeseada y la señal Aanalógica deseada; llamada interferencia Co - Canal $(N \leftarrow N)$.

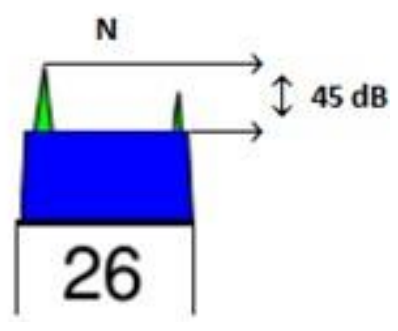




\section{Formula:}

Nivel $(d B)=10 \log \frac{\text { Valor }}{\text { Referencia }}$

\section{Datos:}

Referencia: $2 \mathrm{Kw}$

Nivel $(\mathrm{dB})=45 \mathrm{~dB}$

Solución:

$$
\begin{gathered}
d B=10 \log \frac{\text { Valor }}{2 K w} \\
\text { Valor }=2 K w *\left(10^{4.5 d B}\right) \\
\text { Valor }=63245,55[K w] \\
\text { Valor }=\mathbf{6 3 2 4 6}[\mathbf{K w}]
\end{gathered}
$$

2.- Debe existir una relación de 0 [dB], entre la señal Digital indeseada y la seña Aanalógica deseada; llamada interferencia de Canal Adyacente Inferior (N $\leftarrow \mathrm{N}-1)$.

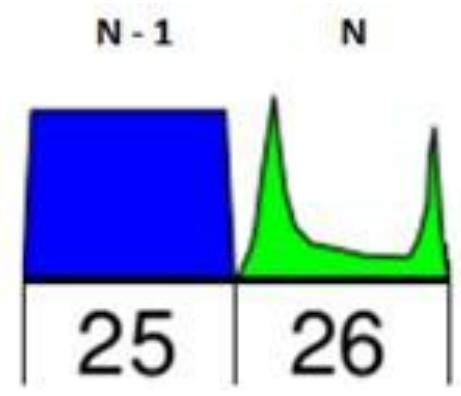




\section{Formula:}

Nivel $(\mathrm{dB})=10 \log \frac{\text { Valor }}{\text { Referencia }}$

\section{Datos:}

Referencia: $2[\mathrm{Kw}]$

Nivel $(\mathrm{dB})=0[\mathrm{~dB}]$

\section{Solución:}

$$
\begin{gathered}
\mathrm{dB}=10 \log \frac{\text { Valor }}{\mathrm{Kw}} \\
\text { Valor }=2[\mathrm{Kw}] *\left(10^{\mathrm{ddB}}\right) \\
\text { Valor }=2[\mathrm{Kw}] *(1) \\
\text { Valor }=2[\mathrm{Kw}]
\end{gathered}
$$

3.- Debe existir una relación de $10 \mathrm{~dB}$, entre la señal Digital indeseada y la señal Aanalógica deseada; llamada interferencia de Canal Adyacente Superior $(\mathrm{N} \leftarrow \mathrm{N}+1)$.

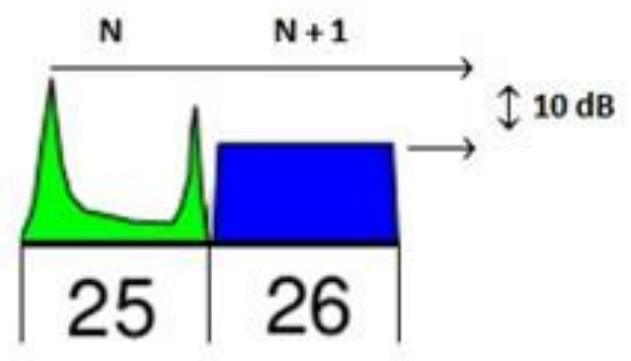




\section{Formula:}

Nivel $(d B)=10 \log \frac{\text { Valor }}{\text { Referencia }}$

\section{Datos:}

Referencia: $2[\mathrm{Kw}]$

Nivel $(\mathrm{dB})=[10 \mathrm{~dB}]$

Solución:

$$
\begin{gathered}
\mathrm{dB}=10 \log \frac{\text { Valor }}{\mathrm{Kw}} \\
\text { Valor }=2 \mathrm{Kw} *\left(10^{1 \mathrm{~dB}}\right) \\
\text { Valor }=20[\mathrm{Kw}] \\
\text { Valor }=20[\mathrm{Kw}]
\end{gathered}
$$

\section{Digital - Analógico:}

4.- Debe existir una relación de $20 \sim 30 \mathrm{~dB}$, entre la seña Aanalógica indeseada y la señal Digital deseada; llamada interferencia Co - Canal $(N \leftarrow N)$.

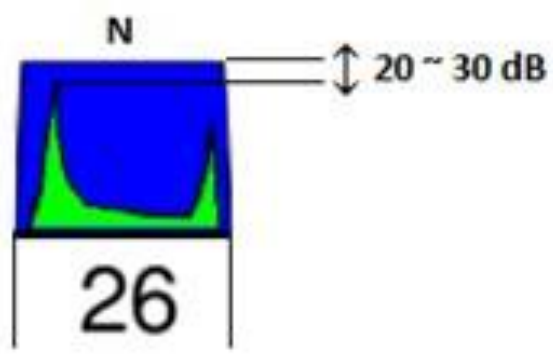




\section{Formula:}

Nivel $(d B)=10 \log \frac{\text { Valor }}{\text { Referencia }}$

\section{Datos:}

Referencia: 6[ Kw]

Nivel $(\mathrm{dB})=20 \sim 30[\mathrm{~dB}]$

\section{Solución:}

(1)

$$
\begin{gathered}
\mathrm{dB}=10 \log \frac{\text { Valor }}{6 \mathrm{Kw}} \\
\text { Valor }=6 \mathrm{Kw} *\left(10^{2 \mathrm{~dB}}\right) \\
\text { Valor }=6[\mathrm{Kw}] * 100 \\
\text { Valor }=600[\mathrm{Kw}]
\end{gathered}
$$

(2)

$$
\begin{gathered}
\mathrm{dB}=10 \log \frac{\text { Valor }}{6 \mathrm{Kw}} \\
\text { Valor }=\mathrm{Kw} *\left(10^{3 \mathrm{~dB}}\right) \\
\text { Valor }=(6 \mathrm{Kw}) * 1000 \\
\text { Valor }=6000[\mathrm{Kw}]
\end{gathered}
$$


5.- Debe existir una relación de $-21 \mathrm{~dB}$, entre la seña Aanalógica indeseada y la señal Digital deseada; llamada interferencia de Canal Adyacente Inferior (N $\leftarrow \mathrm{N}-1)$.

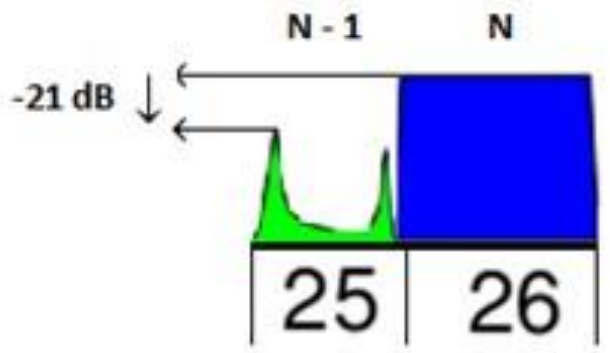

Formula:

Nivel $(\mathrm{dB})=10 \log \frac{\text { Valor }}{\text { Referencia }}$

Datos:

Referencia: $6[\mathrm{Kw}]$

Nivel $(\mathrm{dB})=-21[\mathrm{~dB}]$

Solución:

$$
\begin{gathered}
\mathrm{dB}=10 \log \frac{\text { Valor }}{\mathrm{Kw}} \\
\text { Valor }=6 \mathrm{Kw} *\left(10^{-2.1 \mathrm{~dB}}\right) \\
\text { Valor }=17.96 \approx 18[\mathrm{Kw}] \\
\text { Valor }=18[\mathrm{Kw}]
\end{gathered}
$$


6.- Debe existir una relación de $-24[\mathrm{~dB}]$, entre la señal Analógica indeseada y la señal digital deseada; llamada interferencia de Canal Adyacente Inferior $(\mathrm{N} \leftarrow \mathrm{N}+1)$.

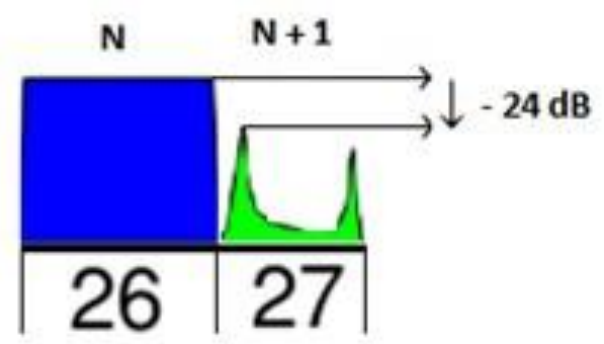

\section{Formula:}

Nivel $(d B)=10 \log \frac{\text { Valor }}{\text { Referencia }}$

\section{Datos:}

Referencia: $6[\mathrm{Kw}]$

Nivel $(\mathrm{dB})=-24[\mathrm{~dB}]$

\section{Solución:}

$$
\begin{gathered}
\mathrm{dB}=10 \log \frac{\text { Valor }}{\mathrm{Kw}} \\
\text { Valor }=6[\mathrm{Kw}] *\left(10^{-2.4 \mathrm{~dB}}\right) \\
\text { Valor }=15.66 \approx 15.7 \mathrm{Kw} \\
\text { Valor }=15.7[\mathrm{Kw}]
\end{gathered}
$$




\section{Digital - Digital:}

7.- Debe existir una relación de $28 \mathrm{~dB}$, entre la seña digital indeseada y la señal digital deseada; llamada interferencia Co - Canal $(N \leftarrow N)$.

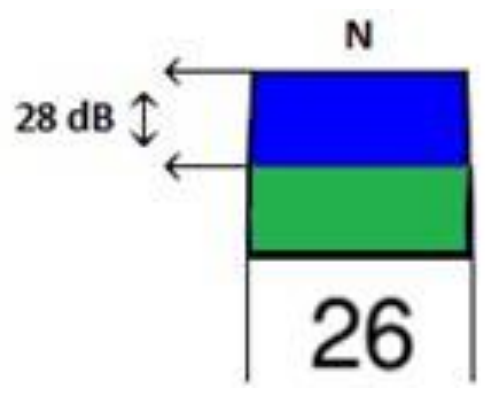

\section{Formula:}

Nivel $(d B)=10 \log \frac{\text { Valor }}{\text { Referencia }}$

\section{Datos:}

Referencia: $2 \mathrm{Kw}$

Nivel $(\mathrm{dB})=28[\mathrm{~dB}]$

\section{Solución:}

$$
\begin{gathered}
\mathrm{dB}=10 \log \frac{\text { Valor }}{\mathrm{Kw}} \\
\text { Valor }=2 \mathrm{Kw} *\left(10^{2.8 \mathrm{~dB}}\right) \\
\text { Valor }=1261.9 \approx 1262 \mathrm{Kw} \\
\text { Valor }=1262[\mathrm{Kw}]
\end{gathered}
$$


8.- Debe existir una relación de $-26 \mathrm{~dB}$, entre la seña digital indeseada y la señal digital deseada; llamada interferencia de Canal Adyacente Inferior $(\mathrm{N} \leftarrow \mathrm{N}$ $-1)$.

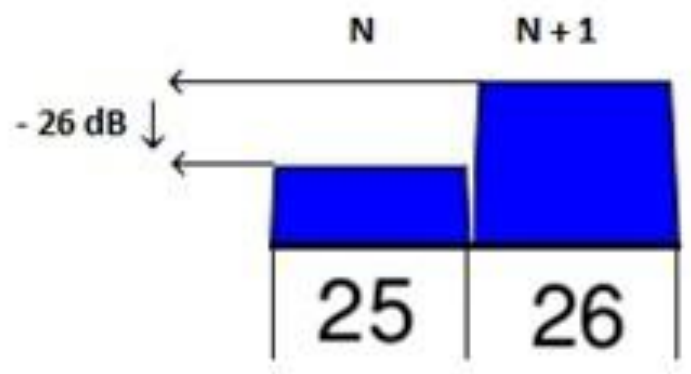

\section{Formula:}

Nivel $(d B)=10 \log \frac{\text { Valor }}{\text { Referencia }}$

\section{Datos:}

Referencia: $2 \mathrm{Kw}$

Nivel $(d B)=-26 d B$

\section{Solución:}

$$
\begin{gathered}
-29 \mathrm{~dB}=10 \log \frac{\text { Valor }}{\mathrm{Kw}} \\
\text { Valor }=2 \mathrm{Kw} *\left(10^{-2.6 \mathrm{~dB}}\right) \\
\text { Valor }=4.84 \approx 4.8 \mathrm{Kw} \\
\text { Valor }=4.8[\mathrm{Kw}]
\end{gathered}
$$


9.- Debe existir una relación de $-29 \mathrm{~dB}$, entre la seña digital indeseada y la señal digital deseada; llamada interferencia de Canal Adyacente Inferior ( $N \leftarrow N$ $+1)$.

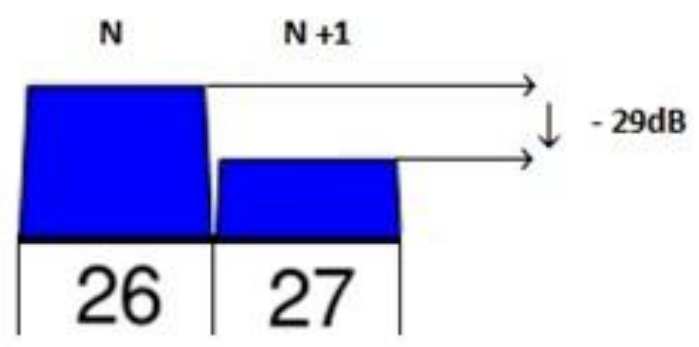

\section{Formula:}

Nivel $(d B)=10 \log \frac{\text { Valor }}{\text { Referencia }}$

\section{Datos:}

Referencia: $2 \mathrm{Kw}$

Nivel $(\mathrm{dB})=-29 \mathrm{~dB}$

\section{Solución:}

$$
\begin{gathered}
-29 \mathrm{~dB}=10 \log \frac{\text { Valor }}{2 \mathrm{Kw}} \\
\text { Valor }=2 \mathrm{Kw} *\left(10^{-2.9 \mathrm{~dB}}\right) \\
\text { Valor }=4.42 \mathrm{Kw} \approx 4.5 \mathrm{Kw} \\
\text { Valor }=4.5 \mathrm{Kw}
\end{gathered}
$$

Nota: La referencia es el nivel de potencia del transmisor en operación, analógico/digital de ECTV. 


\subsubsection{Equipos transmisores para estaciones de televisión}

Las estaciones de televisión analógicas o digitales, cuentan con dos transmisores un principal y auxiliar, para cada una de las señales radiadas, los mismos que están sujetos a las regulaciones vigentes por el CONATEL.

El cual otorga el permiso de funcionamiento, a través de un contrato de concesión y estipula como norma fundamental, que la potencia de transmisión no deberá ser mayor a 1.5 veces la establecida; por dicho contrato.

Al contar con el auspicio de ECTV, para el desarrollo del presenté proyecto de investigación, se han considerará sus transmisores, para el estudio y simulación del comportamiento electromagnético; de señales Análogo Digitales en los capítulos 3 y 4 .

\subsection{Transmisor principal}

El transmisor principal de una estación de televisión, es aquel que esta permanentemente en operación, radiando señal $A / D$, sobre una determinada área de servicio. 
Siendo para el caso de ECTV, transmisores marca HARRIS, cuyas especificaciones técnicas son detalladas en el literal "Equipos Transmisores"; correspondiente al literal 2.2.1.7 "Sistema Radiante".

\subsection{Transmisor auxiliar}

Es el equipo utilizado eventualmente, en cuyo caso el transmisor principal se encuentre en mantenimiento o presenté algún tipo desperfecto, en el cual la potencia de operación deberá ser como mínimo el 10\% y como máximo el 100\%, de la potencia de operación del transmisor principal.

\subsubsection{Estaciones reforzadoras de señal GAPFILLER}

Una estación reforzadora de señal, es un dispositivo de repetición de señal, cuya función primordial es rellenar los espacios vacíos (zonas de sombra) no cubiertos por el transmisor principal de la estación.

El cual se compone de una antena receptora, un repetidor, un amplificador de señal y una antena de transmisión.

Al contar con una antena de recepción, se debe garantizar que la ubicación del GAPFILLER, este dentro del área protegida en la cual la intensidad de campo eléctrico deberá ser de mínimo de $51 \mathrm{~dB} \mu \mathrm{V} / \mathrm{m}$. 
Ya que de esta manera se garantiza la recepción de señal digital.

Una vez que el GAPFILLER, ha recibido la señal deseada, el repetidor convierte dicha señal en una de frecuencia intermedia en la cual el canal deseado es filtrado, evitando la retransmisión de señales no deseadas, y posteriormente amplificada y convertida a la frecuencia original de RF; la cual será final mete radiada por la antena transmisora apuntada hacia la zona de sombra previamente definida.

\section{OMB - GAPFILLER}

OMB Sistemas Electrónicos, es una compañía Europea con cede en España, que desarrolla equipos de telecomunicaciones, entre estos el OMB GAPFILLER o estación reforzadora de señal, cuyas características técnicas son:

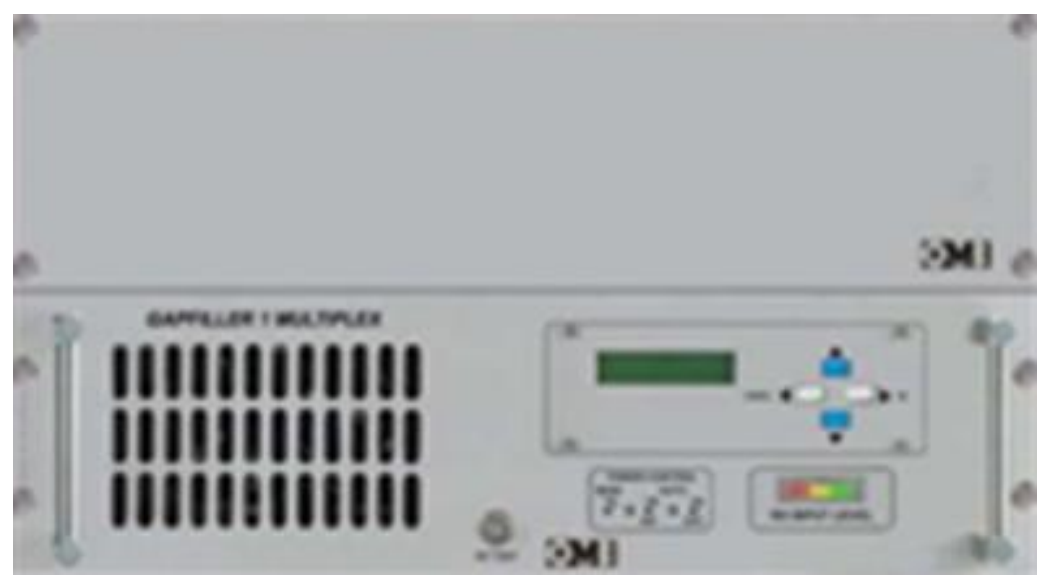

Figura 2.3: GAPFILLER - OMB. (Tesis Estudio y Propuesta de la factibilidad técnica social y económica del sistema ISDB-TV. ) 


\section{Tabla 2.16:}

Consideraciones técnicas del GAPFILLER de OMB. (Tesis Estudio y Propuesta de la factibilidad técnica social y económica del sistema ISDB-TV. )

\begin{tabular}{|c|c|}
\hline \multicolumn{2}{|r|}{ Entrada RF } \\
\hline Tipo de Señal & 1 Multiplex \\
\hline Rango de Frecuencia & $470-870 \mathrm{MHz}$ \\
\hline Banda & IV \& V \\
\hline Conector & N Hembra \\
\hline Perdida de retorno & $>23 \mathrm{~dB}$ \\
\hline \multicolumn{2}{|c|}{ Nivel de RF para Operatividad } \\
\hline Niveles de RF IN & $>45 \mathrm{dBuV}$ \\
\hline MER(rms) & $>23 \mathrm{~dB}$ \\
\hline VER antes del Viterbi & $<1 \mathrm{e}-3$ \\
\hline \multicolumn{2}{|c|}{ Procesado de Señal } \\
\hline Ancho de banda & 1 Multiplex 6 - $8 \mathrm{MHz}$ \\
\hline Tx y antena receptora & 5 Wrms por Multiplex \\
\hline \multicolumn{2}{|c|}{ Transmisión } \\
\hline Potencia de salida & 1 Multiplex hasta $5 \mathrm{Wrms}$ \\
\hline Potencia Máxima & $50 \mathrm{~W}$ \\
\hline
\end{tabular}

\subsubsection{Sistema Radiante}

El sistema radiante de ECTV, constituye una torre de transmisión de 88 metros, con cuatro paneles de antenas marca OMB PD2000, dispuestos a razón de dos panales por azimut $\left(45^{\circ}\right.$ y $\left.135^{\circ}\right)$ y una caseta de transmisión destinada a los dispositivos encargados de la transferencia de la energía de radiofrecuencia desde el transmisor hasta la antenas. 
A continuación detallamos las características técnicas del sistema radiante ECTV, para su mejor comprensión y análisis.

\section{Equipos Transmisores}

\section{Digital}

El sistema radiante de ECTV, se basa en el transmisor UHF de estado solido y refrigeración por aire Harris Maxiva UAX, que incorpora la tecnología PowerSmart ${ }^{\circledR}$ y la tecnología multimedia Apex $\mathrm{M}_{2} \mathrm{X}^{\mathrm{TM}}$, las cuales le permite ofrecer a las emisoras un rendimiento confiable y de muy alta calidad. Diseñado considerando la norma ISDB - Tb, facilitando así la TDT de señales SD, HD y móvil, para dispositivos fijos, móviles/portátiles, y una excelente sincronización con equipos GAPFILLER; permitido así una expansión eficiente de las redes SFN. 


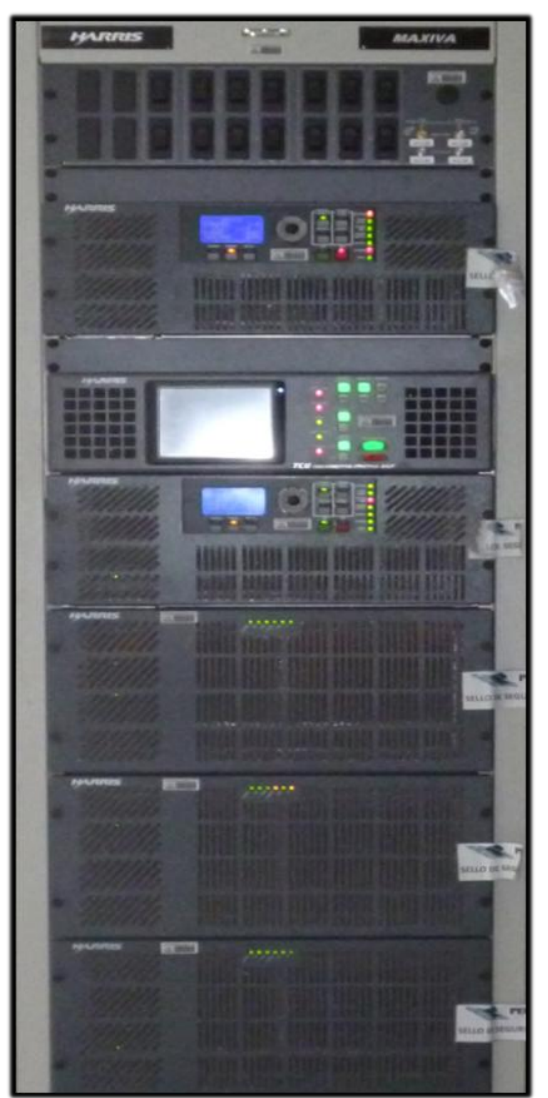

Figura 2.4: Transmisor digital de ECTV. (Fotografía tomada en la estación de ECTV, 2013)

\section{Analógico}

Se trata de un transmisor Harris HT 30HSP, cuya potencia de transmisión es de $6[K w]$, potencia que es liberada al ambiente a través de un arreglo de ocho antenas, a razón de cuatro antenas por azimut $\left(45^{\circ}\right.$ y $\left.135^{\circ}\right)$. 


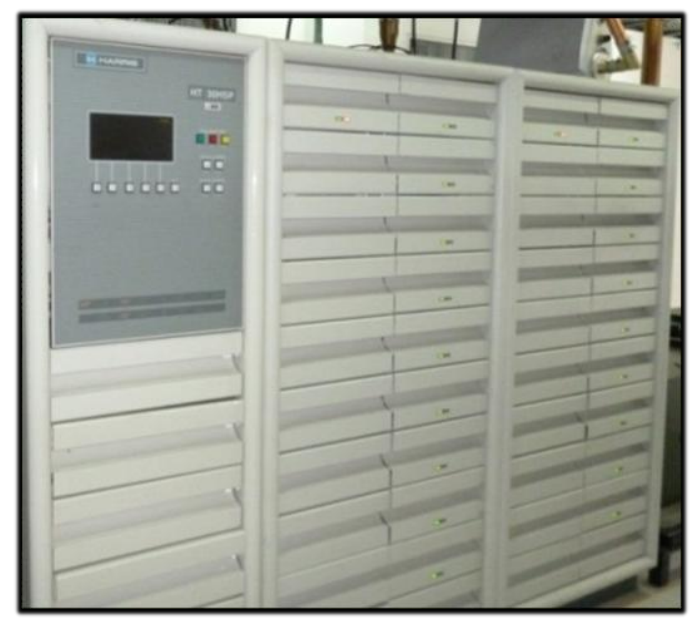

Figura 2.5: Transmisor analógico de ECTV. (Fotografía tomada en la estación de ECTV, 2013)

Tabla 2. 17:

Consideraciones técnicas del Tx Digital. (www.harrismaxiva.com)

\begin{tabular}{cc}
\hline Transmisor & Descripción \\
\hline Modelo & Air -Cooled UHF Multimedia Tv \\
Altura de la torre $(\mathrm{h})$ & $88 \mathrm{~m}$ (Auto sustentada) \\
Potencia & $2 \mathrm{Kw}$ \\
Separación entre Tx (A/D) & $\lambda$ (mayor) \\
Modulación & COFDM \\
Estándares & ATSC/DTV/ISDB-TB \\
Cobertura & Quito y los Valles de (Cumbaya - Los \\
& Chillos). \\
\hline
\end{tabular}

\section{Antena Transmisora}

En cada punto de transmisión se utilizan arreglos de antenas tipo panel, marca OMB PD 2000, cada uno de ellos se compone de 4 dipolos, que operan en la banda de frecuencias de 470 a $860 \mathrm{MHz}$; con una ganancia por panel de $13 \mathrm{dBi}$, tanto en polarización vertical como horizontal, un ancho de lóbulo en el 
plano horizontal de $60^{\circ}$ y $30^{\circ}$ en el plano vertical, admitiendo una potencia máxima de $2 \mathrm{Kw}$.

\section{Antena OMB PD 2000 Tipo Panel UHF}

Tabla 2.18:

Descripción técnica de la antena OMB PD 2000. (KG, 2011)

\begin{tabular}{lc}
\hline Descripción Técnica & Características \\
\hline Rango de Frecuencias & $470 \mathrm{a} 890 \mathrm{MHz}$ \\
Ganancia & $13 \mathrm{dBi}$ \\
Polarización & $\mathrm{H} \mathrm{y} \mathrm{V}$ \\
Impedancia & $50 \mathrm{Ohm}$ \\
VSWR & $<-26 \mathrm{~dB}$ \\
Máxima Potencia & $2000 \mathrm{~W}$ \\
Máxima Potencia RMS & $1500 \mathrm{Wrms}$ \\
\hline Tipo de Conector & DIN $7 / 16 \mathrm{Female}$ \\
Dimensiones (A x A x P) & $48.26 \times 20.32 \times 96.52 \mathrm{~cm}$ \\
Velocidad Máxima de Viento & $200 \mathrm{~K} / \mathrm{h}$ \\
Carga al viento frontal & $740 \mathrm{Nw}$ \\
Carga al viento lateral & $370 \mathrm{Nw}$ \\
Peso & $15.8 \mathrm{Kg}$ \\
Espacio Vertical & $1000 \mathrm{~mm}$ \\
Aterramiento & DC grounding \\
Rango de Temperatura & $\sim 30 \mathrm{C} \mathrm{a} 70 \mathrm{C}$ \\
Humedad & $100 \%$ \\
\hline
\end{tabular}




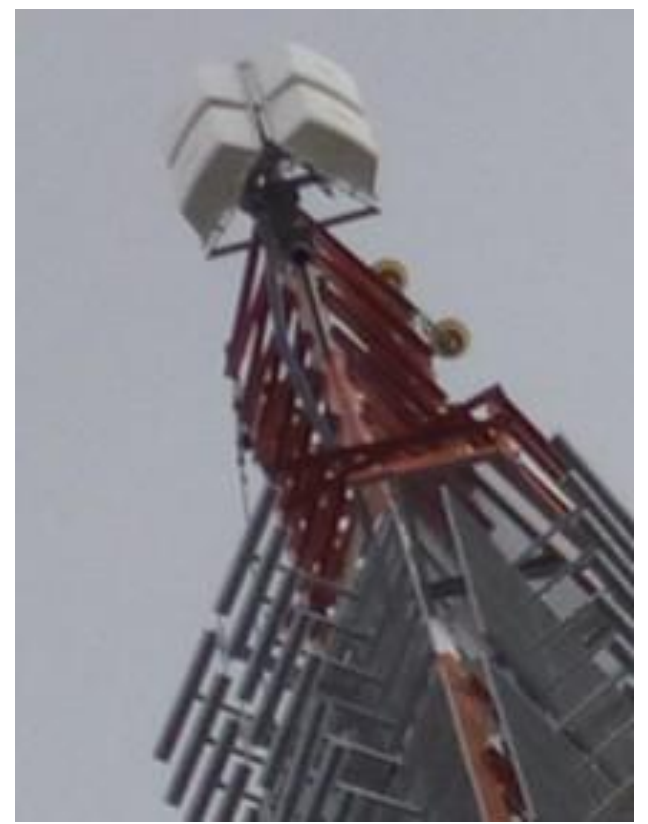

Figura 2.6: Arreglo de antenas OMB PD2000. (Fotografía tomada en la estación de ECTV, 2013)

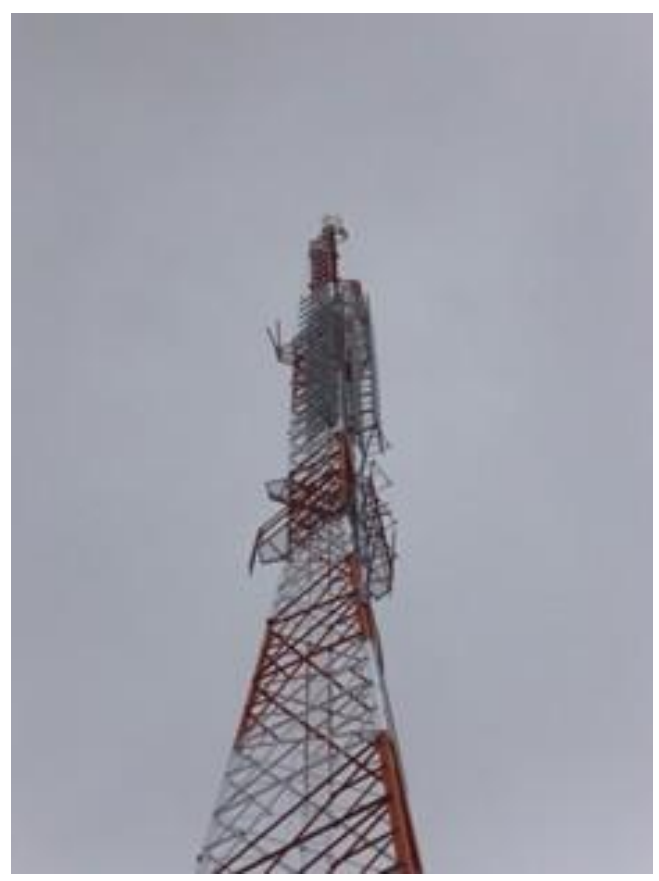

Figura 2.7: Torre de transmisión de ECTV. (Fotografía tomada en la estación de ECTV, 2013) 


\section{Arreglo de Antenas}

El sistema radiante de ECTV, dispone de un arreglo de cuatro paneles OMB PD2000, a razón de dos paneles por azimut, $45^{\circ}$ y $135^{\circ}$ orientados hacia el norte y sur de la ciudad respectivamente y con una inclinación mecánica de $-7^{\circ}$.

A continuación se adjunta un resumen de los parámetros técnicos de operación de la estación de Ecuador Tv, en donde el cálculo del PRA se ha obtenido en considerando perdidas de $1.656 \mathrm{~dB}$ debidas a atenuación en cables, conectores y divisores de potencias; según los datos técnicos de ECTV. (Estudio de Ingeniería del Sistema Radiante de ECTV., 2013)

\section{Tabla 2.19:}

Parámetros técnicos de operación de la estación de Ecuador Tv. (Estudio de Ingeniería del Sistema Radiante de ECTV., 2013)

\begin{tabular}{ccccccc}
\hline $\begin{array}{c}\text { Sitio de } \\
\text { Transmisión }\end{array}$ & $\begin{array}{c}\text { Potencia } \\
{[\mathrm{W}]}\end{array}$ & Azimut & $\begin{array}{c}\mathrm{N}^{\circ} \text { de } \\
\text { Antenas }\end{array}$ & $\begin{array}{c}\text { Ganancia } \\
\text { en [dBi] }\end{array}$ & $\begin{array}{c}\text { PARA } \\
{[\mathrm{W}]}\end{array}$ & Inclinación \\
\hline Cerro & 2000 & $45^{\circ} \mathrm{y}$ & 4 & 20,5 & 33145,9 & $-7^{\circ}$ \\
Pichincha & & $135^{\circ}$ & & & & \\
\hline
\end{tabular}




\section{Sistema de Tierra}

Para este sistema radiante se utilizó un sistema de puesta a tierra tipo malla utilizando varillas de cobre tipo Coperweld, cable desnudo $\mathrm{N}^{\circ} 2$, bornera para conexión de equipos al sistema de tierra y para mejorar la resistividad en los puntos de unión se utilizó suelda exotérmica. (Estudio de Ingeniería del Sistema Radiante de ECTV., 2013)

\section{Protecciones para rayos y corrientes estáticas}

La protección para rayos consiste en un sistema de pararrayos IONIFLAH con dispositivo de cebado, en el cual cuando la descarga es inminente, se observa un rotundo incremento del campo eléctrico, activando el dispositivo eléctrico de cebado que libera la energía acumulada en los electrodos superiores del pararrayos, provocando una ionización en la parte superior de la punta.

En la caseta de alojamiento de equipos transmisores, se instalan protectores de transcientes, a fin de protegerlos de corrientes parasitas, que

junto al sistema de puesta a tierra y el sistema de pararrayos dan seguridad a los equipos prolongando su vida útil. (Estudio de Ingeniería del Sistema Radiante de ECTV., 2013) 


\section{Cable entre el transmisor y las antenas}

La línea de transmisión utilizada es un cable coaxial en espuma tipo HELIAX, marca ANDREW, modelo LDF/-50A de $\left(1 \frac{5}{8} "\right)$ de diámetro, $50 \Omega$ de impedancia y una atenuación promedio de $2.18 \mathrm{~dB}$ por cada $100 \mathrm{~m}$ a una frecuencia máxima de $700 \mathrm{MHz}$.

Los paneles en cada uno de los azimut son alimentados a través de distribuidores de potencia simétricos (Latiguillos), cuya impedancia es de $50 \Omega$.

\section{Energía eléctrica}

La energía eléctrica es tomada por la caseta de ECTV de la línea comercial.

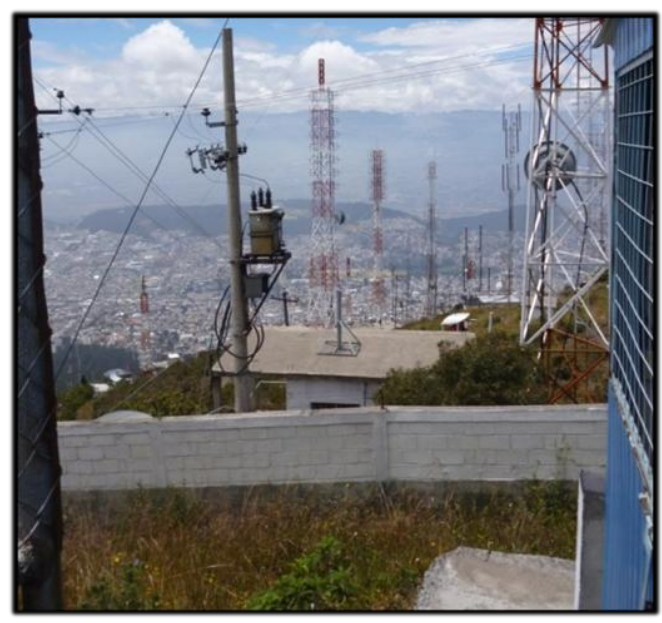

Figura 2.8: Red eléctrica del cerro Pichincha. (Fotografía tomada en la estación de ECTV, 2013) 
La caseta de ECTV cuenta con un respaldo en caso de existir cortes de energía, conformado por dos generadores diesel y un UPS, de 120 KVA, este ultimo basado en un banco de baterías marca FIRMESA, que permite un tiempo máximo de operación de treinta minutos.

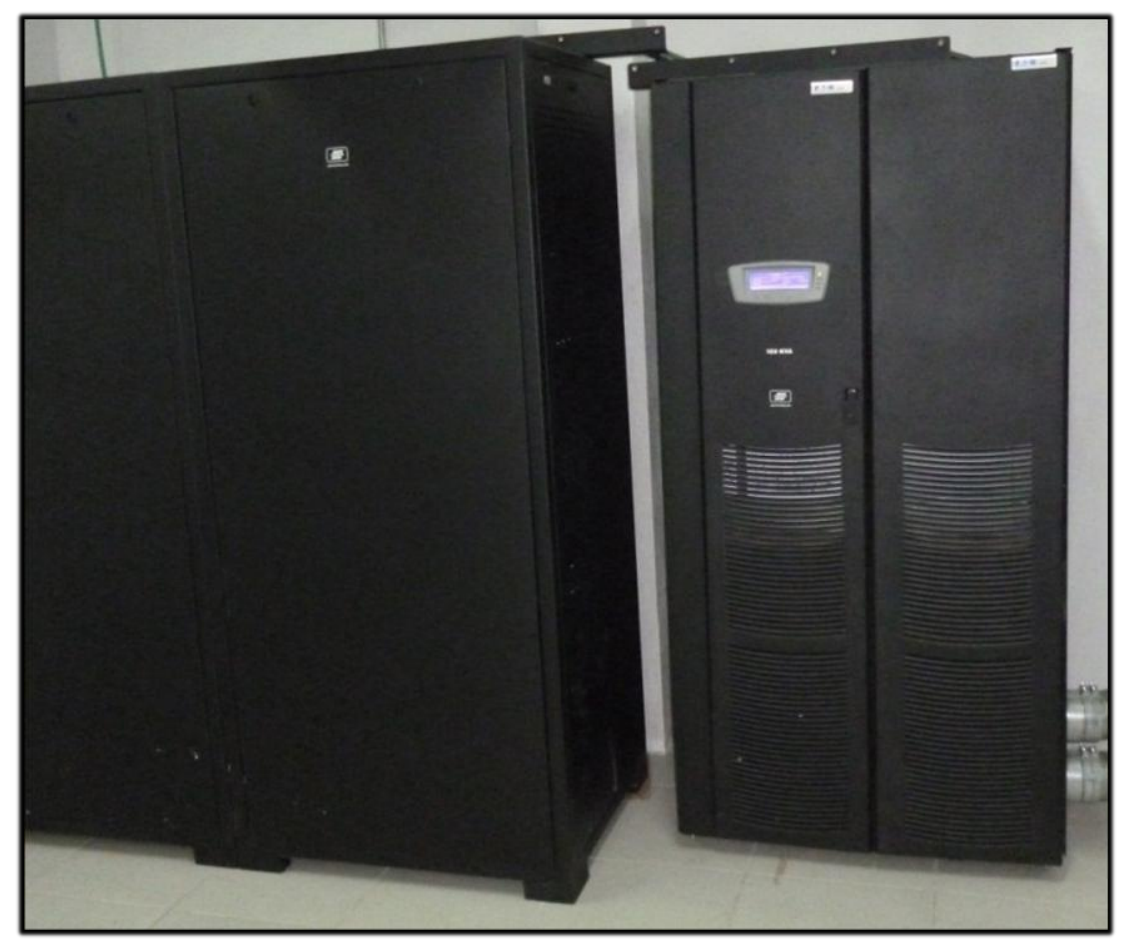

Figura 2.9: Banco de baterías FIRMESA. (Fotografía tomada en la estación de ECTV, 2013)

\section{Mantenimiento}

El mantenimiento de las instalaciones esta a cargo de la jefatura de radiofrecuencia, la cual esta conformada de dos grupos técnicos en radiofrecuencia y electromecánica, que a la vez cuentan con todo el equipo necesario de pruebas y monitoreo, del sistema radiante tales como: 
Monitor de forma de onda, analizador monitor de audio, demodulador de señal de Tv, analizador espectral, analizador de video, etc.

\section{Instalación}

Tanto los equipos análogos como digitales, se encuentran instalados en una caseta de transmisión ubicada en el cerro Pichincha, cuyas dimensiones son:

\section{Tabla 2.20:}

Detalle de las dimensiones de la caseta de transmisión de ECTV. (Diseño Propio producto de la visita técnica de campo, a la estación ECTV en el cerro Pichincha., 2013)

\begin{tabular}{crcccl}
\hline Piso N & Ambientes & Largo[m] & Ancho[m] & Altura[m] & Especificación \\
\hline $\mathbf{1}$ & Cuarto 1 & 9,6 & 6,4 & 2,5 & Sala de Equipos \\
$\mathbf{1}$ & Cuarto 2 & 3,2 & 4,2 & 2,5 & Cuarto de Generadores \\
$\mathbf{2}$ & Cuarto 1 & 5 & 6,4 & 2,5 & Área Social \\
$\mathbf{2}$ & Cuarto 2 & 2,6 & 6,4 & 2,5 & Bodega \\
$\mathbf{3}$ & Terraza & 7,6 & 6,4 & 2,5 & Área de Microondas \\
\hline
\end{tabular}

La caseta cuenta con cerramiento de malla, cercado eléctrico y letreros de identificación de la estación y alerta de peligro. 


\section{Caseta de ECTV}

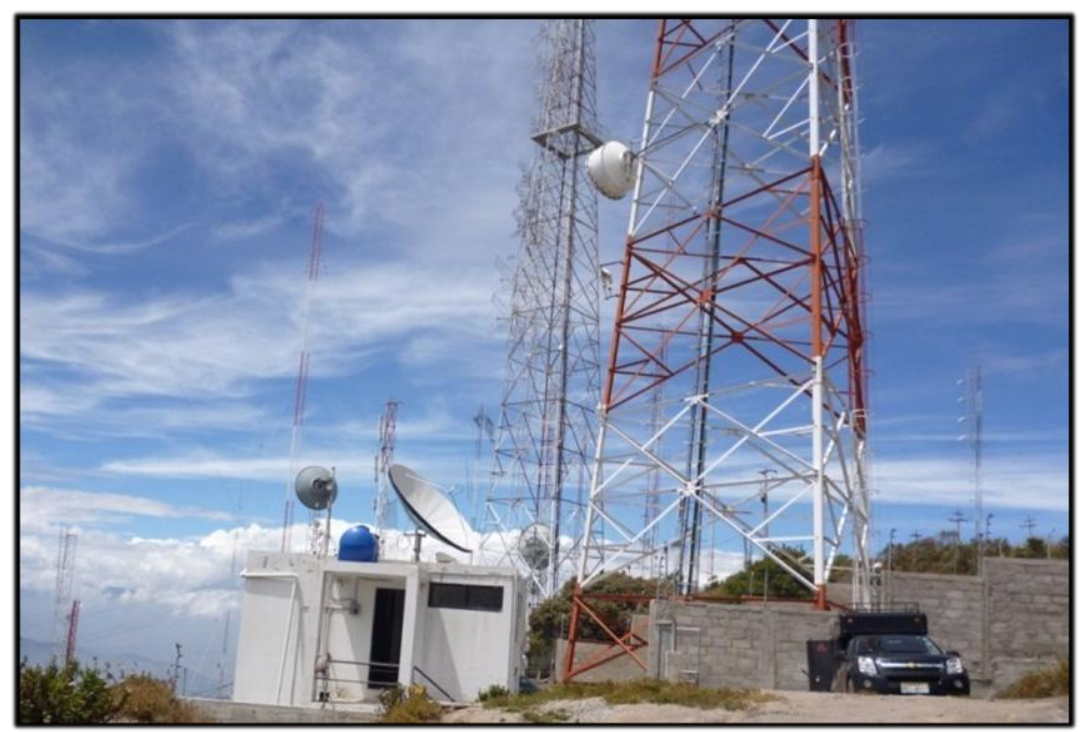

Figura 2.10: Vista frontal de la caseta de transmisión de ECTV. (Fotografía tomada en la estación de ECTV, 2013)

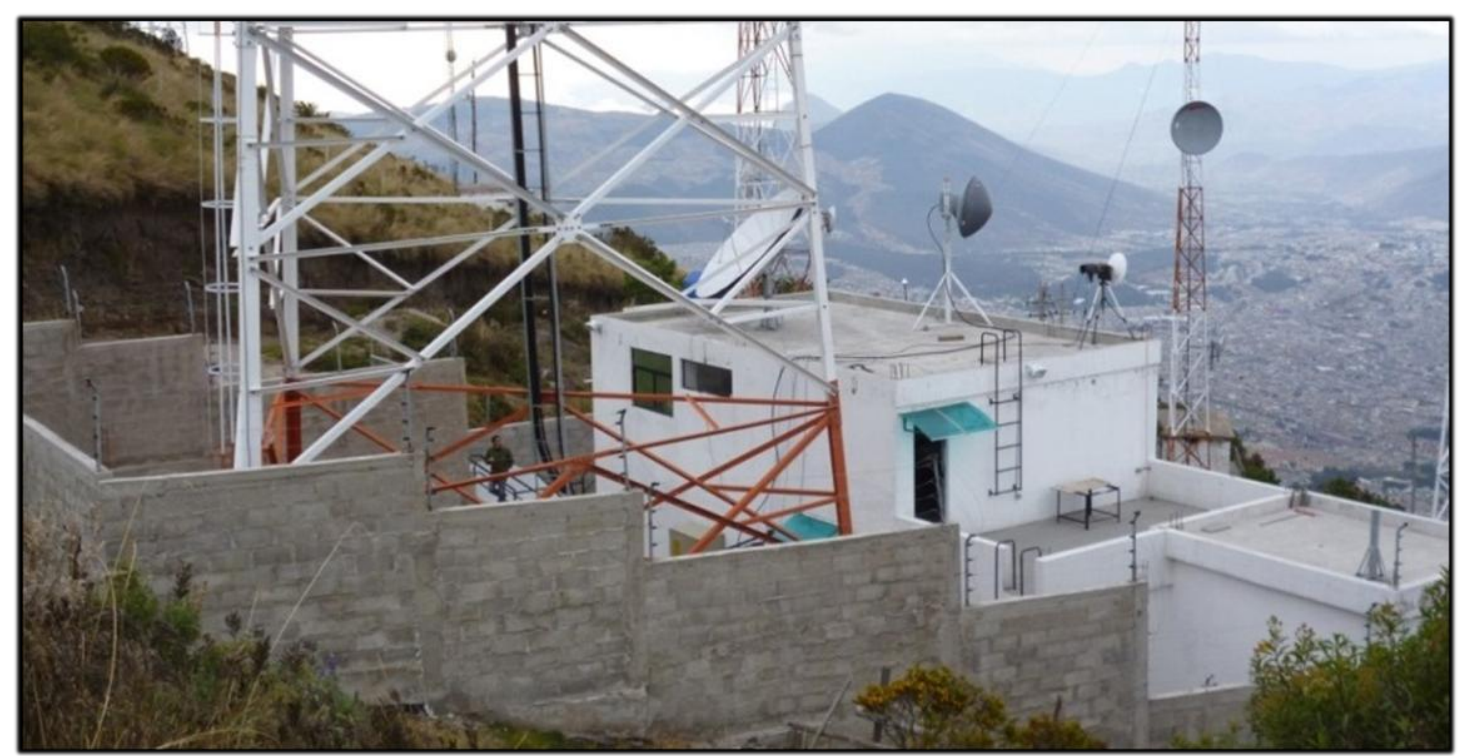

Figura 2.11: Vista lateral de la caseta de transmisión de ECTV. (Fotografía tomada en la estación de ECTV, 2013) 


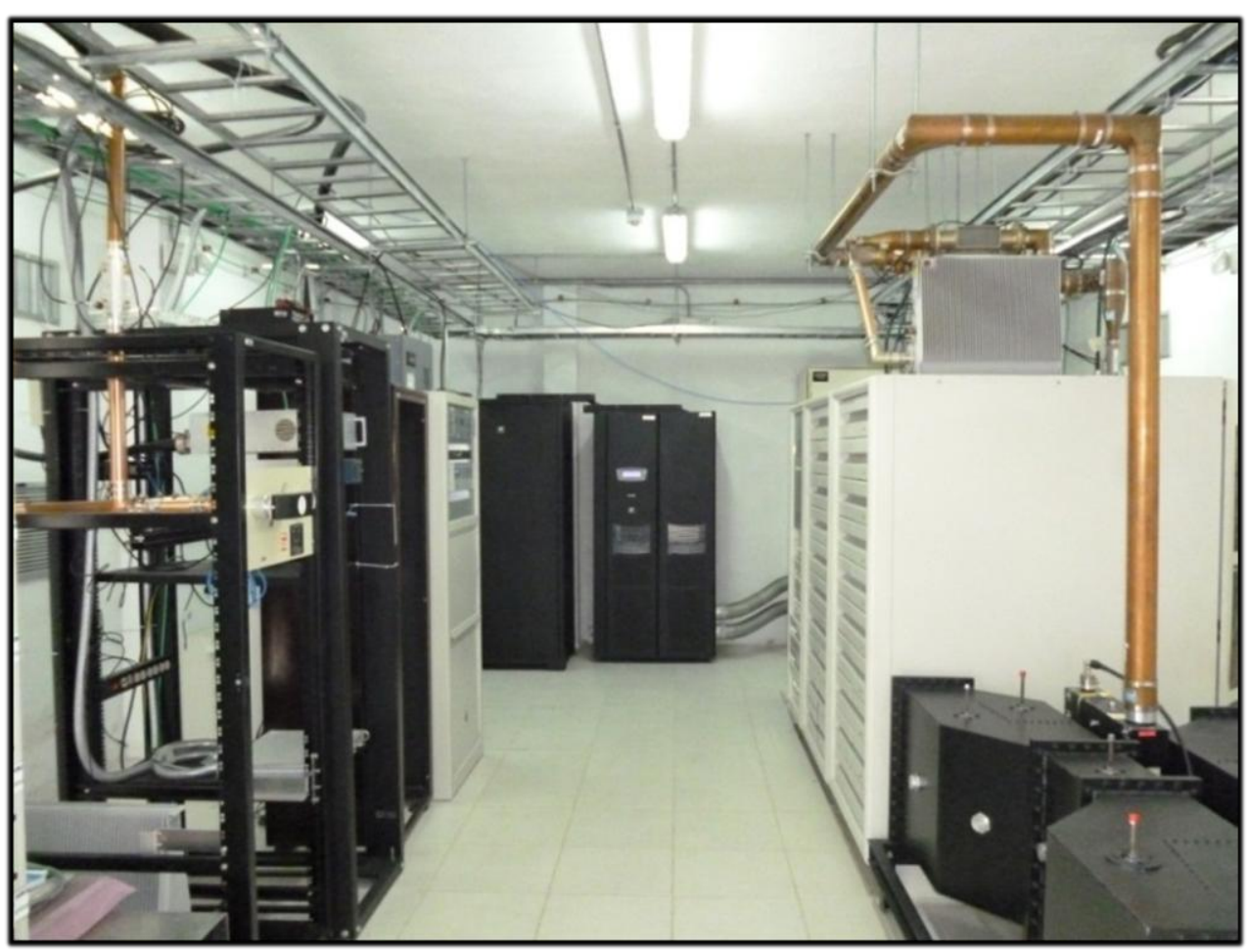

Figura 2.12: Vista interior de la caseta de transmisión de ECTV. (Fotografía tomada en la estación de ECTV, 2013)

\section{Cobertura}

Para determinar el área de cobertura se considera como parámetros fijos:

La potencia de salida del transmisor, altura efectiva, ganancia, características de radiación e inclinación electrónica del sistema radiante en su respectivo sitio de transmisión. 
Los resultados se obtienen a partir de cálculos de propagación según los azimut de interés y distancias que se extienden radialmente desde el punto de transmisión.

Concretamente para el área de cobertura se consideran los métodos recomendados por la UIT - R, 370 y 1546, para televisión analógica y digital respectivamente; utilizando las curvas de propagación para tierra en las bandas (IV - V), normalizadas para potencias de transmisión comprendidas en el rango de $1 \mathrm{Kw}$ a $10 \mathrm{Kw}$ y considerando una altura efectiva (hef) obtenida de los perfiles topográficos para diferentes azimuts y una antena receptora cuya altura sea de $10 \mathrm{~m}$.

El área protegida se encuentra determinada por el contorno de intensidad de campo eléctrico.

\section{Tabla 2.21:}

Parámetros de consideración en la transmisión Análogo / Digital. (Diseño Propio producto de la visita técnica de campo, a la estación ECTV en el cerro Pichincha., 2013)

\begin{tabular}{lll}
\hline & $\begin{array}{l}\text { Broadcast } \\
\text { Digital }\end{array}$ & $\begin{array}{l}\text { Broadcast } \\
\text { Analógico }\end{array}$ \\
\hline $\begin{array}{l}\text { Frecuencia } \\
\begin{array}{l}\text { Intensidad de campo eléctrico } \\
\text { requerido }\end{array}\end{array}$ & $\begin{array}{l}\text { UHF } \\
\text { VHF/UHF }\end{array}$ \\
$\begin{array}{l}\text { Altura de antena Rx } \\
\text { Deterioro de la imagen }\end{array}$ & \multicolumn{1}{c}{$10 \mathrm{~m} \mu \mathrm{V} / \mathrm{m}$} & $70 \mathrm{~dB} \mu \mathrm{V} / \mathrm{m}$ \\
Ajuste de retardo & Cliff effect & \multicolumn{1}{c}{$\begin{array}{l}\text { Gradually } \\
\text { deteriorate }\end{array}$} \\
\hline
\end{tabular}


Cliff effect: Deterioro instantáneo.

Gradually deteriorate: Deterioro gradual.

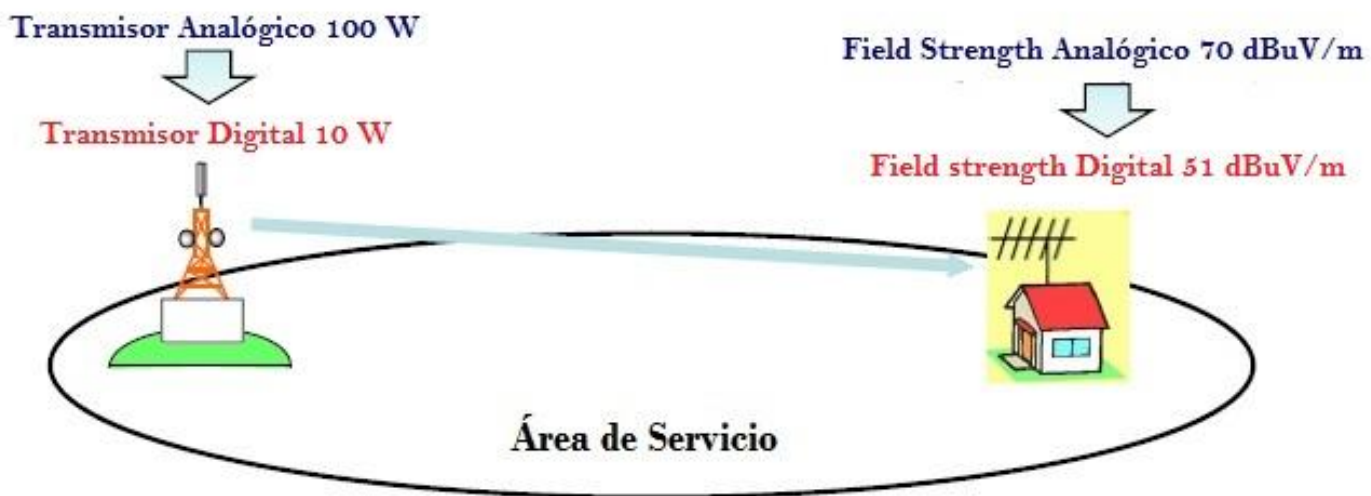

Figura 2.13: Área de servicio, análogo - digital. (Diseño propio producto del análisis del estado de la TDT en Ecuador, 2013)

\section{Forma de recepción de la señal}

La señales de televisión tanto analógica como digital, es recibida a través de un enlace micro onda, entre el estudio de ECTV y la caseta de transmisión en el cerro Pichincha, a una frecuencia de $6 \mathrm{MHz}$.

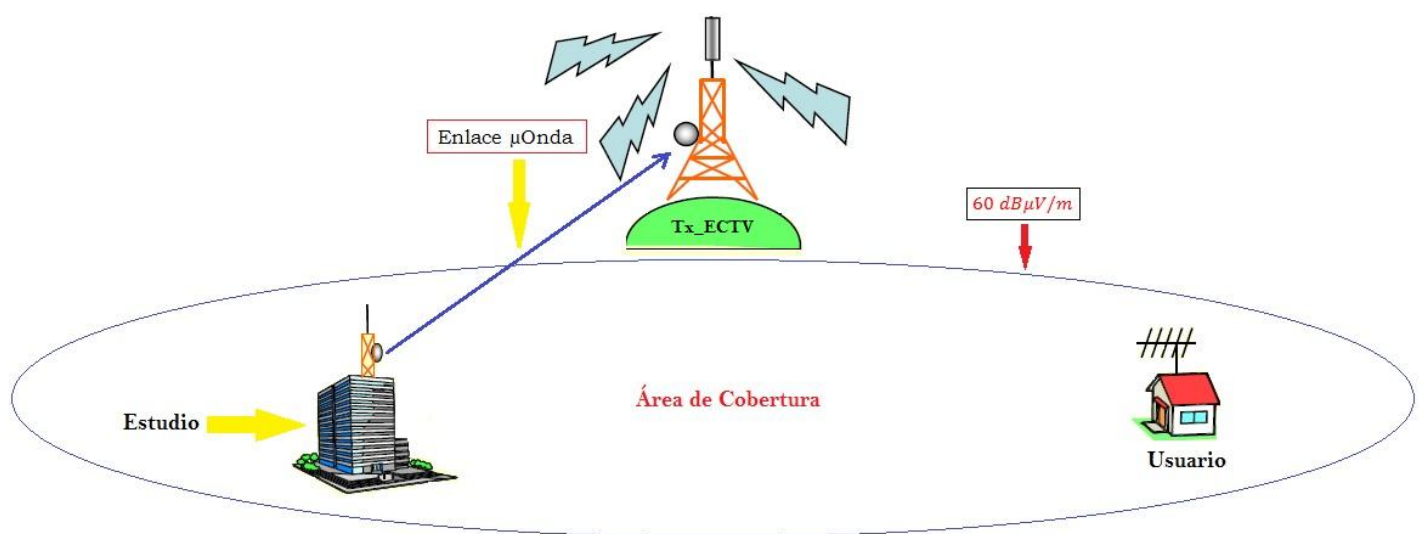

Figura 2.14: Representación grafica del enlace $\mu \mathbf{0}$, entre el estudio de ECTV y el cerro Pichincha. (Diseño propio producto del análisis del estado de la TDT en Ecuador, 2013) 


\section{Frecuencia}

Las frecuencias de operación bajo estudio son las asignadas por la SUPERTEL, las cuales se detallan en la siguiente tabla:

\section{Tabla 2.22:}

Frecuencias de operación $\mathbf{A} / \mathbf{D}$, de las principales operadoras en la ciudad de Quito. (Fotografía tomada en la estación de ECTV, 2013)

\begin{tabular}{llll}
\hline Operadora & Canal & $\begin{array}{l}\text { Frecuencia } \\
\text { Analógica } \\
{[\mathrm{MHz}]}\end{array}$ & $\begin{array}{l}\text { Frecuencia Digital } \\
{[\mathrm{MHz}]}\end{array}$ \\
\hline ECTV & 26 & 545 & 545.142857 \\
Teleamazonas & 32 & 581 & 581.142857 \\
RTS & 34 & 593 & 593.142857 \\
Ecuavisa & 36 & 605 & 605.142857 \\
Telesucesos & 41 & 635 & 635.142857 \\
Oromar & 47 & 671 & 671.142857 \\
\hline
\end{tabular}

\subsection{2 Área de servicio}

El área de servicio constituye todo el territorio geográficamente influenciado por el cerro Pichincha, en el cual las operadoras de televisión ubican sus equipos transmisores.

Por ello es importante reconocer los límites geográficos y las poblaciones asentadas, dentro de esta zona de influencia, ya que de esta forma podremos 
definir el área de estudio, en la cual se llevarán a cabo las pruebas de campo y posterior simulación, concentrando de forma idónea todos los recursos a disposición.

Para ello existen dos patrones:

- $\quad$ Igual que las zonas analógicas, sitio de transmisión.

- Nuevas áreas (diferentes de las zonas analógicas).

En el Ecuador las zonas de servicio analógico y digital son las mismas, diferenciadas únicamente por la intensidad de campo eléctrico mínima necesario para garantizar la recepción de señal.

\section{Limites geográficos de la ciudad de Quito}

El Distrito Metropolitano de Quito, cuenta con parroquias urbanas y rurales, cuyos límites y coordenadas, se detallan en las siguientes tablas.

\section{Tabla 2.23:}

Limites Geográficos. (Fondo Quito, 2013)

\begin{tabular}{ll}
\hline Latitud & Región \\
\hline Norte & Provincia de Imbabura. \\
Sur & Cantones Rumiñahui y Mejía. \\
Este & Cantones Pedro Moncayo y provincia de Napo. \\
Oeste & $\begin{array}{l}\text { Cantones Pedro Vicente Maldonado, Los Bancos y la provincia de Santo } \\
\text { Domingo de los Tsáchilas. }\end{array}$ \\
\hline
\end{tabular}


Tabla 2.24:

Coordenadas Geográficas. (Fondo Quito, 2013)

\begin{tabular}{c}
\hline Estreno Norte: \\
\hline $78^{\circ} 28^{\prime} 21^{\prime \prime} \mathrm{O}$ \\
$0^{\circ} 14^{\prime} 9.01 " \mathrm{~S}$ \\
Estreno Sur: \\
$78^{\circ} 32^{\prime} 47^{\prime \prime} \mathrm{O}$ \\
$0^{\circ} 21^{\prime} 15^{\prime \prime} \mathrm{S}$ \\
\hline
\end{tabular}

Tabla 2.25:

Parroquias urbanas del cantón Quito. (Fondo Quito, 2013)

\begin{tabular}{ccc}
\hline \multicolumn{3}{c}{ Parroquias Urbanas del DM Quito. } \\
\hline Belisario Quevedo & El Inca & Magdalena \\
Carcelén & Guamaní & Mariscal Sucre \\
\hline Centro Histórico & Iñaquito & Ponceano \\
Chilibulo & Itchimbía & Puengasí \\
\hline Chimbacalle & Jipijapa & Quitumbe \\
\hline Chillogallo & Kennedy & Rumipamba \\
\hline Cochapamba & La Argelia & San Bartolo \\
\hline Comité del Pueblo & La Ecuatoriana & San Juan \\
\hline Concepción & La Ferroviaria & Solanda \\
\hline Cotocollao & La Libertad & Turubamba \\
\hline El Condado & La Mena \\
\hline
\end{tabular}


Tabla 2.26:

Parroquias rurales del cantón Quito. (Fondo Quito, 2013)

\begin{tabular}{lll}
\hline Parroquias Rurales del DM Quito. & & \\
\hline Alangasí & Amaguaña & Atahualpa \\
\hline Calacalí & Calderón & Conocoto \\
Cumbayá & Chavezpamba & Checa \\
\hline El Quinche & Gualea & Guangopolo \\
Guayllabamba & La Merced & Llano Chico \\
\hline Lloa & Nanegal & Nanegalito \\
Nayón & Nono & Pacto \\
\hline Perucho & Pifo & Píntag \\
Pomasqui & Puéllaro & Puembo \\
San Antonio de Pichincha & San José de Minas & Tababela \\
Tumbaco & Yaruquí & Zámbiza \\
\hline
\end{tabular}
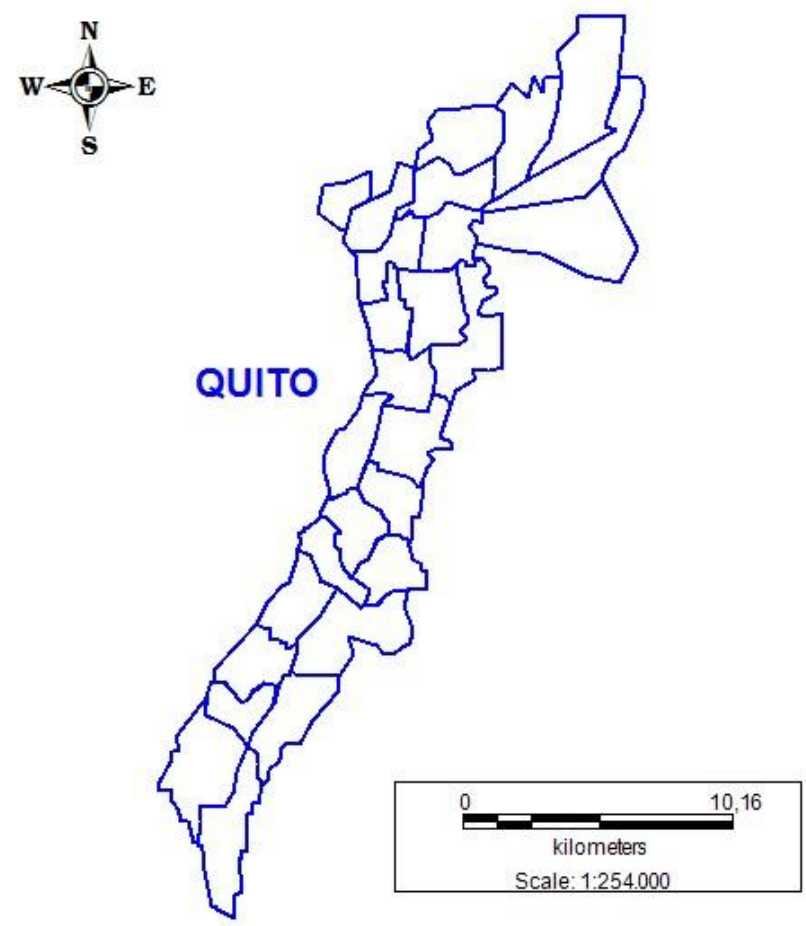

Figura 2.15: Mapa parroquial del distrito metropolitano de Quito. (Diseño Propio, reproducido en MapInfo Professional, según la información suministrada por el Municipio de Quito, en su sitio oficial, 2013) 
A continuación se muestra las parroquias bajo influencia directa del cerro pichincha.

En color azul el Distrito Metropolitano de Quito y en rojo las parroquias aledañas a este.
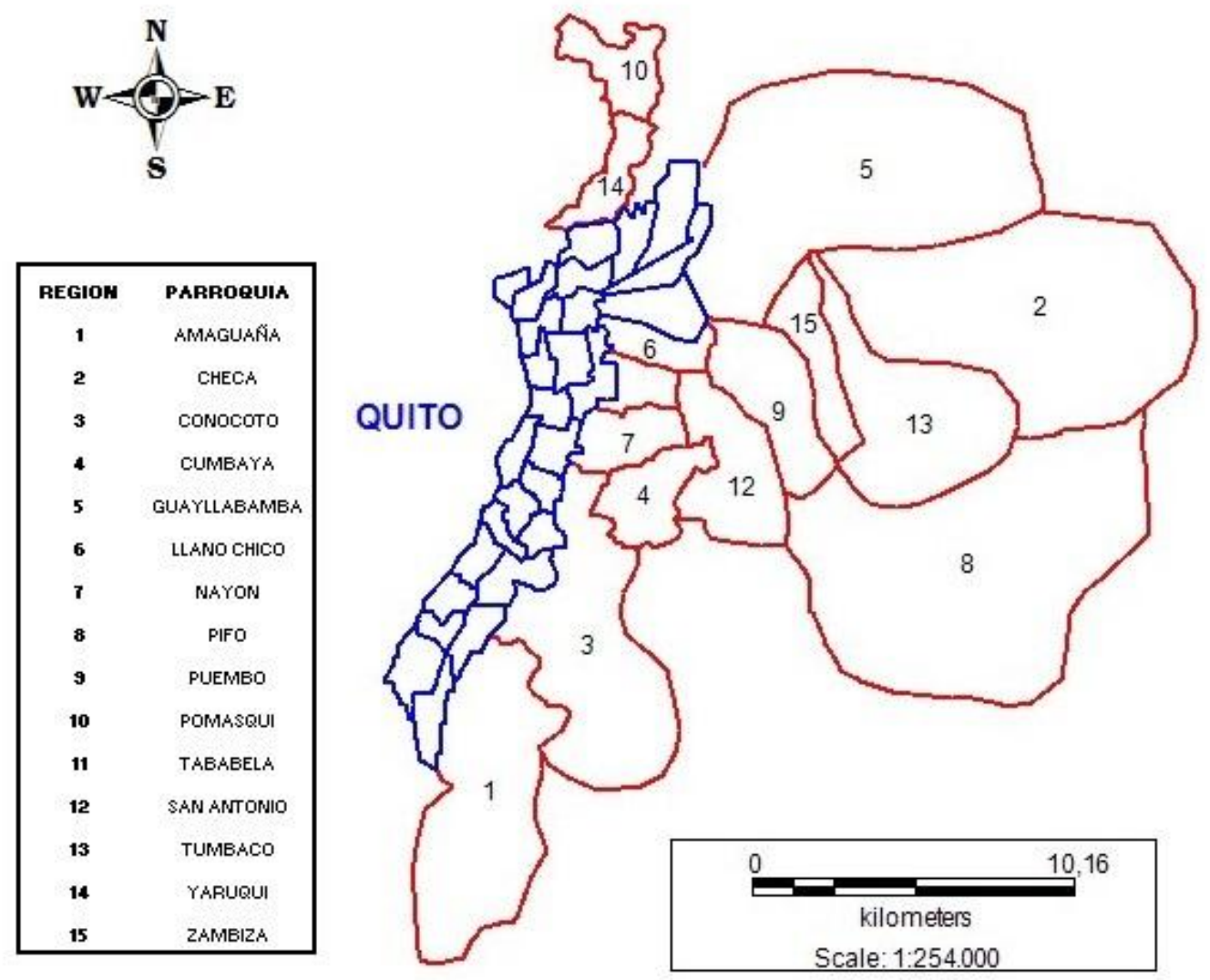

Figura 2.16: Mapa de la provincia de Pichincha. (Diseño Propio, reproducido en Maplnfo Professional, según la información suministrada por el Municipio de Quito, en su sitio oficial, 2013) 
A continuación se muestra las parroquias bajo influencia directa del cerro pichincha, color azul el cantón Quito y en rojo las parroquias aledañas.

\subsubsection{1 Área protegida}

El área protegida es la superficie inscrita dentro del área de servicio, en la cual la intensidad de campo eléctrico ha sido calculada en función de la potencia efectiva radiada PER y la altura efectiva de la antena (Hef), con relación al nivel medio del terreno y según métodos de propagación adecuados (Normas ITU 370 y 1546).

De tal manera que se garantice la recepción fija de señal en el lugar geométrico comprendido entre dos puntos donde la intensidad de campo eléctrico es excedida en el $50 \%$ de las ubicaciones y en $90 \%$ del tiempo, considerando una altura de antena de receptora de 10 metros.

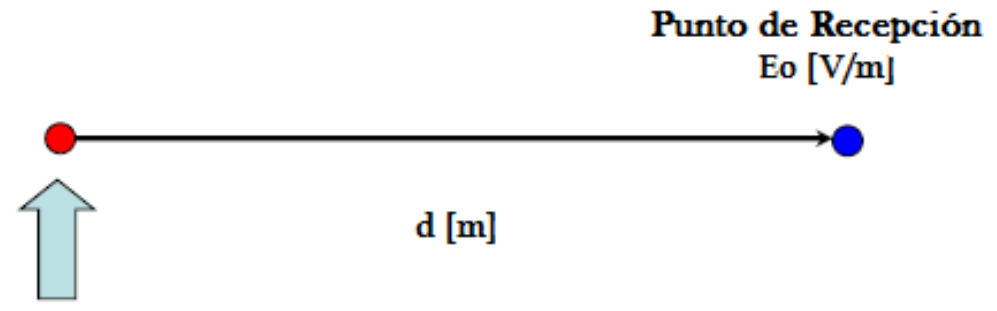

Punto deTransmisión $\mathrm{P}$ [W]

Figura 2.17: Representación grafica del área protegida, entre el Tx y Rx. (Diseño Propio producto de la visita técnica de campo, a la estación ECTV en el cerro Pichincha., 2013) 
El valor de intensidad de campo, utilizando las curvas $F(50,90)$, para determinar el contorno protegido medio es el Servicio de Televisión Digital es de $51 \mathrm{~dB} \mu \mathrm{V} / \mathrm{m}$.

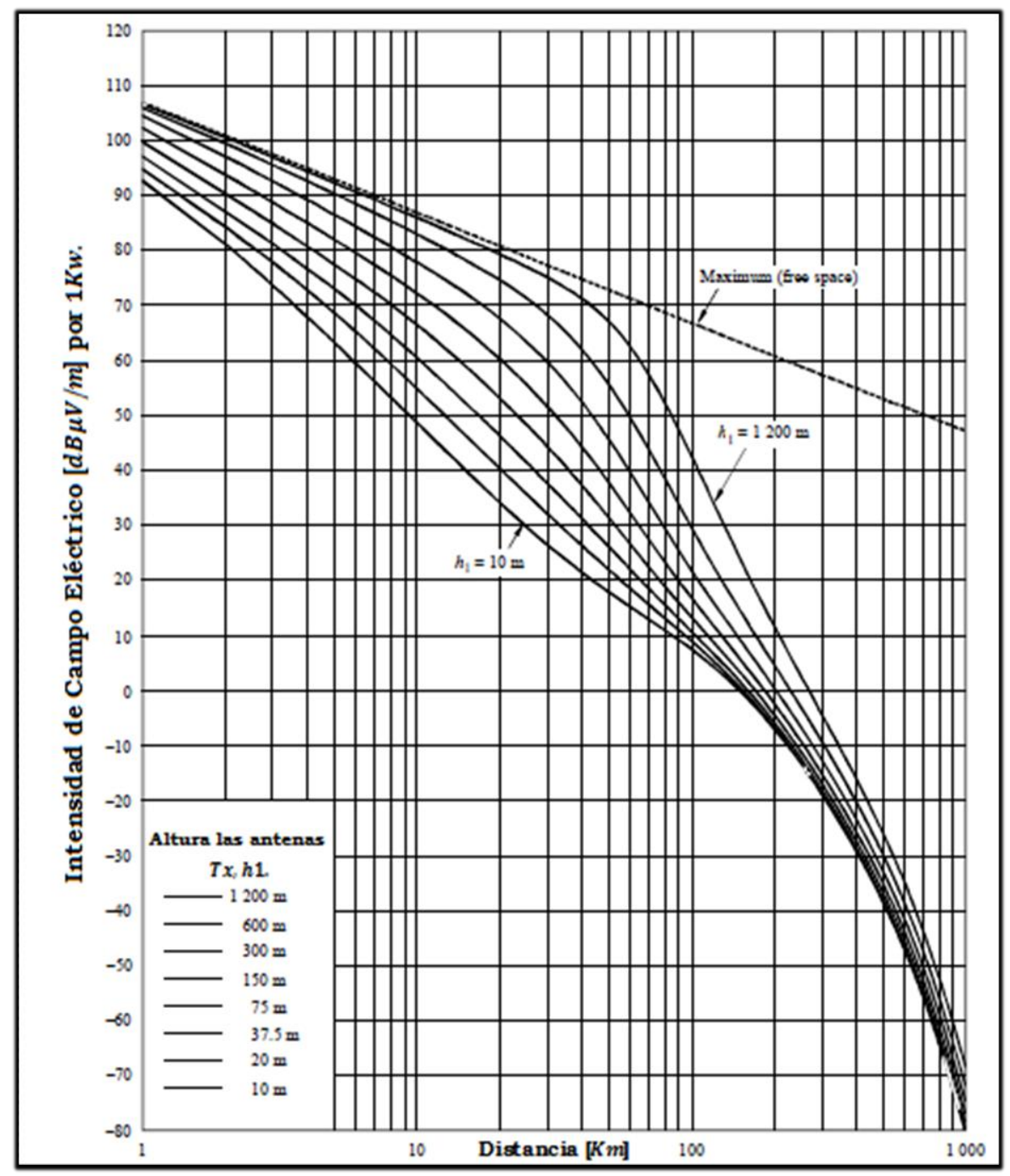

Figura 2.18: Curvas para la determinación del campo eléctrico. (Channel Planning for Digital Terrestrial Television Broadcasting, 2013)

En las siguientes tablas se detalla el valor de la intensidad de campo eléctrico para el contorno a proteger, correspondiente al servicio S-TVDT. 
Tabla 2.27:

Requerimientos para recepción interna en el contorno de la zona de servicio. (Pabón, 2011)

\begin{tabular}{cccc}
\hline Banda & Canal & Frecuencia & ICE $(50,90) \mathbf{d B} \boldsymbol{\mathbf { V }} / \mathbf{m}$ \\
\hline $\mathbf{U H F}$ & $19-49$ & $512-689$ & 63 \\
\hline
\end{tabular}

Tabla 2.28:

Requerimientos para recepción externa en sitios dentro del contorno protegido. (Pabón, 2011)

\begin{tabular}{ccll}
\hline Banda & Canal & Frecuencia & $\begin{array}{l}\text { ICE }(50,90) \\
\mathbf{d b} \boldsymbol{\mu v} / \mathbf{m}\end{array}$ \\
\hline UHF & $19-49$ & $512-689$ & 47 \\
\hline
\end{tabular}

Nota:

ICE: INTENSIDAD DE CAMPO ELÉCTRICO 50,90 [dB $\mu \mathrm{V} / \mathrm{m}]$.

\subsubsection{2 Área de cobertura}

El área de cobertura es definida por el organismo encargado SUPERTEL, a través de un contrato de concesión, el mismo que dependerá de la frecuencia de operación, asignada a una determinada operadora.

El concesionario podrá el área de cobertura dentro de la zona geográfica, mediante la utilización de las frecuencias que corresponden a la zona 
geográfica que estén disponibles mediante el uso de redes de frecuencia única SFN.

A su vez el área de cobertura se divide en dos sub áreas principal y secundaria:

\section{Área de cobertura principal:}

El área de cobertura principal, corresponde a las ciudades a servir y debe tener una intensidad de campo igual o mayor a la intensidad de campo mínima a proteger en el área urbana. (NCK- CTI Training manual , 2011)

\section{Área de cobertura secundaria:}

El área de cobertura secundaria, corresponde a los alrededores de las ciudades a servir y que tendrá una intensidad de campo entre los valores correspondientes a los bordes de área de cobertura, sin rebasar los límites de la correspondiente área geográfica. (NCK- CTI Training manual , 2011)

\subsubsection{Ubicación de las estaciones transmisoras}


Los sistema radiantes de televisión análogo/digital que satisfacen la demanda del servicio en la ciudad de Quito, se encuentran ubicados en el cerro Pichincha, cuyas coordenadas geográficas se detallan a continuación.

Tabla 2.29:

Coordenadas geográficas del Tx de ECTV en el cerro Pichincha. (Pabón, 2011)

\begin{tabular}{lrlrl}
\hline Nombre & Provincia & Longitud & Latitud & $\begin{array}{l}\text { Altura } \\
{[\mathrm{m}]}\end{array}$ \\
\hline $\begin{array}{l}\text { Cerro } \\
\text { Pichincha }\end{array}$ & Pichincha & $78^{\circ} 31^{\prime} 30,21^{\prime \prime} \mathrm{O}$ & $0^{\circ} 10^{\prime} 3,27^{\prime \prime} \mathrm{S}$ & 3855 \\
\hline
\end{tabular}




\section{CAPÍTULO III}

\section{ANÁLISIS Y SIMULACIÓN}

Este capitulo nos permitirá identificar el comportamiento de un sistema de televisión análogo/digital a través del proceso de simulación en la herramienta SIRENET.

\subsection{Introducción}

Como se comentó en un principio el estudio que se ha realizado en la presente investigación es pionero en el país, pues no existe un registro de trabajos que enfoquen lo aquí mencionado.

En tal virtud es indispensable respaldar las pruebas tomadas en campo con un proceso de análisis de los casos mencionados anteriormente y reflejándolos en una plataforma tecnológica que brinde las facilidades de generar un ambiente con parámetros muy cercanos a los reales que otorgue valores que puedan ser considerados como referencia al momento de la implementación u optimización de TDT en el país al tiempo de permitir recrear múltiples 
escenarios con el fin de identificar las mejores configuraciones de las variables involucradas.

Un proceso de simulación consta de varias etapas las cuales garantizan que exista un conocimiento previo para su ejecución, así es necesario en primera instancia conocer claramente el objetivo del problema formulado, seguido de identificar los índices de medición que me permitirán analizar los resultados

para al final determinar con claridad y exactitud los datos que el modelo va a requerir para obtenerlo.

\subsubsection{Sirenet}

SIRENET (Simulation of Radio Electric Networks).

Es una aplicación informática que permite la planificación y gestión de redes de radiodifusión en un ambiente muy amigable para el usuario.

SIRENET contiene en un mismo programa un potente sistema de información geográfica, que permite la representación de entidades y simulaciones radioeléctricas sobre cartografía digital, complementado con los algoritmos de cálculo más difundidos y reconocidos a nivel internacional en materia de comunicaciones inalámbricas. 


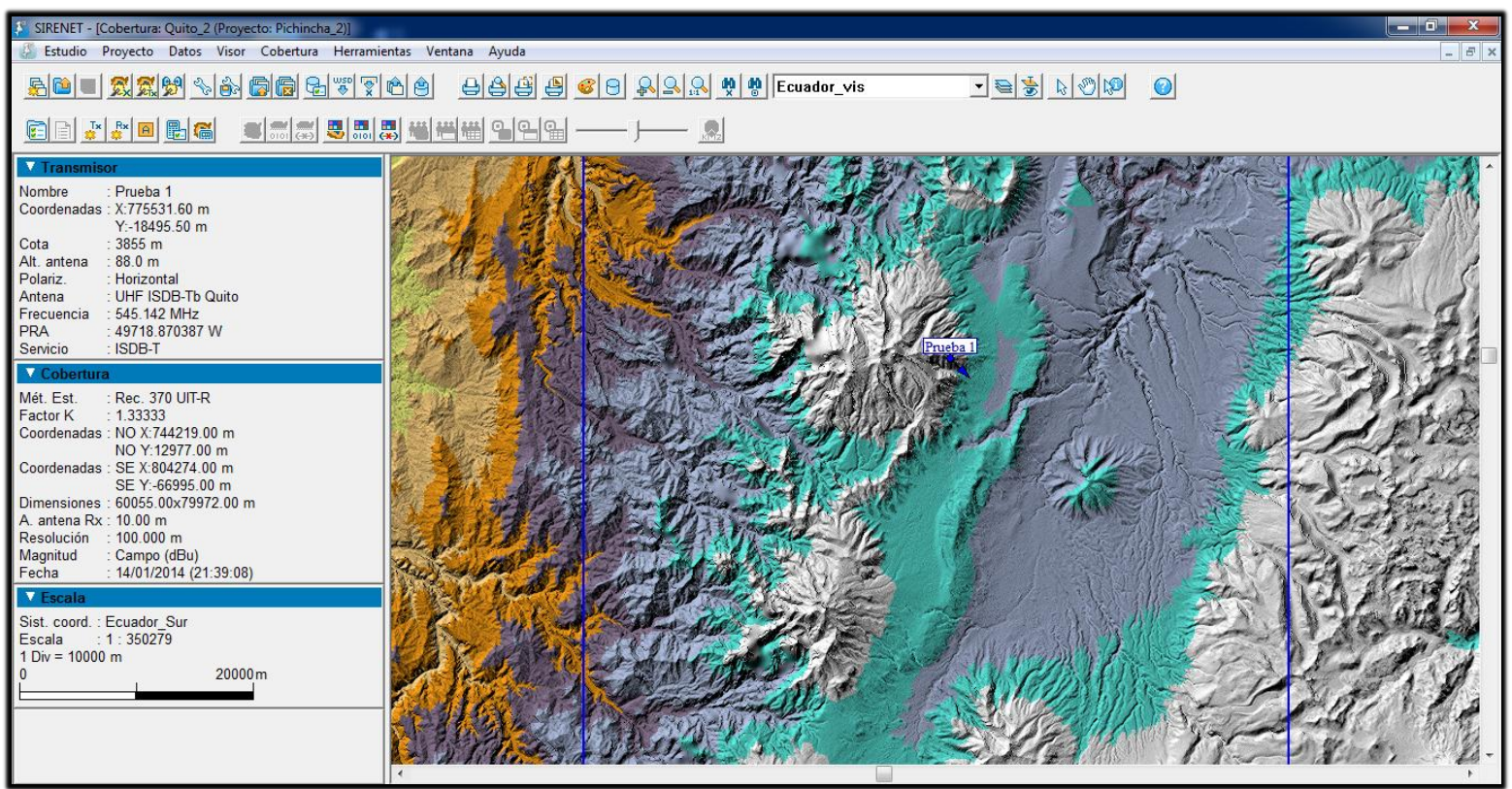

Figura 3.1: Ambiente grafico de SIRENET. (Diseño propio producto del análisis del estado de la TDT en Ecuador, 2013)

Esta herramienta tiene su estructura en "estudios" que ofrecen distintas funcionalidades con gran complejidad que parten desde el simple análisis de la propagación radioeléctrica entre dos puntos, a la asignación automática de frecuencias en una red compuesta por cientos de estaciones base o la comprobación del nivel de interferencia producida en todos los puntos del área cubierta por dicha red.

SIRENET es una herramienta con la que la planificación puede elaborarse desde su punto más genérico, ya que permite trabajar con todo tipo de servicios radioeléctricos y tecnologías, siendo una aplicación idónea para el diseño de redes de radiodifusión, servicios móviles, servicio fijo, etc. 
Los resultados de los estudios realizados pueden ser almacenados, impresos y exportados a formatos de las aplicaciones más comunes del mercado.

\subsubsection{Requisitos}

\section{Hardware}

El hardware mínimo recomendado para el correcto funcionamiento y aprovechamiento de las aplicaciones del simulador es:

- $\quad$ Procesador Intel Pentium Dual Core.

- $\quad 60 \mathrm{~GB}$ de disco duro.

- 1 GB RAM.

- Unidad CD-ROM.

- $\quad$ Tarjeta de vídeo de 256 MB.

\section{Software}

SIRENET deberá ser instalado sobre Windows 95/98/2000, Windows NT, Windows XP/SP2 o Windows Vista 
SIRENET al ser una herramienta muy completa ofrece una amplia gama de aplicaciones, en referencia del presente estudio se enfocara el trabajo sobre las facilidades que brinda el sistema relacionado con la COMPATIBILIDAD ELECTROMAGNETICA, así se definen las siguientes aplicaciones:

- Interferencia sobre receptor

- Interferencia de transmisor

- $\quad$ Degradación de cobertura

- $\quad$ Perfil en ruta interferencias

- $\quad$ Degradación de cobertura múltiple

\subsection{Mapas georeferenciados.}

Los mapas georeferenciados son aquellos que incluyen numeración, sentidos de las calles, información del tipo de suelo o tipo de negocio correspondiente a una dirección, es decir es un espacio determinado por ejemplo de una manzana se puede identificar todos los terrenos que están siendo utilizados como residencias, restaurantes, etc. Esto gracias a un levantamiento previo de información que permiten la representación grafica de una parte de la superficie terrestre y gracias al sistema GPS que mediante la utilización de una constelación de satélites permite determinar la posición de cualquier punto sobre la tierra con gran precisión. 
Los mapas georeferenciados se basan en una información previa otorgada por cartografías para el presente proyecto de investigación se uso la herramienta Google Earth que brinda las utilidades detallas anteriormente.

\subsection{Análisis de requerimientos}

El Ministerio de Telecomunicaciones y la Sociedad de la Información (MINTEL) y la Televisión Pública (ECTV), en su calidad de auspiciantes del presente proyecto de investigación; definieron los siguientes puntos como línea base en el estudio de la compatibilidad electromagnética de señales.

\subsubsection{Limitación de la zona de cobertura}

Limitar la zona de cobertura, consiste en definir geográficamente el área o espacio territorial bajo estudio, a través de mapas georreferenciados (Google Earth) y pruebas especificas de cobertura en el simulador (SIRENET).

Dado que el umbral mínimo de recepción de señal digital es $51 \mathrm{~dB} \mu \mathrm{V} / \mathrm{m}$, se busca identificar en el mapa, el radio de cobertura desde el transmisor hasta el punto en el cual la intensidad de campo eléctrico es $51 \mathrm{dB \mu V} / \mathrm{m}$. 
Como se observa a partir del numeral 3.5 Simulaciones, la ciudad de Quito y sus valles aledaños están dentro de dicho radio de cobertura, por lo tanto se define al Distrito Metropolitano de Quito, como la "Zona de Cobertura".

\subsubsection{Elección de equipos receptores}

El Ecuador como miembro oficial del Foro Internacional de Televisión Digital, a decidido adoptar las recomendaciones hechas por este, como el marco técnico regulatorio que estandarice la distribución y venta, de receptores digitales, a nivel nacional.

Definiendo todas las funcionalidades que el dispositivo receptor, debe disponer embebido en su arquitectura, a fin de recibir señales de televisión digital Full Seg, One Seg, en modo fijo, móvil y portátil.

Dicho foro, hace referencia a tres aspectos fundamentales, que permiten elegir idóneamente los equipos receptores, siendo estos: (ISDB-T, 2012)

\section{- Configuración básica del receptor}

Los receptores de televisión digital, deberán constar de tres elementos básicos, necesarios para garantizar la recepción de TDT; los cuales son: 
1. Antena receptora.

2. Cable de conexión.

3. Decodificador integrado de recepción.

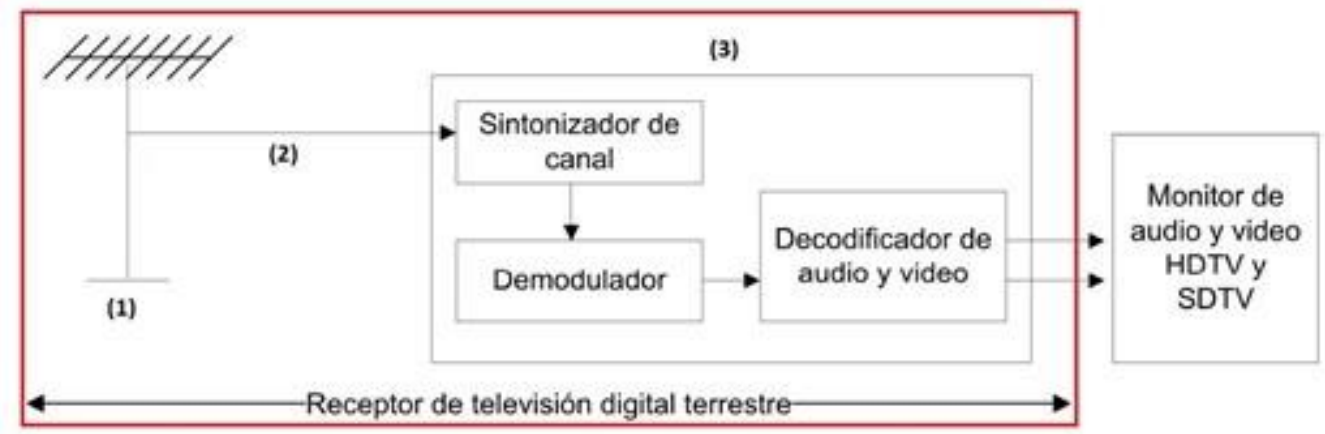

Figura 3.2: Estructura básica de un receptor digital. (ISDB-T, 2012)

Esta estructura puede variar, dependiendo del tipo de recepción fija, móvil y portátil.

\section{- Hardware}

El hardware, es el elementó activo encargad de transformar la señal de entrada recibida, en un flujo de datos, conocido como Transport Stream (TS); previo la sintonización de una determinada señal digital y su posterío demodulación.

Este Transport Stream, es dividido en tres paquetes, audio, video y datos; a través de sus respectivos decodificadores. Una vez que se han separado estas 
señales, pueden ser reproducidas, por cualquier dispositivo de audio y video básico.

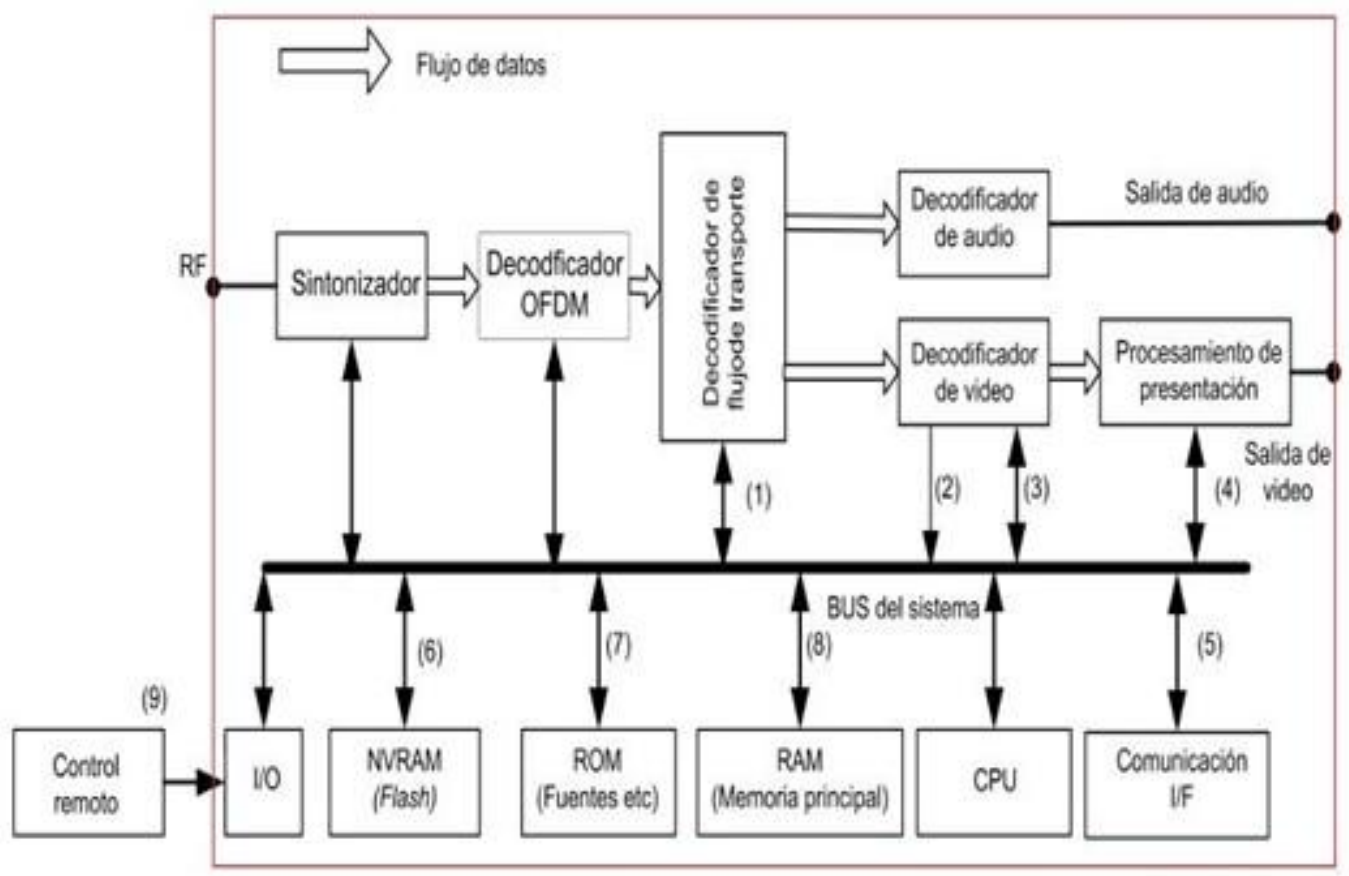

Figura 3.3: Arquitectura de la unidad receptora. (ISDB-T, 2012)

El hardware, deberá constar con las siguientes componentes en su estructura interna, las cuales se detallan en la Tabla 3.1: 
Tabla 3.1:

Componentes del hardware, receptor.

\begin{tabular}{lll}
\hline No & \multicolumn{1}{c}{ Descripción } & \multicolumn{1}{c}{ Observaciones } \\
\hline (1) & $\begin{array}{l}\text { Decodificador de Transport Stream, } \\
\text { recibe datos. }\end{array}$ & $\begin{array}{l}\text { Componente } \\
\text { decodificador del } \\
\text { Transport Stream (TS). }\end{array}$ \\
\hline (2) & $\begin{array}{l}\text { Reproducción del flujo de sistema y } \\
\text { datos de audio almacenados. }\end{array}$ & \\
(3) & $\begin{array}{l}\text { Reproducción de flujo del sistema y } \\
\text { de los datos de video. }\end{array}$ & Presentación. \\
(4) & $\begin{array}{l}\text { Presentación de video, imágenes } \\
\text { fijas, texto, etc. }\end{array}$ & Presentación. \\
(5) & $\begin{array}{l}\text { Función del canal de interactividad a } \\
\text { través de un canal de retorno. }\end{array}$ & Comunicación. \\
(6) & $\begin{array}{l}\text { Tamaño de datos que pueden ser } \\
\text { grabados consecutivamente. }\end{array}$ & Memoria. \\
(7) & $\begin{array}{l}\text { Espacio reservado para } \\
\text { almacenamiento. }\end{array}$ & Memoria. \\
(8) & $\begin{array}{l}\text { Memoria para obtener y decodificar } \\
\text { datos. } \\
\text { Componente receptor de comandos } \\
\text { a través del control remoto. }\end{array}$ & Memoria. \\
\hline
\end{tabular}

\section{- Parámetros del receptor}

Los organismos de control a nivel nacional, han definido ciertos parámetros técnicos de recepción, los mismos que están en concordancia con las normativas internacionales.

La Tabla 3.2, resume los aspectos técnicos mas relevantes, diferenciando claramente los receptores integrados de los STB (Set Top Box), de tal forma que ilustra a los fabricantes; las diferencias que presenta la recepción en formato Full-Seg y One - Seg. 
Tabla 3.2:

Parámetros de la unidad receptor.

\begin{tabular}{|c|c|c|c|}
\hline \multirow[t]{3}{*}{ Funcionalidades } & \multicolumn{2}{|c|}{ Tipo de Receptor } & \multirow[t]{2}{*}{ Observaciones } \\
\hline & Full - seg & One - seg & \\
\hline & \multicolumn{3}{|c|}{ Antena } \\
\hline In Antena & Obligatorio & Opcional & $Z_{\text {in }}=75 \Omega$ \\
\hline Out Antena & Obligatorio & Opcional & Obligatorio para STB \\
\hline \multicolumn{4}{|c|}{ Recepción de Canales } \\
\hline VHF & Obligatorio & Opcional & Ch: 7 al 13 \\
\hline UHF & Obligatorio & Obligatorio & Ch: 14 al 69 \\
\hline \multicolumn{4}{|c|}{ Ancho de Banda del Canal } \\
\hline Full - seg & Obligatorio & $\mathrm{N} / \mathrm{A}$ & $(\approx 5.7 \mathrm{MHz})$ \\
\hline One -seg & N/A & Obligatorio & $(\approx 0.43 \mathrm{MHz})$ \\
\hline \multicolumn{4}{|c|}{ Frecuencia Central } \\
\hline VHF & Obligatorio & Opcional & $V H F+1 / 7 \mathrm{MHz}$ \\
\hline UHF & Obligatorio & Obligatorio & $U H F+1 / 7 M H z$ \\
\hline \multicolumn{4}{|c|}{ Sensibilidad } \\
\hline $\begin{array}{l}\text { Nivel mínimo de } \\
\text { entrada }\end{array}$ & Recomendado & Recomendado & $\leq-77 \mathrm{dBm}$ \\
\hline $\begin{array}{l}\text { Nivel máximo de } \\
\text { entrada }\end{array}$ & Recomendado & Recomendado & $\geq-20 \mathrm{dBm}$ \\
\hline $\begin{array}{l}\text { Recuperación de } \\
\text { sincronismo }\end{array}$ & Obligatorio & Obligatorio & $\begin{array}{l}\text { Sincronización de símbolo } \\
\text { OFDM }\end{array}$ \\
\hline Procesamiento FFT & Obligatorio & Obligatorio & $\begin{array}{l}\text { Duración de símbolo } \\
\text { OFDM }\end{array}$ \\
\hline Extracción de cuadro & Obligatorio & Obligatorio & $\begin{array}{l}\text { Señal de sincronización } \\
\text { OFDM }\end{array}$ \\
\hline TMCC & Obligatorio & Obligatorio & Información de TMCC \\
\hline $\begin{array}{l}\text { Demodulación de } \\
\text { portadora }\end{array}$ & Obligatorio & Obligatorio & Con relación al TMCC \\
\hline Desentrelazado & Obligatorio & Obligatorio & En tiempo y frecuencia \\
\hline $\begin{array}{l}\text { Decodificación de } \\
\text { Viterbi }\end{array}$ & Obligatorio & Obligatorio & Tasa de decodificación 1/2 \\
\hline Regeneración de TS & Obligatorio & Obligatorio & \\
\hline $\begin{array}{l}\text { Decodificación Reed } \\
\text { Solomon }\end{array}$ & Obligatorio & Obligatorio & \\
\hline
\end{tabular}




\subsubsection{Modelo de canalización}

El modelo de canalización definido por el ente regulador garantiza que no se presente interferencia entre los sistemas digitales y analógicos de un operador de Televisión, como se detallará en los ítems posteriores.

\subsection{Zonas de Sombras}

Para definir las zonas de sombra, es necesario conocer los aspectos técnicos involucrados en la transmisión y recepción de señal digital, así como la topografía dentro del área de servicio, ya que esto nos permite comprender, el deterioro que experimenta dicha señal en diferentes zonas de la ciudad de Quito.

\subsubsection{Parámetros técnicos de transmisión}

A continuación, se detallan cada uno de los parámetros técnicos, necesarios para que la recepción y transmisión de señal digital; sea óptima dentro del área de servicio, así tenemos: 


\subsubsection{Intensidad de Campo Eléctrico}

Este es el parámetro de medición más importante a tener en cuenta, ya que determinar el nivel mínimo de señal, que permita garantizar la recepción de televisión digital, definiendo así el área de cobertura, dentro de la zona de servicio de los diferentes operadores.

Los resultados de estas mediciones deberán ser cotejados con las valoraciones técnicas, producto del estudio geográfico, ya que esto permitirá definir las zonas de sombra (Intensidad de Campo Eléctrico $<51 \frac{\mathrm{dB} \mu \mathrm{V}}{\mathrm{m}}$ ), lo cual facilitara la ubicación geográfica de los GAPFILLER, garantizando así la cobertura de televisión digital en toda la ciudad.

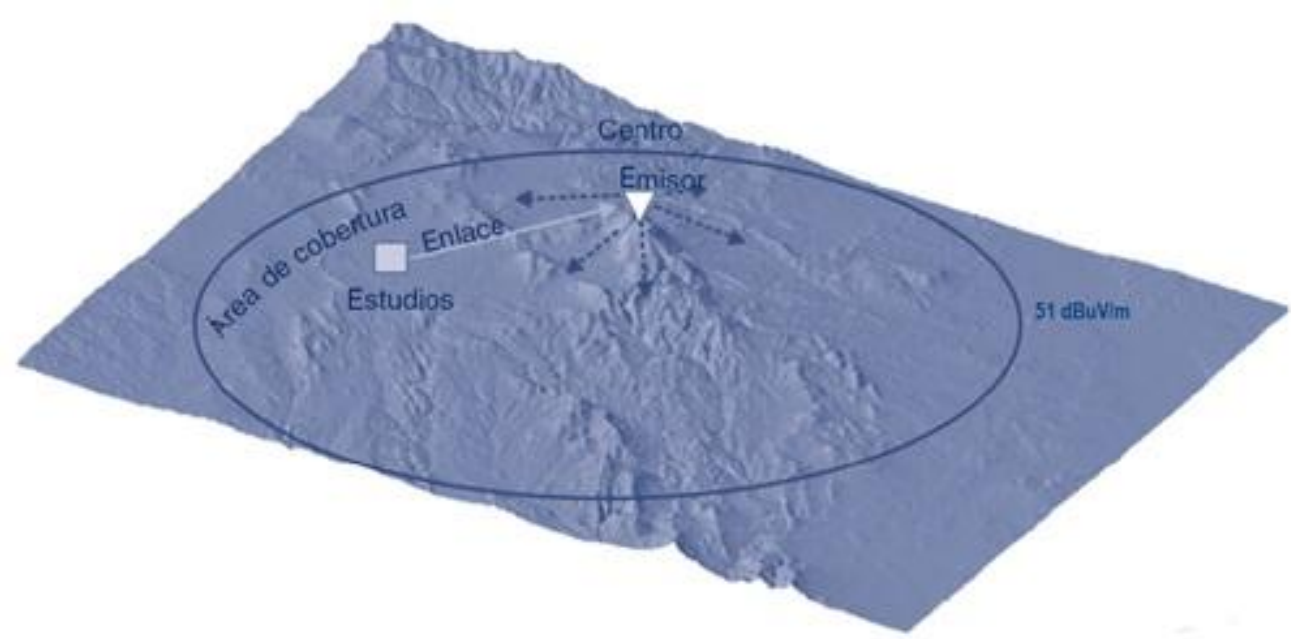

Figura 3.4: Zona de cobertura mínima, bajo el estándar ISDB - Tb.

(Chuurei, 2011) 


\subsubsection{MER (Tasa de Error en la Modulación)}

MER (Modulación Error Ratio), es la relación de potencia entre los vectores, que se extienden desde las posiciones ocupadas por los símbolos ideales de una constelación, y las posiciones ocupada por los símbolos recibidos, los cuales representan el valor ideal de la constelación MER, como se observa a continuación. (Chuurei, 2011)

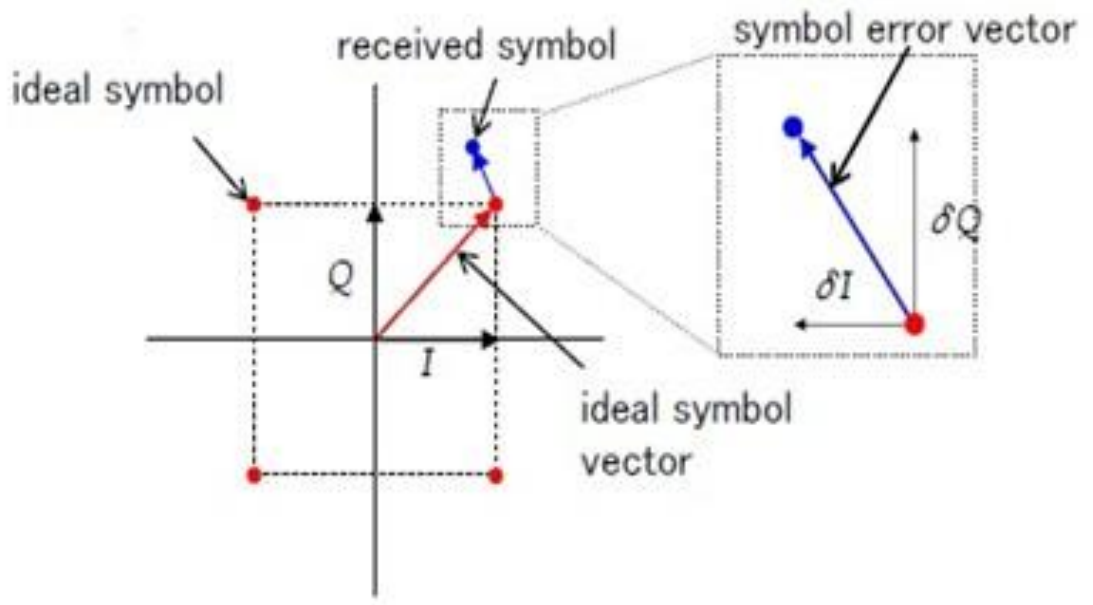

Figura 3.5: Representación grafica del MER. (Chuurei, 2011)

Por lo tanto el MER, se considerar como C / N de la radiodifusión Digital. 


\subsubsection{3 $\mathrm{C} / \mathrm{N}$}

Relación portadora a ruido $(\mathrm{C} / \mathrm{N})$, es la diferencia existente entre la potencia con la que recibimos la señal y la potencia del ruido que siempre la acompaña, presentes al momento de evaluar la calidad de una transmisión.

Una señal de poca potencia y alta relación $\mathrm{C} / \mathrm{N}$, permitirá obtener una mejor calidad que otra en la que, incluso con potencias muy superiores, se reciban con una peor relación portadora/ruido.

Esta realidad está presente en todas las comunicaciones, por lo tanto si hacemos una analogía con transmisiones analógicas, estaríamos hablando de la relación señal a ruido $(\mathrm{S} / \mathrm{N})$, sin embargo en transmisiones digitales, resulta aparentemente caótico, ya que se ven involucrados diferentes parámetros tales como; el modo de transmisión y por consiguiente el numero de portadoras presentes en este.

Por lo cual se utiliza la potencia de dichas portadoras para establecer la relación con el ruido inherente al sistema. 


\subsubsection{Error al medir el MER}

Uno de los errores más comunes al momento de efectuar esta medición, se da cuando no se relacionar el ancho de banda del canal de transmisión, al momento de medir $\mathrm{C} / \mathrm{N}$, razón por la cual es frecuente que el valor entregado por el medidor no coincida con el que se visualiza directamente sobre el espectro, que supone una medida puntual que no considera la anchura del canal utilizado.

Por ello para realizar una medición precisa, es recomendable definir la frecuencia exacta a la que se medirá el nivel de ruido, tomando así el valor mas cercano al real, del canal que se esta midiendo.

\subsubsection{Constelación}

La Constelación, permite realizar comprobaciones de la precisión con que se reciben los símbolos transmitidos. Una vez sintonizados, se detectan las amplitudes y fases de las señales I y Q, representándolos sobre la pantalla del equipo de medición. (http:www.tsc.urjc.es, 2013)

Una rejilla sobre esta pantalla nos informará de los límites en los que se pueden mover los diferentes puntos, y podremos tener una indicación visual de 
la calidad de recepción, en función del grado de nitidez que presente el gráfico. (http:www.tsc.urjc.es, 2013)

Obviamente, el ruido puede hacer que transmitamos uno de los puntos de la constelación (una señal con una fase y amplitud determinada) y que el receptor reciba otro diferente. En este caso, se producirá un error en los bits recibidos. Un buen sistema de transmisión digital minimizará el número de errores de bits cometidos. (http:www.tsc.urjc.es, 2013)

\subsubsection{BER (Tasa de Errores de Bits)}

Es un parámetro que se encarga de comprobar el correcto funcionamiento de los sistemas de corrección de errores y de la calidad de la señal del flujo transporte, analizando el número de fallas de la señal en bits con relación a una hora de tiempo, asignando un valor proporcional a esta relación.

\subsubsection{Códigos correctores de errores $C C E$}

A continuación se detalla brevemente los códigos presentes en el estándar ISDB-Tb. 


\subsection{Reed - Solomon (RS)}

Es una codificación de tipo externa que permite procesar una rata bits (flujo de datos) de forma redundante.

Esta codificación se obtiene al añadir 51 bytes nulos delante de 188 bytes de información, obteniendo 239, a la cual añadimos 16 bytes de paridad obteniendo un total de 255 bytes.

Finalmente Reed Solomon toma estos 255 bytes y elimina los bytes nulos, obteniendo el código corrector de error RS $(204,188 \mathrm{t}=8)$, corrigiendo esta 8 bytes erróneos.

El entrelazado externo altera el orden de los paquetes de trasporte provocando que los errores en las ráfagas que se introducen por el canal no afecten en gran manera a la transmisión, ya que al ordenarse estos paquetes en la recepción, los errores se distribuirán, ayudando a la corrección de errores. 


\subsection{Viterbi}

Codificador/Decodificador Interior (Codificación Convolucional de Viterbi.

Los códigos convolucionales son adecuados para usarse sobre canales con mucho ruido es decir con alta probabilidad de error, estos, son códigos lineales en donde la suma de dos palabras de un código cualquiera da como resultado otra palabra de código.

Después del codificador externo y el entrelazado, la información se somete a un nuevo proceso de codificación, denominados "internos".

La codificación interna es del tipo convolucional y es complementada con un proceso de perforado o puncturing.

El proceso de perforado consiste en que una vez que se baja la capacidad del canal a la mitad el sistema permite seleccionar para la transmisión solo algunos de los datos obtenidos en las salidas $X$ e $Y$ los cuales son posteriormente convertidos a una secuencia en serie, esto con el fin de no limitar tanto la capacidad del canal. 
La codificación convolucional representa una gran ayuda a la corrección de errores, es una codificación que emplea una estrategia diferente a la de ReedSolomon.

Este no aumenta redundancia a los bits de información, sino que cambia los bits de entrada de información por otros, producto de sumas modulo- 2 y combinados con registros.

Lo interesante de los códigos convolucionales está en su método de decodificación, por medio del algoritmo de Viterbi.

El objetivo de tener una segunda y última codificación es la de lograr obtener la mínima probabilidad de error de bit, y con la codificación convolucional bajo los parámetros que indica el estándar ISDB-Tb se logra lo propuesto.

\section{Interpretación teórica del los $C C E$}

Si suponemos un receptor de televisión digital cuyo esquema de modulación sea 64 QAM, en el cual tomamos el valor del BER, a la salida del demodulador, a la salida del corrector de Viterbi, y por ultimo, a la salida del corrector de (Reed-Solomon, RS), obtenemos tres parámetros (mediciones), que al 
relacionarlos nos permitirá comprobar la eficiencia de los sistemas de corrección de errores.

Ahora para definir cuándo una trama de transporte es válida, se define el concepto de señal casi libre de errores (Quasi Error Free - QEF), en la cual según la norma ISDB - Tb, una trama cumple la norma cuando se detectan, luego de los procesos de corrección menos de un fallo por cada hora.

Lo cual supone que a la salida del decodificador (Reed - Solomon, RS), debemos obtener un factor BER menor a $1 \times 10^{-11}$; mientras que a la salida del decodificador de Viterbi, deberá obtenerse una tasa de error de $2 \times 10^{-4}$, lo cual garantiza que está virtualmente libre de errores, y la buena recepción es posible.

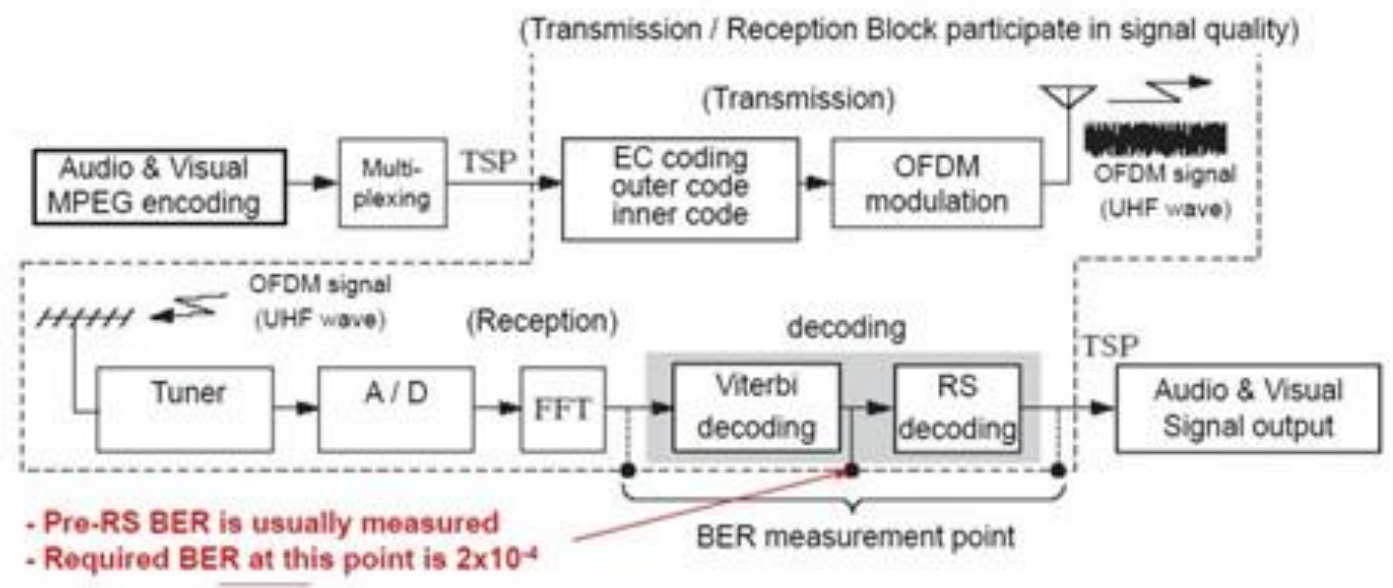

Figura 3.6: Bloques Transmisión / Recepción participantes en la calidad de la señal. (Chuurei, 2011) 
Nota: La cantidad de errores y por lo tanto, el BER depende del punto en el que se hace la medición.

\subsubsection{Intervalo de guarda}

Después de que los símbolos OFDM has sido convertido del dominio de la frecuencia al dominio del tiempo, se añade un intervalo de guarda con una duración $(\Delta)$ que consiste en una continuación cíclica de la parte útil de una señal.

La suma de este intervalo de guarda protege al sistema de ecos generados por ondas multi - trayecto y los ecos producidos por la interferencia Co-canal en las SFN.

Dicho proceso convierte a la señal en una señal mas robusta pues se está añadiendo el denominado "Tiempo de Guarda" al tiempo de duración ( $\mathrm{Tg}$ ).

Quedando como resultado un "Tiempo de Símbolo":

$$
T S=T u+\Delta ; \text { E.C.: (3.1) }
$$

Con este procedimiento el espacio entre símbolos aumenta lo que genera una eliminación de interferencia entre los mismos. 
Se considera al intervalo de guarda como una continuación cíclica de la parte útil de un símbolo, la cual se inserta delante de él.

Si la señal se recibe por dos caminos distintos, con un retardo entre ellos, siempre que este retardo no supere a $\Delta$, coincidirá en las dos señales recibidas la información contenida dentro del tiempo $(\mathrm{Tg})$.

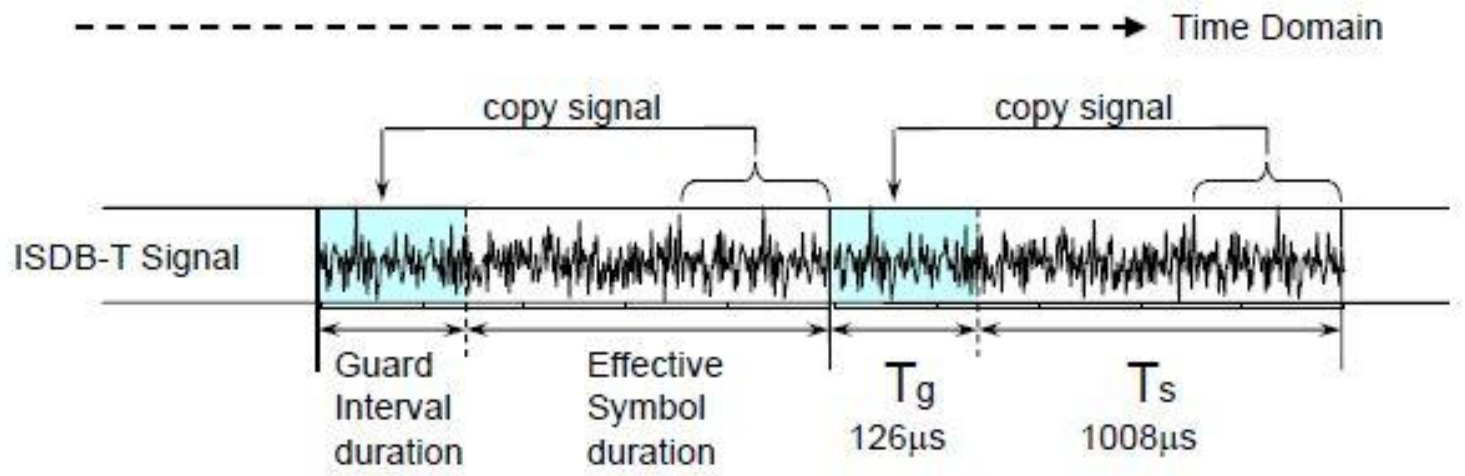

Figura 3.7: Representación grafica del intervalo de guarda ( $\mathbf{T g})$. (Chuurei, 2011)

\subsubsection{Estudio geográfico}

Consiste en el análisis topográfico de la zona de servicio, a fin de evidenciar los obstáculos naturales (Montañas), presentes en la zona de servicio (Ciudad de Quito), los cuales inciden de forma directa en la pérdida gradual de la señal, debido a la degradación considerable que la intensidad de campo eléctrico experimente, producto de los múltiples obstáculos que debe atravesar. 
Esto permitirá definir tentativamente las Zonas de Sombra, en la cual la recepción de TDT, no esta garantizada, ya que la intensidad de campo eléctrico esta bajo los $51 \mathrm{~dB} \mu \mathrm{V} / \mathrm{m}$.

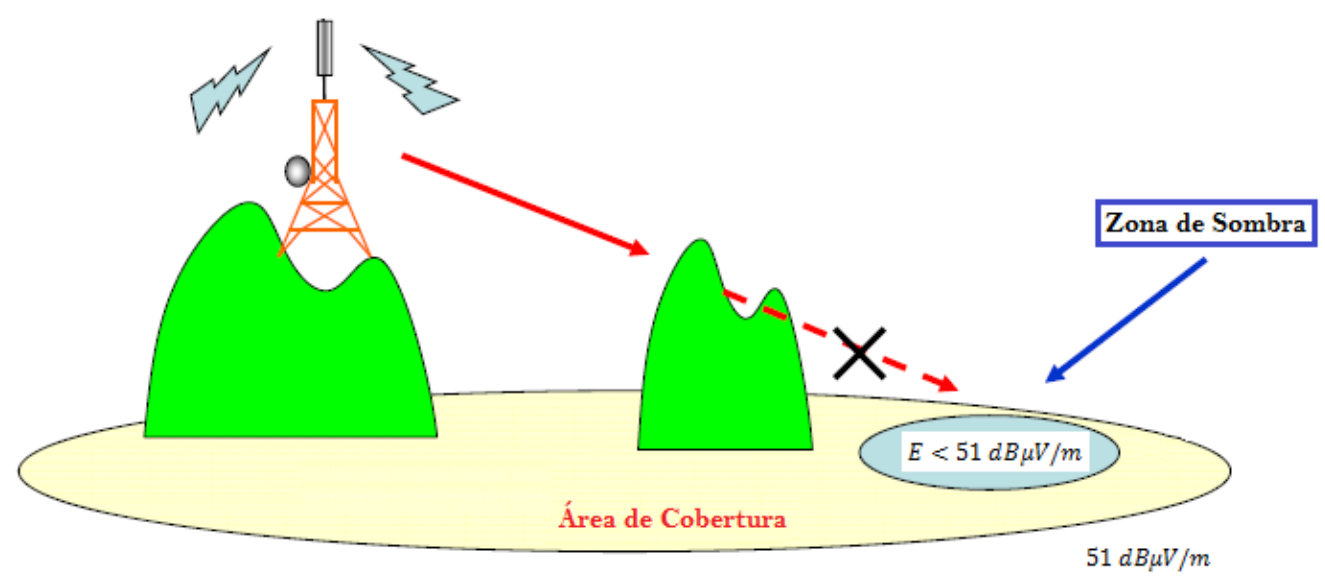

Figura 3.8: Representación gráfica de las Zonas de Sombra. (Diseño propio producto del análisis del estado de la TDT en Ecuador, 2013)

\subsubsection{Estudio del perfil del terreno}

Estudiar el perfil de terreno del área de cobertura, nos permite comprender su topografía, siendo de mucha utilidad al momento de proponer la ubicación de GAPFILLER. 
Permitiendo satisfacer eficiente la transmisión de televisión digital en la ciudad Quito, estos perfiles de terreno se lo obtiene gracias a Google Earth, a través de la herramienta "Mostrar Perfil de Elevación".

Para ello se crea un enlace entre dos puntos, TX_Cerro_Pichincha y Objetivo_de_Cobertura.

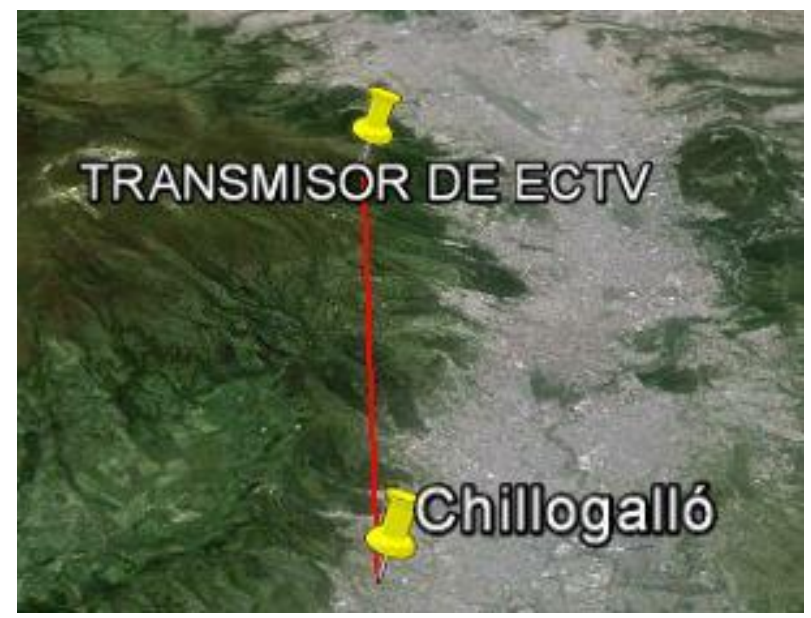

Figura 3.9: Enlace en Google Earth, entre el Cerro Pichincha y la Parroquia de Chillogallo. (Diseño propio producto del análisis del estado de la TDT en Ecuador, 2013)

Es importante definir los objetivos más apartados al transmisor (Cerro Pichincha) y posteriormente analizar los accidentes geográficos que pueden incidir de forma directa en una perdida considerable de señal. 
Tabla 3.3:

Objetivos distantes de cobertura, con relación al cerro Pichincha.

\begin{tabular}{cc}
\hline Latitud & Referencia \\
\hline NORTE & Mitad del Mundo \\
SUR & Mena Dos a Chillogallo \\
ESTE & Loma de Puengasí \\
\hline CENTRO & Panecillo \\
\hline
\end{tabular}

\subsubsection{Definición de las Zonas de Sombra}

A continuación, se muestra el perfil montañoso de los objetivos de cobertura definidos en la Tabla 3.3, en la cuales se evidencia las Zonas de Sombra, y principales obstáculos que impiden la recepción normal de señal en la ciudad de Quito.

\section{Datos:}

- $\quad$ Altura de la Torre: $88 \mathrm{mts}$

- $\quad$ Altura de la ubicación de la torre de ECTV: $3858 \mathrm{mts}$ 


\section{Norte}

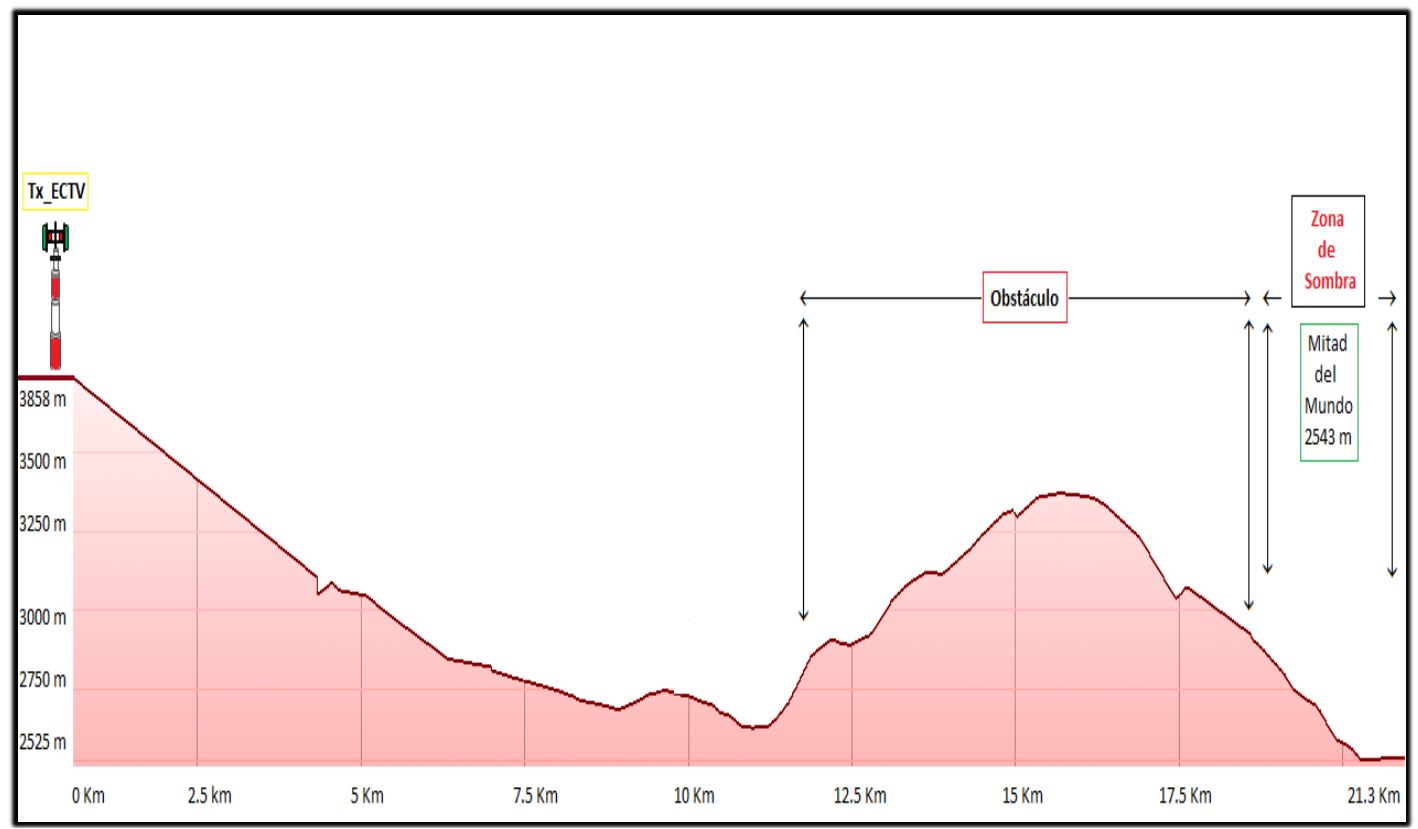

Figura 3.10: Zona de sombra, Mitad del Mundo.

\section{Sur}

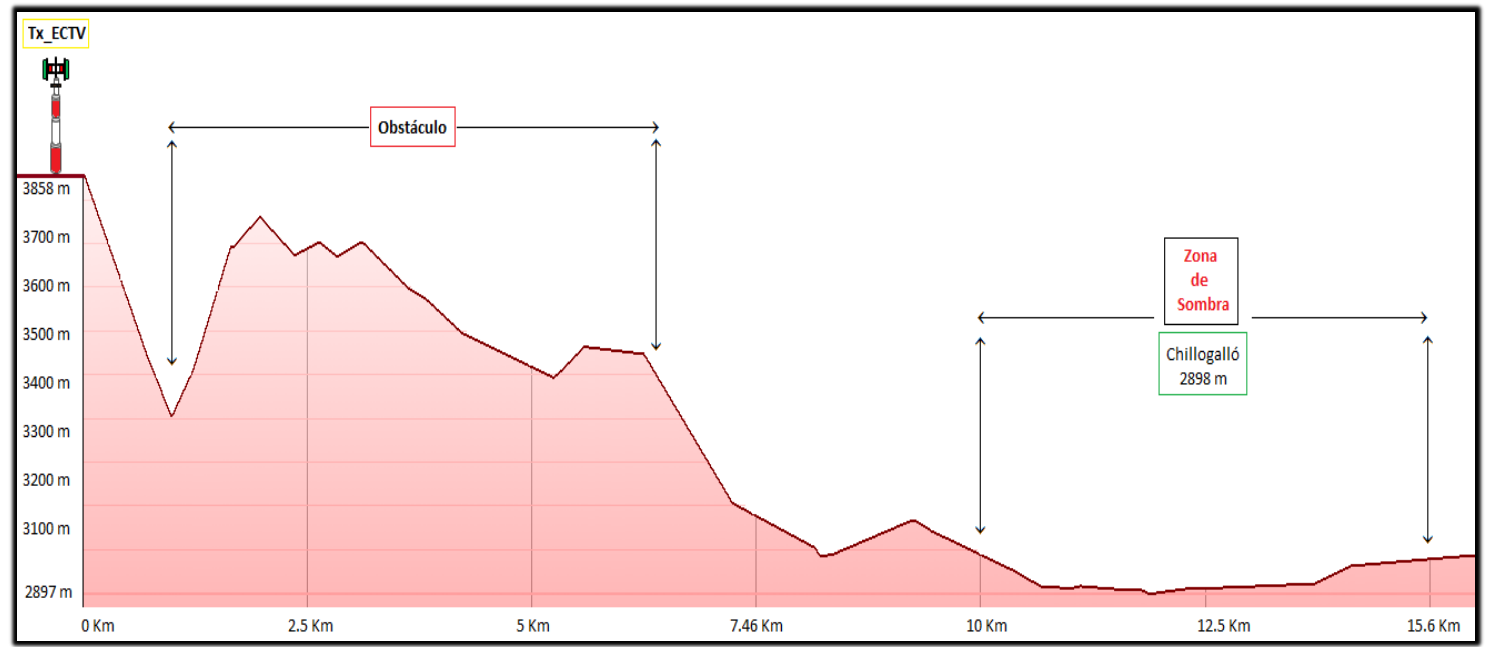

Figura 3.11: Zona de sombra, Chillogallo. 


\section{Este}

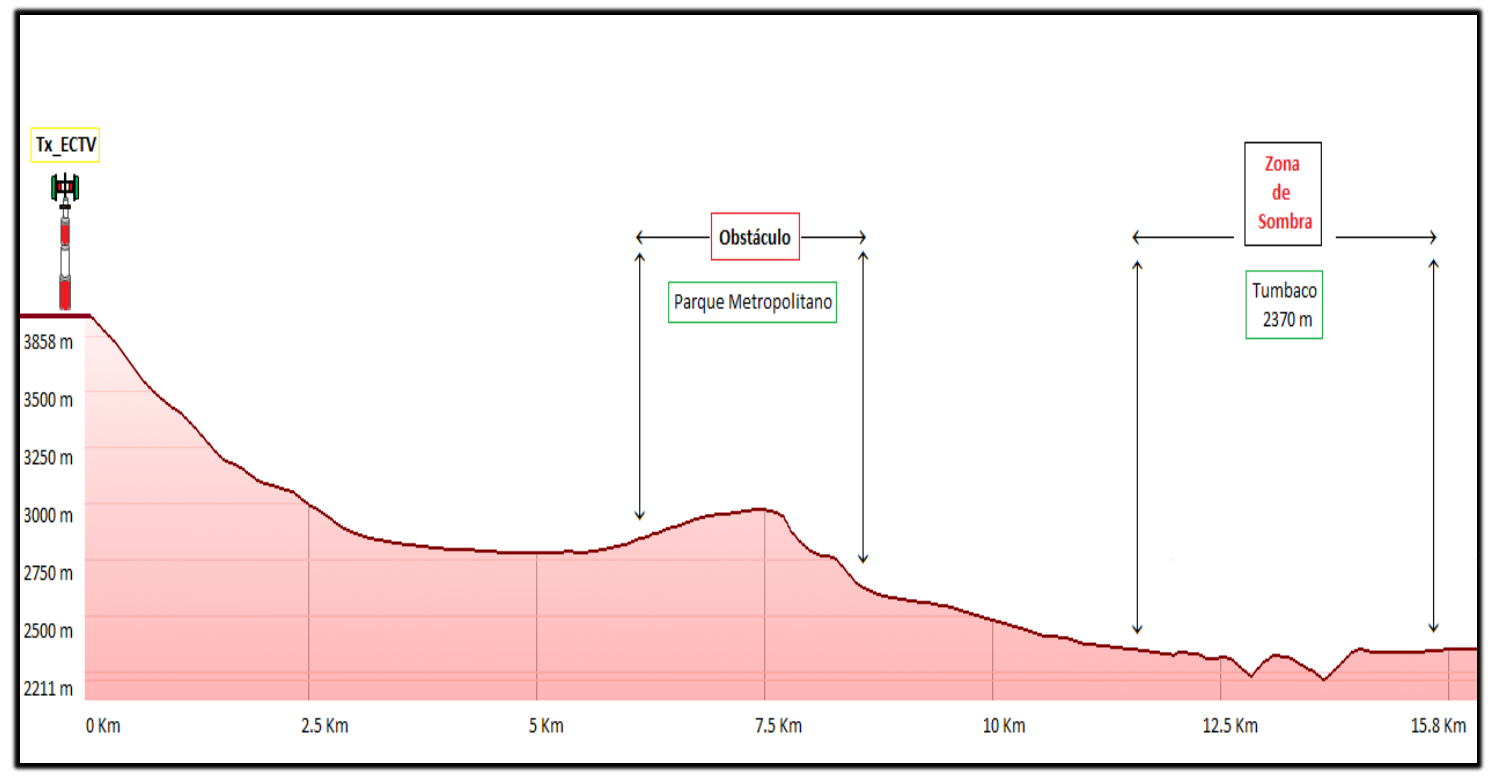

Figura 3.12: Zona de sombra, Tumbaco.

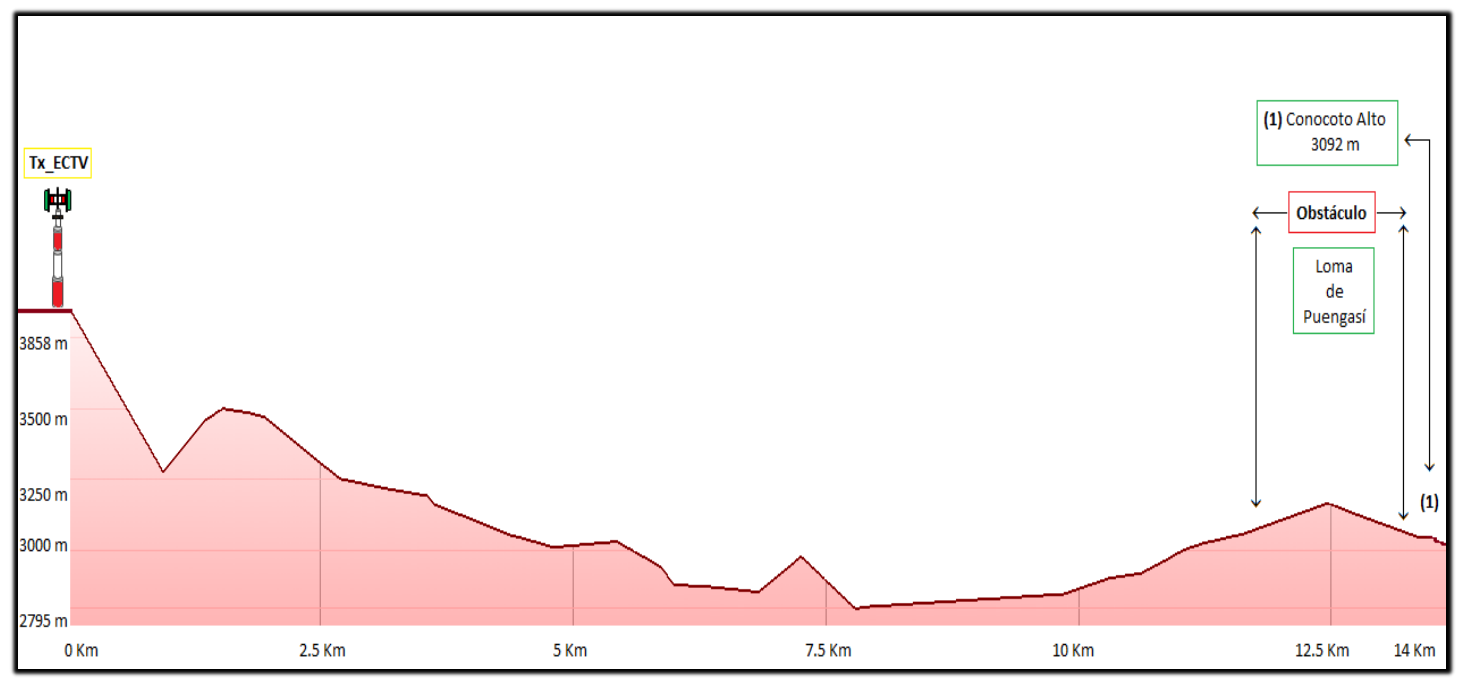

Figura 3.13: Zona de sombra, Conocoto Alto. 


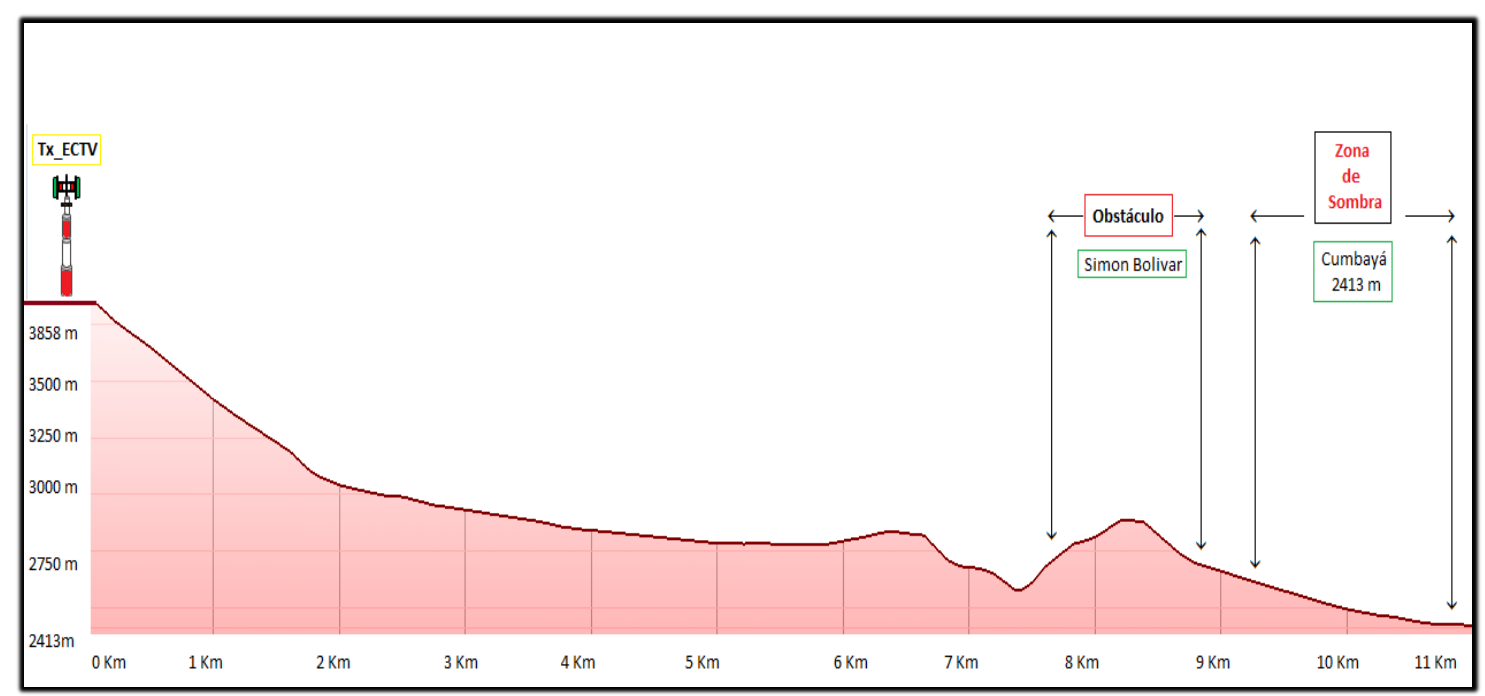

Figura 3.13: Zona de sombra, Cumbayá.

\section{Centro}

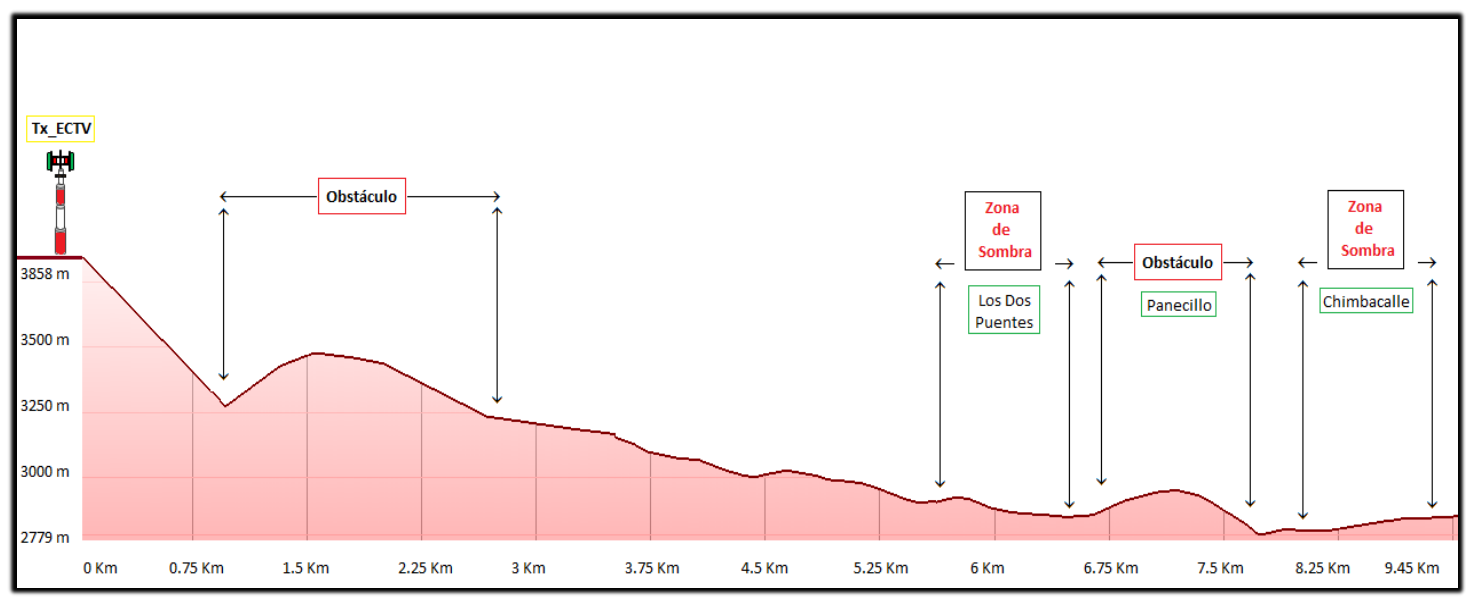

Figura 3.14: Zona de sombra, El Panecillo.

De lo anterior desprendemos tentativamente la existencia de cuatro zonas de sombra en la ciudad de Quito, siendo estas: 
1. En la zona Norte de la ciudad, se define como una zona de sombra la parroquia de San Antonio.

2. En la zona Sur de la ciudad, se define como una zona de sombra el área Sur-Occidental, cuyos limites son la Av. Mariscal Antonio José de Sucre y el cordón montañoso (Sima de la Libertad).

3. En la zona Este de la ciudad, se define como zonas de sombra las parroquias de Conocoto, Cumbayá, Llano Chico y Nayón (áreas altas).

4. En la zona Centro de la ciudad, se define como zonas de sombra las faldas orientales de los cerros El Panecillo, El Itchimbia y La Loma de Puengasí.

Las mismas que serán ratificadas o descartadas, cuando se efectúen las simulaciones de transmisión y recepción, en la herramienta de simulación SIRENET y las mediciones de campo con el analizador de espectros digital.

\subsection{Simulación}

A continuación de detallan los procesos de simulación requeridos para nuestro estudio. 


\subsubsection{Simulación de Cobertura.}

Como primer paso dentro del proceso de simulación se procede a identificar la zona de cobertura que actualmente brinda el Transmisor de ECTV, instalado en el cerro Pichincha.

Como fue detallado en Capitulo II; en la sección relacionada al Sistema Radiante, el transmisor de ECTV dispone de un arreglo de antenas orientado a razón $45^{\circ}$ y $135^{\circ}$.

Con motivos prácticos que permitan un análisis sencillo del patrón de radicación y sus niveles de intensidad de campo eléctrico (ICE), se simulo por separado la cobertura para cada uno de los azimut.

\section{- $\quad$ Patrón de radiación con azimut de $45^{\circ}$}

Orientado hacia el Noreste de Quito, constituido por un arreglo de dos antenas $P A D 2000$, cuya potencia de transmisión es de $500 \mathrm{~W}$ alimentados por dos latiguillos a cada una. 


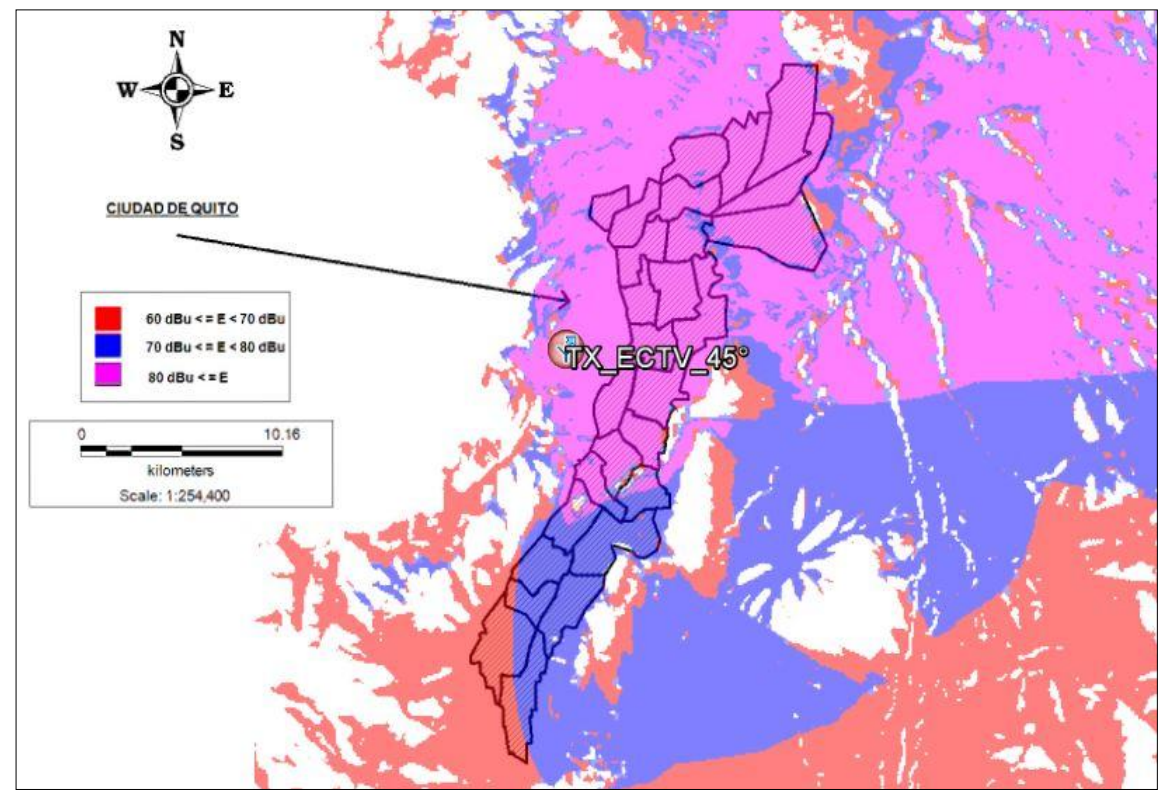

Figura 3.15: Cobertura del transmisor de ECTV, con azimut de $45^{\circ}$.

- Patrón de radiación con azimut de $135^{\circ}$

Orientado hacia el Sureste de Quito, constituido por un arreglo de dos antenas $P A D 2000$, cuya potencia de transmisión es de $500 \mathrm{~W}$ alimentados por dos latiguillos a cada una. 


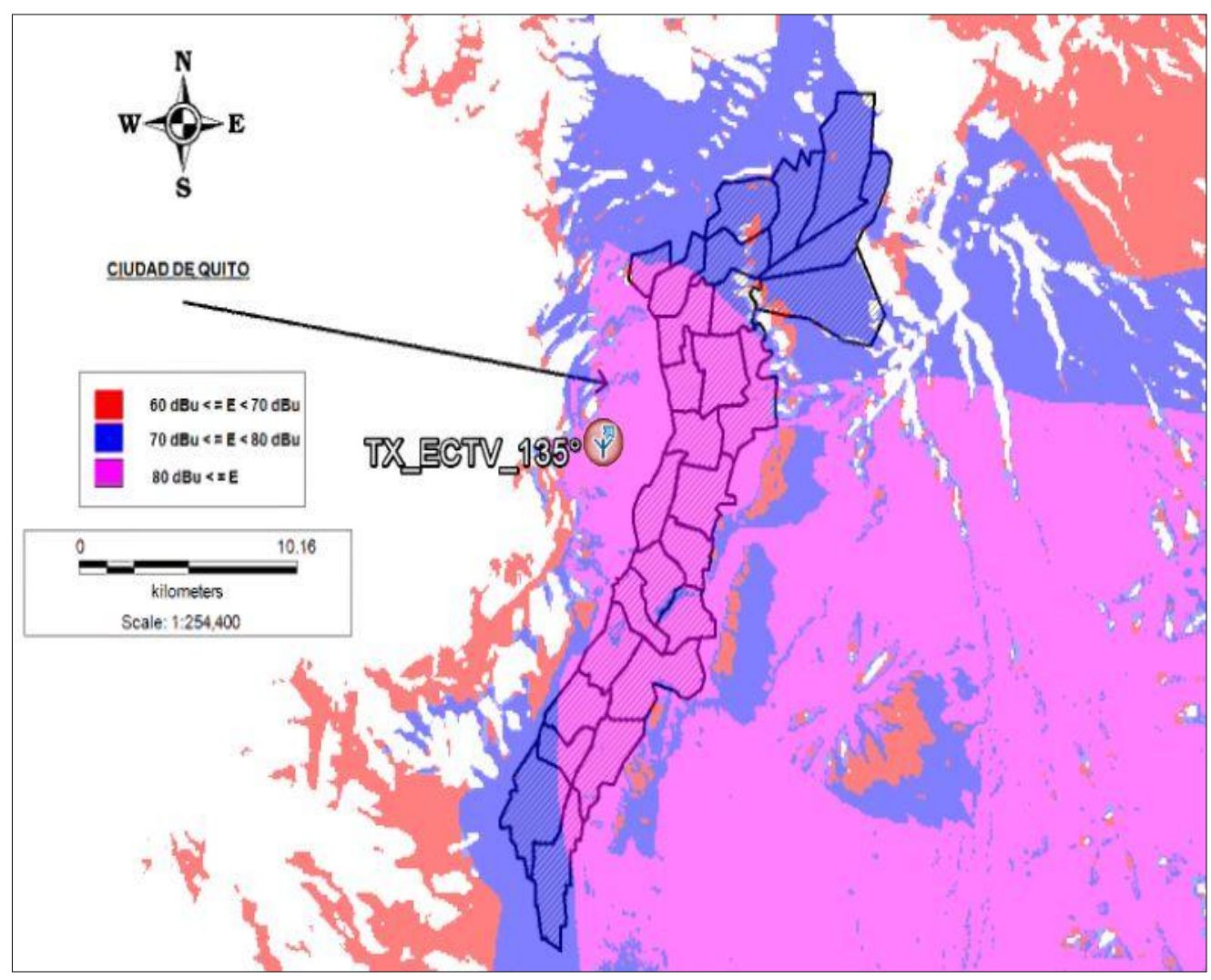

Figura 3.16: Cobertura del transmisor de ECTV, con azimut de $135^{\circ}$.

De las figuras 3.15 y 3.16 , se desprende a partir de la valoración por colores del $I C E$, la calidad de la señal digital a lo largo y ancho de la ciudad de Quito.

El análisis de la simulación de cobertura, nos permite ponderar los resultados obtenidos del ICE, dentro de tres casillas (Deficiente - Aceptable y Óptima), como se ilustra en la siguiente tabla: 


\section{Tabla 3.4:}

Rango de valoración de ICE.

\begin{tabular}{ccc}
\hline Rango de Potencia & Zona de Cobertura & Nivel de señal \\
\hline $\mathbf{6 0} \mathbf{d B u}<=E<70$ & Rojo & Bueno \\
$\mathbf{7 0} \mathbf{d B u}<=E<80$ & Azul & Muy Bueno \\
$\mathbf{8 0} \mathbf{d B u}<=E$ & Rosada & Excelente \\
\hline
\end{tabular}

\subsubsection{Simulación de Perfil}

La simulación del perfil del terreno, es una distribución de la intensidad de campo eléctrico en $(d B u)$ versus la topografía de la zona de estudio en $(\mathrm{Km})$.

Que permite la verificación o no, de línea de vista entre dos puntos de interés, siendo el primero de estos el emplazamiento correspondiente al sistema radiante de ECTV y un sector, parroquia o aglomeración urbana de alto interés; debido a la presencia masiva de usuarios.

Estas simulaciones nos permite corroborar o descartar, lo propuesto en el presente capitulo, en la sección 3.5.2.2 Definición de las Zonas de Sombra.

A continuación se presenta el resultado obtenidos de la simulación: 


\section{- $\quad$ Perfil Mitad del Mundo}

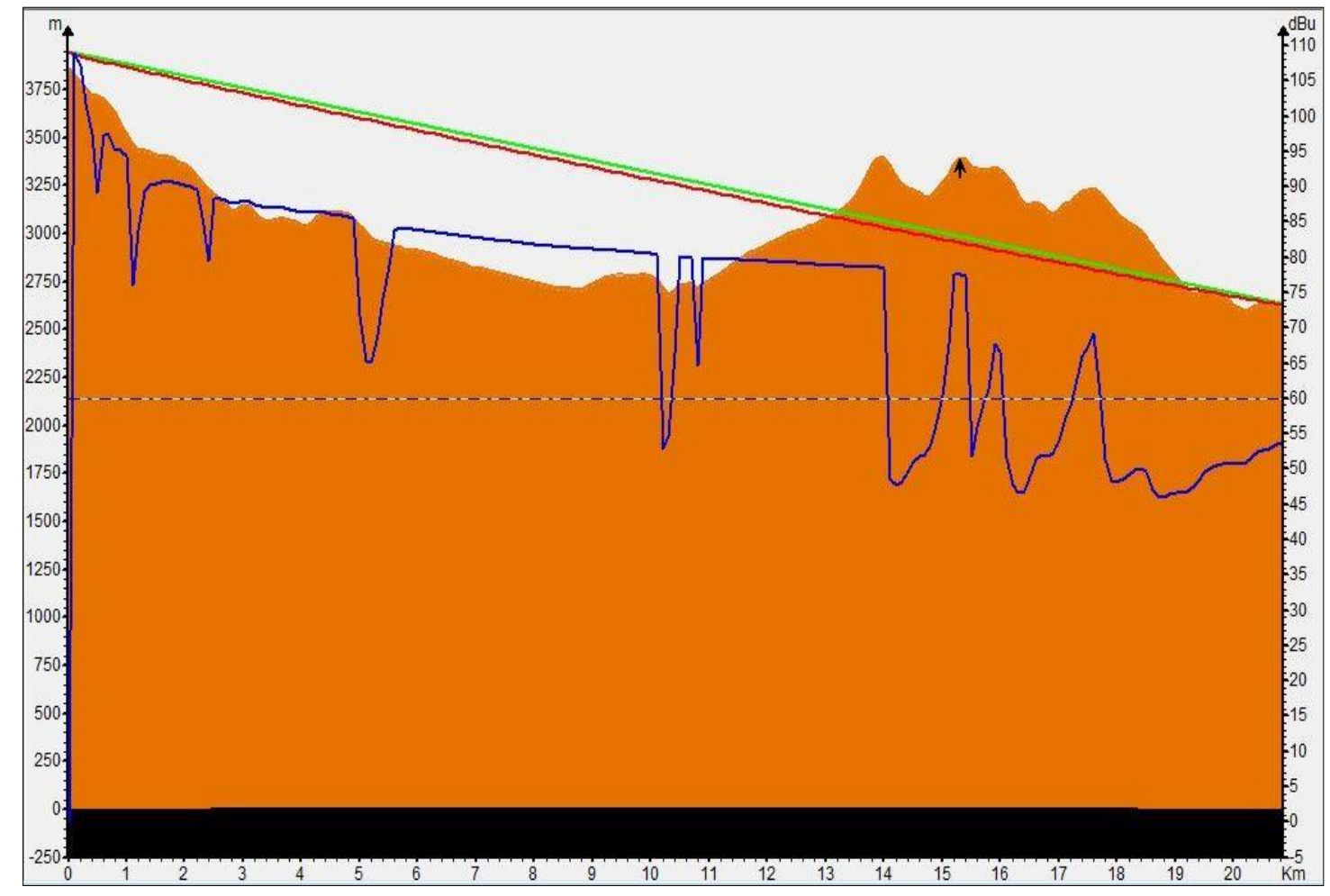

Figura 3.17: Perfil de cobertura, Mitad del Mundo.

Se identifica una zona de sombra en el sector de la Mitad del Mundo, como el gráfico lo reflejan existe un obstáculo lo que impide contar con línea de vista hacia dicho sector, cuantificando un nivel de señal de $53[\mathrm{dBu}]$. 


\section{- $\quad$ Sur de Quito}

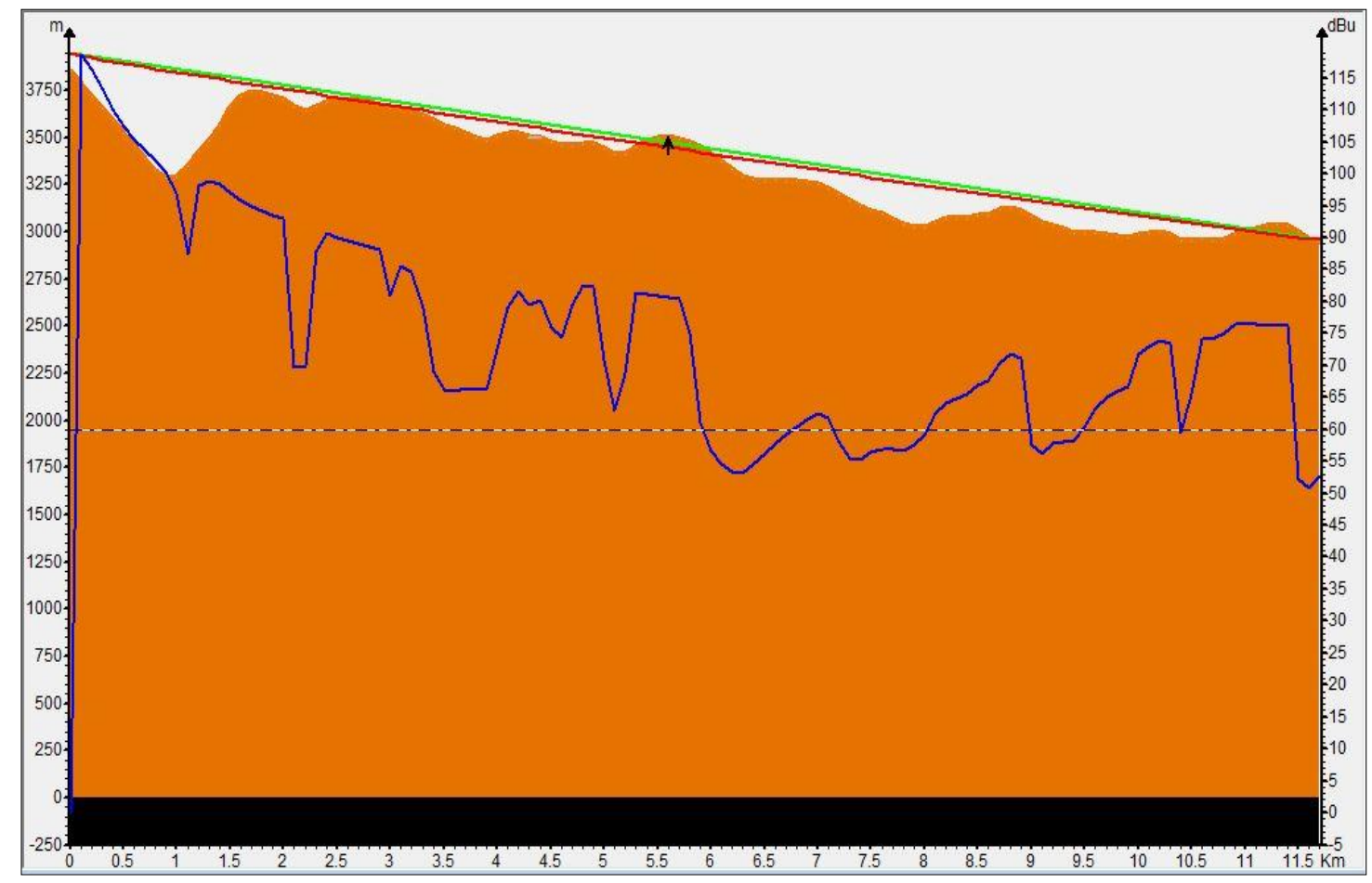

Figura 3.18: Perfil de cobertura, Sur de Quito.

Se identifica una zona de sombra en el sector de Sur de Quito, como el gráfico lo reflejan existe un obstáculo lo que impide contar con línea de vista hacia dicho sector, cuantificando un nivel de señal de $52[d B u]$. 
- Conocoto Alto

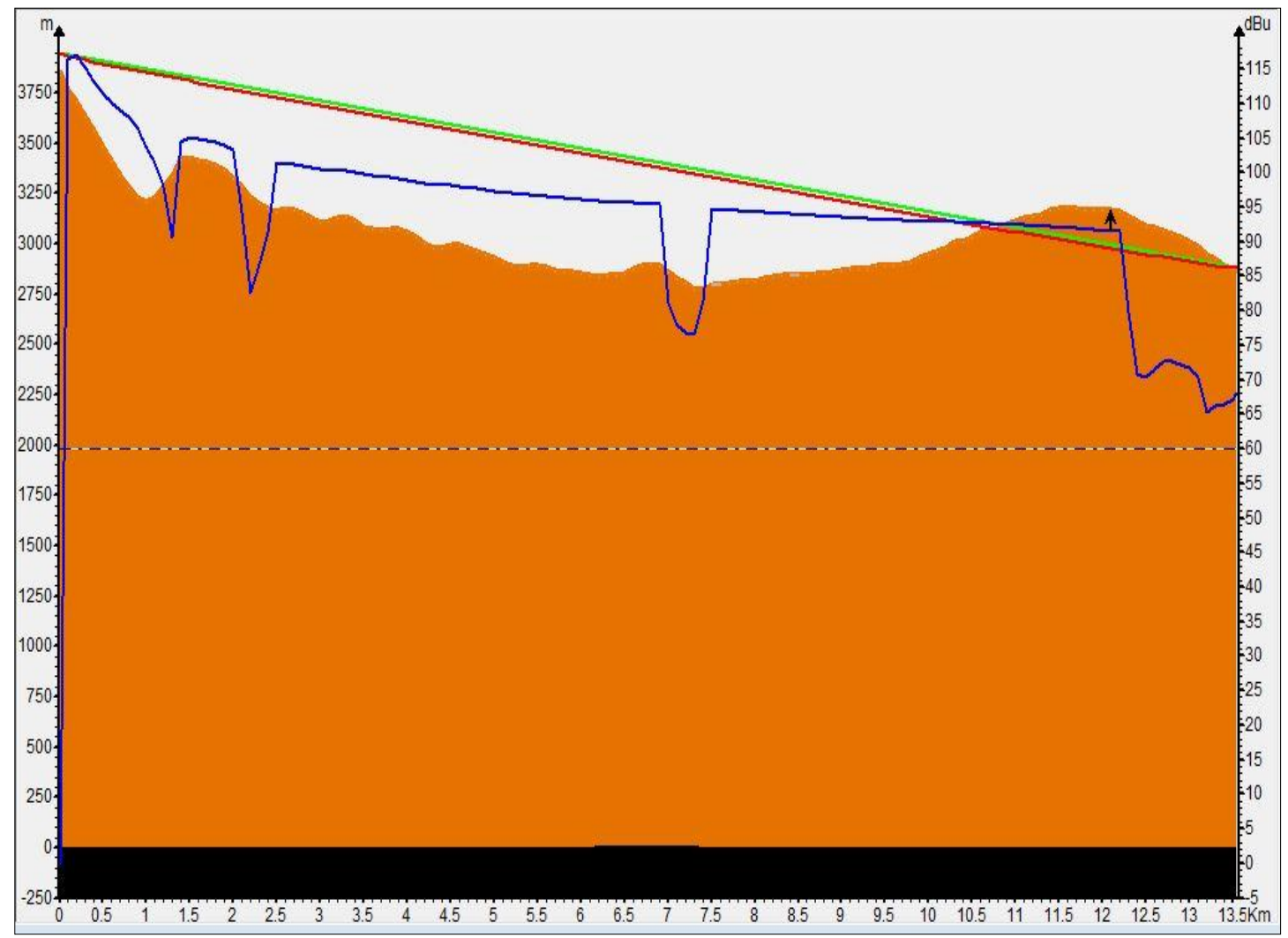

Figura 3.19: Perfil de cobertura, Conocoto Alto.

Se identifica una zona de sombra en el sector de Conocoto Alto, como el gráfico lo reflejan existe un obstáculo pero de baja importancia, ya que no impide contar con línea de vista hacia dicho sector, cuantificando un nivel de señal de $67[d B u]$. 


\section{- $\quad$ Cumbayá Alto}

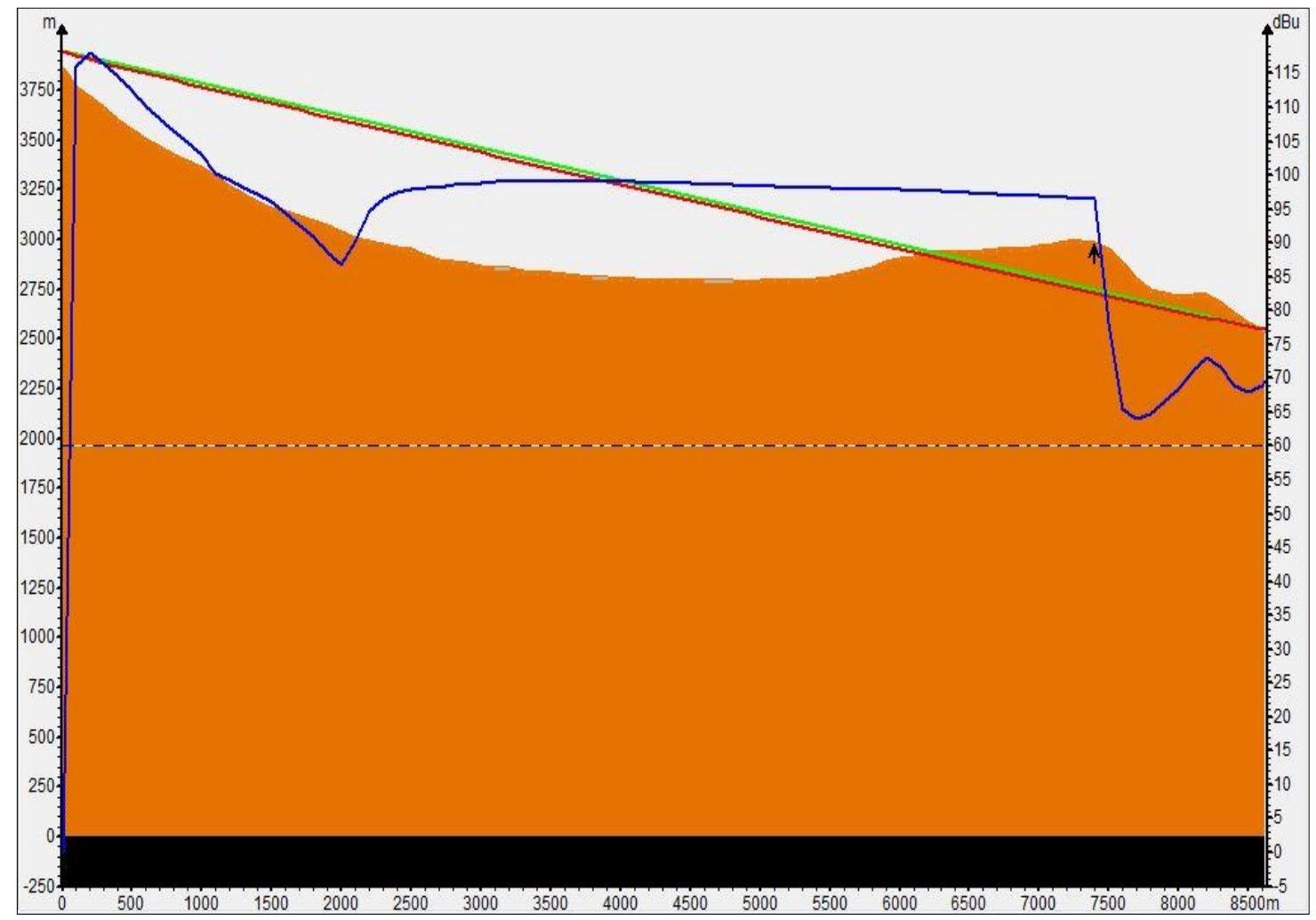

Figura 3.20: Perfil de cobertura, Cumbayá Alto.

Para el sector de Cumbayá Alto, a pesar de no existir línea de vista se identifica un perfil más regular lo que se refleja en el valor de la señal $69[d B u]$. 
- $\quad$ El Panecillo

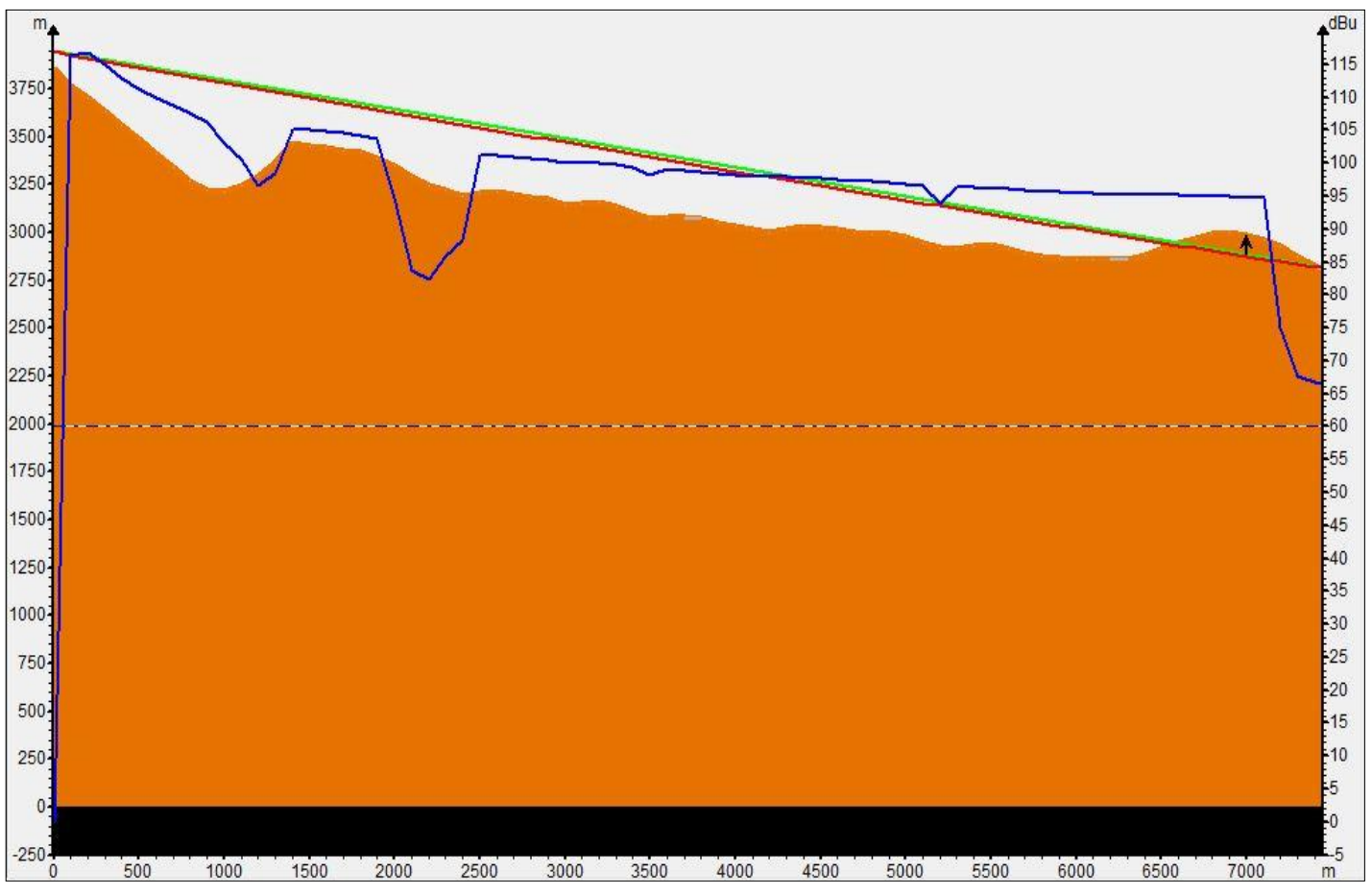

Figura 3.21: Perfil de cobertura, Panecillo.

Para el sector del Panecillo, no existe línea de vista pero la regularidad del perfil entrega un valor de señal de $66[d B u]$.

\section{Interpretación de la simulación de perfiles:}

En base a los resultados de las simulaciones anteriores se verifica la existencia de dos zonas de sombra (Sur de Quito - La Mitad del Mundo) y se descartan los escenarios restantes. 


\subsubsection{Ubicación de GAPFILLER}

Una vez que han sido diferenciadas las zonas de sombra en la ciudad de Quito, es precisó definir la ubicación de estaciones reforzadoras de señal o Gap Fillers, a fin de mejorar la cobertura.

\subsubsection{Estación reforzadora Sur de Quito}

En el proceso de la búsqueda de la solución para esta parte de la ciudad, se identifican dos emplazamientos para la ubicación del GAP FILLER, considerando al primer candidato como el que mejor cobertura brinda, mientras que el segundo candidato es el que mayor viabilidad con respecto a la instalación brinda al encontrarse en un perímetro de estaciones existentes, así se definen: 
- $\quad$ Primer candidato: Loma de Puengasí.

Tabla 3.5:

Coordenadas del GAPFILLER - Loma de Puengasí.

\begin{tabular}{cccc}
\hline Nombre & Longitud & Latitud & Altura [m] \\
\hline Loma de Puengasí & $78^{\circ} 31^{\prime} 16,72^{\prime \prime} \mathrm{O}$ & $0^{\circ} 17^{\prime} 11,82^{\prime \prime} \mathrm{S}$ & 3142 \\
\hline
\end{tabular}

Simulación de cobertura del transmisor de ECTV, con azimut de $135^{\circ}$.

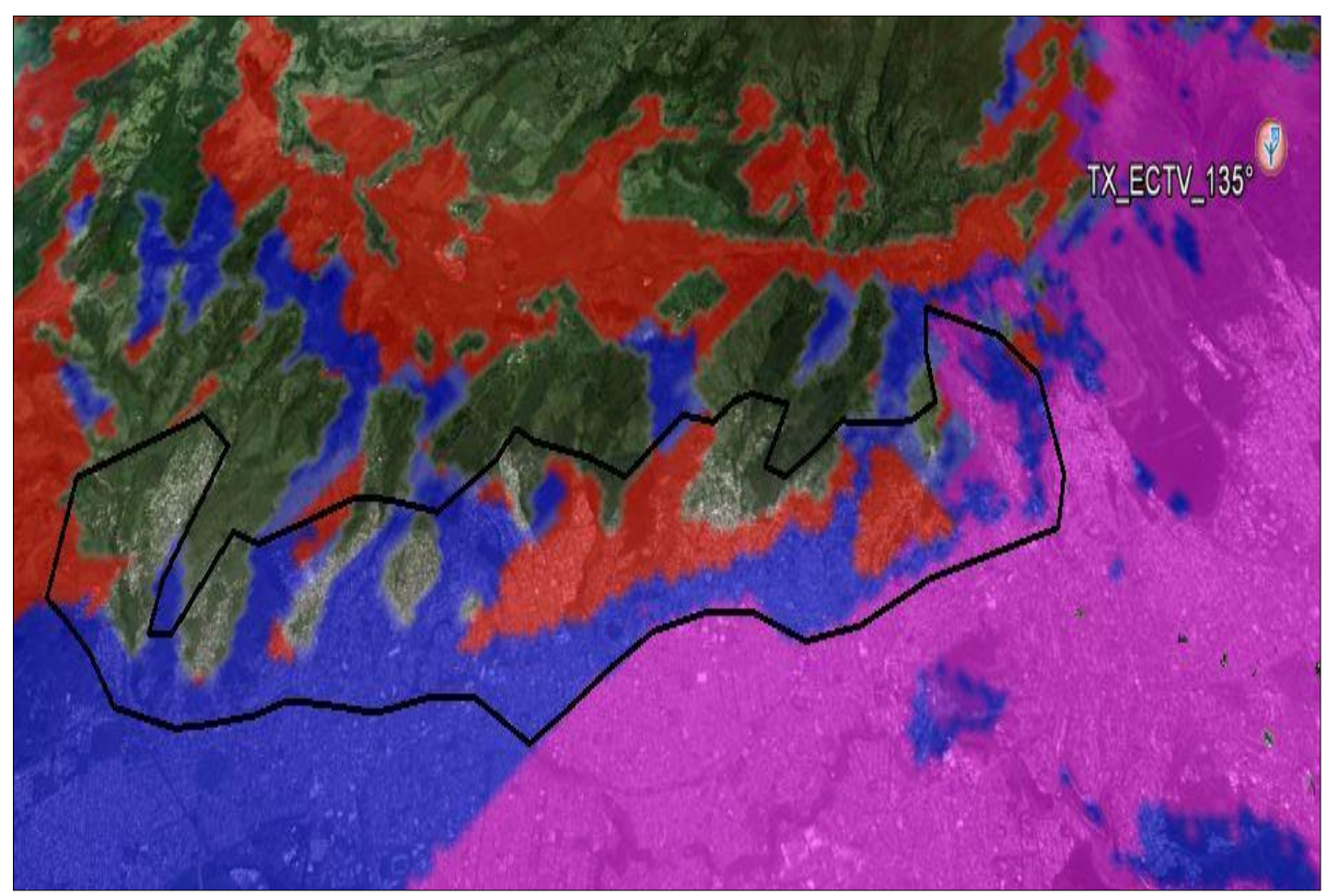

Figura 3.22: Zona de Sombra, Sur de Quito.

Se identifica la zona de sombra dentro del polígono de color negro, en el cual se desea mejorar los niveles de señal. 
Simulación de cobertura del GAPFILLER - Loma de Puengasí, con azimut de $300^{\circ}$.

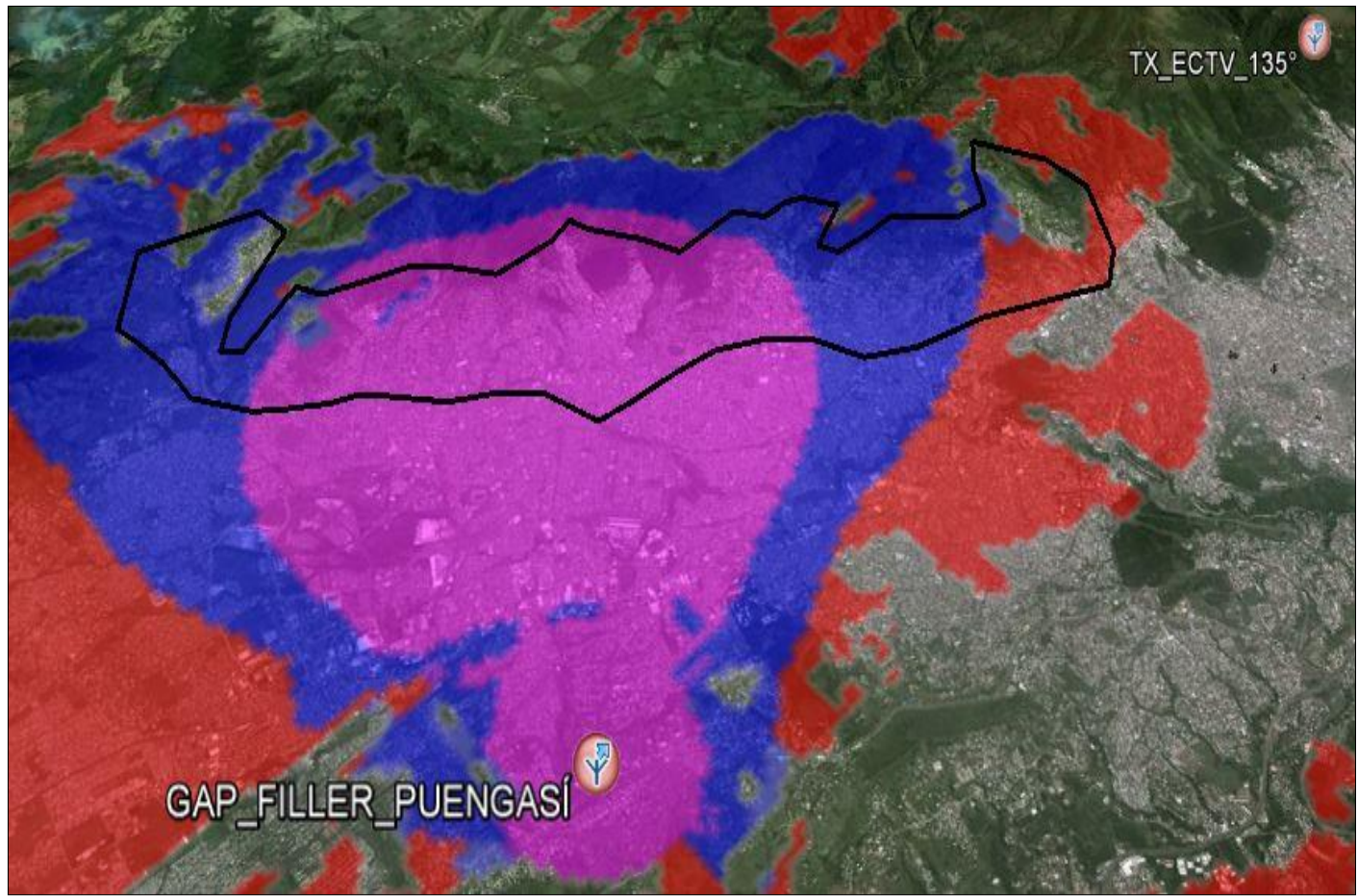

Figura 3.23: Cobertura de GAPFILLER - Loma de Puengasi.

Con la ubicación del GAPFILLER, se observa que los niveles de señal mejoran notablemente, convirtiéndose en una solución altamente viable para este sector de la ciudad.

La figura 3.24, ilustra el radio de cobertura en kilómetros del GAPFILLER Loma de Puengasí, con relación al sur de la ciudad representado por el polígono en color azul. 


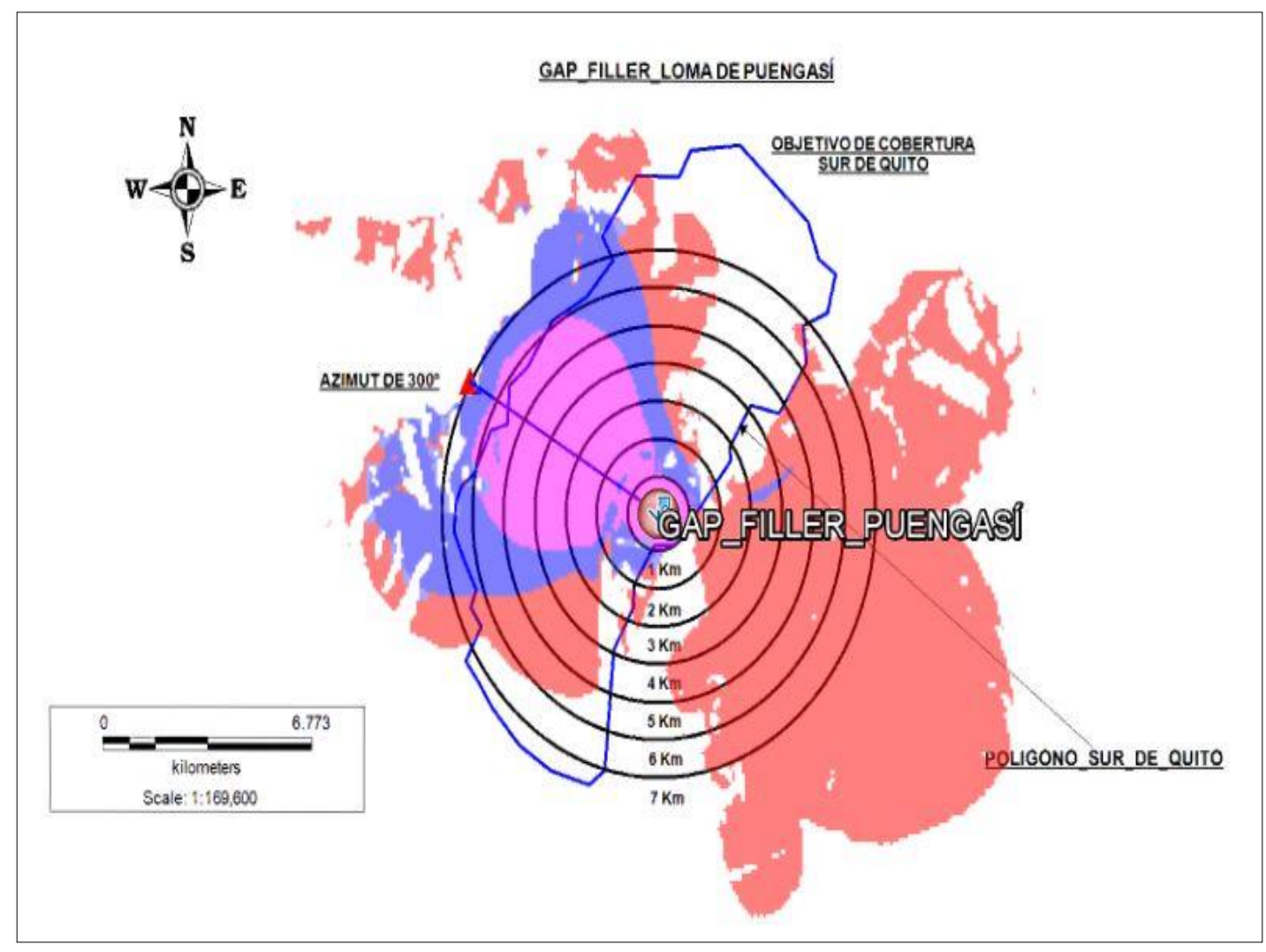

Figura 3.24: Cobertura de GAPFILLER - Loma de Puengasí, con relación a la zona Sur de Quito.

- $\quad$ Segundo candidato: La Ferroviaria.

Tabla 3.6:

Coordenadas del GAPFILLER - La Ferroviaria.

\begin{tabular}{cccc}
\hline Nombre & Longitud & Latitud & Altura [m] \\
\hline Ferroviaria & $78^{\circ} 30^{\prime} 25,00^{\prime \prime} \mathrm{O}$ & $0^{\circ} 15^{\prime} 48,00^{\prime \prime} \mathrm{S}$ & 3149 \\
\hline
\end{tabular}


Este punto de la ciudad, brinda todas las condiciones necesarias para la implementación del GAPFILLER, ya que en la zona existen instalaciones semejantes que cuentan con vías de acceso pavimentada, línea eléctrica y toda la obra civil necesaria.

Simulación de cobertura del GAPFILLER - La Ferroviaria, con azimut de $300^{\circ}$.

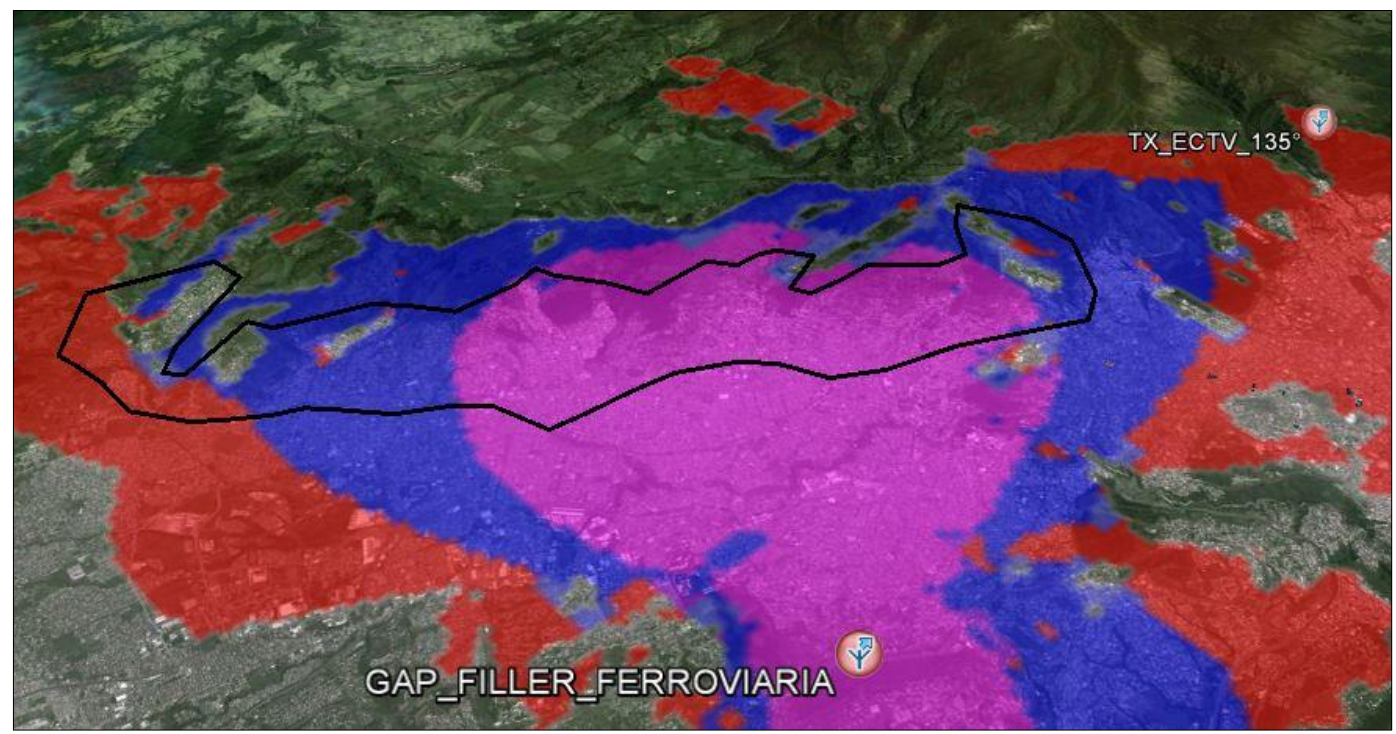

Figura 3.25: Cobertura de GAPFILLER (Ferroviaria).

De igual manera se observa como mejora el nivel de señal en la zona de sombra identificada. 


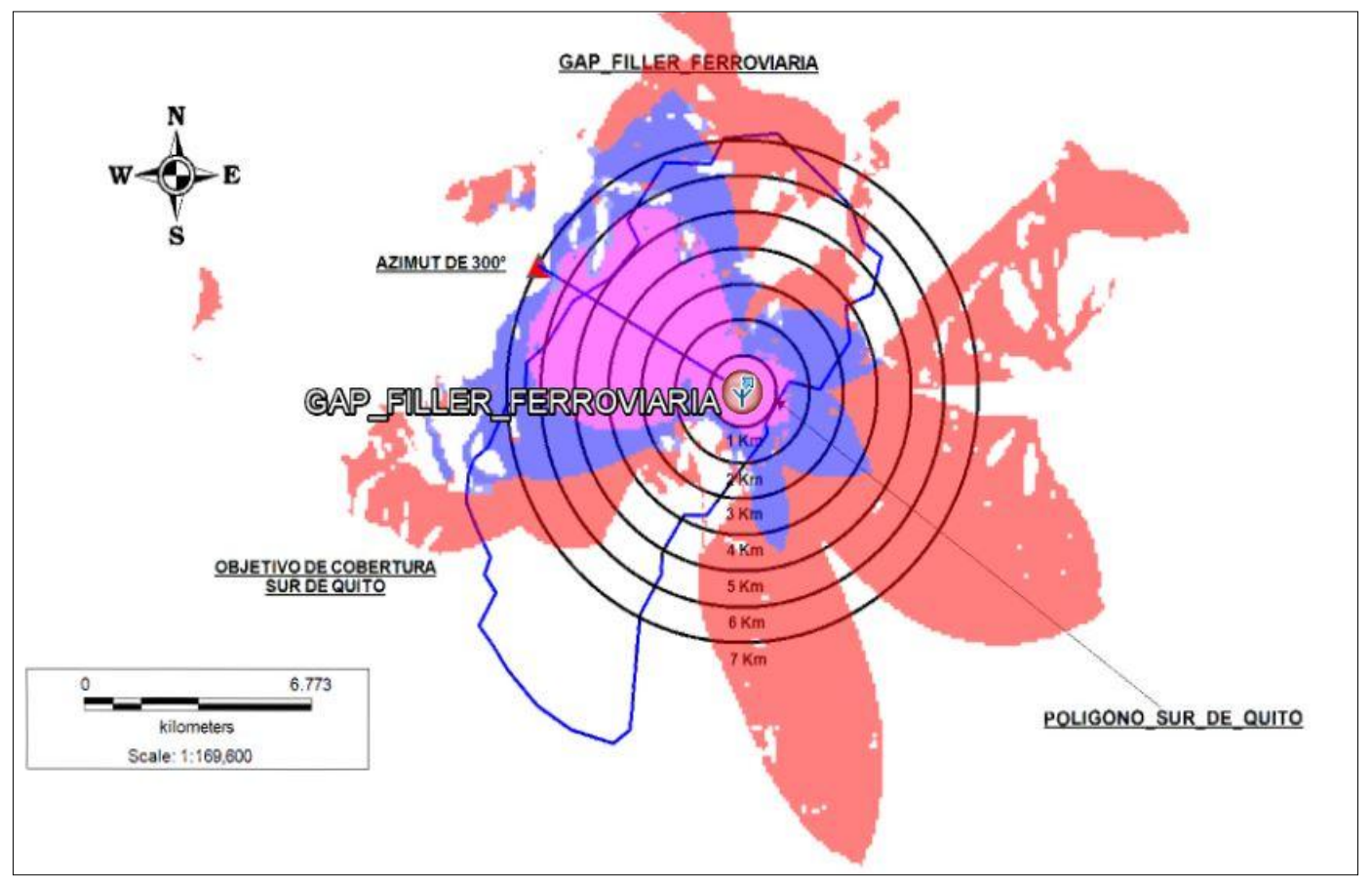

Figura 3.26: Cobertura de GAPFILLER - Ferroviaria, con relación a la zona Sur de Quito.

La figura 3.26, ilustra el radio de cobertura en kilómetros del GAPFILLER Ferroviaria, con relación al sur de la ciudad representado por el polígono en color azul.

\subsubsection{Estación reforzadora Mitad del Mundo}

Se recomienda la ubicación de una estación reforzadora de señal en las siguientes coordenadas: 
Tabla 3.7:

Coordenadas del GAPFILLER - Mitad del Mundo.

\begin{tabular}{llll}
\hline Nombre & Longitud & Latitud & Altura [m] \\
\hline Mitad del Mundo & $78^{\circ} 25^{\prime} 57,53^{\prime \prime} \mathrm{O}$ & $0^{\circ} 2^{\prime} 39,13^{\prime \prime S}$ & 3142 \\
\hline
\end{tabular}

EL sector de la Mitad del Mundo, es también un sector en el cual no se observan niveles de bajos (ICE), que impiden la óptima recepción de (TDT).

Simulación de cobertura del transmisor de ECTV, con azimut de $45^{\circ}$.

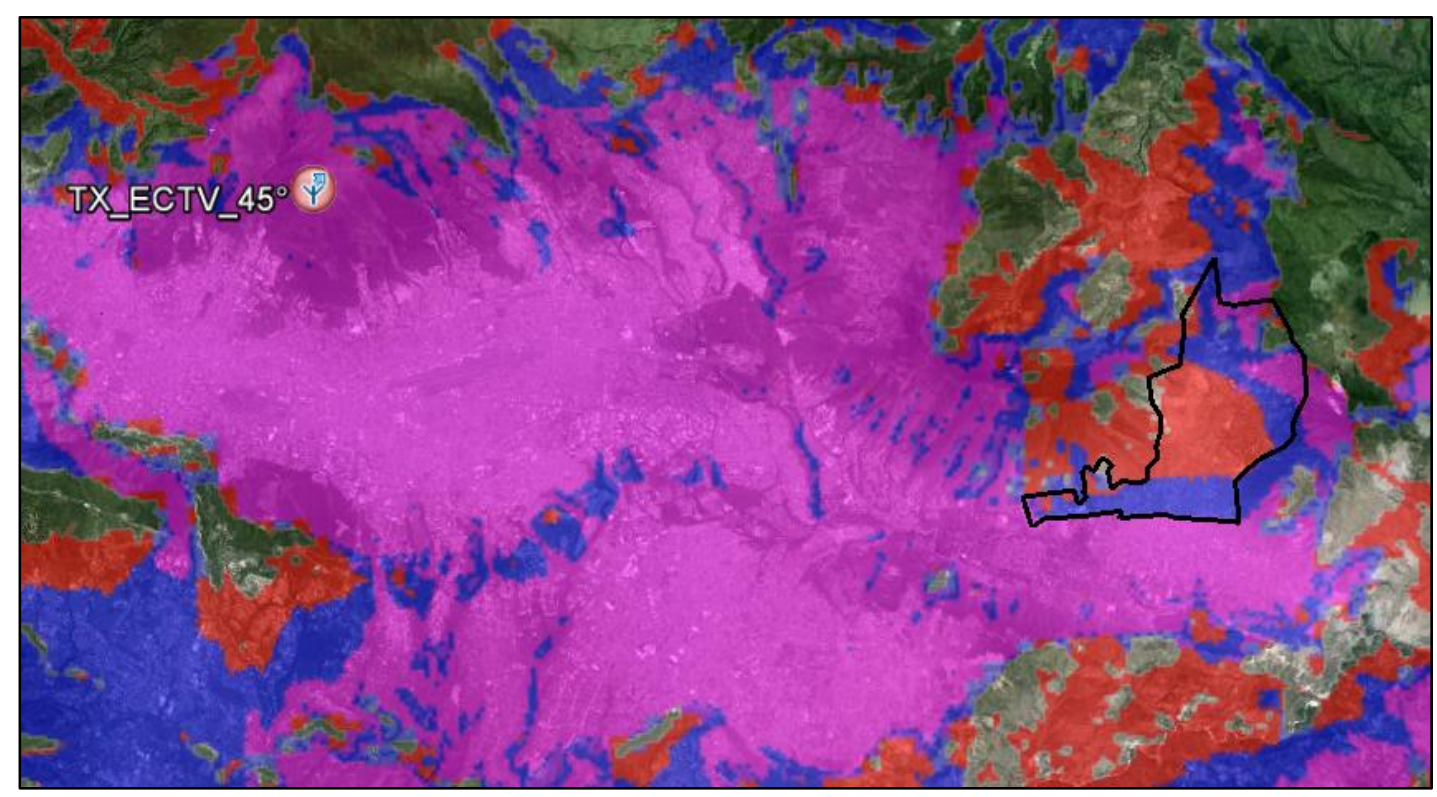

Figura 3.27: Zona de Sombra Mitad del Mundo.

Se identifica la zona de sombra dentro del polígono de color negro, en el cual se desea mejorar los niveles de señal. 
Simulación de cobertura del GAPFILLER - Mitad del Mundo, con un azimut de $330^{\circ}$.

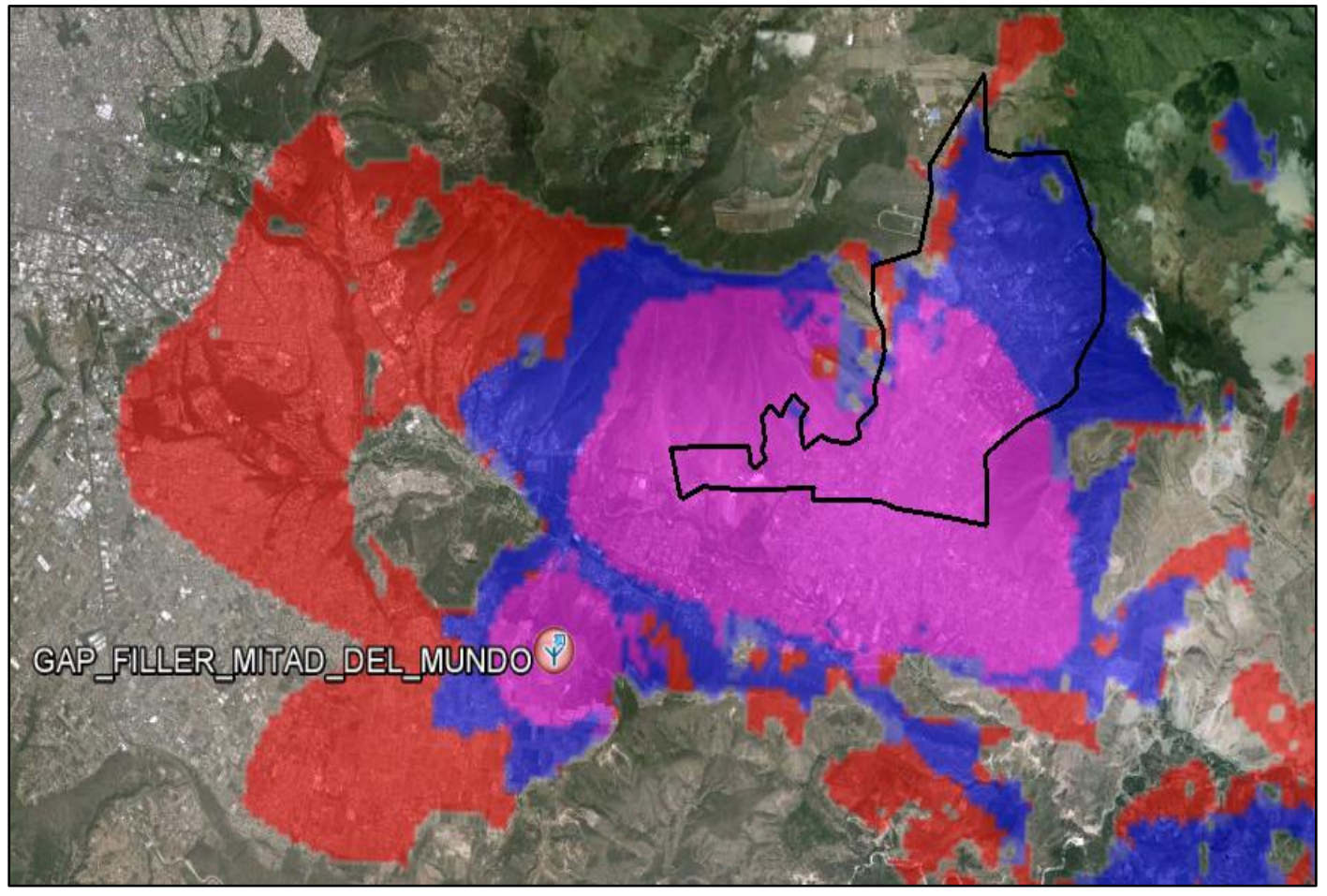

Figura 3.28: Cobertura de GAPFILLER (Mitad del Mundo).

Con la ubicación del GAPFILLER - Mitad del Mundo, se observa que la cobertura mejora, así como el nivel de la señal; lo que garantiza una buena recepción del servicio en este sector de la ciudad. 


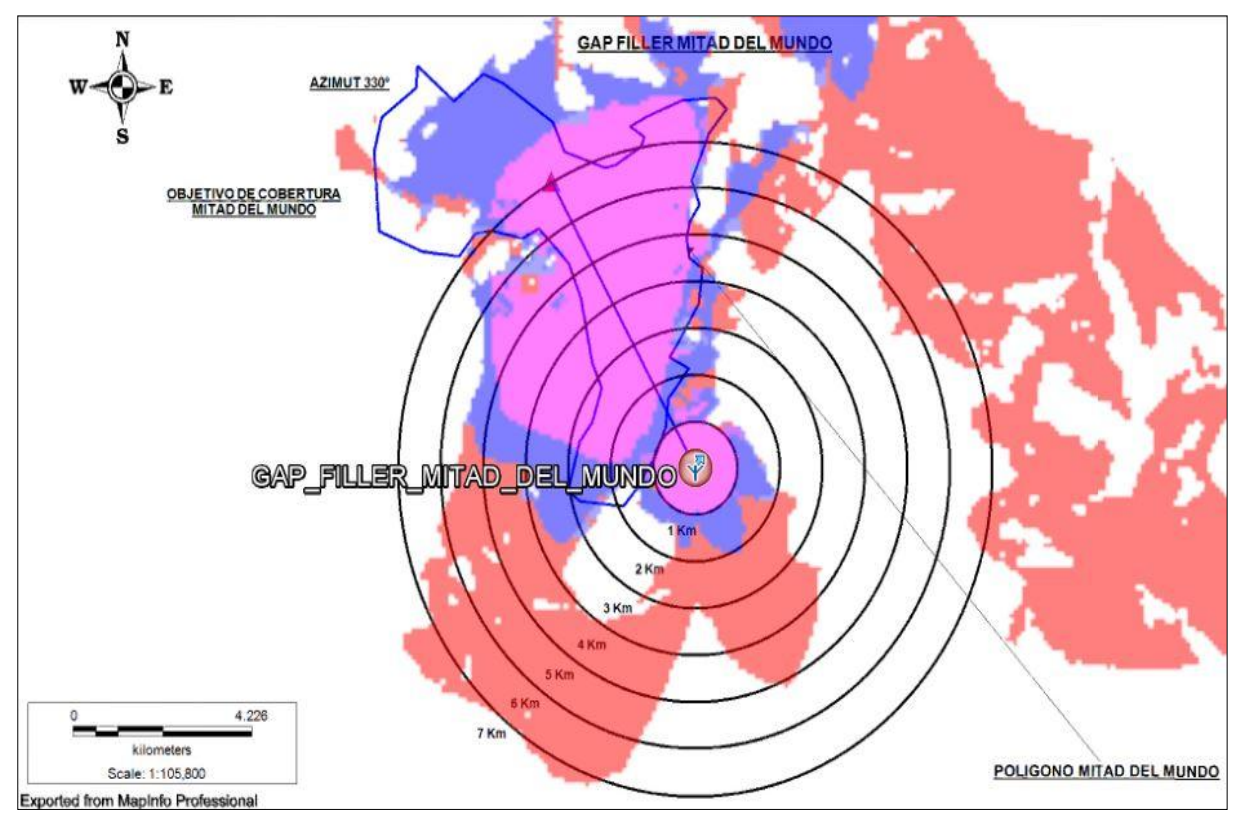

Figura 3.29: Cobertura de GAPFILLER (Mitad del Mundo) con relación a la zona Mitad del Mundo.

La figura 3.29, ilustra el radio de cobertura en kilómetros del GAPFILLER Mitad del Mundo, con relación al sur de la ciudad representado por el polígono en color azul.

\subsubsection{Simulación de compatibilidad electromagnética de señales}

Dentro del estudio de la compatibilidad electromagnético, Sirenet nos permite la creación de algunos escenarios de estudio, como es el caso de la interferencia sobre receptor. 
Cuando un área determinada de servicio es radiada por múltiples fuentes, es muy posible que un receptor sufra interferencias.

Dado que el tema central de este proyecto, es el estudio de la compatibilidad electromagnético de señales analógicas y digitales de televisión, resulta importante simular el comportamiento de ambas señales, a fin de verificar si existen interferencias de canal Adyacente o Co-canal entre ellas.

\section{- Creación en SIRENET del estudio de interferencia sobre} receptor

Creamos un estudio de compatibilidad electromagnética, llamado interferencia sobre receptos.

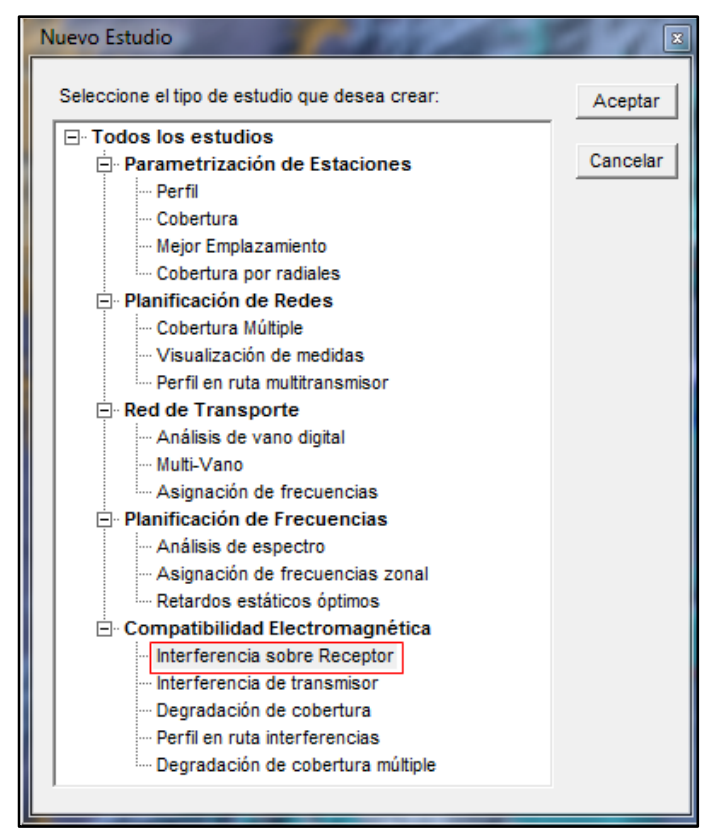

Figura 3.30: Selección de un nuevo estudio, Interferencia sobre Receptor. 


\section{- Configuración de equipos:}

Una vez que se ha seleccionado el tipo de estudio, debemos configurar los datos de los equipos presentes en el escenario de simulación, así tenemos:

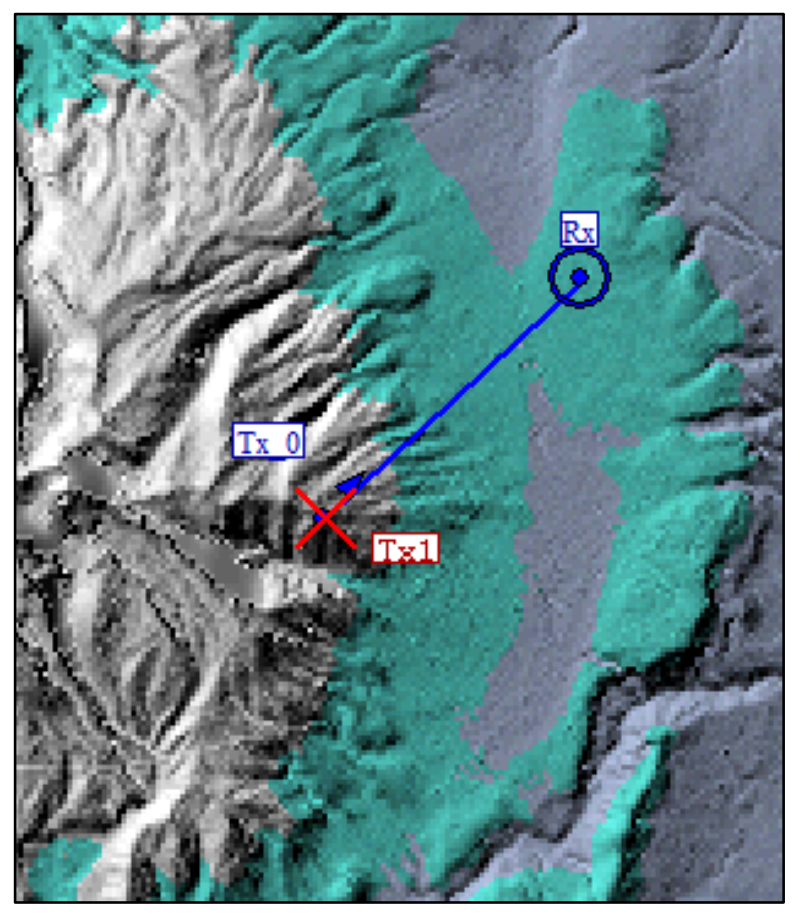

Figura 3.31: Escenario de simulación de la interferencia sobre receptor.

$\checkmark \quad$ Tx_0: Es el trasmisor que radiara la señal de interés.

$\checkmark \quad$ Tx_1: Es el transmisor que radiara la señal interferente.

$\checkmark \quad \mathbf{R x}$ : Es el equipo que recoge la señal deseada, y a través del cual se analiza la interferencia sobre receptor. 


\section{- Configuración del transmisor deseado}

Para configurar el transmisor se deben configurar cuatro ventanas, Identificación, Parámetros de Radio, Parámetros de Antena y Fuente.

$\checkmark \quad$ Identificación: Esta ventana de configuración nos permite ingresar los datos correspondientes al nombre del transmisor, sus coordenadas geográficas y la cota o altura donde se ubicara el sistema radiante.

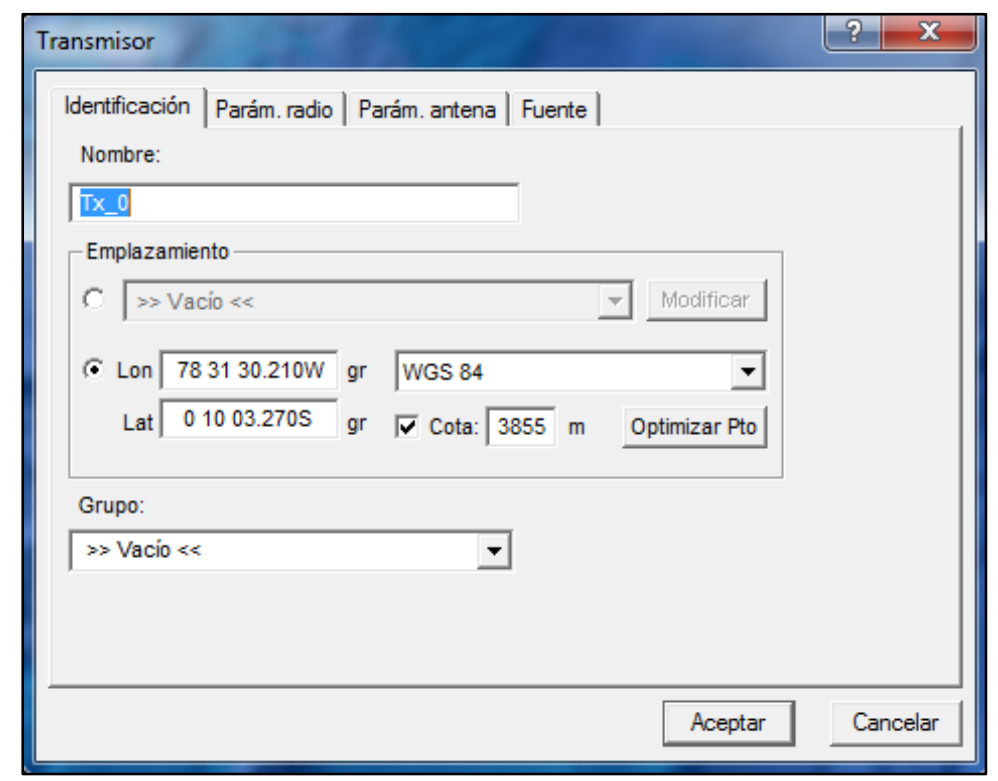

Figura 3.32: Ventana de identificación del transmisor.

$\checkmark \quad$ Parámetros de Radio: Esta venta nos permite definir los parámetros de radio necesarios para efectuar la simulación, tales como tipo de servicio, fase, red, banda y la frecuencia deseada de transmisión. 


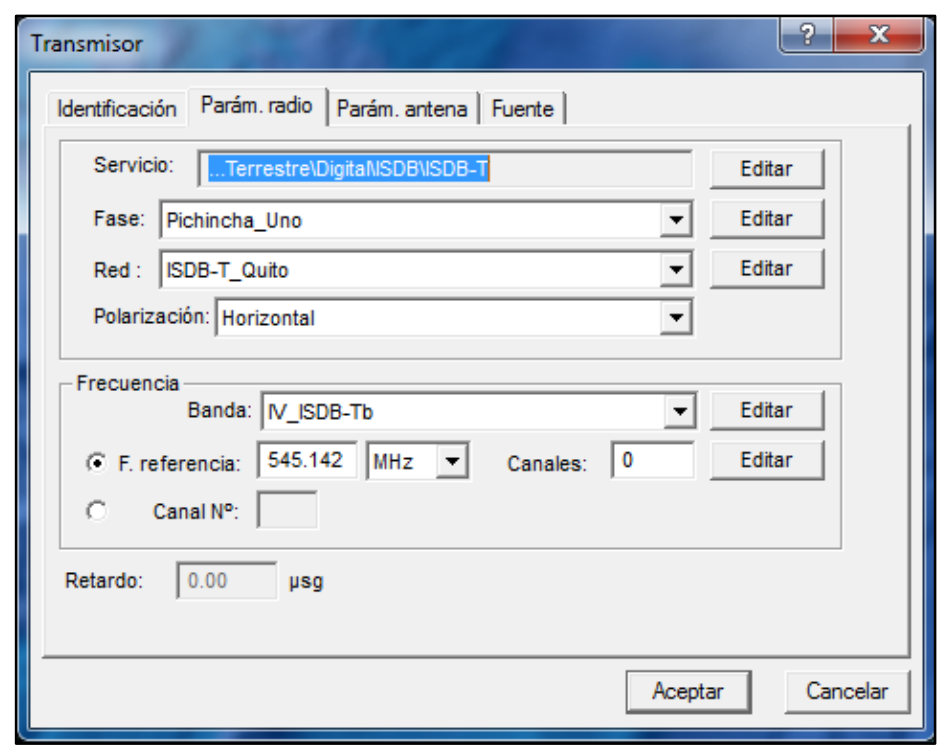

Figura 3.33: Ventana de identificación de los parámetros de radio.

$\checkmark \quad$ Parámetros de antena: Esta venta nos permite definir los parámetros de la antena, potencia de transmisión, tipo de antena, acimut e inclinación.

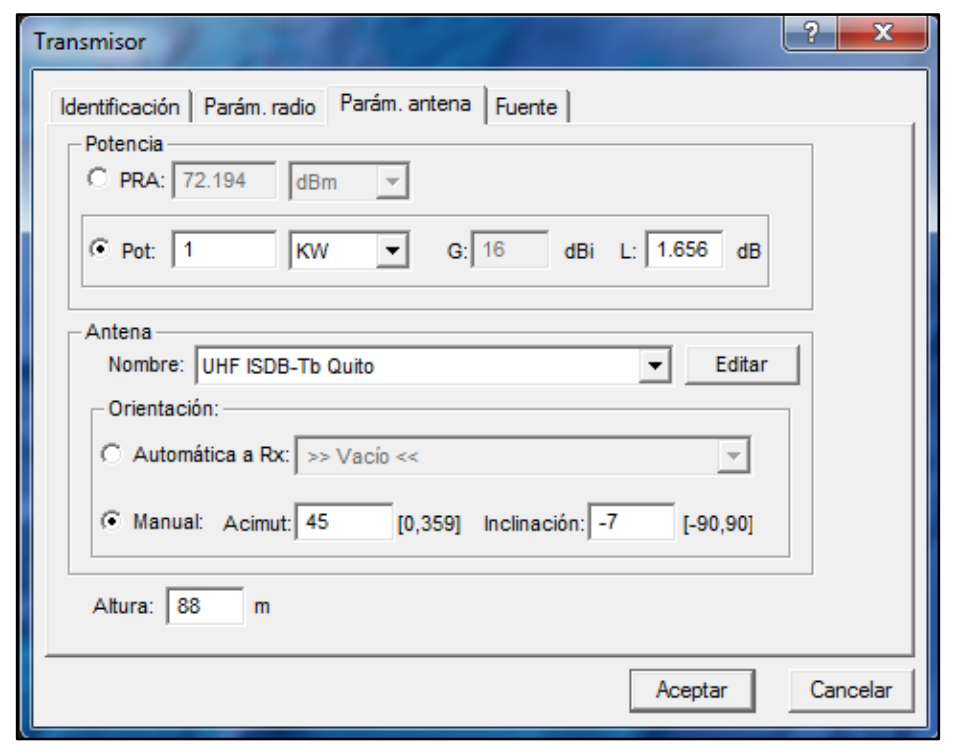

Figura 3.34: Ventana de identificación de los parámetros de la antena. 


\section{- Configuración del transmisor no deseado}

La configuración para el transmisor no deseado es la misa que para el caso anterior, difiriendo únicamente en los datos sobre el sistema radiante interferente.

Dependiendo del escenario que se dese evaluar los parámetros de radio y de antena cambiara, específicamente con relación al tipo de servicio, potencia de transmisión, frecuencia y tipo de antena.

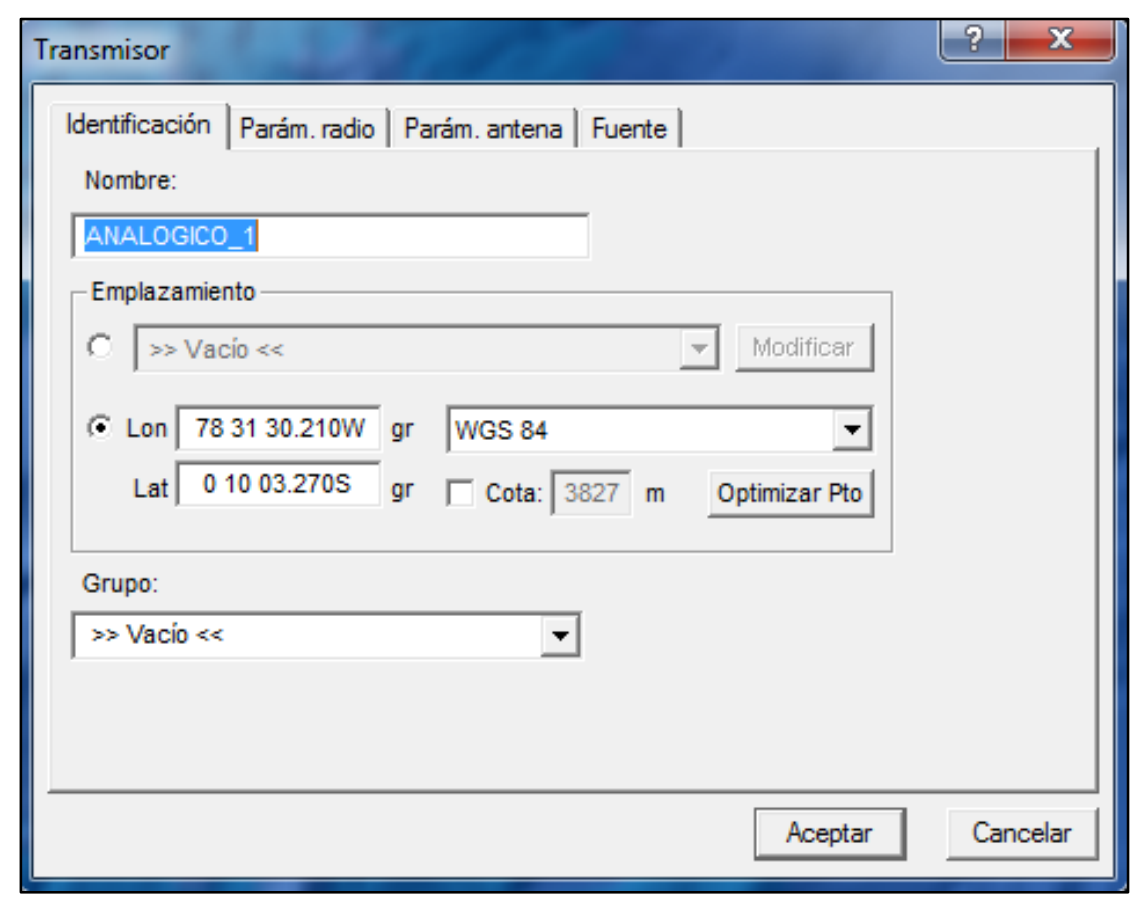

Figura 3.35: Ventana de identificación del transmisor. 


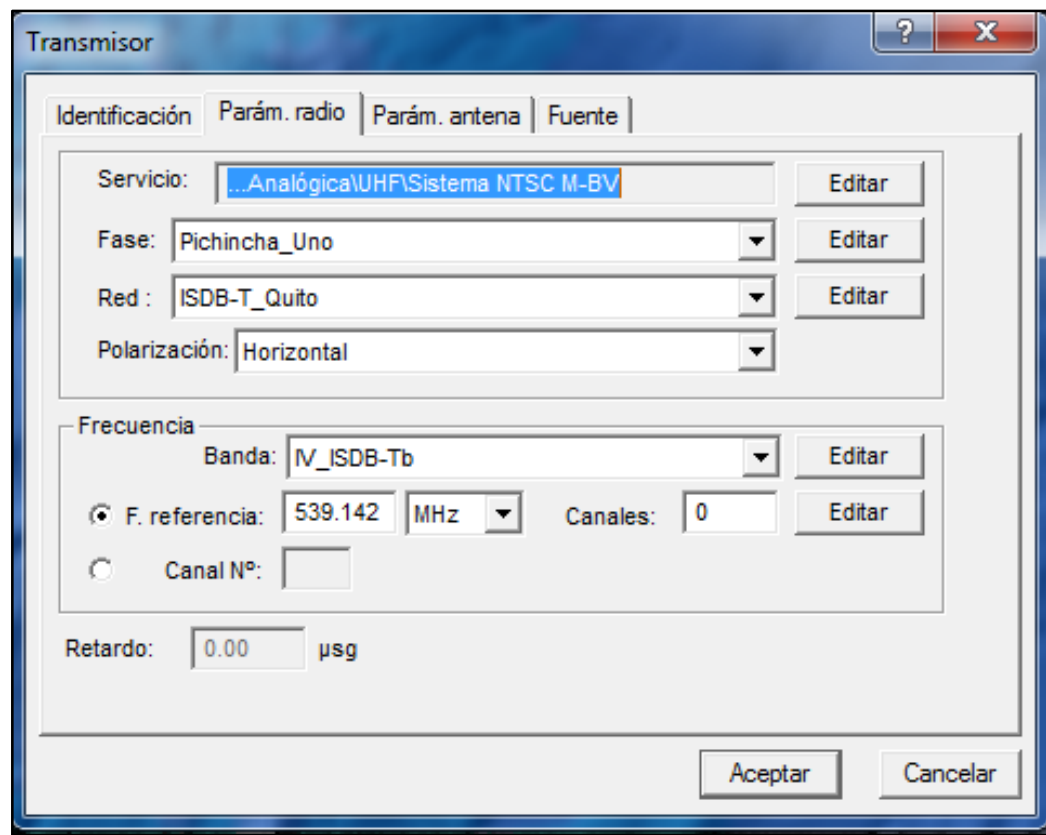

Figura 3.36: Ventana de identificación de los parámetros de radio.

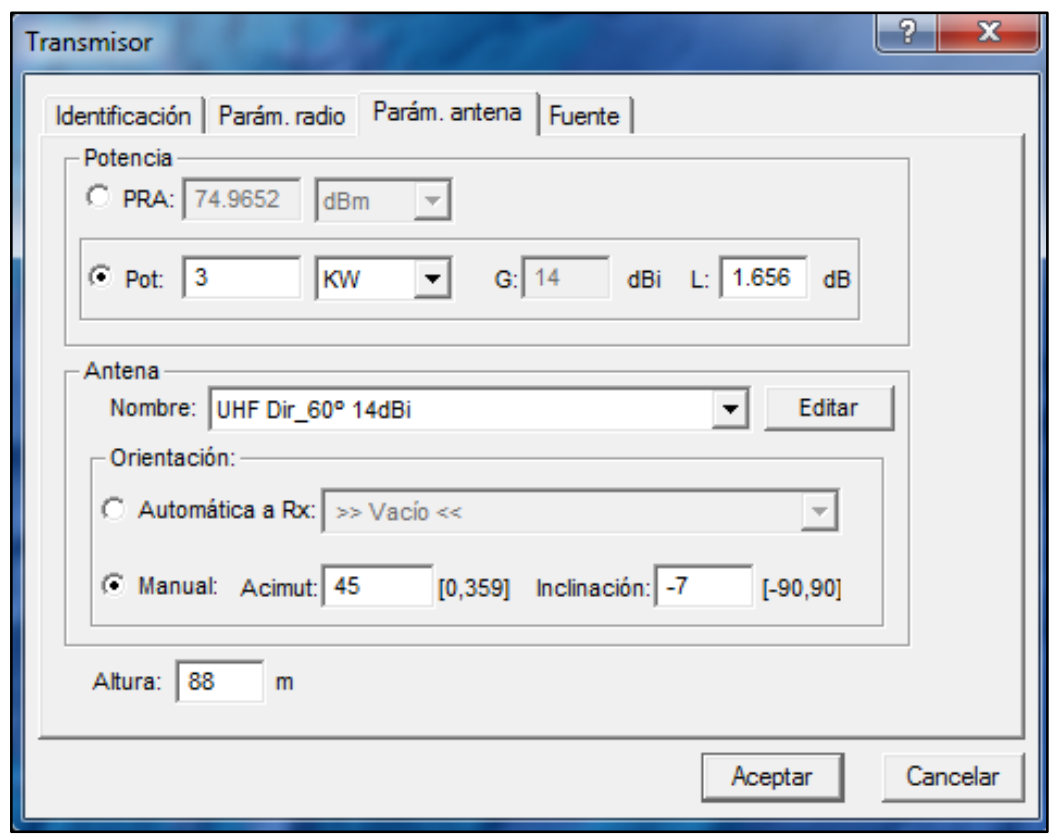

Figura 3.37: Ventana de identificación de los parámetros de la antena. 


\section{- $\quad$ Configuración del Rx}

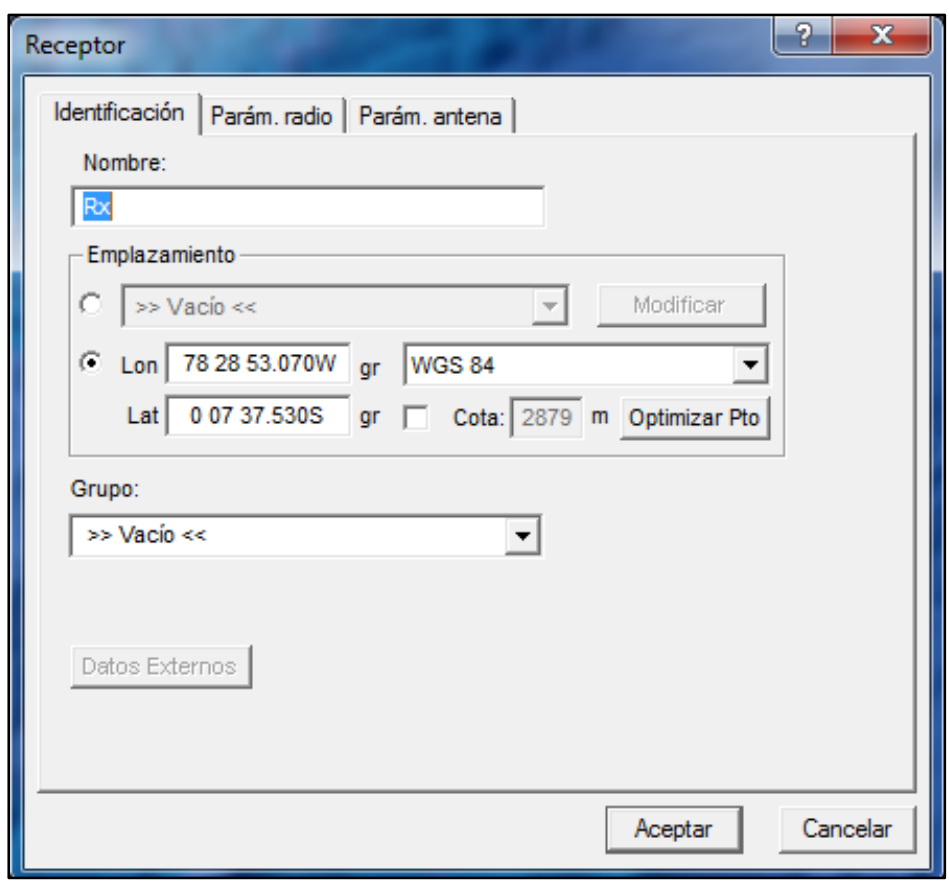

Figura 3.38: Ventana de identificación del receptor.

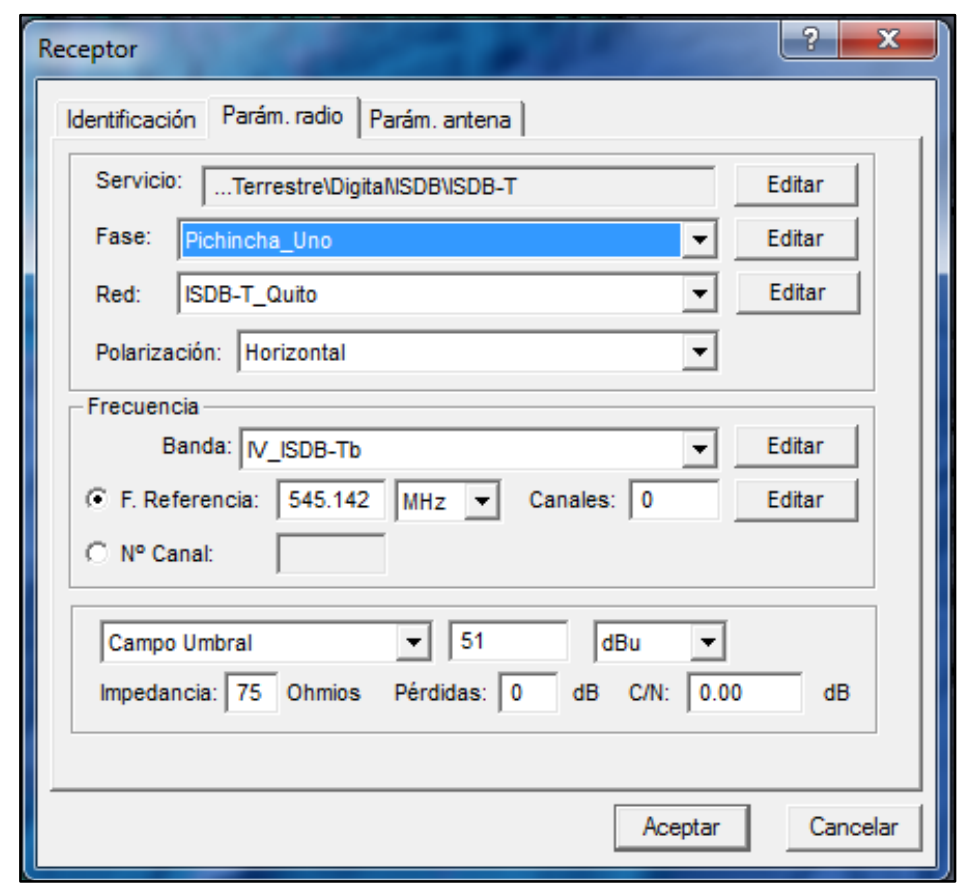

Figura 3.39: Ventana de identificación de los parámetros de radio. 


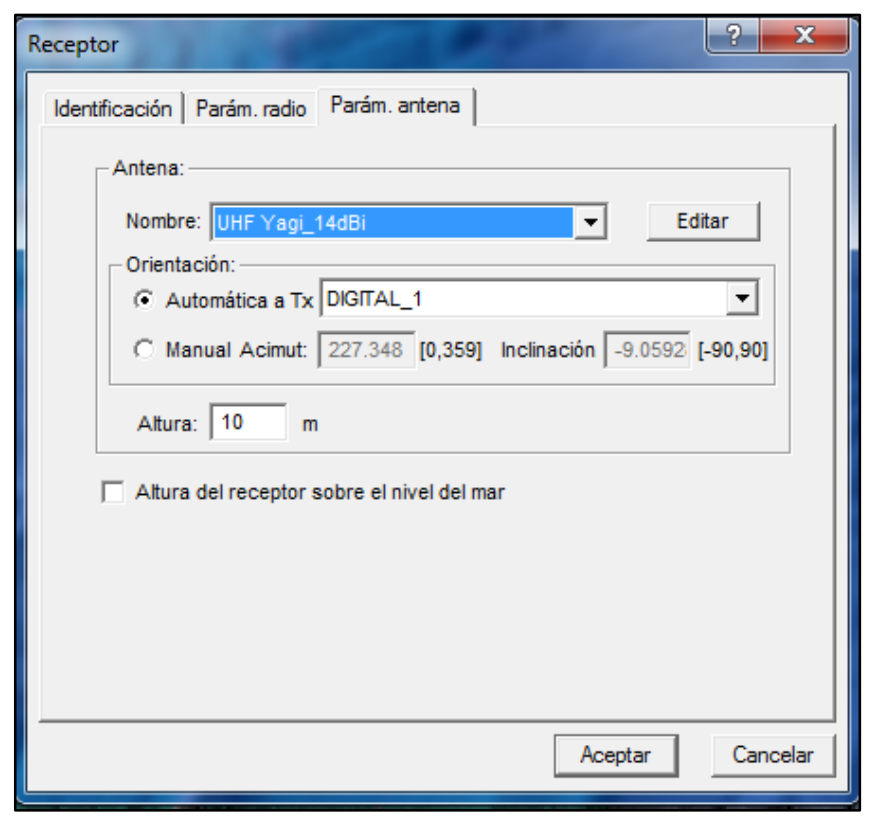

Figura 3.40: Ventana de identificación de los parámetros de la antena.

\section{Factor de rechazo}

El factor de rechazo es una herramienta que permite al receptor discriminar de entre todas las frecuencias que están siendo captadas por este, aquellas que no son de su interés, aceptando únicamente la que se encuentra dentro de sus umbrales de sensibilidad.

El modelo de gestión SIRENET cuenta con varios factores de rechazo, para cada uno diferentes servicios de radiodifusión existentes, siendo de interés para el presenté estudio el factor de rechazo UHF/VHF o de radiodifusión sonora. 
Sin embargo también nos brinda la posibilidad de crear nuestro propio factor de rechazo, en base a nuestros intereses.

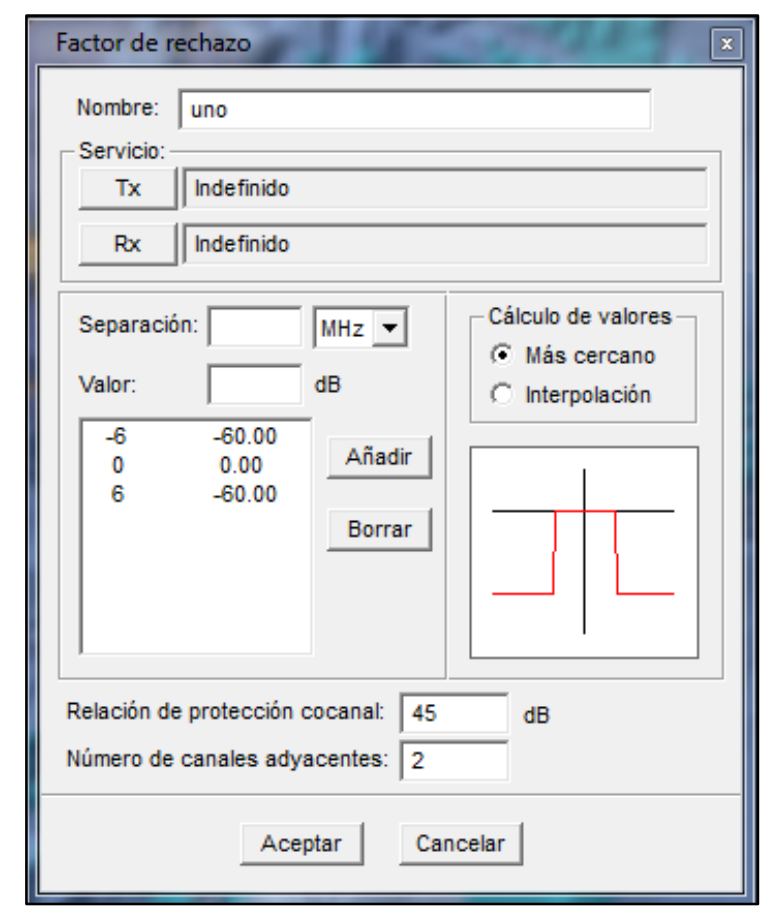

Figura 3.41: Ventana de identificación de los parámetros de la antena.

Al configurar el factor de rechazo debemos ingresar la separación en $(\mathrm{MHz})$ entre canales y la sensibilidad mínima en (dB), a la cual deseamos que nuestro receptor capte la señal de interés.

\section{Definición de los escenarios de simulación}

Una vez que se ha simulado la cobertura generada por el sistema radiante de ECTV y se han identificado las zonas de sombra mediante la simulación del 
perfil del terreno, nos resta por conocer la existencia o no de interferencia entre las señales de televisión analógica y digital radiadas en la ciudad de Quito.

Bajo esta premisa se han definido los siguientes escenarios posibles dentro de la transmisión simultánea de señales, con el fin de identificar cual de estos es más viable dentro del actual proceso de transición que esta viviendo la televisión previa al apagón analógico.

Simularemos dos casos en cada uno de los escenarios, transmisión analógica deseada y transmisión digital deseada.

En el rango de frecuencias definidas en la siguiente tabla.

\section{Tabla 3.8:}

Descripción técnica para los canales adyacentes.

\begin{tabular}{lll}
\hline Canal & Frecuencia (MHz) & Descripción del Canal \\
\hline $\mathbf{2 5}$ & 539,142857 & Analógico \\
$\mathbf{2 6}$ & 545,142857 & Digital \\
$\mathbf{2 7}$ & 551,142857 & Analógico \\
\hline
\end{tabular}




\section{Escenarios:}

- Una torre de transmisión con dos transmisores a diferentes alturas.

Se simulo la transmisión de señal (Análogo - Digital), ubicando los transmisores en una sola torre a alturas diferentes.

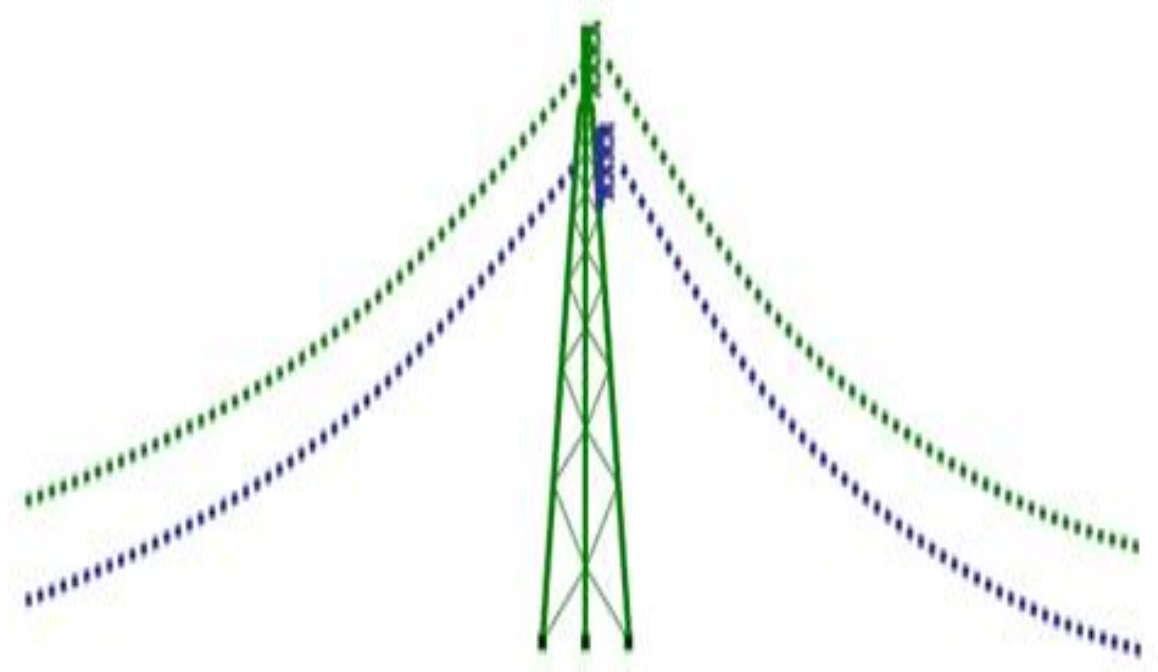

Figura 3.42: Transmisión a diferentes alturas. (ANATEL) 


\section{Tabla 3.9:}

Datos técnicos del transmisor.

\begin{tabular}{|c|c|c|c|c|c|c|}
\hline $\begin{array}{c}\text { Nombr } \\
\mathrm{e}\end{array}$ & Ubicación & $\begin{array}{c}\text { Coordenada } \\
\text { s }\end{array}$ & $\begin{array}{l}\text { Tipo se } \\
\text { Servicio }\end{array}$ & $\begin{array}{c}\text { Altura } \\
\text { [m] }\end{array}$ & $\begin{array}{c}\text { Potencia } \\
\text { [Kw] }\end{array}$ & Azimut \\
\hline \multirow[t]{2}{*}{ Tx1 } & Cerro & $0^{\circ} 2 ' 39,13 " \mathrm{~S}$ & \multirow[t]{2}{*}{ Digital } & \multirow[t]{2}{*}{88} & \multirow[t]{2}{*}{1} & \multirow[t]{2}{*}{$45^{\circ}$} \\
\hline & Pichincha & $\begin{array}{l}78^{\circ} 25^{\prime} 57,53^{\prime \prime} \\
\text { O }\end{array}$ & & & & \\
\hline \multirow[t]{2}{*}{ Tx0 } & Cerro & 0²'39,13"S & \multirow[t]{2}{*}{ Analógico } & \multirow[t]{2}{*}{78} & \multirow[t]{2}{*}{3} & \multirow[t]{2}{*}{$45^{\circ}$} \\
\hline & Pichincha & $\begin{array}{l}78^{\circ} 25^{\prime} 57,53^{\prime \prime} \\
\text { O }\end{array}$ & & & & \\
\hline \multirow[t]{2}{*}{$R x$} & Ciudad de & $0^{\circ} 7{ }^{\prime} 37.53 " S$ & \multirow[t]{2}{*}{ Digital } & \multirow[t]{2}{*}{10} & \multirow[t]{2}{*}{$\mathrm{N} / \mathrm{A}$} & Automáti \\
\hline & Quito & $\begin{array}{c}78^{\circ} 28^{\prime} 53.07 \\
\text { "O }\end{array}$ & & & & $\mathrm{co}$ \\
\hline
\end{tabular}

$\checkmark \quad$ Simulación

Caso 1: Transmisor deseado analógica.

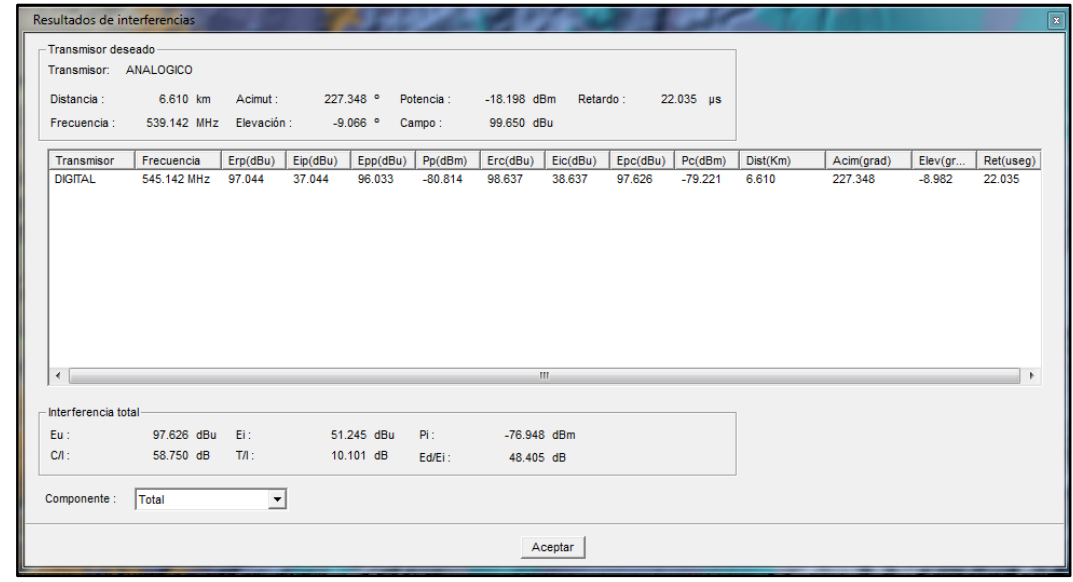


Figura 3.43: Resultados de la simulación de interferencia sobre receptor en Sirenet.

Caso 2: Transmisor deseado digital.

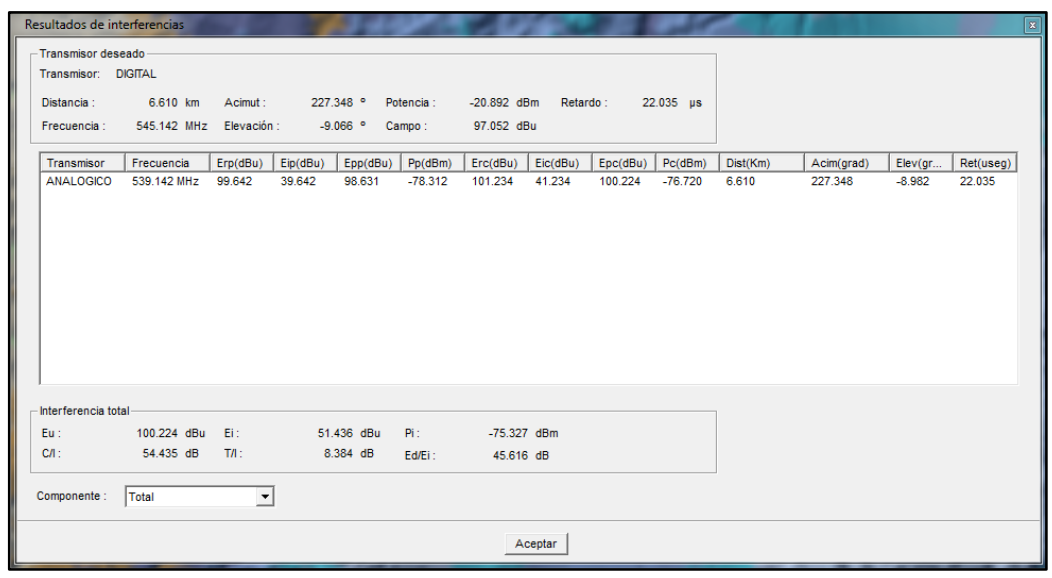

Figura 3.44: Resultados de la simulación de interferencia sobre receptor en Sirenet.

Tabla 3.10:

Potencia y campo eléctrico obtenidos de la transmisión en la misma torre pero a diferente altura.

\begin{tabular}{|c|c|c|c|c|}
\hline \multicolumn{5}{|c|}{ Caso 1: Transmisor deseado analógico } \\
\hline Mediciones & & Transmisión & & Interferencia \\
\hline Potencia & $P_{d}$ & $-18.198 \mathrm{dBm}$ & $\boldsymbol{P}_{\boldsymbol{i}}$ & $-76.948 \mathrm{dBm}$ \\
\hline Campo & $\boldsymbol{E}_{\boldsymbol{d}}$ & $99.650 \mathrm{dBu}$ & $\boldsymbol{E}_{\boldsymbol{i}}$ & $51.245 d B u$ \\
\hline Canal & 25 & $539.1428 \mathrm{Mhz}$ & 26 & $545.1428 M h z$ \\
\hline \multicolumn{5}{|c|}{ Caso 2: Transmisor deseado digital } \\
\hline Mediciones & & Transmisión & & Interferencia \\
\hline Potencia & $P_{d}$ & $-20.892 d B m$ & $\boldsymbol{P}_{\boldsymbol{i}}$ & $-75.327 \mathrm{dBm}$ \\
\hline Campo & $E_{d}$ & $97.052 d B u$ & $\boldsymbol{E}_{\boldsymbol{i}}$ & $51.436 \mathrm{dBu}$ \\
\hline Canal & 26 & $545.1428 \mathrm{Mhz}$ & 25 & 539.1428 Mhz \\
\hline
\end{tabular}




\section{- Una torre de transmisión con dos transmisores a la misma} altura.

Se simulo la transmisión de señal (Análogo - Digital), ubicando los transmisores en una sola torre a la misma altura.

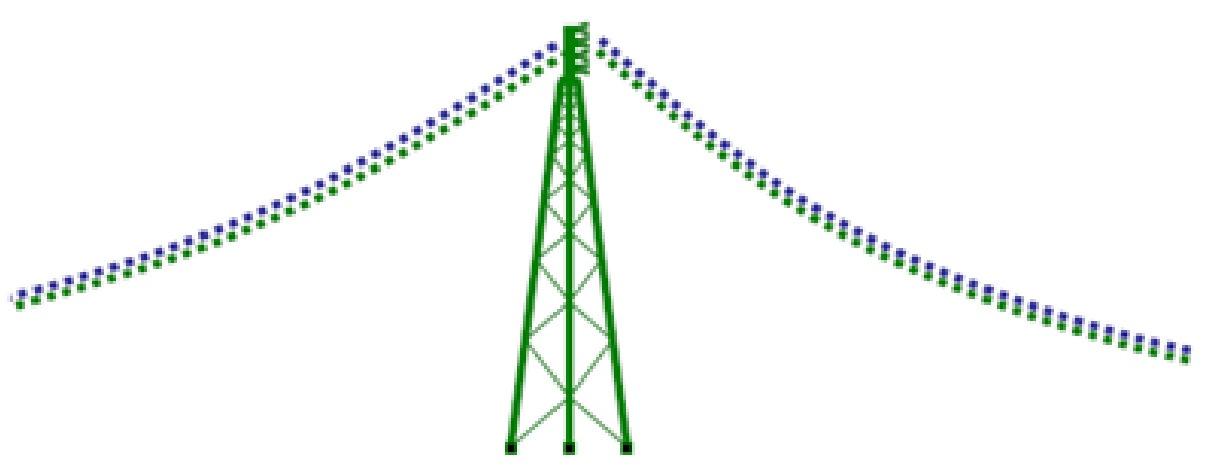

Figura 3.45: Transmisión en una misma torre. (ANATEL)

\section{Tabla 3.11:}

Datos técnicos del transmisor.

\begin{tabular}{|c|c|c|c|c|c|c|}
\hline Nombre & Ubicación & Coordenadas & Tipo se Servicio & Altura [m] & Potencia [Kw] & Azimut \\
\hline \multirow[t]{2}{*}{ Tx1 } & Cerro Pichincha & 0²'39,13"S & Digital & 88 & 1 & $45^{\circ}$ \\
\hline & & $78^{\circ} 25^{\prime} 57,53^{\prime \prime O}$ & & & & \\
\hline \multirow[t]{2}{*}{ TxO } & Cerro Pichincha & $0^{\circ} 2 ' 39,13 " \mathrm{~S}$ & Analógico & 88 & 3 & $45^{\circ}$ \\
\hline & & $78^{\circ} 25^{\prime} 57,53^{\prime \prime O}$ & & & & \\
\hline \multirow[t]{2}{*}{$R x$} & Ciudad de Quito & $0^{\circ} 7{ }^{\prime} 37.53 " S$ & Digital & 10 & $\mathrm{~N} / \mathrm{A}$ & Automático \\
\hline & & $78^{\circ} 28^{\prime} 53.07^{\prime \prime O}$ & & & & \\
\hline
\end{tabular}


Caso 1: Transmisor deseado analógica.

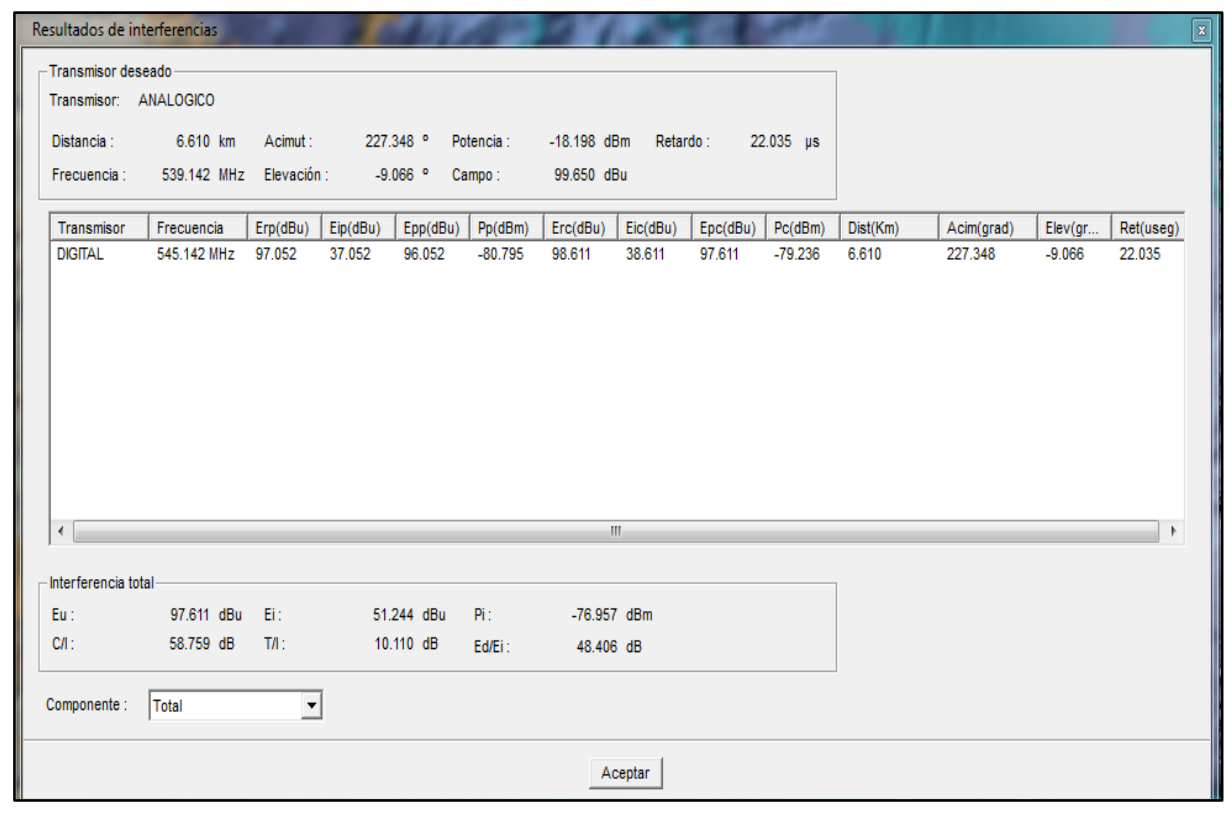

Figura 3.46: Resultados de la simulación de interferencia sobre receptor en

Sirenet.

Caso 2: Transmisor deseado digital.

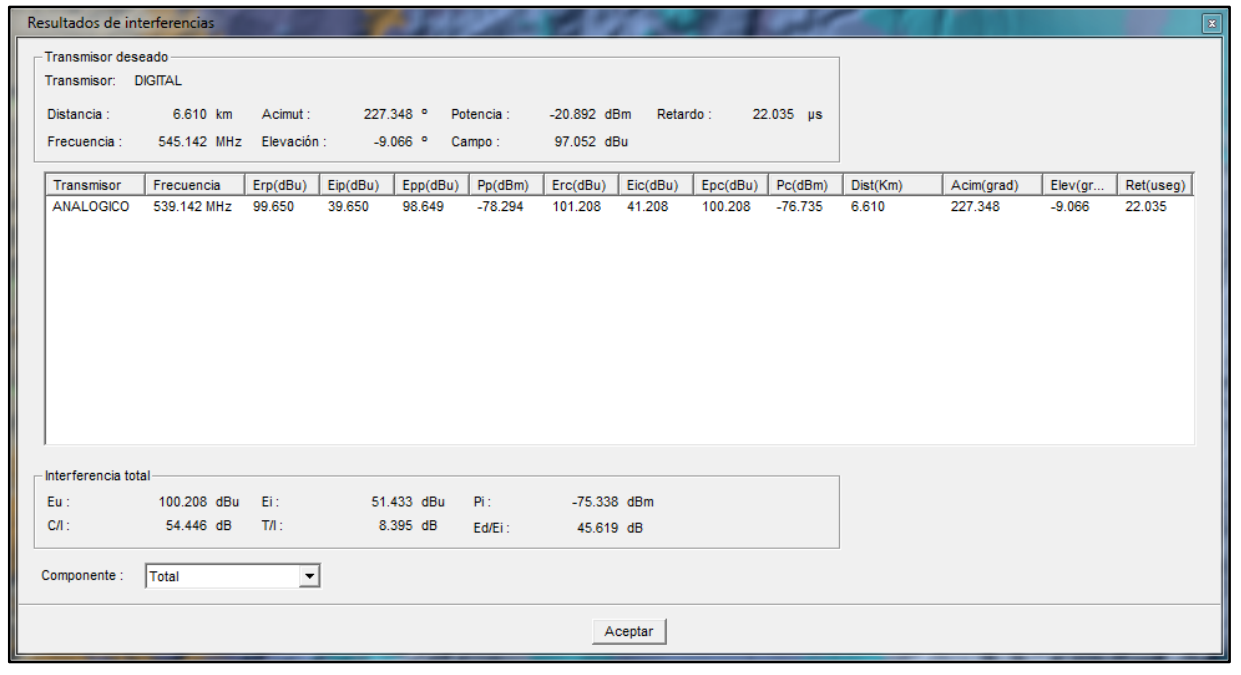


Figura 3.47: Resultados de la simulación de interferencia sobre receptor en Sirenet.

Tabla 3.12: Potencia y campo eléctrico obtenidos de la transmisión en una misma torre y a la misma altura.

\begin{tabular}{|c|c|c|c|c|}
\hline \multicolumn{5}{|c|}{ Caso 1: Transmisor deseado analógico } \\
\hline Mediciones & & Transmisión & & Interferencia \\
\hline Potencia & $P_{d}$ & $-18.198 \mathrm{dBm}$ & $\boldsymbol{P}_{\boldsymbol{i}}$ & $-76.957 \mathrm{dBm}$ \\
\hline Campo & $\boldsymbol{E}_{\boldsymbol{d}}$ & $99.650 \mathrm{dBu}$ & $E_{i}$ & $51.244 \mathrm{dBu}$ \\
\hline Canal & 26 & $545.1428 M h z$ & 25 & 539.1428 Mhz \\
\hline \multicolumn{5}{|c|}{ Caso 2: Transmisor deseado digital } \\
\hline Mediciones & & Transmisión & & Interferencia \\
\hline Potencia & $P_{d}$ & $-20.892 \mathrm{dBm}$ & $\boldsymbol{P}_{\boldsymbol{i}}$ & $-75.388 \mathrm{dBm}$ \\
\hline Campo & $E_{d}$ & $97.052 \mathrm{dBu}$ & $\boldsymbol{E}_{\boldsymbol{i}}$ & $51.433 d B u$ \\
\hline Canal & 26 & 545.1428 Mhz & 25 & 539.1428 Mhz \\
\hline
\end{tabular}

\section{- Dos torres de transmisión.}

Se simulo la transmisión de señal (Análogo - Digital), ubicando los transmisores en dos torres con la misma altura y a una separación máxima de 2 $\mathrm{Km}$.

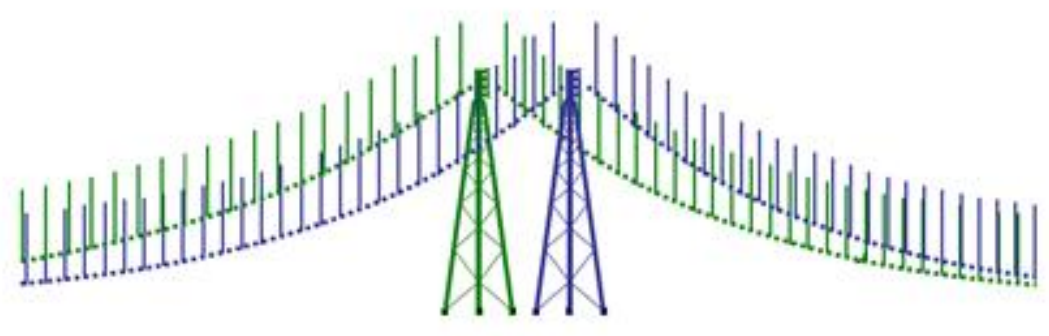

Figura 3.48: Transmisión en dos torres. (ANATEL) 
Tabla 3.13:

Datos técnicos del transmisor.

\begin{tabular}{|c|c|c|c|c|c|c|}
\hline Nombre & Ubicación & Coordenadas & $\begin{array}{l}\text { Tipo se } \\
\text { Servicio }\end{array}$ & $\begin{array}{l}\text { Altura } \\
{[\mathrm{m}]}\end{array}$ & $\begin{array}{l}\text { Potencia } \\
{[\mathrm{Kw}]}\end{array}$ & Azimut \\
\hline Tx1 & $\begin{array}{c}\text { Cerro } \\
\text { Pichincha }\end{array}$ & $\begin{array}{c}0^{\circ} 2 ' 39,13 " \mathrm{~S} \\
78^{\circ} 25^{\prime} 57,53^{\prime \prime O}\end{array}$ & Digital & 88 & 1 & $45^{\circ}$ \\
\hline Tx0 & $\begin{array}{c}\text { Cerro } \\
\text { Pichincha }\end{array}$ & $\begin{array}{c}0^{\circ} 10^{\prime} 59.11^{\prime \prime} \\
78^{\circ} 32^{\prime} 3.50^{\prime \prime O}\end{array}$ & Analógico & 88 & 3 & $45^{\circ}$ \\
\hline $\mathrm{Rx}$ & $\begin{array}{l}\text { Ciudad de } \\
\text { Quito }\end{array}$ & $\begin{array}{l}0^{\circ} 7^{\prime} 37.53^{\prime \prime S} \\
78^{\circ} 28^{\prime} 53 . \\
07 " \mathrm{O}\end{array}$ & Digital & 10 & $\mathrm{~N} / \mathrm{A}$ & Automático \\
\hline
\end{tabular}

Caso 1: Transmisor deseado analógica.

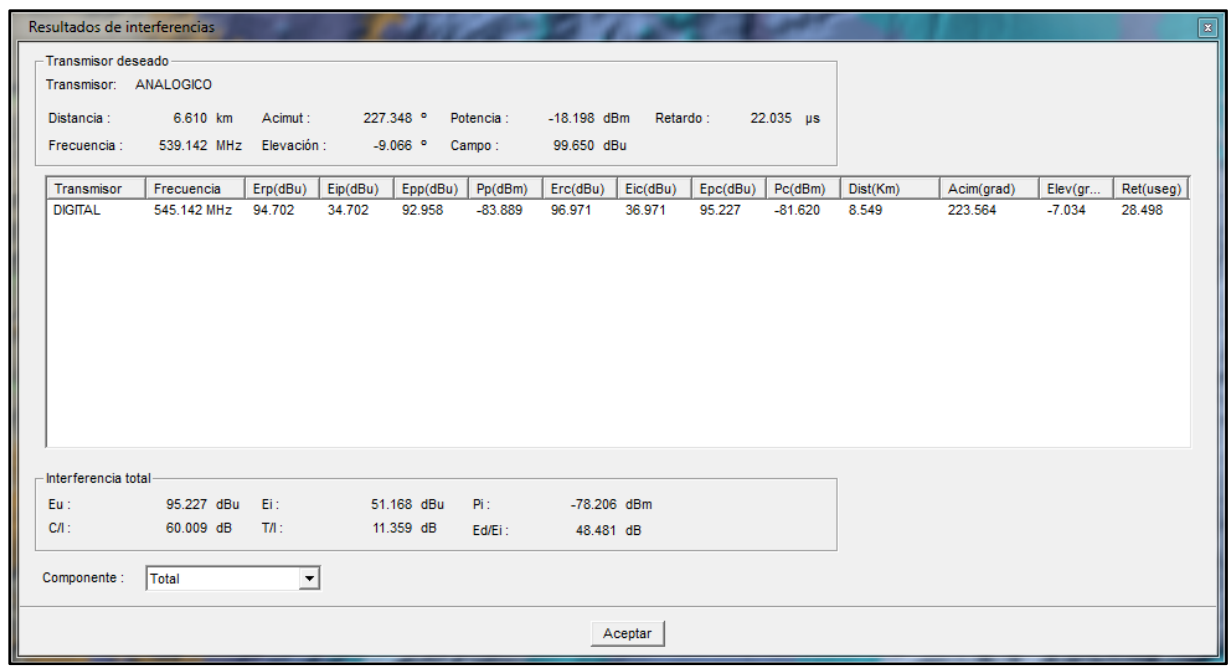

Figura 3.49: Resultados de la simulación de interferencia sobre receptor en Sirenet. 
Caso 2: Transmisor deseado digital.

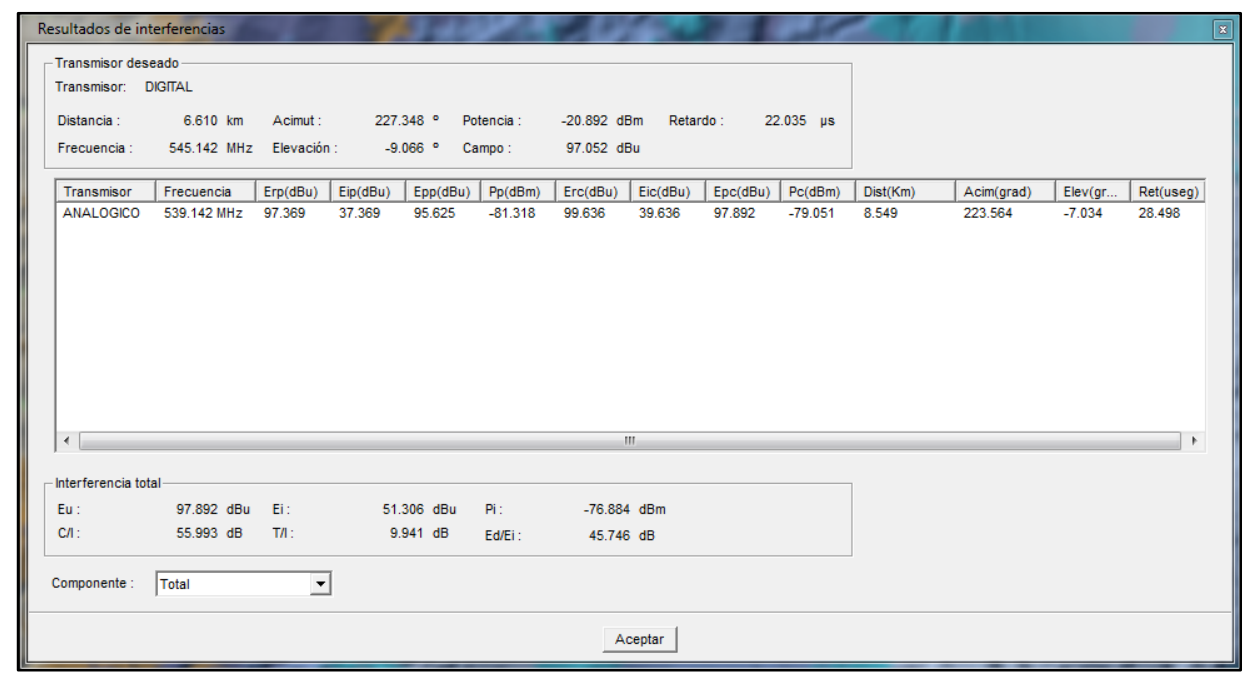

Figura 3.50: Resultados de la simulación de interferencia sobre receptor en Sirenet.

Tabla 3.14:

Potencia y campo eléctrico obtenidos de la transmisión en dos torres a la misma altura.

\begin{tabular}{ccccc}
\hline & \multicolumn{3}{c}{ Caso 1: Transmisor deseado analógico } \\
\hline Mediciones & \multicolumn{3}{c}{ Transmisión } & \multicolumn{2}{c}{ Interferencia } \\
Potencia & $\boldsymbol{P}_{\boldsymbol{d}}$ & $-18.198 \mathrm{dBm}$ & $\boldsymbol{P}_{\boldsymbol{i}}$ & $-78.206 \mathrm{dBm}$ \\
Campo & $\boldsymbol{E}_{\boldsymbol{d}}$ & $99.650 \mathrm{dBu}$ & $\boldsymbol{E}_{\boldsymbol{i}}$ & $51.168 \mathrm{dBu}$ \\
Canal & $\mathbf{2 6}$ & $545.1428 \mathrm{Mhz}$ & $\mathbf{2 5}$ & $539.1428 \mathrm{Mhz}$ \\
\multicolumn{5}{c}{ Caso 2: Transmisor deseado digital } \\
Mediciones & \multicolumn{3}{c}{ Transmisión } & Interferencia \\
Potencia & $\boldsymbol{P}_{\boldsymbol{d}}$ & $-20.892 \mathrm{dBm}$ & $\boldsymbol{P}_{\boldsymbol{i}}$ & $-75.884 \mathrm{dBm}$ \\
Campo & $\boldsymbol{E}_{\boldsymbol{d}}$ & $97.052 \mathrm{dBu}$ & $\boldsymbol{E}_{\boldsymbol{i}}$ & $51.306 \mathrm{dBu}$ \\
Canal & $\mathbf{2 6}$ & $545.1428 \mathrm{Mhz}$ & $\mathbf{2 5}$ & $539.1428 \mathrm{Mhz}$ \\
\hline
\end{tabular}


Las tablas $3.10,12$ y 14 resumen los efectos de la transmisión de canales adyacentes en las cuales se observar que la potencia interferente es mínima por lo cual podemos decir que los canales que se tienen al aire no interfieren con sus adyacentes.

\subsection{Ubicación de antenas}

Ubicar correctamente los emplazamientos de los diferentes sistemas radiantes presentes dentro una misma área de servicio, influye directamente en el comportamiento electromagnético de señales (ausencia o presencia de interferencia) y en el correcto despliegue de una red de radiodifusión terrestre.

Para ello el presente proyecto de investigación se basa en las experiencias brasileras (estudio similar llevado a cabo por ANATEL), en cuyo trabajo se definen ciertas consideraciones con relación a la distancia que debe existir entre sistemas radiantes.

Recomendando una distancia máxima de $2 \mathrm{Km}$ de separación entre las torres de transmisión de señal (Análogo - Digital), destinadas a cubrir un mismo entorno (ciudad de Quito). 
Definiéndose los siguientes escenarios:

- $\quad$ Poca posibilidad de interferencia.

La posibilidad de interferencia se reducirá para una distancia menor a $2 \mathrm{Km}$.

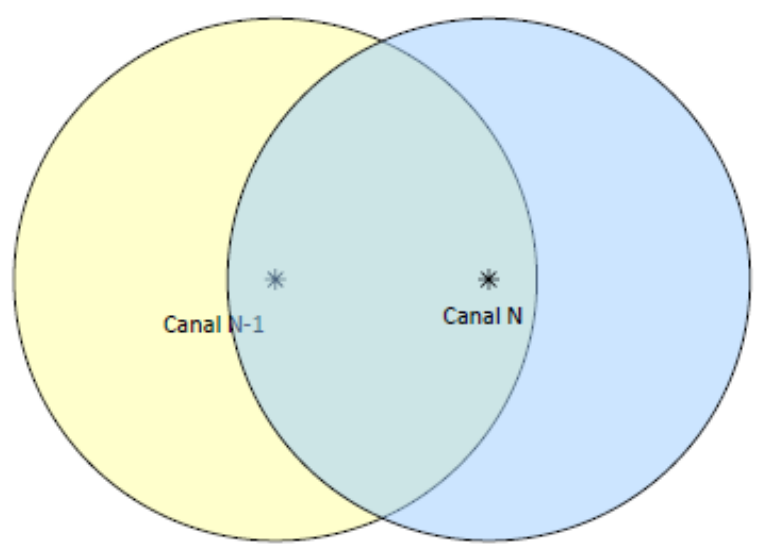

Figura 3.51: Poca posibilidad de interferencia. (ANATEL)

- $\quad$ Gran posibilidad de interferencia.

La posibilidad de interferencia aumentara para distancias mayores a $2 \mathrm{Km}$.

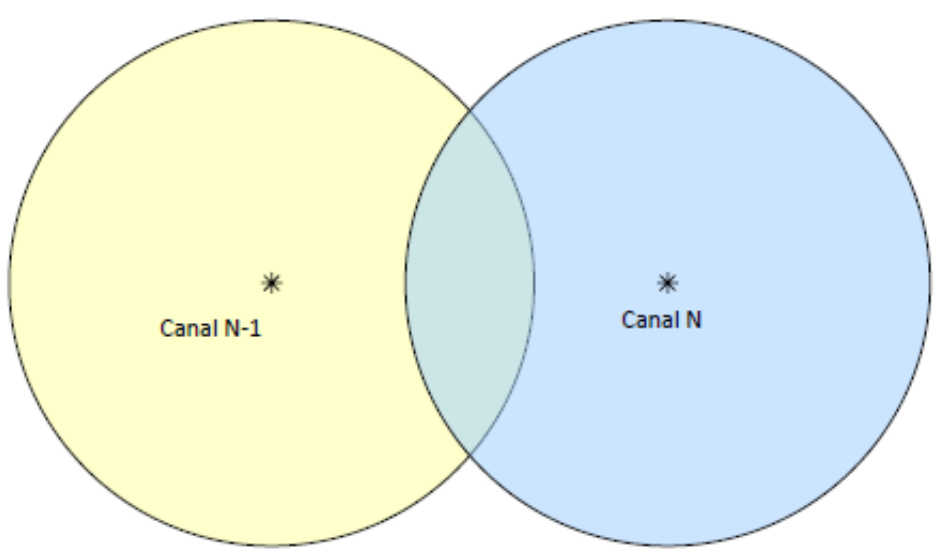

Figura 3.52: Gran posibilidad de interferencia. (ANATEL) 
Dado que el estudio que hemos venido efectuando se limita a la ciudad de Quito, en la cual todos los transmisores de radiodifusión sonora se encuentran ubicados en el cerro Pichincha, se garantiza que la distancia entre sistemas radiantes es menor a dos kilómetros; por lo cual la posibilidad de interferencia es mínima.

\subsection{Análisis de simulación}

\section{- $\quad$ Simulación de cobertura:}

Se observó en el Distrito Metropolitano de Quito y sus Valles aledaños, que alrededor del $90 \%$ del área cubierta, presenta una intensidad de campo eléctrico superior ha ( $51 \mathrm{dB \mu V} / \mathrm{m})$.

\section{- $\quad$ Simulación de perfil:}

Como segundo estudio se realizó la simulación del perfil de terreno, lo cual permitió identificar huecos de cobertura, en donde la intensidad de campo eléctrico (señal recibida), es menor ha ( $51 \mathrm{~dB} \mu \mathrm{V} / \mathrm{m}$ ) impidiendo la recepción de la señal digital. 
Estableciéndose conforme a los resultados obtenidos en las pruebas de campo dos zonas de sombra, así tenemos:

$\checkmark \quad$ Sur de Quito: Av. Mariscal Sucre, hacia la cima de la Libertad.

$\checkmark \quad$ Norte de Quito: Parroquia San Antonio en la Mitad del Mundo.

\section{- Estaciones reforzadoras de señal:}

Las estaciones reforzadoras o "GAPFILLER", mejorar los niveles de señal en las zonas de sombra de la ciudad de Quito, ya que sus emplazamientos han sido ubicados frente a éstas, consiguiendo que un nuevo patrón de radiación cubra en su totalidad aquellos huecos que el transmisor principal (Cerro Pichincha), no logra cubrir por problemas propios de la topografía de la ciudad.

Obteniendo niveles de señal por encima de los $70 \mathrm{~dB} \mu \mathrm{V} / \mathrm{m}$.

\section{- Compatibilidad electromagnética:}

La simulación de compatibilidad electromagnética nos ha permite observar que no existe interferencia Co-Canal o Adyacente entre señales Análogo/Digitales, debido a la diferencia en la potencia de transmisión y la tecnología involucrada. 
A continuación se analiza matemáticamente los resultados obtenidos en la simulación, a fin de evidenciar la poca interferencia que genera un transmisor no deseado sobre un receptor.

\section{Formulas:}

$$
\begin{gathered}
K\left(\frac{d B}{m}\right)=20 \log (F(M H z))-G_{\text {Antena }}(d B)-29.8 d B ; E c:(1) . \\
K\left(\frac{d B}{m}\right)=20 \log (F(M H z))-2.15 d B-29.8 d B \\
K\left(\frac{d B}{m}\right)=20 \log (F(M H z))-31.95 d B \\
V_{r}(d B \mu V)=\operatorname{Lectura}(d B m)+107 d B ; E c:(2) . \\
E\left(\frac{d B \mu V}{m}\right)=V_{r}(d B \mu V)+K\left(\frac{d B}{m}\right) ; E c:(3) .
\end{gathered}
$$

\section{Descripción de variables:}

$$
\boldsymbol{K}\left(\frac{d B}{m}\right)=\text { Parámetro de configuración de la antena con relación a la }
$$
Frecuencia del canal deseado. 
Lectura $(\boldsymbol{d B m})=$ Potencia en $(\mathrm{dBm})$ de la señal radiada, obtenida por el simulador o el instrumento de medición.

$\boldsymbol{G}_{\text {Antena }}(\boldsymbol{d} \boldsymbol{B})=$ Ganancia de antena, es un valor constante con relación a una antena isotrópica.

$\boldsymbol{E}\left(\frac{d B \mu V}{m}\right)=$ Intensidad de campo eléctrica, medida en $\left(\frac{d B \mu V}{m}\right)$.

\section{Datos:}

Tabla 3.15:

Potencia y campo eléctrico obtenidos al analizar la compatibilidad electromagnética.

\begin{tabular}{cc}
\hline \multicolumn{2}{c}{ Canal deseado analógico } \\
\hline $\boldsymbol{P}_{\boldsymbol{d}}=-\mathbf{1 8 . 1 9 8} \mathbf{d B m}$ & $P_{i}=-78.206 \mathrm{dBm}$ \\
$\boldsymbol{P}_{\boldsymbol{d}}=-\mathbf{2 0 . 8 9 2} \mathbf{d B m}$ & Canal deseado digital \\
$P_{i}=-75.884 \mathrm{dBm}$ \\
\hline
\end{tabular}




\section{Solución:}

\section{- Canal deseado analógico}

(1) Calculo en base a la potencia deseada:

$$
\begin{gathered}
V_{r}(d B \mu V)=-18.198 d B m+107 d B \\
V_{r}(d B \mu V)=88.802 d B m \\
K\left(\frac{d B}{m}\right)=20 \log (F(M H z))-G_{\text {Antena }}(d B)-29.8 d B \\
K\left(\frac{d B}{m}\right)=20 \log (539.1428(M H z))-31.95 d B \\
K\left(\frac{d B}{m}\right)=54.634076-31.95 d B \\
K\left(\frac{d B}{m}\right)=22.68 \\
E\left(\frac{d B \mu V}{m}\right)=V_{r}(d B \mu V)+K\left(\frac{d B}{m}\right) \\
E\left(\frac{d B \mu V}{m}\right)=88.802 d B m+22.68
\end{gathered}
$$




$$
E\left(\frac{d B \mu V}{m}\right)=111.486076
$$

(2) Calculo en base a la potencia interferente:

$$
\begin{gathered}
V_{r}(d B \mu V)=-78.206 d B m+107 d B \\
V_{r}(d B \mu V)=28.794 d B m \\
K\left(\frac{d B}{m}\right)=20 \log (F(M H z))-G_{\text {Antena }}(d B)-29.8 d B \\
K\left(\frac{d B}{m}\right)=20 \log (545.1428(M H z))-31.95 d B \\
K\left(\frac{d B}{m}\right)=54.634076-31.95 d B \\
E\left(\frac{d B \mu V}{m}\right)=V_{r}(d B \mu V)+K\left(\frac{d B}{m}\right) \\
K\left(\frac{d B}{m}\right)=22.78 \\
E\left(\frac{d B}{m}\right)=28.794 d B m+22.78 \\
K
\end{gathered}
$$




$$
E\left(\frac{d B \mu V}{m}\right)=51.574
$$

\section{- Canal deseado digital}

(1) Calculo en base a la potencia deseada:

$$
\begin{gathered}
V_{r}(d B \mu V)=-20.892 d B m+107 d B \\
V_{r}(d B \mu V)=86.802 d B m \\
K\left(\frac{d B}{m}\right)=20 \log (F(M H z))-G_{\text {Antena }}(d B)-29.8 d B \\
K\left(\frac{d B}{m}\right)=20 \log (545.1428(M H z))-31.95 d B \\
K\left(\frac{d B}{m}\right)=54.730205-31.95 d B \\
K\left(\frac{d B}{m}\right)=22.78 \\
E\left(\frac{d B \mu V}{m}\right)=V_{r}(d B \mu V)+K\left(\frac{d B}{m}\right) \\
E\left(\frac{d B \mu V}{m}\right)=86.802 d B m+22.78
\end{gathered}
$$




$$
E\left(\frac{d B \mu V}{m}\right)=109.582
$$

(2) Calculo en base a la potencia interferente:

$$
\begin{gathered}
V_{r}(d B \mu V)=-75.884 d B m+107 d B \\
V_{r}(d B \mu V)=31.116 d B m \\
K\left(\frac{d B}{m}\right)=20 \log (F(M H z))-G_{\text {Antena }}(d B)-29.8 d B \\
K\left(\frac{d B}{m}\right)=20 \log (539.1428(M H z))-31.95 d B \\
K\left(\frac{d B}{m}\right)=54.634076-31.95 d B \\
K\left(\frac{d B}{m}\right)=22.68 \\
E\left(\frac{d B \mu V}{m}\right)=V_{r}(d B \mu V)+K\left(\frac{d B}{m}\right) \\
E\left(\frac{d B V}{m}\right)=31.116 d B m+22.68
\end{gathered}
$$




$$
E\left(\frac{d B \mu V}{m}\right)=53.796
$$

Como se observa en ambos casos la intensidad de campo eléctrico de la señal deseada es mayor que la interferente, lo cual nos permite concluir que no existe interferencia sobre receptor a nivel de canal adyacente. 


\section{CAPÍTULO IV}

\section{MEDICIONES Y ANÁLISIS DE RESULTADOS}

El presente capitulo abarca las pruebas de campo y el análisis de las muestras obtenidas.

\subsection{Definición del protocolo de pruebas}

El protocolo de pruebas, se debe entender como la planificación previa a la adquisición de información del comportamiento electromagnético de un determinado patrón de radiación, en cuyo caso resulta predominantemente necesario realizar mediciones da la intensidad de campo eléctrico reflejado por un transmisor sobre su zona de influencia (Ciudad de Quito).

Por ello deben ser definidos los límites geográficos de la zona de estudio donde se llevaran a cabo las mediciones de campo, ya que los operadores de redes de radiodifusión terrestre deben cubrir por completo y de manera fiable toda la superficie de una zona de servicio. 
Por lo tanto resulta fundamental estudiar la geografía de dicha zona y tomar en consideración los parámetros técnicos que el estándar de televisión digital terrestre (ISDB-Tb) nos proporciona, en el cual se define el borde de cobertura en $51 \mathrm{~dB} \mu \mathrm{V} / \mathrm{m}$, que no es más que la mínima intensidad de campo eléctrico necesaria para garantizar la recepción de Tv Digital.

Es por esto que ya en la fase de planificación se recurre a herramientas de simulación como SIRENET, a fin de comprobar si las estaciones transmisoras logran garantizar una cobertura suficiente, sin embargo las características de propagación en una región son sumamente complejas y no pueden ser descritas por completo de manera teórica, entonces una vez que la red está en funcionamiento resulta necesario comprobar la situación real de cobertura a través de numerosas mediciones en campo.

\subsection{Mediciones y pruebas de campo}

A continuación se detalla los equipos y procesos involucrados en la toma de muestras.

\subsubsection{Equipos de Medición}

Los equipos utilizados durante el proceso de mediciones de campo son: 
- $\quad$ Analizador de Espectros Rohde \& Schwazer TV Analyzer ETL.

- $\quad$ Módulo GPS R \& STSMX - PPS.

- $\quad$ Software controlador del módulo GPS, R \& S Broadcast Drive TEST.

Nota: Los equipos y el software controlador son desarrollados por la empresa alemana Rohde \&Schwazer, y proporcionados por ECTV; a fin de permitir el desarrollo del presenta proyecto de grado.

\section{R\&S TV Analyzer ETL}

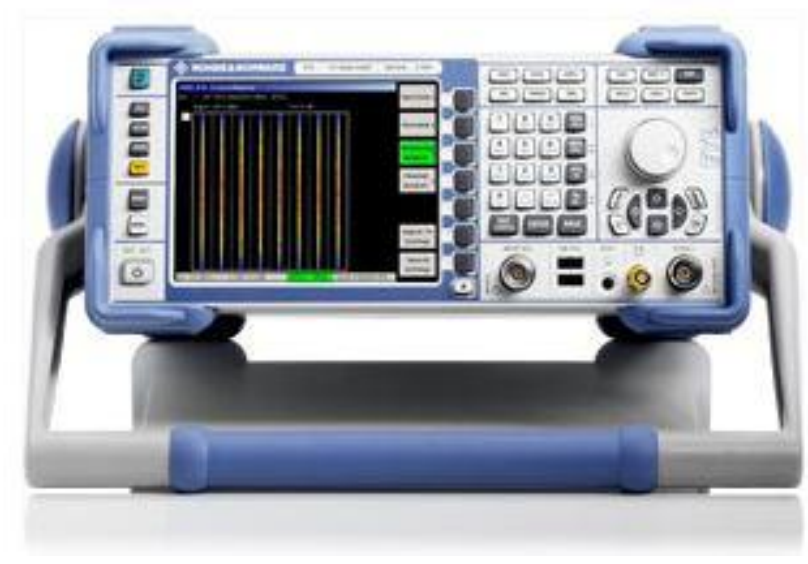

Figura 4.1: Equipo de medición ETL TV Analyzer.

ETL TV Analyzer, es un analizador de espectros digital de alta capacidad, fabricado por la empresa alemana Rohde \& Schwarz, especialmente diseñado para la medición e interpretación teórica de señales de televisión fija y móvil. 
Rohde \& Schwarz, a logrado combinar de forma efectiva la recepción de televisión y la funcionalidad de analizador de espectro en una sola unidad, al mismo tiempo que proporciona una alta precisión al efectuar mediciones de campo.

Este instrumento de medición es una herramienta altamente eficiente al momento de planificar el estudio de redes SFN de televisión, su software y hardware es altamente amigable al momento de tratar señales analógicas y digitales, en múltiples estándares de televisión.

Sus características más importantes, son:

- $\quad$ Amplio rango de frecuencia: De $500 \mathrm{kHz}$ a $3 \mathrm{GHz}$.

- $\quad$ Mediciones versátiles para ATV y DTV: Ofrece una amplia gama de funciones para mediciones en señales de televisión digital, tales como: $C$ / $N, B E R, M E R, T M C C$ y en particular, los diagramas de constelación que se muestran en detalle muy fino y muy alta velocidad.

- $\quad$ Análisis y seguimiento MPEG: Proporciona información detallada del flujo de transporte MPEG-2

- $\quad$ Pantalla de imagen de TV: La resolución de su monitor es de alta calidad, al nivel de un TV, proporcionando una indicación muy rápido de la calidad de la trayectoria de transmisión entera y sus componentes. 


\section{R \& S TSMX -PPS}

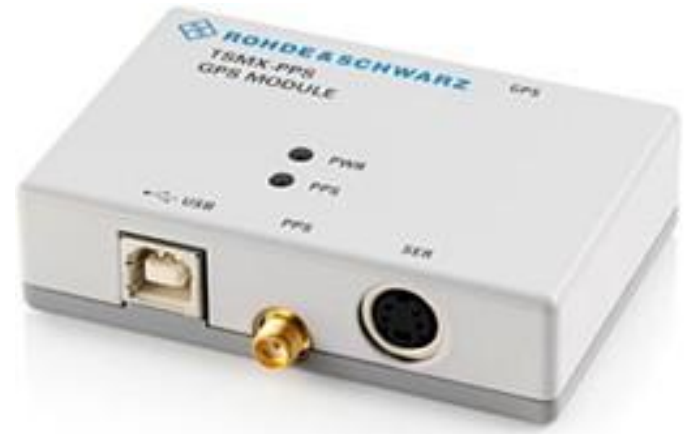

Figura 4.2: Módulo de GPS.

\section{R\&S BCDRIVE Broadcast Drive Test}

Broadcast Drive Test, es un software que en combinación con el analizador de espectros digital TV R\&S ETL, facilita la interpretación rápida, sencilla y fiable de una señal en función de su intensidad de campo eléctrico, evaluando la calidad de esta y el análisis de sus causas, tomando en consideración varios estándares de radiodifusión terrestre, en relación a un trayecto de prueba previamente definido (Drive Test); permitiendo el ahorro de tiempo y recursos facilitando el análisis de cobertura. 


\begin{tabular}{|c|c|c|c|c|c|c|c|c|c|c|c|}
\hline & \multicolumn{2}{|c|}{$\begin{array}{l}\text { Intensidad de } \\
\text { campo recibida }\end{array}$} & \multicolumn{2}{|c|}{$\begin{array}{l}\text { Sincronización } \\
\text { de señal }\end{array}$} & \multicolumn{2}{|c|}{$\begin{array}{l}\text { Tasas de error de } \\
\text { modulación }\end{array}$} & \multicolumn{3}{|c|}{$\begin{array}{l}\text { Tasas de error de } \\
\text { bit }\end{array}$} & \multicolumn{2}{|c|}{$\begin{array}{l}\text { Respuesta impul- } \\
\text { sional del canal }\end{array}$} \\
\hline DVB-T / DVB-H & \multicolumn{2}{|c|}{$\bullet$} & \multicolumn{2}{|c|}{$\bullet$} & \multicolumn{2}{|c|}{ - } & \multicolumn{3}{|c|}{$\bullet$} & \multicolumn{2}{|c|}{$\bullet$} \\
\hline ISDB-T & \multicolumn{2}{|l|}{$\bullet$} & \multicolumn{2}{|l|}{$\bullet$} & \multicolumn{2}{|l|}{$\bullet$} & \multicolumn{3}{|l|}{$\bullet$} & \multicolumn{2}{|l|}{$\bullet$} \\
\hline \multicolumn{12}{|c|}{ R\&S ETL: soporte de numerosos estándares de radiodifusión } \\
\hline & $\begin{array}{l}\text { Intensidad } \\
\text { de campo } \\
\text { recibida }\end{array}$ & \multicolumn{2}{|c|}{$\begin{array}{l}\text { Sincroni- } \\
\text { zación de } \\
\text { señal }\end{array}$} & $\begin{array}{l}\text { Tasas de } \\
\text { error de } \\
\text { modulación }\end{array}$ & $\begin{array}{l}\text { Tasas de } \\
\text { error de } \\
\text { bit }\end{array}$ & \multicolumn{2}{|c|}{$\begin{array}{l}\text { Respuesta } \\
\text { impulsional } \\
\text { del canal }\end{array}$} & $\begin{array}{l}\text { Relación } \\
\text { señal/ } \\
\text { ruido }\end{array}$ & \multicolumn{2}{|c|}{$\begin{array}{l}\text { Nivel MPX / } \\
\text { desviación } \\
\text { de cresta }\end{array}$} & $\begin{array}{l}\text { Tasa de error } \\
\text { de bit RDS }\end{array}$ \\
\hline $\begin{array}{l}\text { ATSC } \\
\text { ATSC Mobile DTV }\end{array}$ & $\bullet$ & $\circ$ & & $\circ$ & $\circ$ & $\circ$ & & & & & \\
\hline DAB / T-DMB & $\bullet$ & $\bullet$ & & $\bullet$ & $\bullet$ & $\bullet$ & & & & & \\
\hline DTMB & $\bullet$ & $\circ$ & & $\circ$ & o" & ०11 & & & & & \\
\hline DVB-T / DVB-H & $\bullet$ & $\bullet$ & & $\bullet$ & $\bullet$ & $\bullet$ & & & & & \\
\hline DVB-T2 & $\bullet$ & $\bullet$ & & $\bullet$ & $\bullet$ & $\bullet$ & & & & & \\
\hline FM (radio) & $\bullet$ & & & & & & & & $\bullet$ & & 0 \\
\hline ISDB-T & $\bullet$ & $\bullet$ & & $\bullet$ & $\bullet$ & $\bullet$ & & & & & \\
\hline TV analógica & 0 & & & & & & & $\circ$ & & & \\
\hline - Registro móvil & egistro estático & & ara señ & OFDM & & & & & & & \\
\hline
\end{tabular}

Figura 4.3: Estándares interpretados por el analizador TV R\&S ETL. (http://www.rohde-schwarz-)

Lo cual permite al operador determinar con facilidad las zonas críticas para la recepción denominadas Zonas de Sombra, a través de la interpretación de las mediciones obtenidas y su importación a Google Earth.

Su interfaz se basa en una distribución amigable e intuitiva de las opciones de trabajo que la herramienta ofrece, garantizando su inicio rápido y sin necesidad de usar un manual. 


\section{Configuración del Software}

Si bien el software es una herramienta amigable, existen parámetros que deben ser configurados; tales como:

- $\quad$ Tipo de Antena

- $\quad$ Rango de Frecuencias

- $\quad$ Factor $K$ de la antena

- $\quad$ Etc.

Esto permitirá enlazar correctamente el software controlador y el analizador R\&S TV Analyzer ETL, para ello se detalla a continuación una serie de pasos necesarios para efectuar las mediciones de campo.

Pasó 1: Una vez que se ha iniciado la sesión de trabajo en analizador R\&S TV Analyzer ETL, presionar la tecla de MODE, desplegándose las opciones de trabajó que ofrece el equipo; escogemos la opción R\&S Broadcast Drive Test.

Pasó 2: Una vez que se ha escogido la opción deseada, se despliega el siguiente menú, ofreciéndonos tres opciones: 
- $\quad$ Perform a new drive test.

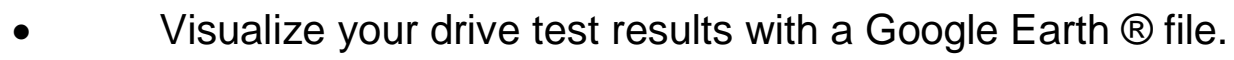

- $\quad$ Postprocess your drive test results with a spreadsheet (.csv) file.

Estas deben ser escogidas en orden descendente, ya que el procesamiento de los datos es concatenado.

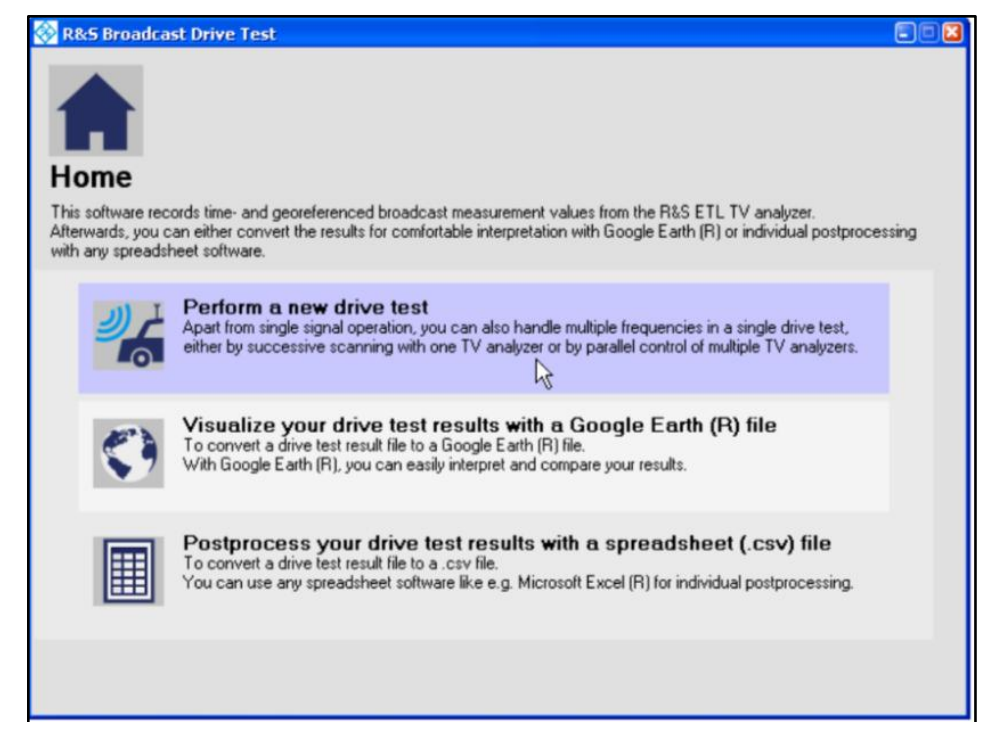

Figura 4.4: Interfaz gráfica del Software, R\&S BCDRIVE Broadcast Drive Test.

- $\quad$ Nuevo Drive Test.

Pasó 3: La primera opción del menú desplegado, permitirá configurar parámetros técnicos y la posterior adquisición de datos, para ello el software 
instruye al operador sobre la selección de parámetros necesarios que deben ser ingresados o seleccionados a través de cinco pasos.

Sub Pasó 1: El sistema nos ofrece la posibilidad de seleccionar tres parámetros de trabajo y direccionar los archivos generados a una carpeta contenedora Disco C: \Mediciones.

- $\quad$ Broadcast standard: Permite escoger el estándar de Televisión en el cual se desea trabajar.

- Level unit: Permite escoger las unidades en las que deseamos, interpretar las mediciones de la intensidad de campo.

- $\quad$ Distance unit: Permite escoger las unidades en las que deseamos visualizar nuestras mediciones, de las distancias recorridas durante el Test Drive.

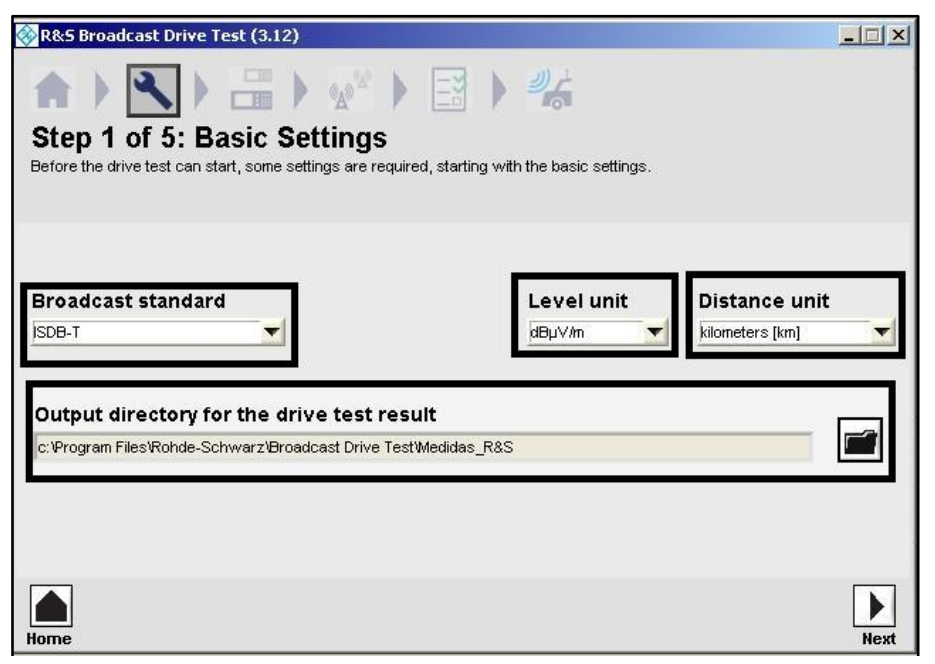

Figura 4.5: Configuración de las unidades de medición y estándar de Tv. 
Sub Pasó 2: Ahora el sistema nos permite seleccionar el hardware con el cual deseamos trabajar, estos son:

- Selection: Nos permite seleccionar el modulo GPS con el cual deseamos trabajar (R\&S TSMX $-P P S)$.

- $\quad$ Input: Nos permite seleccionar la impedancia de entrad 50 o $75 \Omega$.

- $\quad$ Antenna: Nos permite configurar la antena con la cual realizaremos las mediciones.

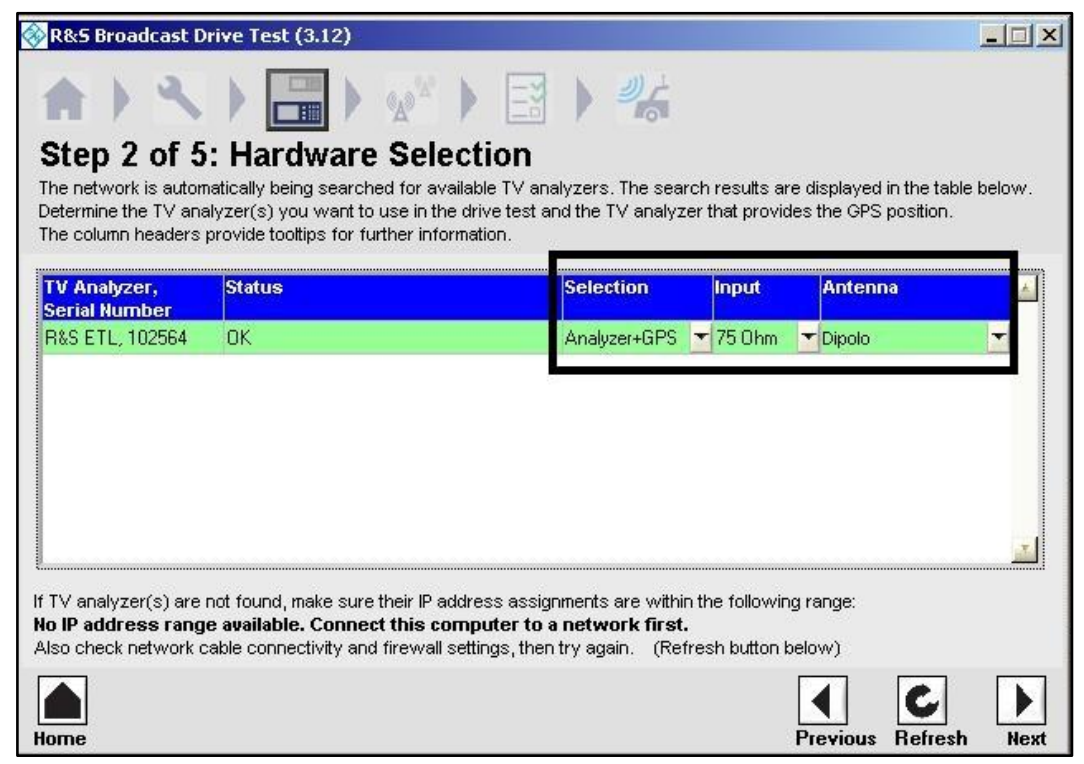

Figura 4.6: Selección y configuración de Hardware. 


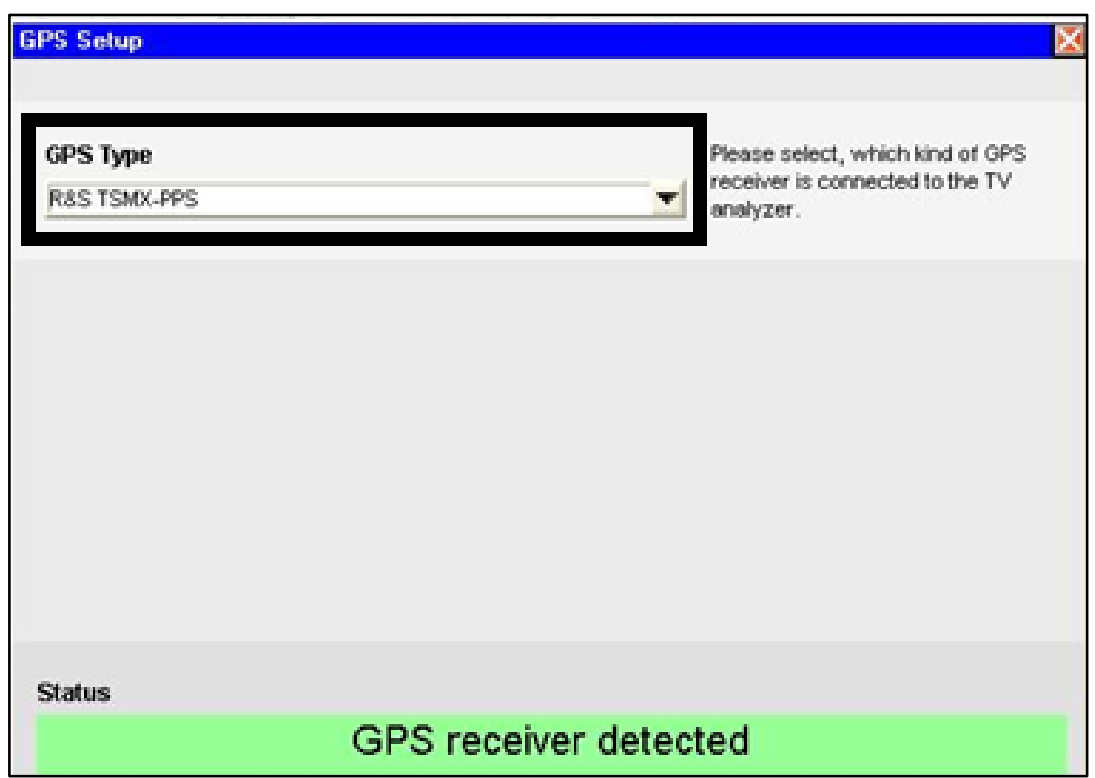

Figura 4.7: Ventana de inicialización del moduló GPS.

\section{Configuración de Antena}

Para configurar los parámetros de la antena es necesario calcular el factor $\mathrm{K}$ de esta, en relación al rango de frecuencias del canal deseado (Ancho del canal $6 \mathrm{MHz}$ ); a través de la ecuación (1).

\section{Canal 26:}

$$
K\left(\frac{d B}{m}\right)=20 \log _{10} F(M H z)-G_{\text {Antena }}(d B)-29.8(d B) ; E c:
$$


Tabla 4.1:

Factor $\boldsymbol{K}$ del canal 26 (ECTV).

\begin{tabular}{ll}
\hline \multicolumn{1}{c}{ Rango de Frecuencias } & \multicolumn{1}{c}{ Factor K } \\
\hline $\mathbf{5 4 2} \mathbf{~ M H z}$ & 22.72 \\
$\mathbf{5 4 5 . 1 4 2 8 5 7} \mathbf{~ M H z}$ & 22.78 \\
$\mathbf{5 4 8} \mathbf{~ M H z}$ & 22.82 \\
\hline
\end{tabular}

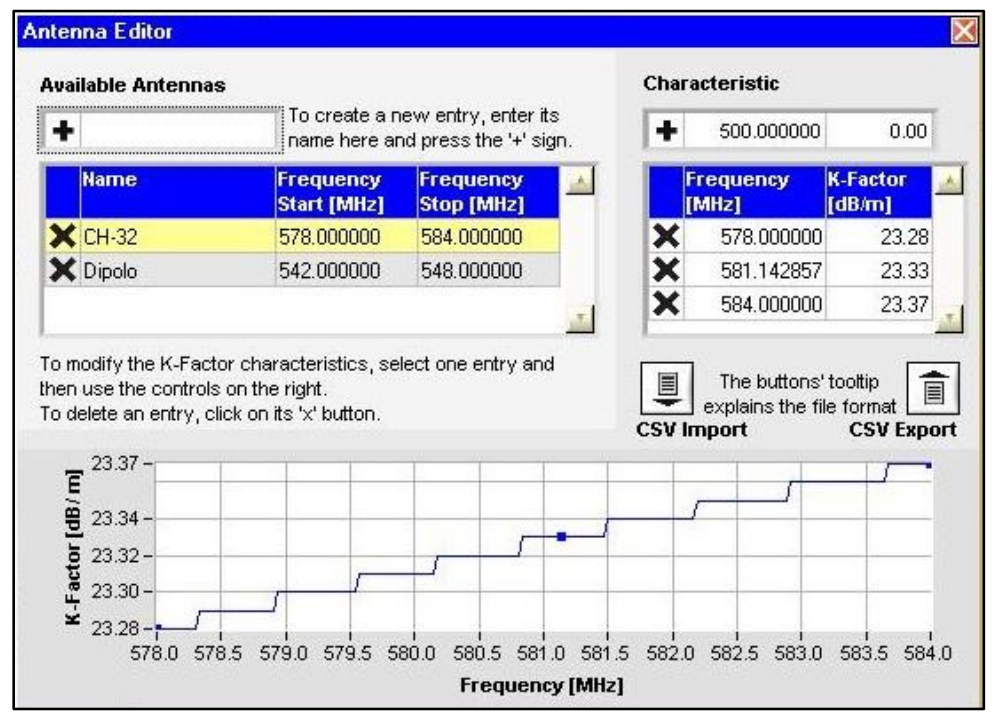

Figura 4.8: Ventana de configuración de parámetros de antena.

Pasó 3: Signal Selection, permite dar un nombre al estudio de Test Drive que deseamos efectuar e ingresar la frecuencia central del canal o canales a ser estudiados. 


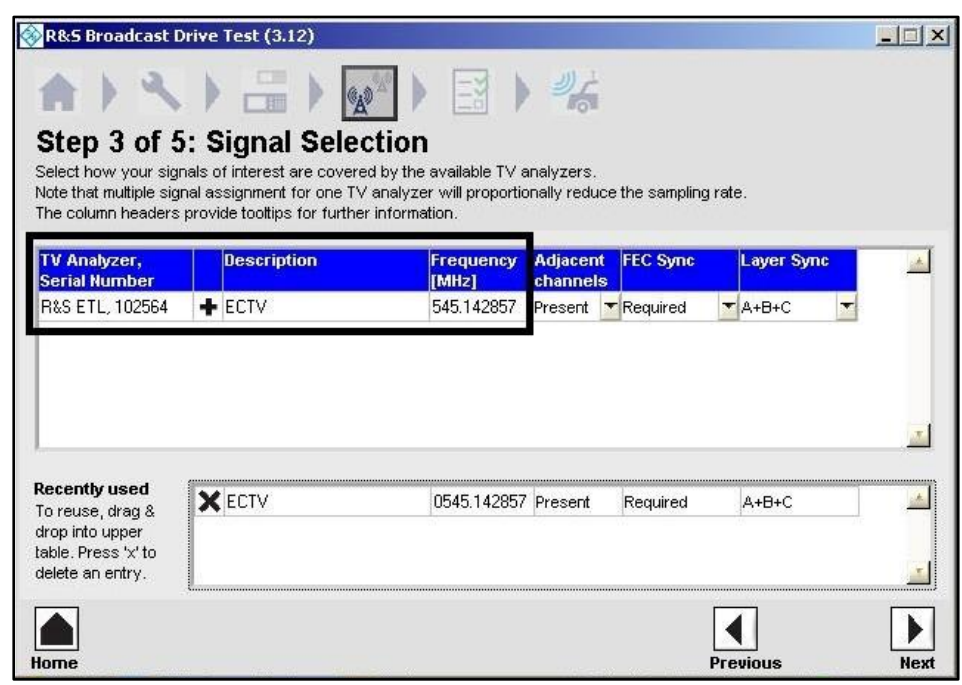

Figura 4.9: Ventana de configuración de la frecuencia intermedia y asignación de nombre al Test Drive.

Pasó 4: Measurement Selection, este paso nos presenta la posibilidad de escoger entre dos opciones, que nos permitirá definir las mediciones que deseamos realizar.

- $\quad$ Default: Nos presenta valores por defecto a ser medidos.

- User Defined: Nos presenta la opción de definir que parámetros deseamos medir. 


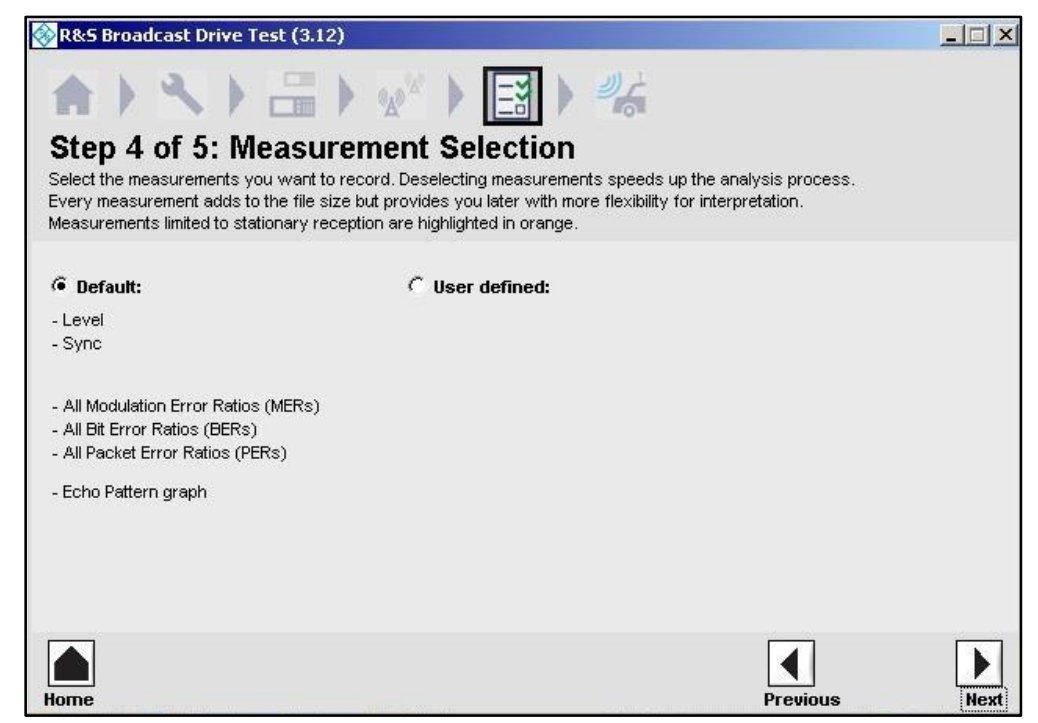

Figura 4.10: Ventana de configuración de mediciones.

Pasó 5: Drive Test, es el último paso que resta por hacer una vez que han sido configurados todos los parámetros de mediciones.

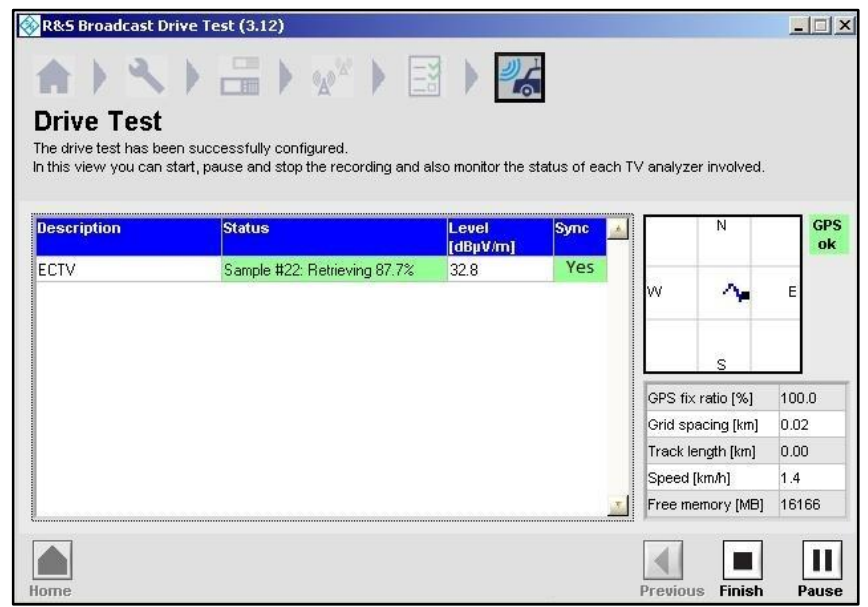

Figura 4.11: Ventana de Drive Test. 
Una vez que terminamos el recorrido, presionamos Finish y el sistema crea un archivo . dtr, el cual contiene todos los datos adquiridos por el sistema y se encuentran almacenados en el Disco C: $\backslash$ Mediciones $\backslash$ NOMBRE, con el nombre respectivo con el cual haya sido grabado según el PASO 3; ejemplo ECTV.

\section{Visualización de resultados en Google Earth}

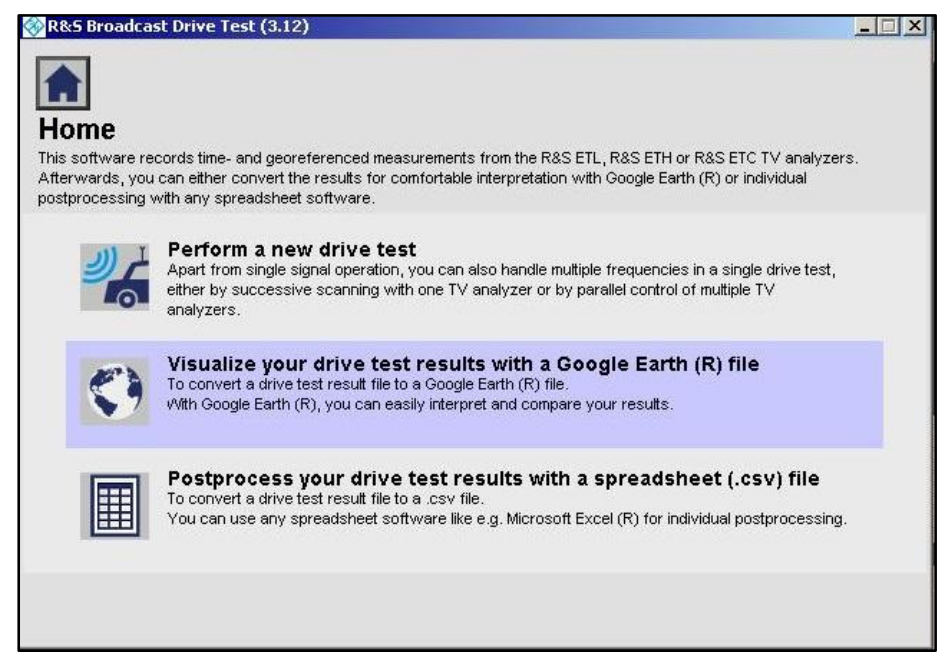

Figura 4.12: Ventana de importación de archivos a Google Eatrh.

Pasó 1: File Selection, esta opción permite cargan los archivos .dtr, contenidos en el Disco C: \Mediciones \NOMBRE. dtr. 


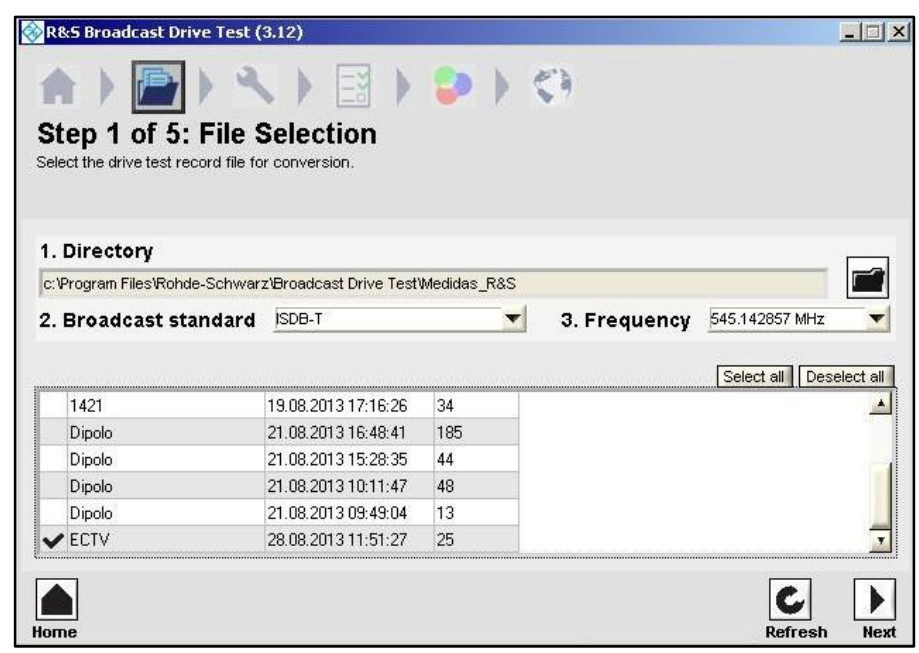

Figura 4.13: Ventana de selección de archivos.

Pasó 2: Level configuration, presenta el archivo .dtr y nos permite escoger el que sea de nuestro interés, a más de proporciona información básica sobre sus configuraciones.

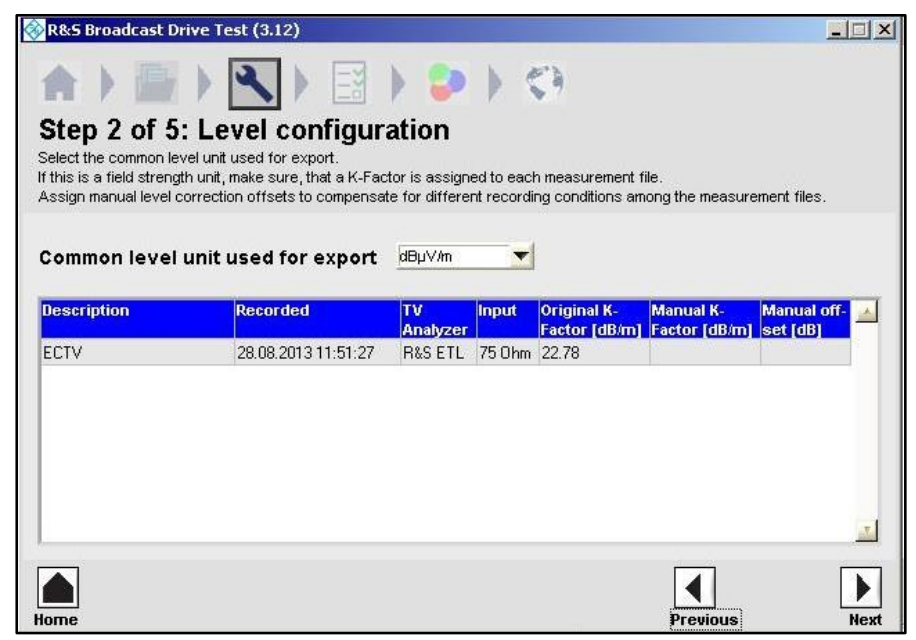

Figura 4.14: Ventana de configuración de parámetros de configuración.

Pasó 3: Scope Selection, a través de esta ventana seleccionamos las mediciones que deseamos observar y son de nuestro interés. 


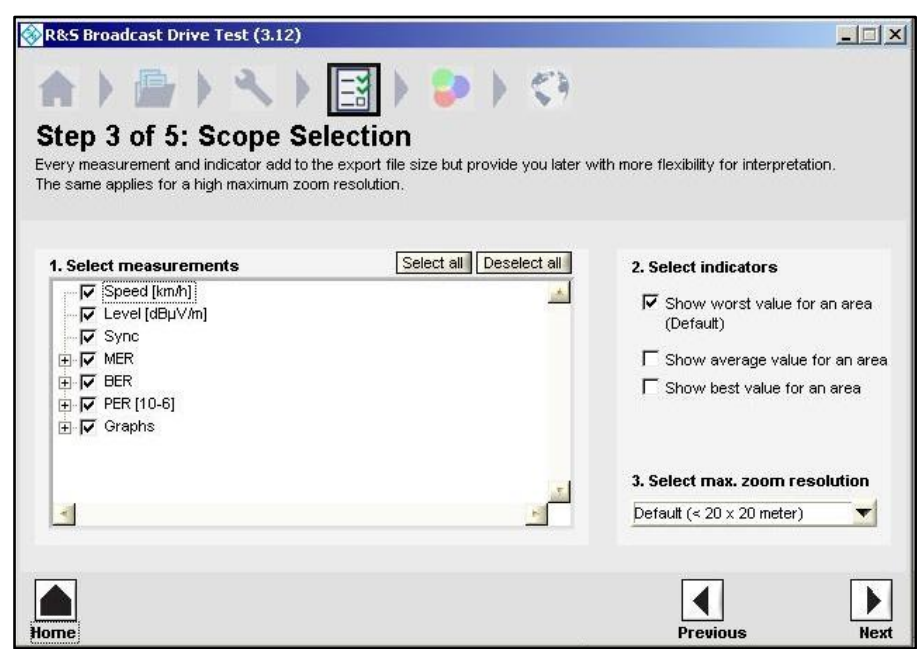

Figura 4.15: Ventana de discriminación de mediciones.

Pasó 4: Color Assignment, a través de esta ventana configuramos cada una de las mediciones escogidas en el paso anterior y le asignamos un parámetro de valoración dentro de una escala de colores (Rojo - Amarillo - Verde), lo cual permitirá la representación de resultados en Coogle Earth.

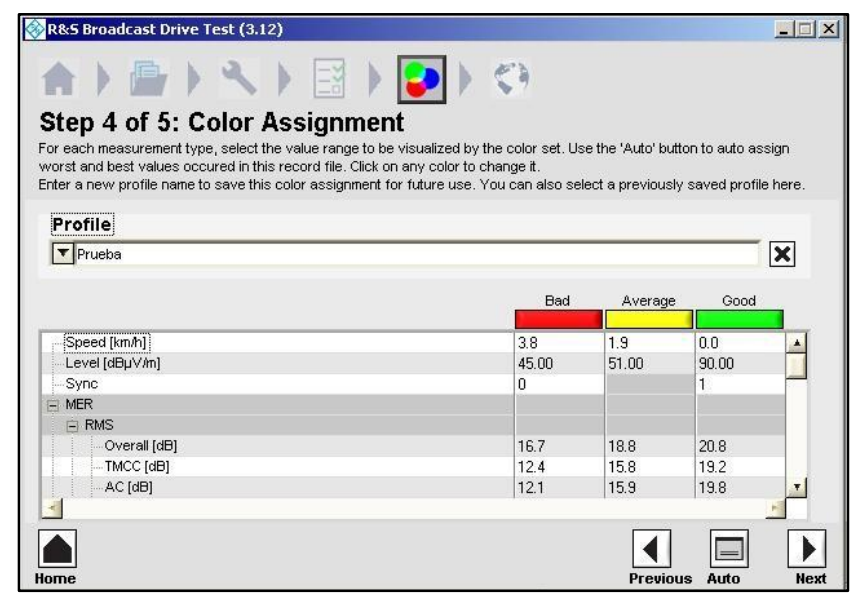

Figura 4.16: Ventana de asignación de patrón de colores a las variables a ser medidas. 
Pasó 5: Google Earth ${ }^{\circledR}$ File Generation, esta última opción genera los archivos . kmz; facilitando la visualización de resultados en Google Earth.

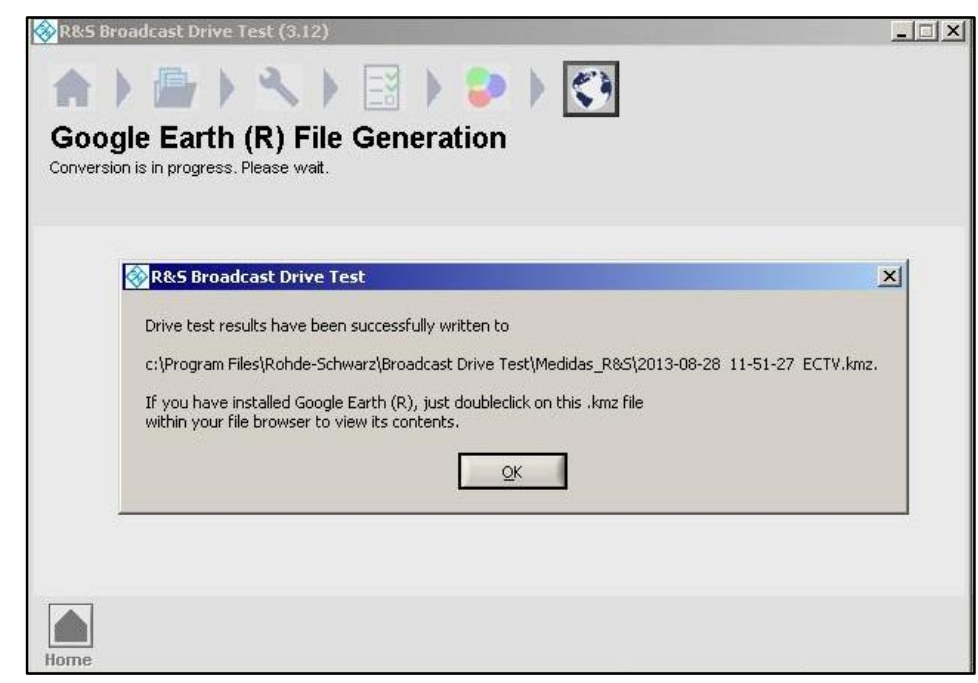

Figura 4.17: Ventana de confirmación de la creación de archivos . $\boldsymbol{k m z}$.

Al final el sistema pregunta si deseamos grabar el archivo . $k m z$, en la carpeta contenedora en el Disco $C: \backslash$ Mediciones $\backslash$ NOMBRE. kmz

\section{Procesamiento de resultados del Drive Test, en una hoja de cálculo Excel}

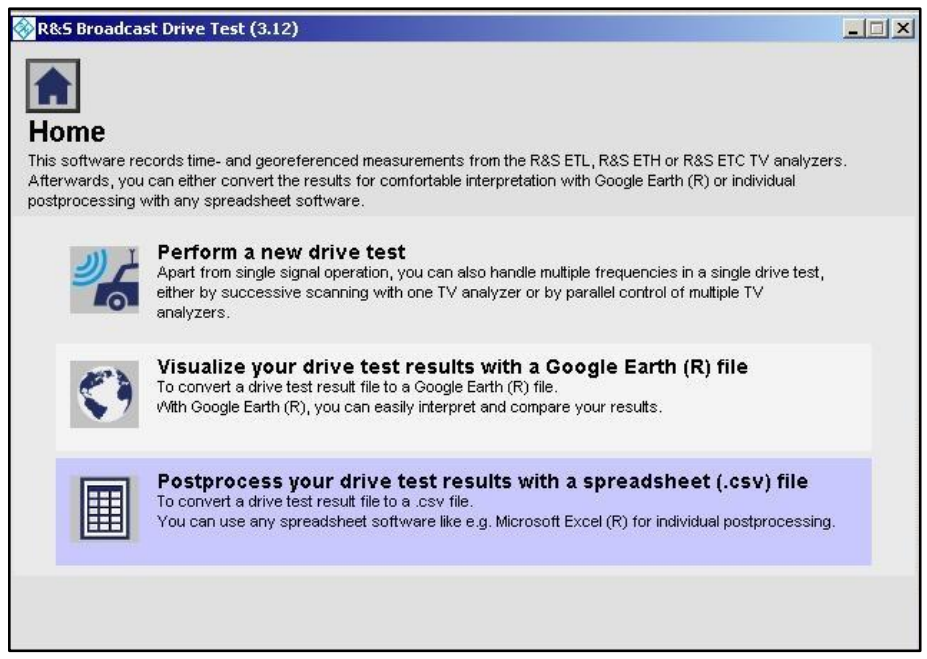

Figura 4.18: Ventana de importación de archivos a Ecxel. 
Pasó 1: File Selection, esta opción permite cargan los archivos .dtr, contenidos en el Disco C: \Mediciones \NOMBRE.dtr

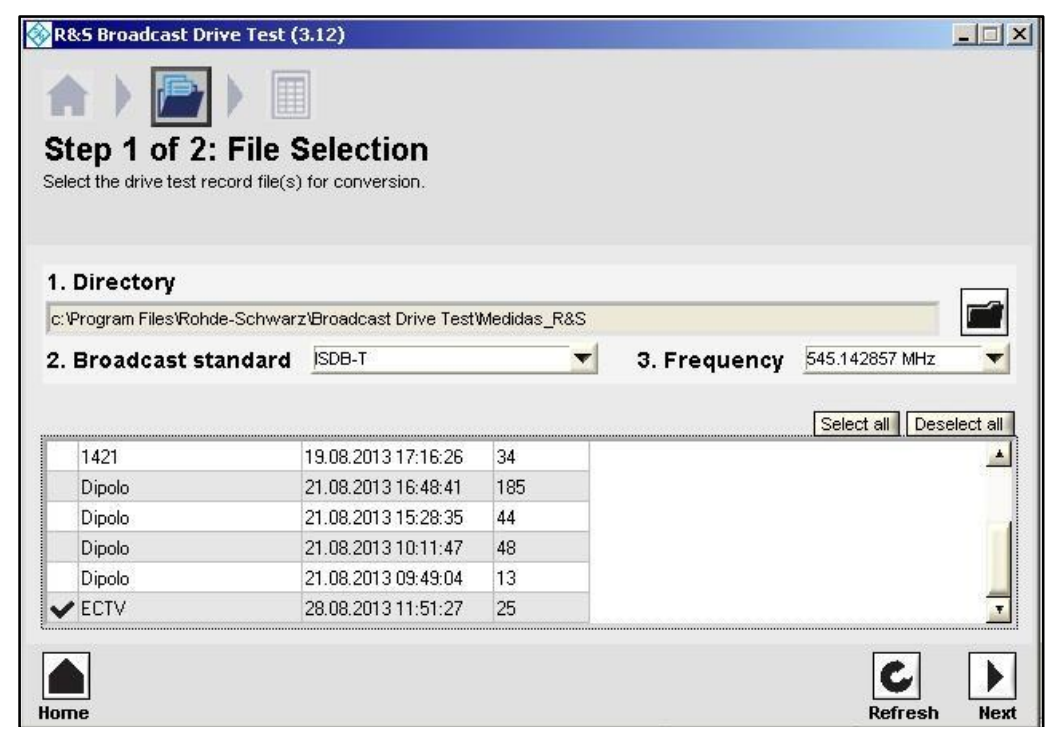

Figura 4.19: Ventana de selección de archivos.

Pasó 2: File Generation, esta ventana nos permite crear los archivos .csv, compatibles con la hoja de cálculo (Excel).

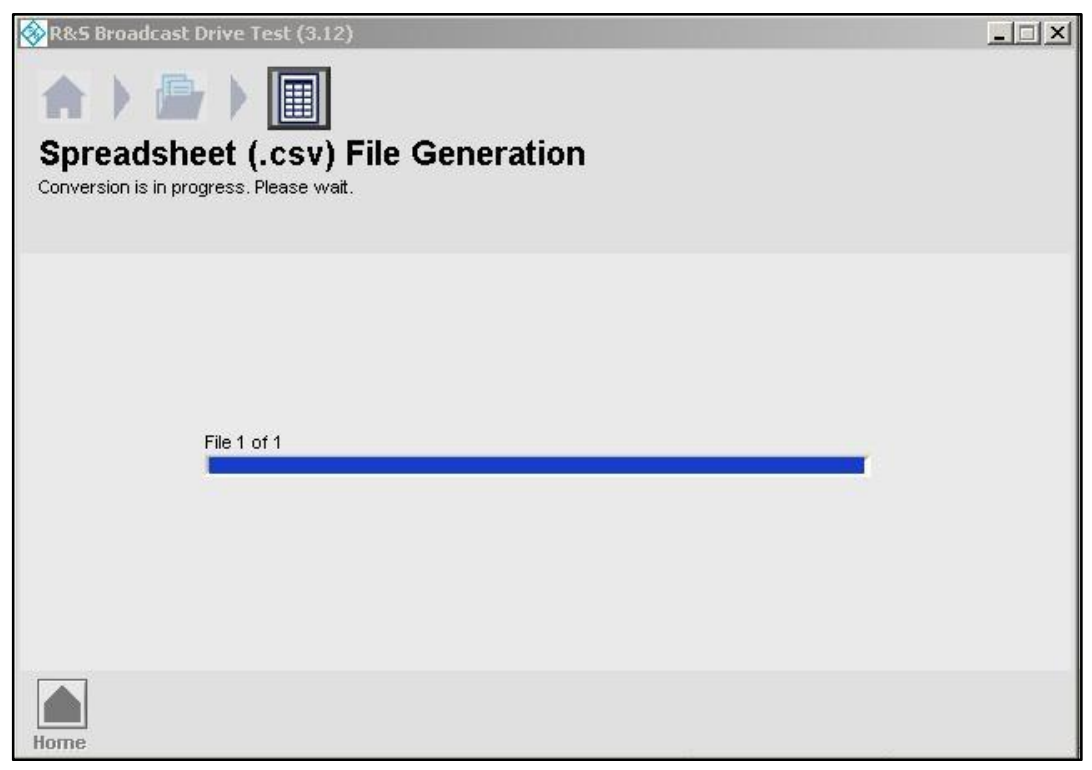

Figura 4.20: Creación de archivos .csv. 
Al final el sistema pregunta si deseamos grabar el archivo . kmz, en la carpeta contenedora en el Disco $C: \backslash$ Mediciones $\backslash$ NOMBRE.csv.

\section{Notas:}

1.- Los archivos (. kmz) y (.csv), se crean a partir del archivo madre (.dtr).

2.- Todos los archivos se almacenan en una misma carpeta en el Disco C: $\backslash$ Mediciones \Archivo (.dtr), (. kmz) y (.csv).

\subsubsection{Mediciones}

Las mediciones de campo permiten analizar el comportamiento electromagnético de la señal digital, a través de múltiples muestras (mediciones), en diferentes sitios dentro del área de cobertura.

Estas mediciones nos ayudan a conocer cual es el estado real de la señal digital, lo cual se consigue a través de la valoración, de múltiples parámetros técnicos presentes en la transmisión digital; siendo estos:

- ICE

- $\quad$ MER

- $\quad$ TMCC

- $\quad$ BER (Viterbi)

- $\quad$ BER (Reed Solomon)

- $\quad$ Tipo de capa (A, B o C) 
Algunas de estas muestras fueron tomadas en las zonas de sobra definidas en el estudio geográfico del "Capitulo III", con la ayuda del analizador de espectros digital R\&S TV Analyzer ETL, de ECTV.

\subsubsection{Muestras}

A continuación se presentan el resultado, para cada uno de los tramos evaluados durante el Drive Test, evidenciando los porcentajes de intensidad de campo eléctrico (ICE) sobre y por debajo del umbral necesarios para la óptima recepción de la (TDT) de [51 dB $\mu \mathrm{V} / \mathrm{m}]$.

\section{Rutas Norte}

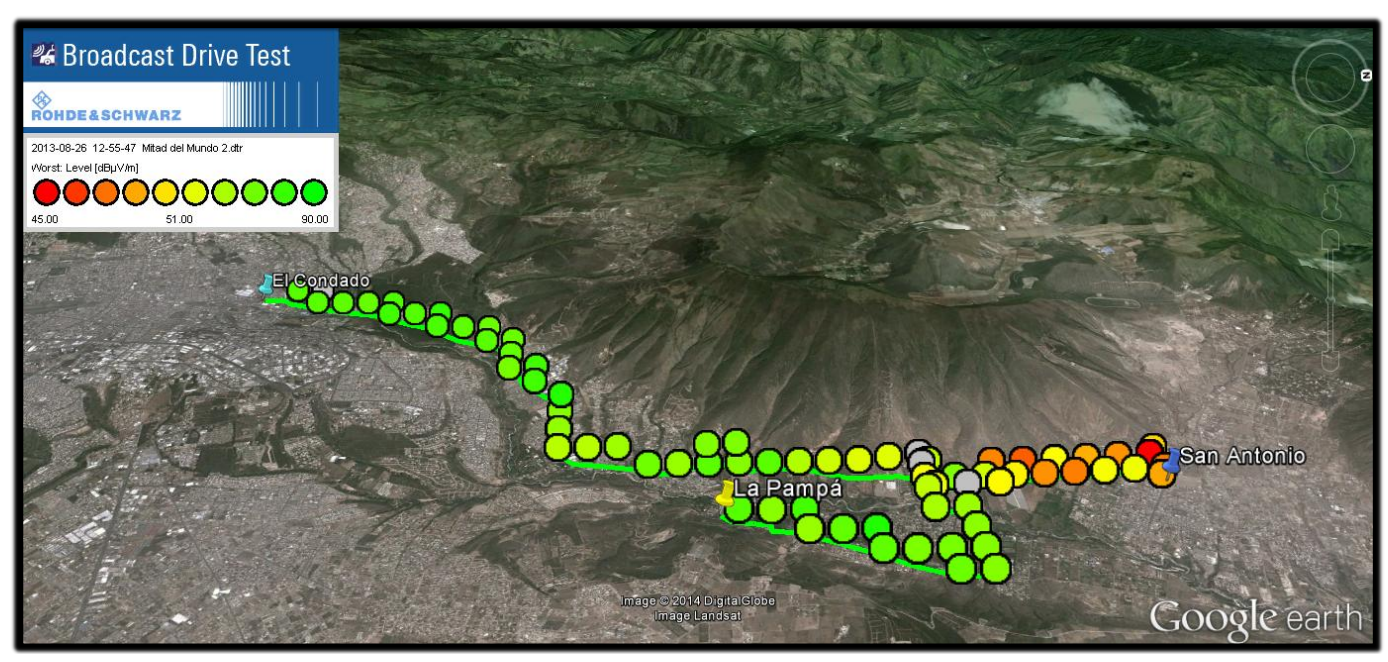

Figura 4.21: Muestras tomadas en la ruta, La Pampá - San Antonio - El Condado. 


\section{La Pampá - San Antonio - El Condado \\ $\square$ VOSCURO $\square$ VCLARO $\square$ AMARILLO $\square$ NARANJA}

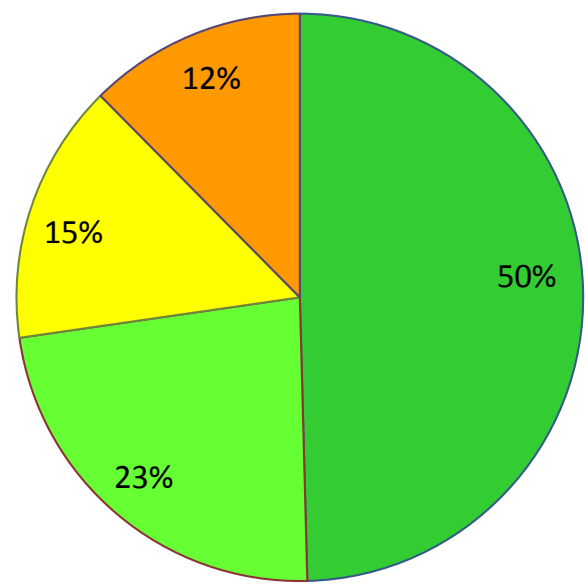

Figura 4.22: Porcentaje de cobertura por colores, La Pampá - San Antonio - El Condado.

\section{Tabla 4.2:}

Valores promedio del ICE, a lo largo del Drive Test.

\begin{tabular}{cc}
\hline Color & $\boldsymbol{I C E}[\boldsymbol{d B} \boldsymbol{\mu} \boldsymbol{V} / \boldsymbol{m}]$ \\
\hline V OSCURO & 78,49 \\
V CLARO & 60,74 \\
AMARILLO & 50,52 \\
NARANJA & 47,83 \\
ROJO & 42,83 \\
\hline
\end{tabular}




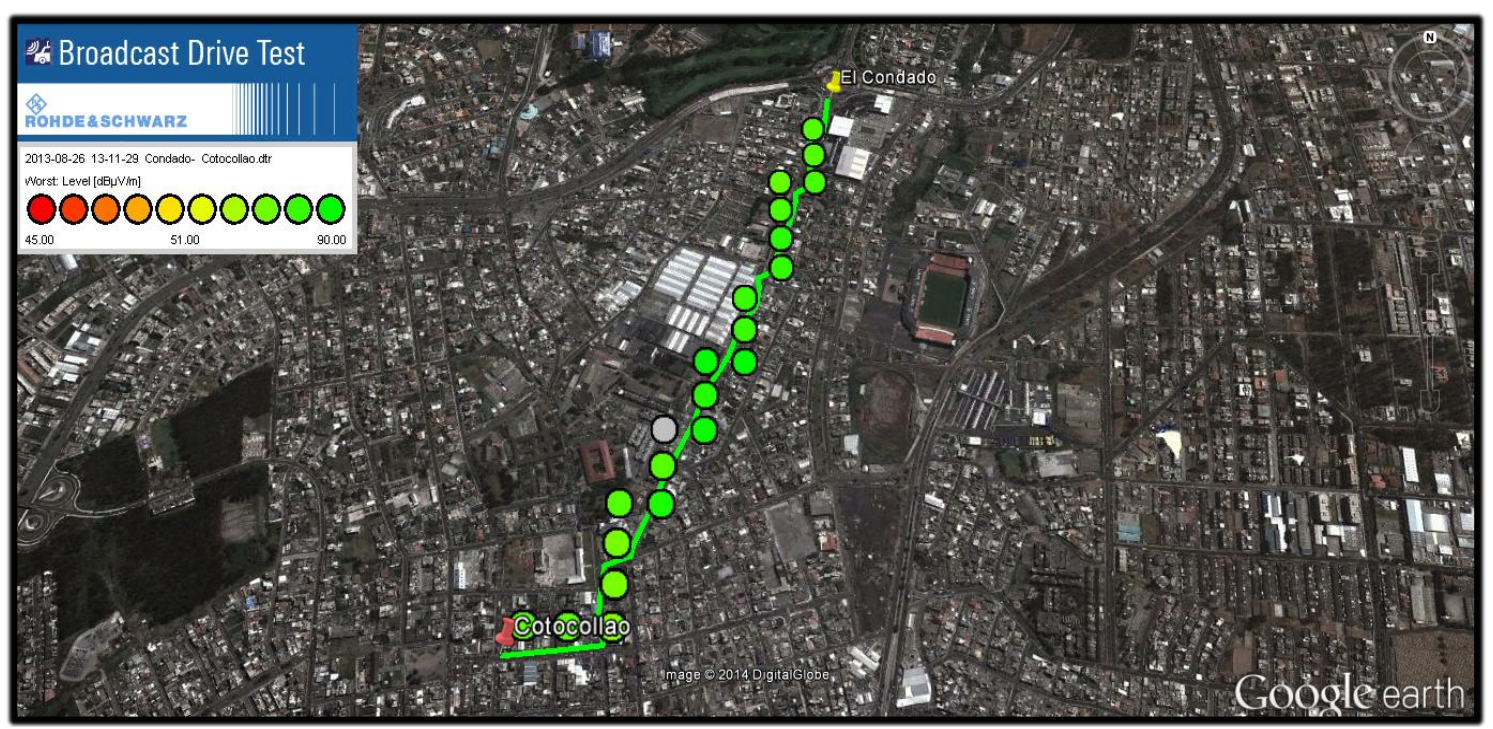

Figura 4.23: Muestras tomadas en la ruta, El Condado - Cotocollao.

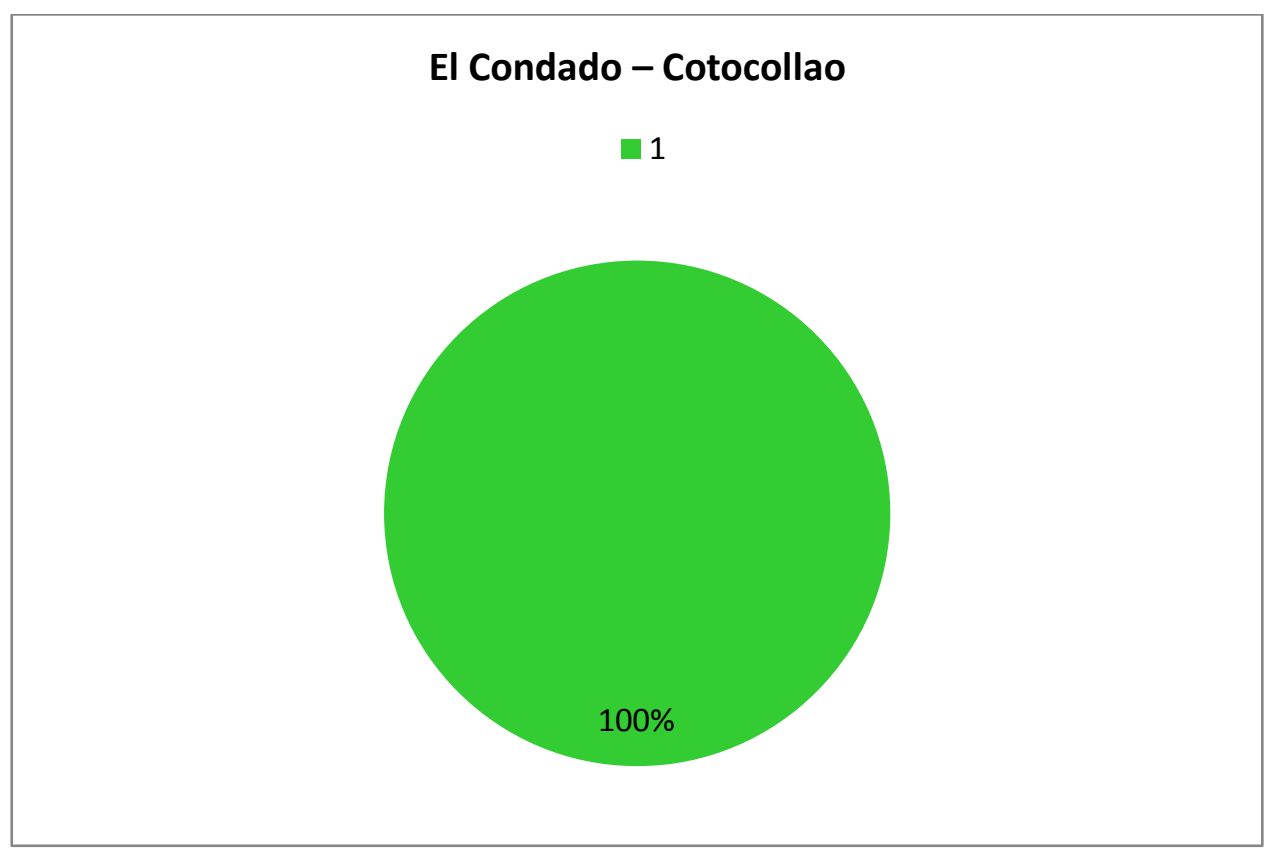

Figura 4.24: Porcentaje de cobertura por colores, El Condado - Cotocollao. 


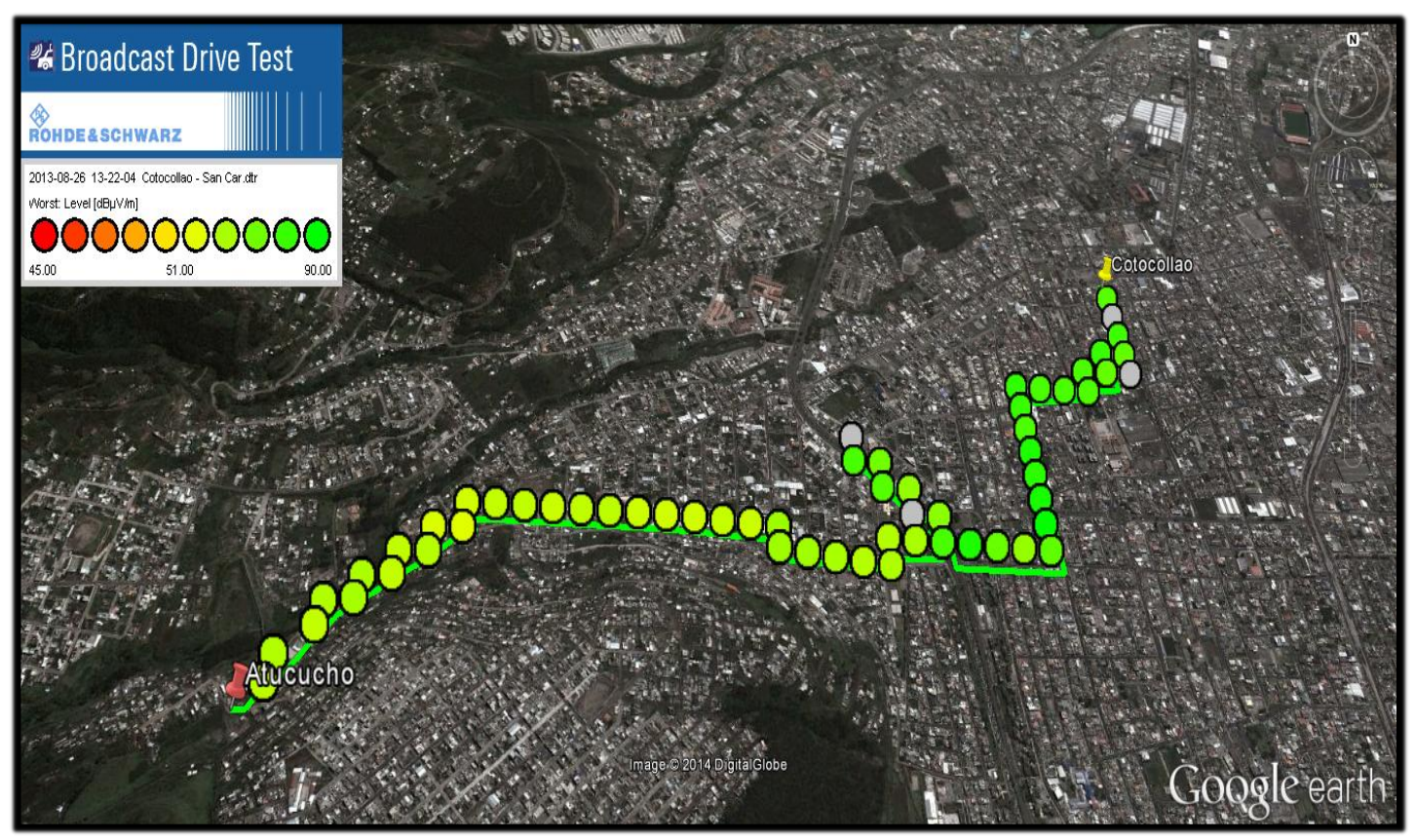

Figura 4.25: Muestras tomadas en la ruta, Cotocollao - Atucucho.

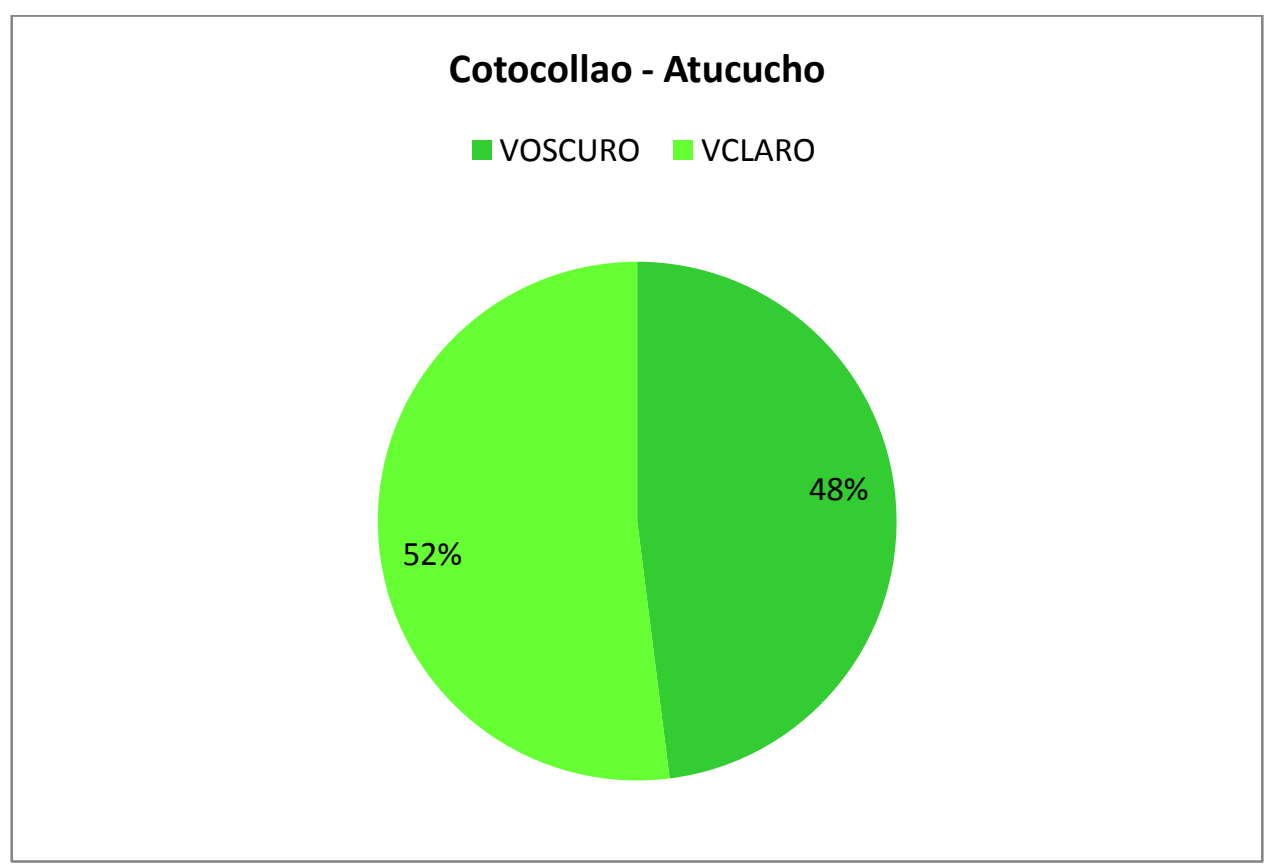

Figura 4.26: Porcentaje de cobertura por colores, Cotocollao - Atucucho. 
Tabla 4.3: Valores promedio del ICE, a lo largo del Drive Test.

\begin{tabular}{cc}
\hline Color & ICE $[\boldsymbol{d B \mu \boldsymbol { N } / \boldsymbol { m } ]}$ \\
\hline VOSCURO & 77,03 \\
VCLARO & 62,96 \\
\hline
\end{tabular}

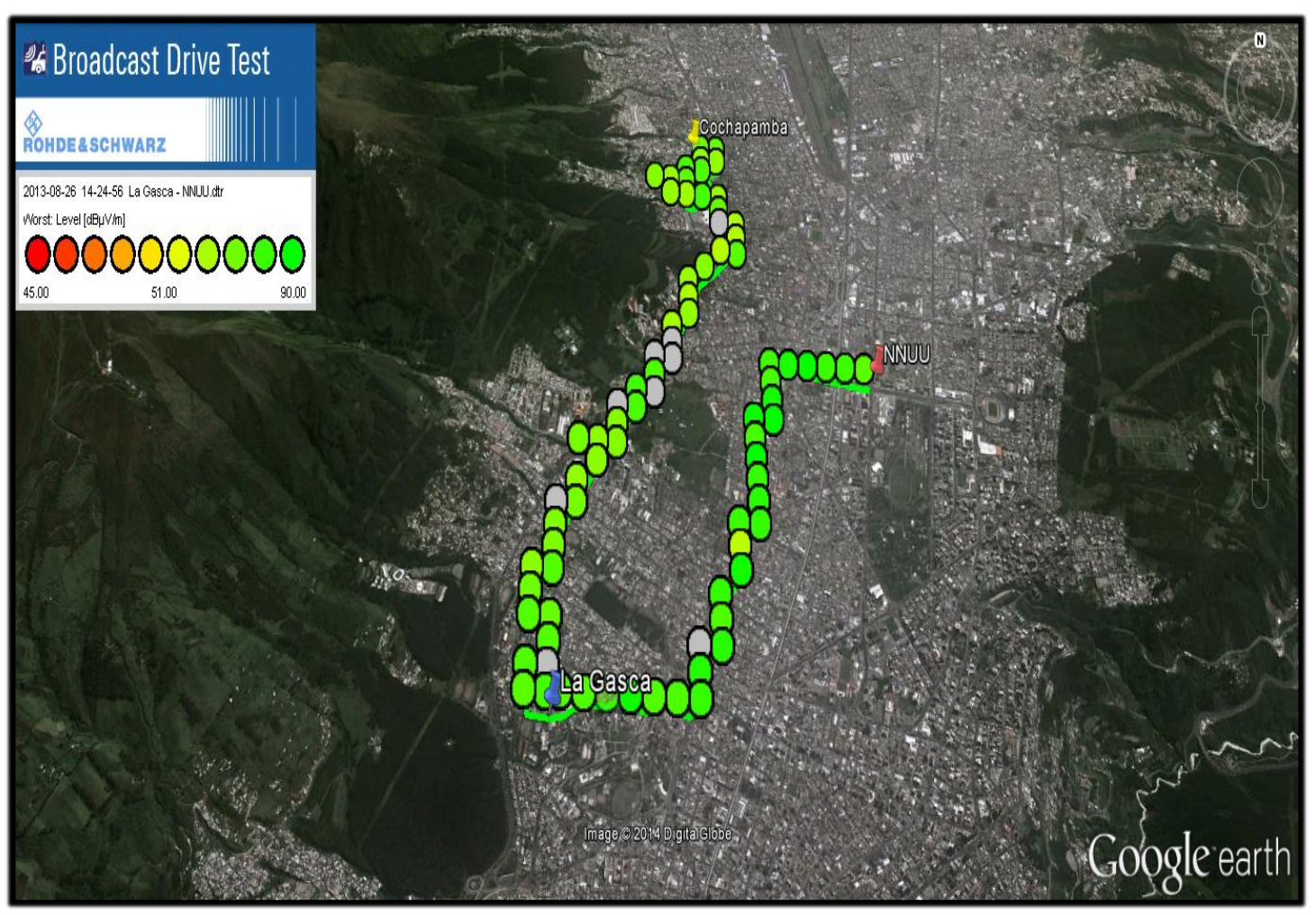

Figura 4.27: Muestras tomadas en la ruta, Cochapamba - La Gasca NNUU. 


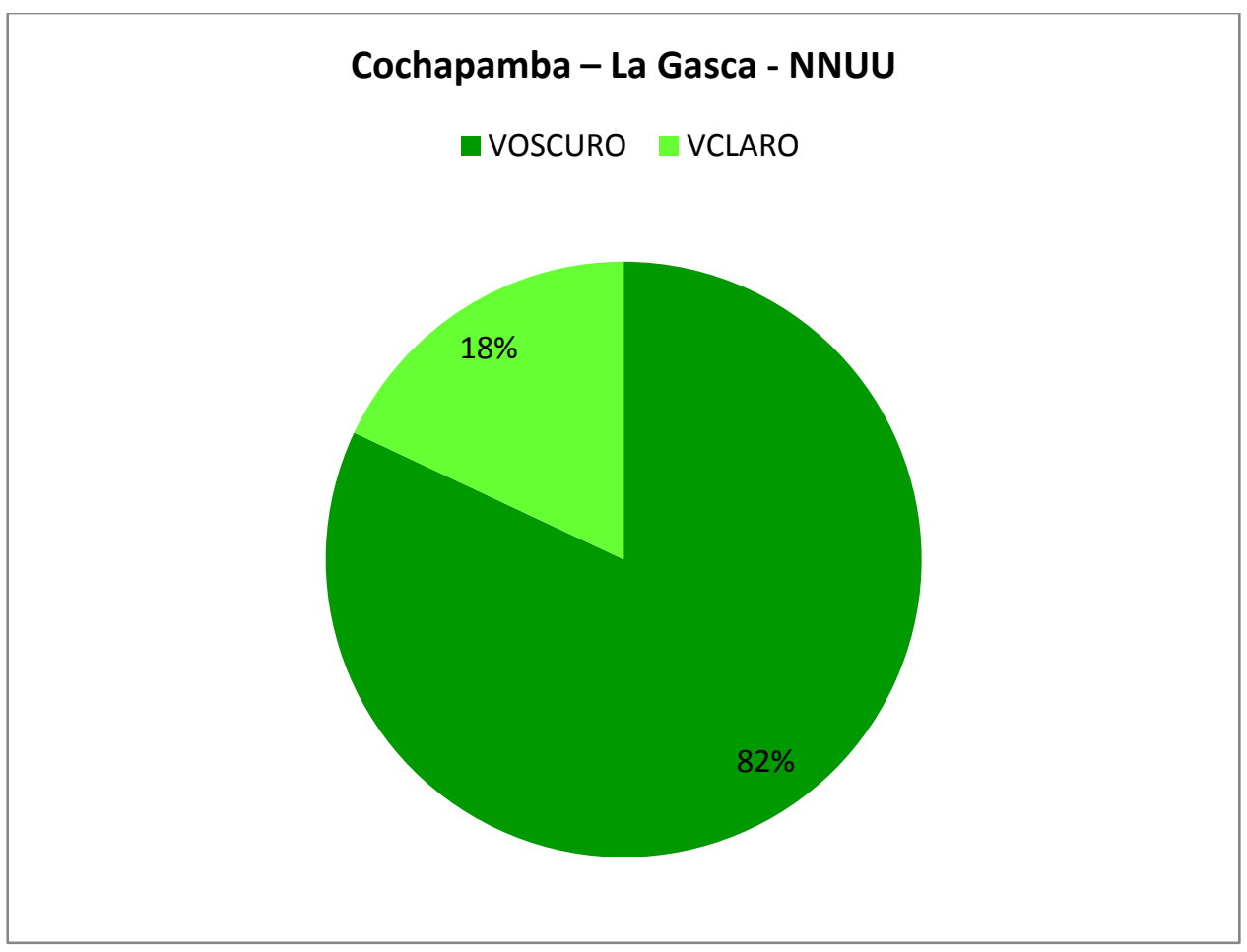

Figura 4.28: Porcentaje de cobertura por colores, Cochapamba - La Gasca - NNUU.

\section{Tabla 4.4:}

Valores promedio del ICE, a lo largo del Drive Test.

\begin{tabular}{lc}
\hline Color & $\boldsymbol{I C E}[\boldsymbol{d B \boldsymbol { \mu }} / \boldsymbol{m}]$ \\
\hline VOSCURO & 62,96 \\
VCLARO & 70,79 \\
\hline
\end{tabular}




\section{Rutas Sur}

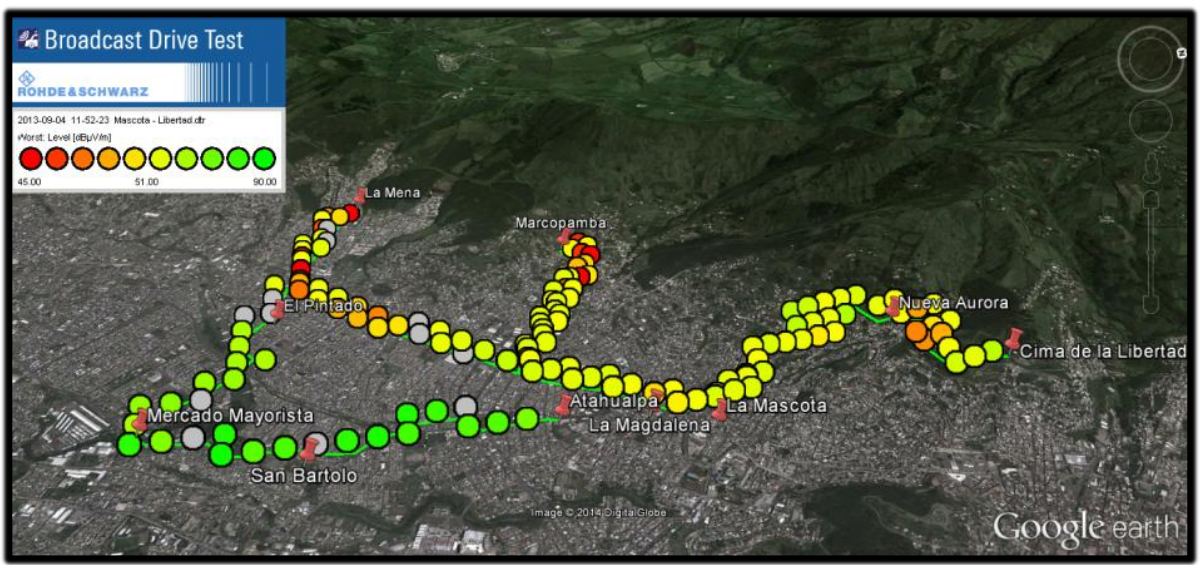

Figura 4.29: Muestras tomadas en la ruta, Cima de La Libertad - La Mena Atahualpa.

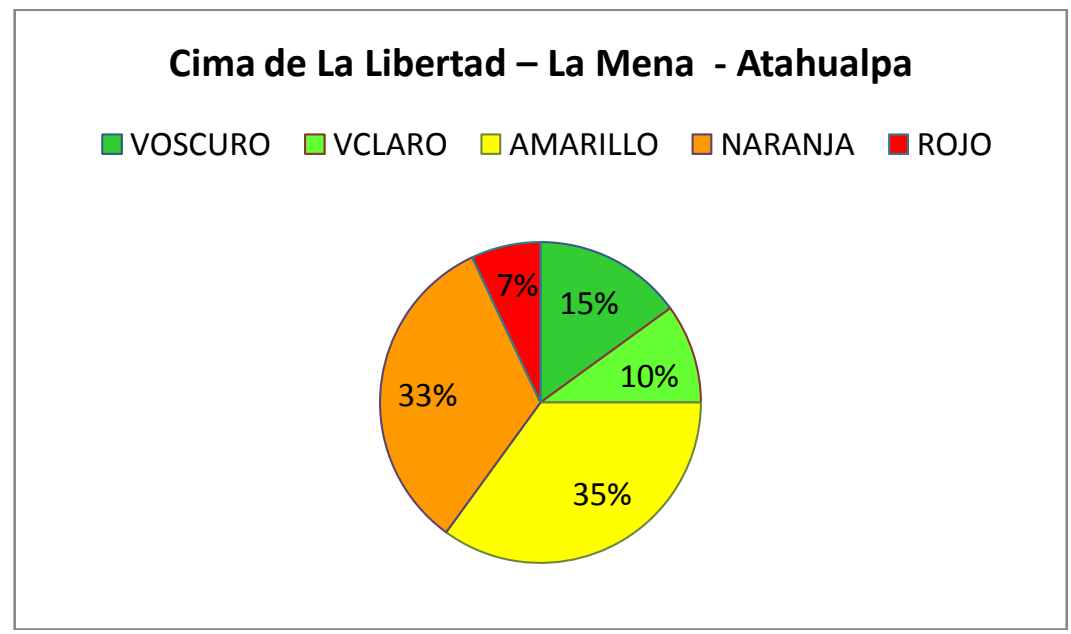

Figura 4.30: Porcentaje de cobertura por colores, Cima de La Libertad - La Mena - Atahualpa. 
Tabla 4.5:

Valores promedio del ICE, a lo largo del Drive Test.

\begin{tabular}{cc}
\hline Color & $\boldsymbol{I C E}[\boldsymbol{d B} \boldsymbol{\mu} \boldsymbol{V} / \boldsymbol{m}]$ \\
\hline VOSCURO & 78,49 \\
VCLARO & 60,74 \\
AMARILLO & 50,52 \\
NARANJA & 47,83 \\
ROJO & 42,83 \\
\hline
\end{tabular}

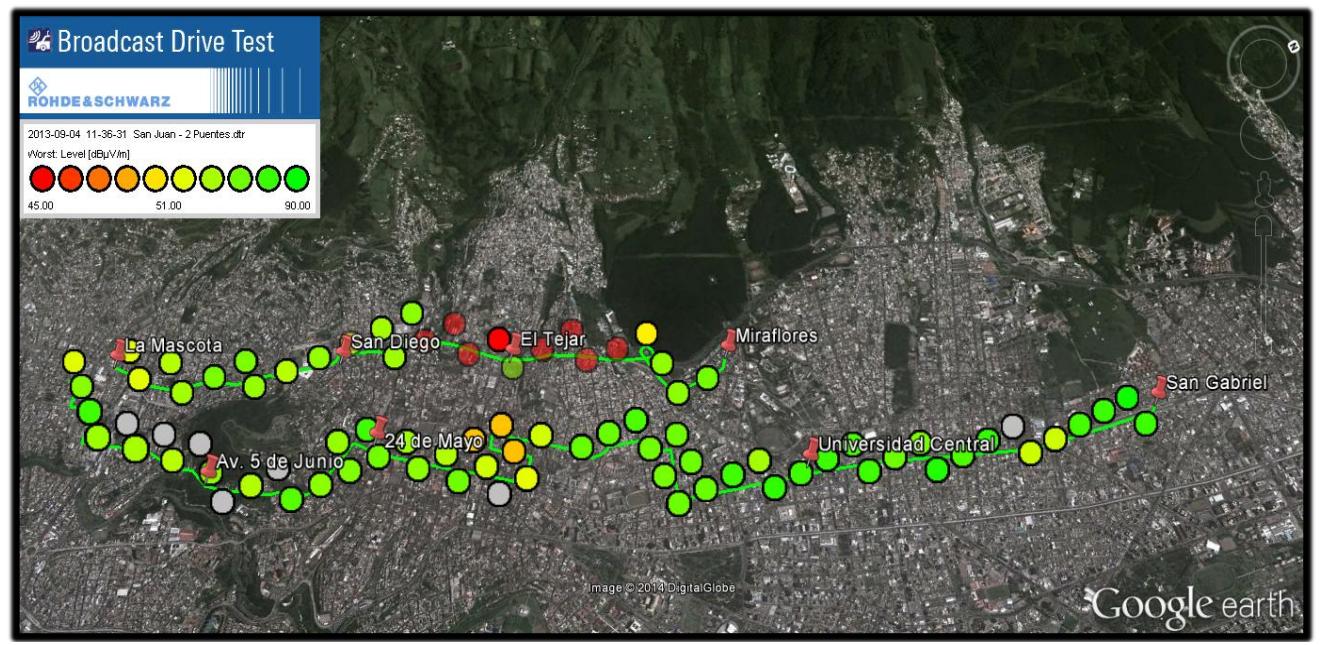

Figura 4.31: Muestras tomadas en la ruta, Miraflores - La Mascota - San Gabriel. 


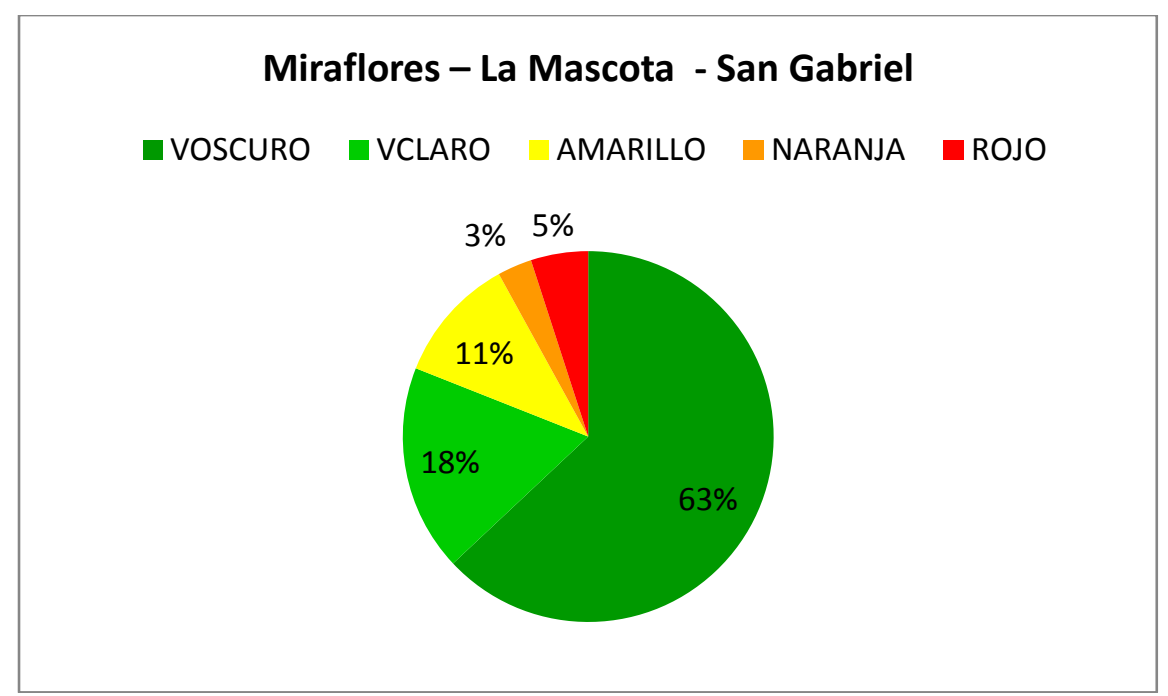

Figura 4.32: Porcentaje de cobertura por colores, Miraflores - La Mascota San Gabriel.

\section{Tabla 4.6:}

Valores promedio del ICE, a lo largo del Drive Test.

\begin{tabular}{cc}
\hline Color & $\boldsymbol{I C E}[\boldsymbol{d B} \boldsymbol{\mu} \boldsymbol{V} / \boldsymbol{m}]$ \\
\hline VOSCURO & 67.29 \\
VCLARO & 61,12 \\
AMARILLO & 54,23 \\
NARANJA & 48,82 \\
ROJO & 45,08 \\
\hline
\end{tabular}

\subsection{Análisis de parámetros de radiación}

Hablar de un parámetro es referirse a aquella consideración que determinará lineamientos en un estudio, en virtud a lo mencionado en la presente investigación se considera parámetros de acuerdo a los organismos internaciones de regulación referentes a las tecnologías aquí detalladas. Así, es 
un valor ya establecido el manejar $51 \mathrm{~dB} \mu \mathrm{V} / \mathrm{m}$ como el valor mínimo para garantizar una recepción óptima en una antena receptora de TDT con estándar ISDB- Tb.

Adicionalmente se observa que dentro de los elementos de radiación usados se manejan parámetros propios de los fabricantes como niveles de potencia bajo regulaciones de organismos internacionales o propios de cada país, en orden a esto se identifica que las estaciones repetidoras GAPFILLERS manejan una potencia máxima de 50 [W].

Las antenas transmisoras manejan una potencia individual de $0.5[\mathrm{Kw}]$ por antena logrando a través de un arreglo de 2 antenas por sector $1[\mathrm{Kw}]$ y alcanzado una potencia total del transmisor de $2[\mathrm{Kw}]$.

Los azimuths con los que se orientan las antenas transmisoras $45^{\circ}$ y $135^{\circ}$ obedecen a un estudio previo de cobertura, línea de vista, propagación y demás variables a nivel de radio frecuencia de acuerdo a la topografía de la ciudad, así como la configuración del Tilt Eléctrico y Tilt Mecánico influye directamente en la forma de onda, zona de cobertura, y forma de propagación de la señal.

Dichas consideraciones son indispensables para garantizar el correcto funcionamiento operativo conforme a las regulaciones de radiación. 


\subsection{Análisis de resultados obtenidos}

En base a lo antes mencionado se puede hacer un análisis a partir del nivel mínimo de recepción determinado en $51 \mathrm{~dB} \mu V / m$ con los valores obtenidos de las rutas realizadas.

Así:

- $\quad$ En la ruta, La Pampá - San Antonio - El Condado.

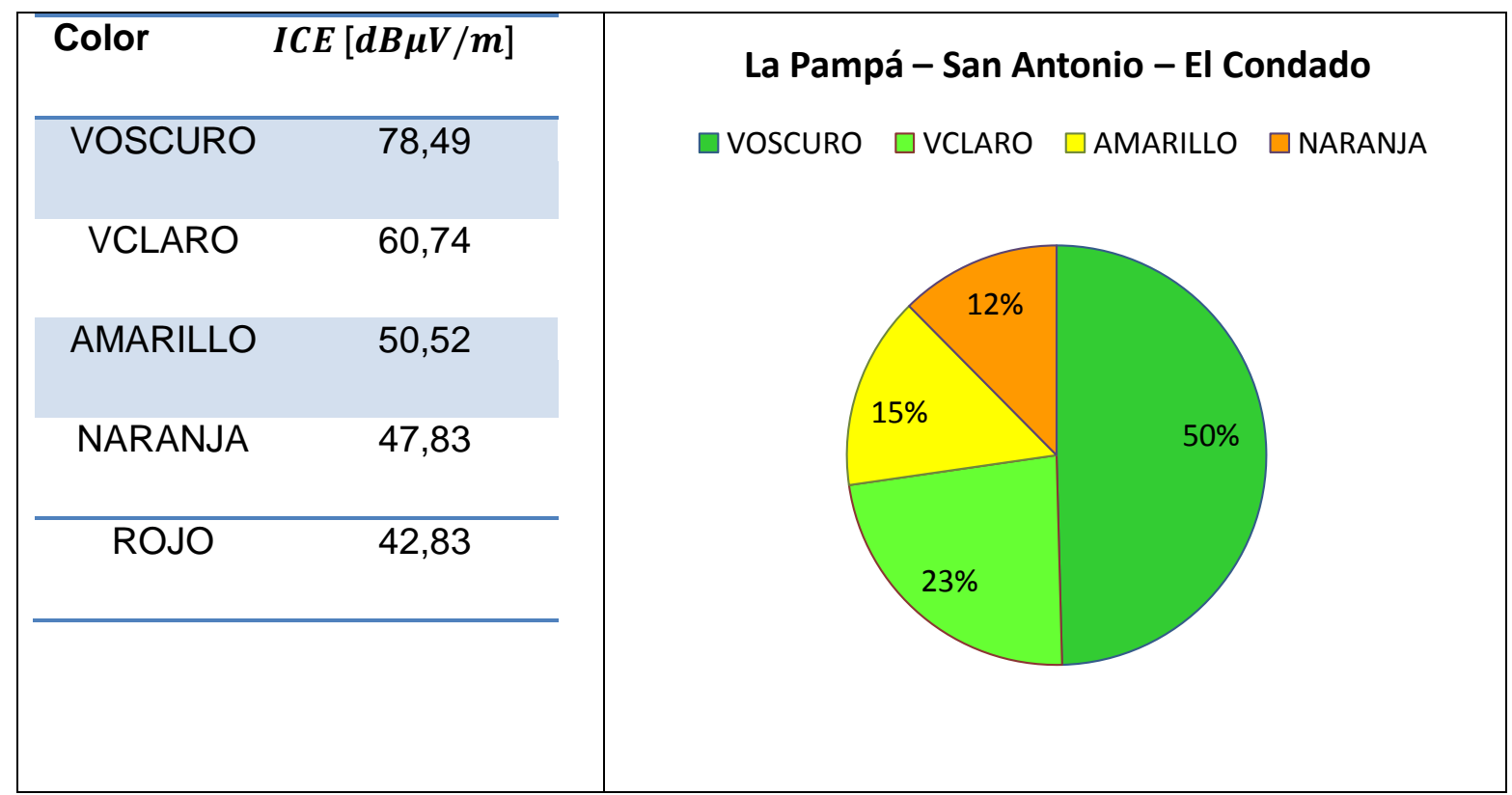

Figura 4.33: Resumen Ruta, La Pampa - San Antonio - El Condado.

Se puede observar que es necesaria la ubicación de una estación repetidora en la ruta entre la Pampa y San Antonio zona de la Mitad del Mundo ya que en base a las pruebas obtenidas en ciertos lugares se presenta valores 
inferiores a $51 \mathrm{~dB} \mu V / m$, esto debido a los accidentes geográficos que se encuentran en dicho sector que limitan la cobertura.

- $\quad$ En la ruta, Cima de La Libertad - La Mena - Atahualpa.

\begin{tabular}{|c|c|c|}
\hline Color & $I C E[d B \mu V / m]$ & Cima de La Libertad - La Mena - \\
\hline $\begin{array}{c}\text { VOSCUR } \\
\text { O }\end{array}$ & 78,49 & Atahualpa \\
\hline VCLARO & 60,74 & $\square$ VOSCURO \\
\hline $\begin{array}{l}\text { AMARILL } \\
\text { O }\end{array}$ & 50,52 & \\
\hline $\begin{array}{l}\text { NARANJ } \\
\text { A }\end{array}$ & 47,83 & $33 \%$ \\
\hline ROJO & 42,83 & \\
\hline
\end{tabular}

Figura 4.34: Resumen Ruta, Cima de la Libertad - La Mena - Atahualpa.

En esta ruta se evidencia el mayor porcentaje de muestras con valores inferiores al mínimo de recepción, estas mediciones están acordes con la topografía de la ciudad puesto que no existe línea de vista y es una zona que por su ubicación presenta dificultades en la recepción de la señal, siendo el principal obstáculo natural "Cruz Loma" en el cerro Pichincha. 
En las dos rutas detallas se evidencia que se encuentran en las denominadas zonas de sombra comprobadas a través de la herramienta de simulación, por tal motivo es indispensable la ubicación de GAPFILLERS, que permitan cubrir los huecos de cobertura en dichos sectores de la ciudad.

En el resto de rutas evaluadas se evidencia que los valores de las muestras tomadas está sobre los $51 \mathrm{~dB} \mu \mathrm{V} / \mathrm{m}$ lo que garantiza una recepción óptima de señal dejando a un lado la necesidad de ubicar estaciones repetidoras.

\subsection{Desventajas y limitaciones}

Se puede considerar como desventaja que las pruebas de campo fueron realizadas con una antena facilitada por ECTV de $1.50 \mathrm{~cm}$, y lo recomendable es usar una antena con una altura de $10 \mathrm{~m}$ para garantizar una recopilación de muestras con menor factor de error.

Es necesario entender como limitante la interferencia que generan sistemas de radio frecuencia, adicionales al sistema de televisión que pueden introducir ruido a la onda propagada alternando la medida obtenida. 
La recopilación de muestras en todo el distrito metropolitano de Quito que por disponibilidad del equipo usado no pudo realizarse, sino en lugares estratégicos como se detalla.

Al realizar una simulación se crea un escenario ideal, que constituye una limitante al conocer que por la influencia de factores naturales puede comportarse de manera distinta un sistema de radiación, por lo que los resultados de la simulación manejarían un factor de error, propio del software como tal. 


\section{CAPÍTULO V}

\section{CONCLUSIONES Y RECOMENDACIONES}

\subsection{Conclusiones}

- La información técnica proporcionada por la Televisión publica ECTV y el Ministerio de Telecomunicaciones y la Sociedad de la Información (MINTEL), permitió conocer al detalle la arquitectura y funcionamiento del estándar de televisión digital terrestre adoptado por el país ISDB-Tb.

- $\quad$ Para el estudio de la compatibilidad electromagnética de señales se utilizó como base técnica el sistema radiante de ECTV, debido ha la experiencia ganada por esta estación en sus dos años como único operador simultaneo de señales análogo/digital, tiempo en el cual ECTV supero varias limitaciones técnicas involucradas en la transmisión digital (generación de los parámetros de transmisión), limitaciones que son hoy visibles en las operadoras que han ido

paulatinamente sumando la nueva tecnología a su infraestructura; por ello ECTV fue el caso más idóneo de estudio durante el desarrollo de este proyecto de grado. 
- La huella digital obtenida en la ciudad de Quito y sus valles aledaños, refleja condiciones optimas para la recepción de televisión digital, salvo ciertas excepciones (Zonas de Sombras), debido en gran medida a que los emplazamientos de radiodifusión sonora, se encuentran en el cerro Pichincha, facilitando la propagación de la señal con un arreglo sencillo de cuatro o seis paneles, configurados con $1 / 3$ de su potencia máxima de transmisión.

- La simulación del Perfil del Terreno y el Drive Test, permitieron discriminar ciertas zonas de la ciudad de Quito en las cuales existen huecos de cobertura, donde la intensidad de campo eléctrico (ICE) esta por debajo de los $51 \mathrm{~dB} \mu \mathrm{V} / \mathrm{m}$ necesarios para garantizar la recepción digital, en base a esto se define como "Zonas de Sombra", el sur occidente la ciudad de Quito (Av. Mariscal Sucre hacia la cima de la Libertad) y La Parroquia San Antonio en la Mitad del Mundo.

- Se demostró mediante la herramienta de simulación SIRENET, que las estaciones reforzadoras de señal o "GAPFILLER", permiten cubrir los huecos de cobertura presentes en la ciudad de Quito. 
- Como resultado de la simulación de compatibilidad electromagnética, se concluyó que no existe interferencia Co-canal o Adyacente, entre canales análogo/digitales.

- $\quad$ Se verificó que el modelo de canalización establecido por el ente regulador MINTEL, se ajusta a la realidad previniendo conflictos a nivel del espectro radioeléctrico, permitiendo que durante el proceso simultaneo de operación "SIMULCAST" no exista ningún tipo de afectación electromagnética, ya que asigna rangos de frecuencias lejanos entre tecnologías, lo cual en una red poco saturada como la ecuatoriana es altamente beneficioso.

- Se observa que dentro del Distrito Metropolitano de Quito, las condiciones de transmisión para la diferentes operadoras de televisión son óptimas, debido a que la distancia de separación entre sistema radiantes es menor a dos kilómetros, ya que los emplazamientos se encuentran limitados a una misma área geografía Cerro Pichincha (separación máxima entre torres $500 \mathrm{~m}$ ), lo cual se traduce en una ausencia de interferencia. 


\subsection{Recomendaciones}

- Se recomienda realizar el mismo trabajo en la región costa ya que por sus características topográficas existe mayor posibilidad de presentarse interferencia co-canal o adyacente al momento de desplegar el sistema digital.

- $\quad$ Se recomienda que las operadoras de TDT consideren necesario instalar estaciones reforzadoras de señal (GAPFILLERS) a fin de garantizar un despliegue óptimo de su servicio.

- $\quad$ Tener presente para futuros estudios utilizar equipos de Drive Test adecuados para disminuir el factor de error en las muestras.

- $\quad$ Se recomienda socializar ante los usuarios de TDT la necesidad de orientan sus Atenas Rx hacia el GAPFILLER a fin de garantizar un optimo servicio. 


\section{BIBLIOGRAFÍA}

ANATEL. (s.f.). Tv Digital Terrestre- Plajamiento de Canis, Superintendência de Serviços de Comunicaçao de Massa.

Channel Planning for Digital Terrestrial Television Broadcasting. (2013). Japan.

Chuurei, \&. T. (2011). Measurement of digital Transmite rNHK-CTI Training Material. Japón.

Diseño Propio. (2014). Análisis del estado de la TDT en Ecuador. Quito.

Diseño Propio producto de la visita técnica de campo, a la estación ECTV en el cerro Pichincha. (16 de Septiembre de 2013). Quito, Pichincha, Ecuador.

Diseño propio producto del análisis del estado de la TDT en Ecuador. (15 de Agosto de 2013). Quito, Pichincha, Ecuador.

Diseño Propio, reproducido en Maplnfo Professional, según la información suministrada por el Municipio de Quito, en su sitio oficial. (2013).

Espinoza, F. (s.f.). TDT-Audiencia Pública. Televisión Digital Terrestre en el Perú.

Estado de la TDT en América Latina, EPN. (2013).

Estudio de Ingeniería del Sistema Radiante de ECTV. (20 de 08 de 2013). Quito, Pichincha, Ecuador.

Fondo Quito. (09 de 10 de 2013). Obtenido de http://fondoquito.blogspot.com/2008/03/geografia-de-quito.html

Fotografía tomada en la estación de ECTV. (26 de 08 de 2013). Quito, Pichincha, Ecuador. http://www.rohde-schwarz-. (s.f.).

http:www.tsc.urjc.es. (29 de 08 de 2013).

http:www.tsc.urjc.es/Master/RETEPAD/sites/default/files/Curso0_Ficha4. $p d f$.

ISDB-T. (03 de 2012). ISDB-T Documento para Armonización - Hardware. Quito, Pichincha, Ecuador. 
KG, K. W. (2011). Diseño propio producto del análisis del manual técnico. Alemania.

NCK- CTI Training manual . (2011). JAPAN.

Pabón, B. (2011). Propuesta de norma técnica del servicio de televisión digital. DRTV, MINTEL.

Propio, D. (2014).

Tesis Estudio y Propuesta de la factibilidad técnica social y económica del sistema ISDB-TV. . (s.f.).

Werker, K. (2011). NCK-CTI Training Manual. Japan.

www.harrismaxiva.com. (s.f.). 